\title{
The Root of Sustainability: Investigating the relationship between medicinal plant conservation and surface mining in Appalachia
}

Jessica B. Turner

Follow this and additional works at: https://researchrepository.wvu.edu/etd

\section{Recommended Citation}

Turner, Jessica B., "The Root of Sustainability: Investigating the relationship between medicinal plant conservation and surface mining in Appalachia" (2015). Graduate Theses, Dissertations, and Problem Reports. 6839.

https://researchrepository.wvu.edu/etd/6839

This Dissertation is protected by copyright and/or related rights. It has been brought to you by the The Research Repository @ WVU with permission from the rights-holder(s). You are free to use this Dissertation in any way that is permitted by the copyright and related rights legislation that applies to your use. For other uses you must obtain permission from the rights-holder(s) directly, unless additional rights are indicated by a Creative Commons license in the record and/ or on the work itself. This Dissertation has been accepted for inclusion in WVU Graduate Theses, Dissertations, and Problem Reports collection by an authorized administrator of The Research Repository @ WVU.

For more information, please contact researchrepository@mail.wvu.edu. 
The Root of Sustainability: Investigating the relationship between medicinal plant conservation and surface mining in Appalachia

\author{
Jessica B. Turner \\ Dissertation submitted to the \\ Eberly College of Arts and Sciences \\ at West Virginia University \\ in partial fulfillment of the requirements \\ for the degree of
}
Doctor of Philosophy
in
Biology
James B. McGraw, Ph.D., Chair
Sunshine Brosi, Ph.D. Jonathan Cumming, Ph.D. Donna Ford-Werntz, Ph.D. Jeff Skousen, Ph.D.

\author{
Department of Biology \\ Morgantown, West Virginia \\ 2015
}

Keywords: medicinal plants, ginseng, conservation, surface mining, sustainability

Copyright 2015, Jessica B. Turner 


\title{
ABSTRACT \\ The Root of Sustainability: Investigating the relationship between medicinal plant conservation and surface mining in Appalachia
}

\author{
Jessica B. Turner
}

Since European colonization, Appalachian culture has been based on resource extraction, such as coal mining, timbering, and Non-Timber Forest Product (NTFP) harvest. Surface mining degrades forest habitat for medicinal plants, especially the habitat for the internationally valuable medicinal herb, American ginseng (Panax quinquefolius L.), and the NTFP culture associated with this plant. The relationship between medicinal plant conservation and surface mining must be studied with a nontraditional, multi-faceted approach: culturally, economically, and ecologically. (1) Using community-based participatory surveys, I determined how ginseng harvesters and nonharvesters in West Virginia communities view the relationship between surface mining and ginseng harvest. Harvester culture is one worth preserving, as they value conservation. However, most harvesters admit to illegal harvesting practices. By determining what harvesters and non-harvesters prioritize and value, and understanding what is the most effective way to connect with these two groups, this research can aid in the development of successful environmental education and conservation outreach. (2) Challenging the perceptions that economic growth is incompatible with ecological consciousness, an economic analysis comparing the short-term gains of surface mining to the potential economic value of sustainable ginseng harvest or a large-scale ginseng farm operation was completed. Through an in-depth economic modeling approach I showed that stewarded ginseng harvest can be economically advantageous in the long-term while maintaining the integrity of the forest. (3) For reintroduction purposes, the concept of 'indicator species' is frequently used. These species are often selected based on anecdotal information, rather than scientific rigor. In order to maximize the efficiency of ginseng reintroductions, I analyzed the ability of select putative indicators (herbs, shrubs, and trees) to serve as site and microsite predictors of ginseng growth. Most indicators were ineffective, and the ones that did show a relationship to growth were contraindicators, predicting reduced individual plant growth. This research may aid reintroduction and agroforestry projects, and thereby reduce the frequency of reintroductions that fail because plants are introduced into suboptimal locations. (4) By experimentally reintroducing two medicinal plants, ginseng and goldenseal, to two sites with three types of disturbance history, I determined that degraded landscapes can return to a forested state that supports medicinal plant growth and reproduction, although microsite and soil conditions were found to be important to consider when reintroducing plants. As such, appropriate future land-management decisions can be made based on land-use legacy. By combining social, economic, and ecological studies, medicinal plant conservation can be implemented through the development of environmental outreach and effective reintroduction strategies. 


\section{ACKNOWLEDGMENTS}

First, I need to thank Dr, James B. McGraw. I could not have asked for a better advisor for this experience. My esteemed committee was always helpful in providing feedback, opportunities, and guiding me to develop my skills as a scientist. I am grateful for the opportunity to learn and grow from you all.

There are a plethora of interns, experts, and fellow graduate students that helped me: Bob Beyfuss, Dr. Kristjansson, Dr. Mooney, Dr. Cavender, Shana Byrd, Dr. Larson, Al Parker, Phil Crim, Zac Zacavish, Kyle Gregory, Michael Elza, Chris Mallow, Anne Jarrell, Mark Arbuiso, Jake Richards, and the many others who gave their time and energy so this project could be a success. I am indebted to the staff at the Wilds for their help and advice. Thank you to everyone associated with the Health Science and Technology Academy.

Thank you to the wonderful people at Phipps Conservatory. The Botany in Action Fellowship was one of the most positive influences in my professional development. Thank you to the talented staff and the wonderful fellows I was able to spend several years with, especially Aurélie Jacquet, Chelsie Romulo, and Anna Johnson. I am lucky to count you as colleagues and as friends.

Thank you to Sean Cahill for creating the best ginseng conservation joke ever: "What can we do to keep ginSENG from becoming ginSUNG." Anna, thanks for all of the support. Doug McClain, thank you for using your vacation days to help me in the field. You are a true friend. Amy Hruska, thank you for your help. Jennifer Chandler, you are a continuous inspiration. Thank you for switching to a $\mathrm{PhD}$ so we could have this journey together. Alix Wagner, you deserve a special thank you. Your countless hours in the field, from beginning to end, have been invaluable. Ryann Righter, thank you for your support through the whole process, from application to graduation.

To my cousin Chuck and his lovely wife Paula, thanks for always making me feel like a million bucks. To my future in-law family, thank you for your overwhelming support and kindness. I will never turn down an opportunity to enjoy a ML with you all. My brother, Joshua, thank you for motivating me.

Words cannot express how grateful I am to my parents. One of the greatest experiences I have had with this process is that I was able to become even closer to the two people that raised me. The time I spent with you both in the field will remain as some of my favorite memories. I am touched by your generosity. Thank you, ma, for showing me by example (and telling me), that I can get a doctorate. Your help in the field, your willingness to talk about the struggles and triumphs go above and beyond. Without any hesitation, I can tell people my mom is a personal hero for being tough as nails, but a person of compassion. Pa, you are my number one field hand. Thank you for spending your summers in the field with me, for being a calming influence, and for always packing the best lunches. You made rough days fun. Thank you for all that you have done. I hope I can become half the person you are. 
To the love of my life, Justin, thank you for absolutely everything. Over the past three years, you have been a sounding board, an escape, a support, an editor, a collaborator, a best friend, a travel buddy, and a goofball. Thank you. As these six chapters come to an end, I am ecstatic that I can start the next chapter with you.

This research was supported by a National Science Foundation Long Term Research in Environmental Biology Grant to J.B. McGraw (DEB-0613611 and DEB-1118702), and the Botany in Action Fellowship (2013, 2014, 2015), through Phipps Conservatory to J.B.Turner, Pittsburgh, PA. Additional funding was provided by the Earl Core Memorial Fellowship, the David Blaydes Dissertation Scholarship, West Virginia Biology Department, and the Office of the Dean of Eberly Arts and Sciences. 


\section{Table of Contents}

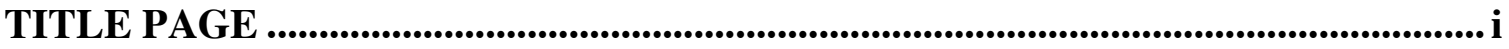

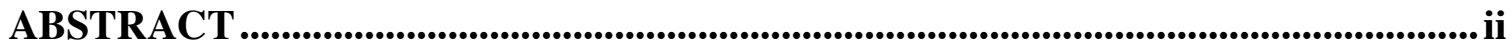

ACKNOWLEDGMENTS .........................................................................................ii

LIST OF FIGURES …......................................................................................... vii

LIST OF TABLES ……...................................................................................................... ix

CHAPTER I: GENERAL INTRODUCTION .....................................................1

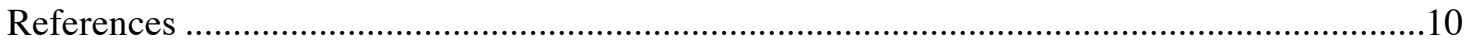

CHAPTER II: CONFLICTING VALUES ASSOCIATED WITH RENEWABLE VERSUS NON-RENEWABLE RESOURCE EXTRACTION IN APPALACHIA......... 15

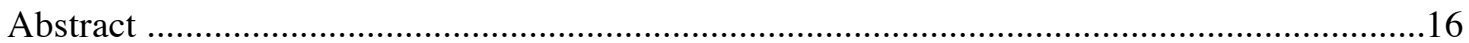

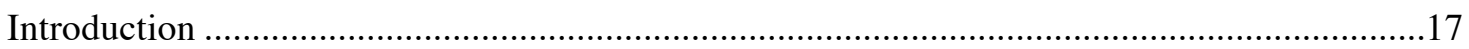

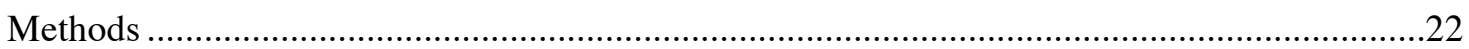

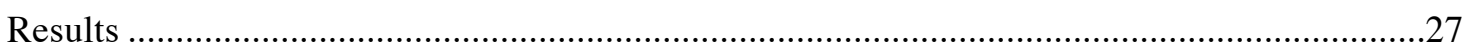

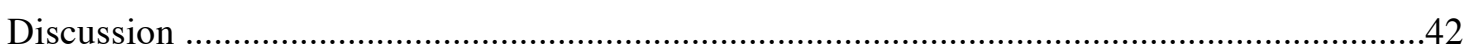

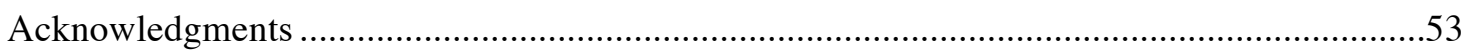

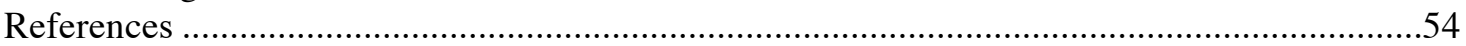

CHAPTER III: GREEN VERSUS BLACK GOLD: AN ECONOMIC COMPARISON

OF LAND-USE IN APPALACHIA ............................................................................................61 61

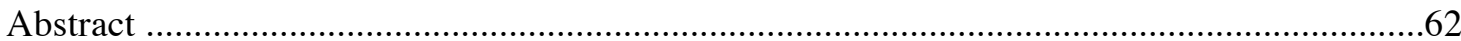

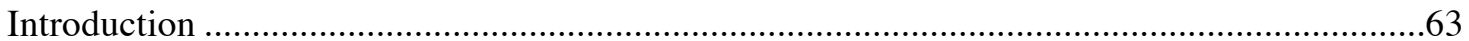

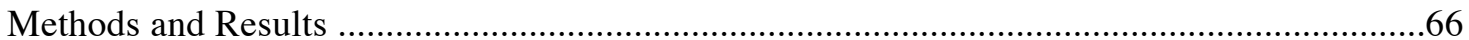

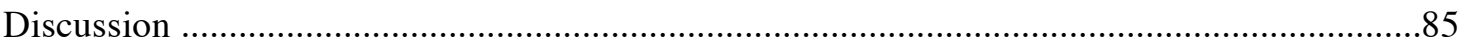

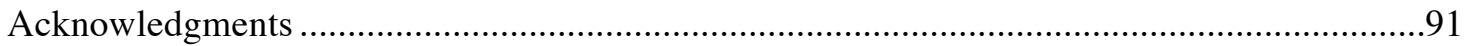

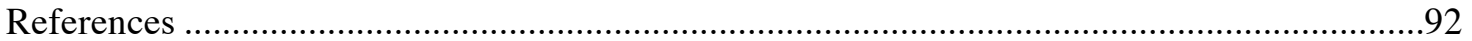

CHAPTER IV: CAN PUTATIVE INDICATOR SPECIES PREDICT HABITAT QUALITY FOR A RARE UNDERSTORY HERB? ........................................................97

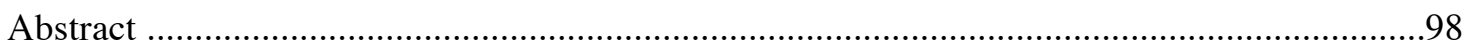

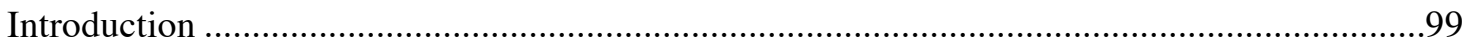

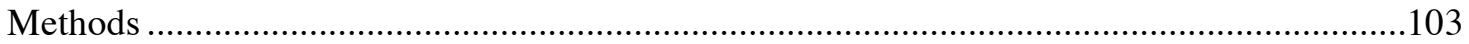

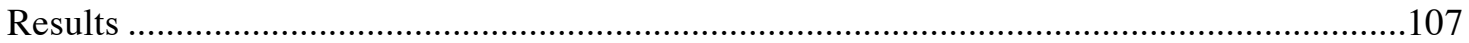

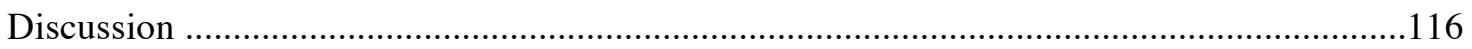

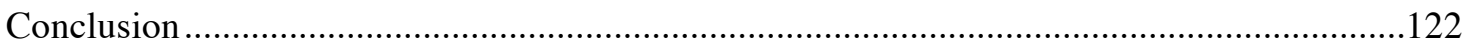

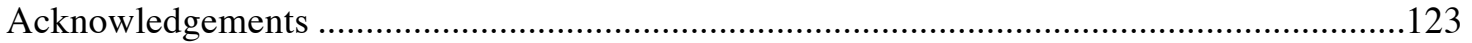

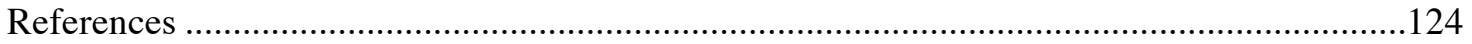

CHAPTER V: DOES LAND-USE HISTORY INFLUENCE REINTRODUCTION SUCCESS OF MEDICINAL PLANTS IN APPALACHIA? ...............................................130

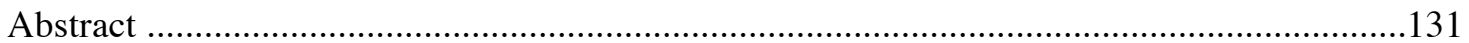

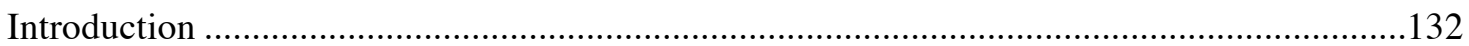

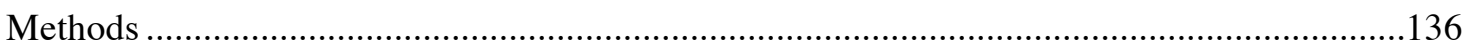

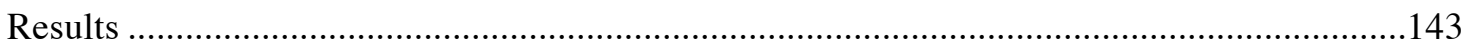

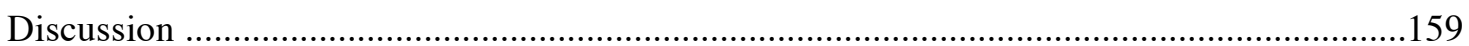

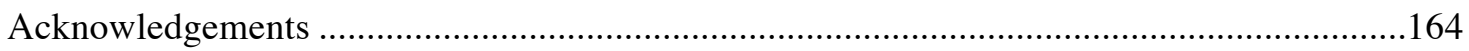

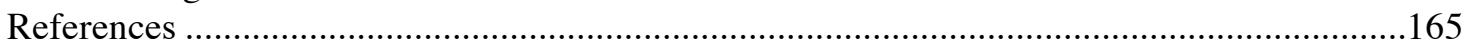


CHAPTER VI: OVERALL CONCLUSIONS OF THE DISSERTATION ................170

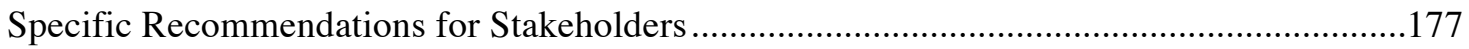

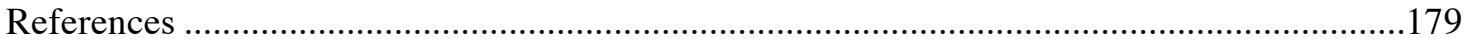

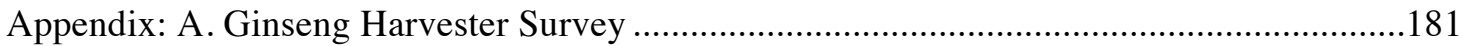

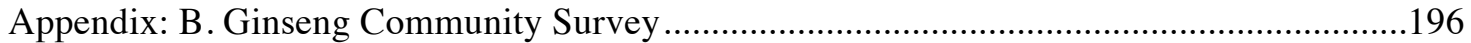

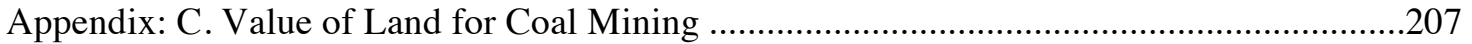

Appendix: D. Ginseng Harvest Projection Model, Case: Stewarded .....................................210

Appendix: E. Ginseng Harvest Projection Model, Case: Commercial Ginseng Farm.............218 


\section{LIST OF FIGURES}

Figure 2.1. Frequencies of select Likert-item question responses between harvesters and non-harvesters. Compass charts are organized using collapsed responses of (A) strongly agree/agree and (B) strongly disagree/disagree. *indicates only strongly disagree responses

Figure 2.2. Effect of sample frame on participants' scores in three concepts: (A) ginseng conservation, (B) ginseng knowledge, and (C) opinion of conservation................... 38

Figure 2.3. Effect of (A, B, C) employment, (D) education, and (E) gender on participants' concept scores, depending on sample frame.

Figure 2.4. Effects of sample frame on concept scores for (A) ginseng conservation, and (B) trust in environmental experts depended on the level of agreement involving personal empowerment in Appalachia.

Figure 2.5. The effect of participant's level of agreement that "they have a say in environmental issues in Appalachia" on the concepts of (A) ginseng conservation and (B) opinion of conservation.

Figure 3.1. Illustration of the mass of an average root through its life cycle, and the projected price by age.

Figure 3.2. Investor rate of return for a ginseng farm, based on average price per root. . 84

Figure 4.1. Graphical scenarios of the relationship between the niche of $P$. quinquefolius and several key 'putative indicator' species niches.

Figure 4.2. Effect of putative indicator species presence in the population on relative growth rate (RGR $\mathrm{RA}_{\mathrm{LA}}$ ) of $P$. quinquefolius plants over a 10 -year period.

Figure 4.3. Effect of the presence or absence of two putative indicator species on relative growth rate $\left(\mathrm{RGR}_{\mathrm{LA}}\right)$ of $P$. quinquefolius plants over a 10-year period.

Figure 4.4. The effect of the putative indicator species L.tulipifera presence in the microsite of $P$. quinquefolius on relative growth rate $\left(\mathrm{RGR}_{\mathrm{LA}}\right)$ of $P$. quinquefolius plants over a 10 -year period.

Figure 5.1. Statistical layout of the design of the reintroduction experiment. Plots are the columns. Subplots are the small clouds nested within the plots.

Figure 5.2. Effect of land-use history on the persistence of (A) ginseng and (B) goldenseal over four years. 
Figure 5.3. Effect of land-use history on the persistence rate of goldenseal depended on

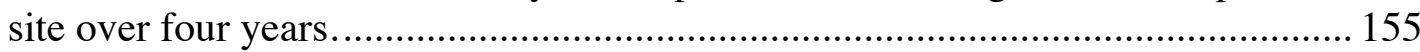

Figure 5.4. Effect of site on the Mean $\mathrm{RGR}_{\mathrm{LA}}$ across both species. Land-use history (LUH) types are abbreviated: Highwall plots $(\mathrm{H})$, Secondary Plots $(\mathrm{S})$, and Mature Plots (M). 156

Figure 5.5. Effect of land-use history on the percent of reproductive ginseng plants... 157

Figure 5.6. Effect of site on the percent of reproductive goldenseal plants 158 


\section{LIST OF TABLES}

Table 2.1. Demographic overview of survey respondents, organized by sample frame.. 33

Table 2.2. Community relationship between ginseng and coal mining among survey participants, organized by sample frame.

Table 2.3. Rank of how harvesters and non-harvesters view the trustworthiness of certain groups (organized by harvester trust).

Table 2.4. Percentage of harvesters who participated in illegal ginseng harvesting practices.

Table 3.1. Total cash value to the land-owner, post taxes, at three time-points. To establish the value in 2047 for the surface mining scenario, the total cash value of coal royalties in 2035 was invested with an annual $3.5 \%$ interest.

Table 4.1. List of indicator species along with number of populations in which they were found, as well as percent of those populations included in microsite analysis....... 111

Table 5.1. Mean age range of plots as determined by tree ring analysis. 147

Table 5.2. Composition and size of dominant trees at each plot, as measured by the diameter at breast height $(\mathrm{cm})$. The two largest trees of different species were listed. Land-use history (LUH) types are abbreviated: Highwall plots $(\mathrm{H})$, Secondary Plots (S), and Mature Plots (M). 148

Table 5.3. Soil test results from 27 wild populations of American ginseng. 149

Table 5.4. Soil test results from all plots organized by sites. 150

Table 5.5. Compilation of the results of one-tailed t-tests of $\mathrm{RGR}_{\mathrm{LA}}$, determining if the mean RGR $_{\mathrm{LA}}$ was greater than zero, for each plant species for each site in each landuse history and weighted by the number of plants in each subplot. Asterisks indicate statistical significance $(\mathrm{p}<0.05)$.

Table 5.6. The results of a t-test comparing the mean $\mathrm{RGR}_{\mathrm{LA}}$ of ginseng from each landuse history*site to the mean $\mathrm{RGR}_{\mathrm{LA}}$ of 27 wild populations of ginseng. A superscript ' $\mathrm{t}$ ' $\left({ }^{\mathrm{t}}\right)$ indicate a trend $(\alpha<0.10)$. 


\section{CHAPTER I: GENERAL INTRODUCTION}


Earth is currently entering its sixth mass extinction (Barnosky et al. 2011), with land-use change being one of the biggest drivers of biodiversity loss (Sala et al. 2000). Land-use change, or habitat conversion, is due to anthropogenic activities, such as the expansion of agriculture (Gragson \& Bolstad 2006), urbanization (Radeloff et al. 2005), or timbering and mining (Gragson \& Bolstad 2006). In the United States, over 2.4 million hectares of land have been impacted by mining since the early part of the $20^{\text {th }}$ century (Skousen et al. 2006). In the Appalachian highlands between 1973 and 2000, over 420,000 hectares of forest cover were lost to surface mining; during this time period, mining has been the greatest driver of forest cover loss in the Appalachian highlands (Drummond \& Loveland 2010). As the Appalachian region is roughly $4 / 5$ forested (Zipper et al. 2011), and as the Appalachian highlands are over 52 million hectares in size (Drummond \& Loveland 2010), this loss of forest cover is less than one percent of the total size of the region. However, surface mining can disproportionally impact certain regions or watersheds within Appalachia. For instance, in Georges Creek watershed in Maryland, over 15\% of the land is reclaimed mine sites (Townsend et al. 2009). Surface mining can have longterm negative ecological effects on the health of terrestrial and aquatic ecosystems (Palmer et al. 2010, Bernhardt \& Palmer 2011, Lindberg et al. 2011), yet it is considered one of the main economic drivers in the Appalachian region, especially in West Virginia (Bell \& York 2010).

Before 1977, while some states required reclamation of mined sites (Emerson et al. 2009), thousands of hectares of mined lands were abandoned (as cited in Skousen et al. 1994), whereafter natural succession occurred (Skousen et al. 1994). In 1977, 
reclamation became a national priority when the Surface Mine Control and Reclamation Act (SMCRA) was enforced (Emerson et al. 2009). Despite this effort to reclaim mined sites, there is no evidence that many of these sites have returned to pre-mined conditions (Palmer et al. 2010). Often, these reclaimed or un-reclaimed sites are grasslands or stands of early successional forests. The forest understory can be responsible for $90 \%$ of the plant diversity in the forest (Gilliam 2007), so understanding the impacts of surface mining on herbaceous species, specifically culturally significant medicinal plants, is important.

Often, hunting, fishing, and gathering of Non-timber Forest Products (NTFP) are important hobbies for individuals throughout Appalachia. The process of surface mining can influence these outdoor activities. While surface mining can directly reduce the habitat for native animals, the novel ecosystem of a reclaimed mine site can be used to introduce large mammals for hunting purposes. Reclaimed surface mines in Kentucky have been used as habitat to introduce elk (Cervus elaphus), and these introduced elk have been hunted for over a decade (Cox 2011). Fishing can also be impacted, as the indirect and direct impacts of surface mining can reduce the diversity of native, sensitive species in stream communities (Vaughan 1979; Pond et al. 2008), or destroy the streams altogether (Palmer et al. 2010). Finally, the harvest of NTFPs can be reduced due to surface mining, as the forest is cleared before mining occurs, and the reclaimed landscape is one that is not suitable habitat for understory herbaceous species. The loss of NTFPs can be detrimental to the Appalachian region, as the harvest of medicinal plants can provide valuable supplementary incomes in a region with high poverty levels (Bailey 
1999). Arguably, the most important NTFP harvested by individuals in Appalachia is American ginseng (Panax quinquefolius L.) (Van der Voort 1998; Robbins 2000, McGraw et al. 2013), hereafter referred to as ginseng.

Ginseng is a small, herbaceous perennial plant found across the eastern United States (McGraw et al. 2003, 2013), and it is used extensively as a medicinal plant for Traditional Chinese Medicine (TCM) (Robbins 2000, Yin et al. 2008). Individuals in Appalachia harvest the root of ginseng to earn an important secondary income (Bailey 1999, Robbins 2000), as well as to enjoy time outside with family and friends (Hufford 2003). Ginseng can be found on numerous slopes and aspects across eastern North America (McGraw et al. 2003), but as it has been heavily harvested since the 1700's for the Asian herbal market, this plant has become increasingly rare (McGraw et al. 2013).

While ginseng harvest is a legal activity and harvest is regulated by state laws, most ginseng harvest is done illegally with respect to one or more of those laws (Van der Voort and McGraw 2006, McGraw et al. 2010). Due to a long history of unsustainable harvest, ginseng is listed on Appendix II of the Convention on International Trade in Endangered Species of Wild Fauna and Flora (CITES Secretariat n.d.). To exacerbate the loss of ginseng due to harvest, habitat of this valuable species is being lost due to surface mining. This conversion results in long-term consequences for the cultural heritage of Appalachia (Hufford 2003), as well as for the health of the ecosystem (Palmer et al. 2010), and habitat of ginseng. 
To study the relationship between two different forms of resource extraction, ginseng harvest and surface mining, a conservation biology lens must be trained on the subject. According to Ticktin and Shackleton (2011), a NTFP has the potential to be sustainably harvested if the species has a wide distribution; however, the potential for sustainable harvest is reduced if the habitat where the plant grows undergoes land-use change, and if the NTFP has a high market value. The current harvest culture and environmental stressors are causing harvest to be unsustainable (Souther and McGraw 2014). 'Cultural keystone species' are species that are fundamentally important to maintain the culture identity of a region (Garibaldi \& Turner 2004). Ginseng can be considered an 'intercultural species,' as ginseng is a medicinal plant that is culturally, economically, and ecologically valuable on an international scale. Without ginseng, the culture of harvest in Appalachia, and the use of one of the most important forms of TCM would be lost. Local communities can be empowered to actively work towards conservation and restoration of the ecosystem as a whole by using a species that is as culturally and economically important as a catalyst for sustainability (Garibaldi \& Turner 2004). Policymakers can help conserve ginseng and the eastern deciduous forest through identifying ginseng as an inter-cultural keystone species, understanding the importance of this plant to the cultural and economic fabric of Appalachia, and by understanding the direct and indirect impacts of surfacing mining on ginseng.

Both surface mining and ginseng harvest are historically rooted in Appalachian culture (Hufford 2003, Bell \& York 2010). The first objective of Chapter 2 was to determine how both ginseng harvesters and non-harvesters view, prioritize, and implement 
conservation, specifically in terms of the relationship between surface mining and ginseng harvest. Rural Appalachian communities are typically distrustful of outsiders or experts (Katz et al. 2009) and, therefore typical survey methods and interview procedures may yield biased and invalid results. Focusing on two sample frames, ginseng harvesters and non-harvesters, I worked with the Health Science and Technology Academy (HSTA) through West Virginia University (WVU) to study these populations. HSTA is a science and math enrichment program implemented through science clubs of rural high schools in 26 counties in the state of West Virginia (Branch et al. 2011), and these students were used as recruiters to facilitate a non-random sampling protocol (Kelley et al. 2003) by distributing surveys.

The second purpose of Chapter 2 was to determine if ginseng harvesters practice sustainable harvest methods, and if their harvest methods relate to their opinions and knowledge of conservation, as well as their trust of environmental experts. Additionally, I wanted to understand how West Virginia community members and harvesters justify surface mining as being the main economic option of the region, and if they prioritize mining over the deciduous forest and ginseng harvest. Understanding the level of knowledge about, and opinion of, conservation, ginseng, and surface mining that the Appalachian community members and harvesters have is important for outreach and policy. This information can be integral to implementing science-based conservation strategies and education about ginseng in an area with historic low scientific-literacy (Haight \& González-Espada 2009). 
The postulate that conservation and economic growth are incompatible goals has often been expressed (Rasker 1993, MacDonald 2010). While ginseng harvest is monitored heavily by the state, there has been no effort to monitor the amount of ginseng that is lost through the process of surface mining (Hufford 2002), nor the economic opportunities that are lost from the local extirpation of this NTFP. Given that there is uncertainty and assumptions for the future of coal production in Appalachia, and the price, reserves, and market (Höök \& Aleklett 2009, Hammond 2011), individuals or companies who own mineral rights should consider all economic opportunities available through their land. Further, there is the unseen economic implication of externalities (Epstein et al. 2011), as well as the diminishing cultural importance of coal (Bell \& York 2010). Chapter 3 presents an economic analysis that evaluates the financial opportunities associated with a hypothetical 100 hectares of land. I determine if harvesting a stewarded ginseng population, or developing a large-scale ginseng farm, is an economically viable land-use option for a property and mineral rights owner, vis-a-vis surface mining royalties. If the economic viability of harvesting a NTFP in a sustainable manner can be demonstrated, then ginseng may act as a vehicle for conservation for numerous other, less charismatic species.

A valuable in situ conservation method for preserving ginseng for future generations is reintroducing these plants into the forest. The overarching objectives of Chapters 4 and 5 were to determine what microsite and macrosite criteria relate to optimized medicinal plant performance, because often a main reason reported for the failure of a 
reintroduction project is that plants were reintroduced to an ill-suited habitat (Godefroid et al. 2011).

A commonly used idea for ginseng reintroductions is the concept of indicator species, or species that indicate suitable habitat for ginseng (Fountain 1986, Anderson et al. 1993, Burkhart 2013). However, the ability of these indicators to predict ginseng performance had not been tested. Using a Panax-centric approach (Wixted \& McGraw 2009) and twenty-six natural populations of ginseng, ginseng plants were chosen through stratifiedrandom methods. Using popular putative indicator species selected from other studies (Fountain 1986, Anderson et al. 1993, Burkhart 2013), as well as from popular literature (Pritts 1995, Davis \& Persons 2014), and through an interview with someone with extensive knowledge of ginseng agroforestry (Beyfuss, personal communication 2013), a compiled list of herb, shrub, and tree indicators was developed for evaluation. Using a long-term ecological dataset, I calculated growth of ginseng plants that had the select indicator species present or absent within the population, or if the ginseng plant was in the microsite of the indicator.

Understanding what can maximize the success of medicinal plant reintroduction has the potential to reduce the waste of resources, time, and effort associated with unsuccessful projects. Historic land-use can have long-term impacts on the growth of herbaceous plants or the community of species in a forest (Dupouey et al. 2002, Vellend 2005, Fraterrigo et al. 2006). Since land-use history can influence the performance of plants, the historic use of the land may be an important consideration for reintroduction projects. 
Chapter 5 investigated if reintroduced medicinal plants, ginseng and goldenseal, have differential performance on sites that are mature forest, sites that were previously surface mined, or sites that have a history of agricultural activity. Reintroducing medicinal plants on sites of varying land-use histories will help land managers understand whether these valuable species can be restored to degraded lands, or whether mined-lands are 'permanently' lost as producers of NTFPs for the foreseeable future. Further, I wanted to determine if there was differential performance between goldenseal, a clonal plant, and ginseng, an aclonal plant that propagates via sexual reproduction. If there is a difference, will species performance depend on the land-use history? Finally, this chapter addressed if ginseng reintroduced to sites of varying land-use history, such as previously mined or agriculture lands, will have performance similar to natural populations of ginseng.

These four research chapters can help determine effective practices for in situ medicinal plant conservation. Understanding (a) how individuals perceive and implement conservation, (b) the potential economic value of ginseng harvest long-term, (c) if there are successful putative indicator species, or (d) if medicinal plants can grow on degraded landscapes, alone, would be beneficial knowledge to help conserve ginseng. This information could inform policy decisions or be used to develop in situ conservation strategies. However, these four studies, taken together, provide a holistic approach to understanding the social, economic, and ecological relationship between surface mining and ginseng, and what can be done to ensure ginseng survives for future generations. All of these objectives contribute to answering the overarching question: 'How is surface mining influencing ginseng sustainability and conservation?' 


\section{References}

Anderson, R. C., J. S. Fralish, J. E. Armstrong, and P. K. Benjamin. 1993. The ecology and biology of Panax quinquefolium L. (Araliaceae) in Illinois. American Midland Naturalist 129:357-372.

Bailey, B. 1999. Dissertation. Social and economic impacts of wild harvested products. West Virginia University.

Barnosky, A. D., N. Matzke, S. Tomiya, G. O. U. Wogan, B. Swartz, T. B. Quental, C. Marshall, J. L. McGuire, E. L. Lindsey, K. C. Maguire, B. Mersey, and E. A. Ferrer. 2011. Has the Earth's sixth mass extinction already arrived? Nature 471:51-57.

Bell, S. E., and R. York. 2010. Community economic identity: The coal industry and ideology construction in West Virginia. Rural Sociology 75:111-143.

Bernhardt, E. S., and M. A. Palmer. 2011. The environmental costs of mountaintop mining valley fill operations for aquatic ecosystems of the Central Appalachians. Annals of the New York Academy of Sciences 1223:39-57.

Branch, R. A., A. Chester, C. Morton-McSwain, S. Udin Al Ayubi, K. Bhat Schelbert, P. Brimson, S. Buch, Y. Cannon, S. Groark, S. Hanks, T. Nukui, P. Pancoska, B. Parmanto, S. Paulsen, and E. Wahl. 2011. A novel approach to adolescent obesity in rural Appalachia of West Virginia: Educating adolescents as family health coaches and research investigators. Pages 309-340 in M. B. Zimering, editor. Topics in the Prevention, Treatment and Complications of Type 2 Diabetes. INTECH Open Access Publisher.

Burkhart, E. P. 2013. American ginseng (Panax quinquefolius L.) floristic associations in Pennsylvania: guidance for identifying calcium-rich forest farming sites. Agroforestry Systems:1157-1172.

CITES Secretariat. (n.d.). Convention on International Trade in Endangered Species of Wild Fauna and Flora (CITES). www.cites.org.

Cox, J. J. 2011. Tales of a repatriated megaherbivore: Challenges and opportunities in the management of reintroduced elk in Appalachia. Pages 632-642 in Proceedings of the 17th Central Hardwood Forest Conference. Lexington, KY.

Davis, J. M., and W. S. Persons. 2014. Growing and marketing ginseng, goldenseal and other woodland medicinals. Revised ed. New Society Publishers, Gabriola Island, BC, Canada.

Drummond, M. A., and T. R. Loveland. 2010. Land-use pressure and a transition to forest-cover loss in the eastern United States. BioScience 60:286-298. 
Dupouey, J. L., E. Dambrine, J. D. Laffite, and C. Moares. 2002. Irreversible impact of past land use on forest soils and biodiversity. Ecology 83:2978-2984.

Emerson, P., J. Skousen, and P. Ziemkiewicz. 2009. Survival and growth of hardwoods in brown versus gray sandstone on a surface mine in West Virginia. Journal of Environmental Quality 38:1821-1829.

Epstein, P.R., Buonocore, J.J., Eckerle, K., et al. 2011. Full cost accounting for the life cycle of coal. Annals of the New York Acadamy of Science 1219:73-98.

Fountain, M. 1986. Vegetation associated with natural populations of ginseng (Panax quinquefolium) in Arkansas. Castanea 51:42-48.

Fraterrigo, J. M., M. G. Turner, and S. M. Pearson. 2006. Interactions between past land use, life-history traits and understory spatial heterogeneity. Landscape Ecology 21:777-790.

Garibaldi, A., and N. Turner. 2004. Cultural Keystone Species : Implications for Ecological Conservation and Restoration. Ecology and Society 9: [online].

Gilliam, F. S. 2007. The ecological significance of the herbaceous layer in temperate forest ecosystems. BioScience 57:845-858.

Godefroid, S., C. Piazza, G. Rossi, S. Buord, A. D. Stevens, R. Aguraiuja, C. Cowell, C. W. Weekley, G. Vogg, J. M. Iriondo, I. Johnson, B. Dixon, D. Gordon, S. Magnanon, B. Valentin, K. Bjureke, R. Koopman, M. Vicens, M. Virevaire, and T. Vanderborght. 2011. How successful are plant species reintroductions? Biological Conservation 144:672-682

Gragson, T. L., and P. V. Bolstad. 2006. Land use legacies and the future of southern Appalachia. Society and Natural Resources 19:175-190.

Haight, A. D., and W. J. González-Espada. 2009. Scientific literacy in central Appalachia through contextually relevant experiences: The "Reading the River" Project. International Journal of Environmental and Science Education 4:215-230.

Hammond, G. W. 2011. Consensus coal production and price forecast for West Virginia: 2011 Update. West Virginia Department of Environmental Protection, Office of Special Reclamation.pp.1-35.

Hook, M., and K. Aleklett. 2009. Historical trends in American coal production and a possible future outlook. International Journal of Coal Geology 78:201-216.

Hufford, M. 2002. Reclaiming the commons: Narratives of progress, preservation, and ginseng. Pages 100-120 in B. J. Howell, editor. Culture, Environment, and Conservation in the Appalachian South. Chicago, IL. 
Hufford, M. 2003. Knowing ginseng: The social life of an Appalachian root. Cahiers de Littérature Orale: 53-54:265-295.

Katz, M.L., Reiter, P.L., Heaner, S. et al. 2009. Acceptance of the HPV vaccine among women, parents, community leaders, and healthcare providers in Ohio Appalachia. Vaccine 27:3945-3952.

Kelley, K., B. Clark, V. Brown, and J. Sitzia. 2003. Good practice in the conduct and reporting of survey research. International Journal for Quality in Health Care 15: 261-266.

Lindberg, T. T., E. S. Bernhardt, R. Bier, A. M. Helton, R. B. Merola, A. Vengosh, and R. T. Di Giulio. 2011. Cumulative impacts of mountaintop mining on an Appalachian watershed. Proceedings of the National Academy of Sciences 108:20929-20934.

MacDonald, K. I. 2010. The devil is in the (bio)diversity: Private sector "engagement" and the restructuring of biodiversity conservation. Antipode 42:513-550.

McGraw, J. B., A. E. Lubbers, M. Van der Voort, E. H. Mooney, M. A. Furedi, S. Souther, J. B. Turner, and J. Chandler. 2013. Ecology and conservation of ginseng (Panax quinquefolius) in a changing world. Annals of the New York Academy of Sciences: The Year in Ecology and Conservation Biology:1286:62-91.

McGraw, J. B., S. Souther, and A. E. Lubbers. 2010. Rates of harvest and compliance with regulations in natural populations of American ginseng (Panax quinquefolius L.). Natural Areas Journal 30:202-210.

McGraw, J., S. Sanders, and M. Van der Voort. 2003. Distribution and abundance of Hydrastis canadensis L. (Ranunculaceae) and Panax quinquefolius L. (Araliaceae) in the Central Appalachian Region. Journal of the Torrey Botanical Society 130:62-69.

Palmer, M. A., E. Bernhardt, W. Schlesinger, K. Eshleman, E. Foufoula-Georgiou, M. Hendryx, A. Lemly, G. Likens, O. Loucks, M. Power, and others. 2010. Mountaintop mining consequences. Science 327:148-149.

Pond, G. J., M. E. Passmore, F. A. Borsuk, L. Reynolds, and C. J. Rose. 2008. Downstream effects of mountaintop coal mining: comparing biological conditions using family-and genus-level macroinvertebrate bioassessment tools. Journal of the North American Benthological Society 27:717-737.

Pritts, K. D. 1995. Ginseng: How to find, grow, and use America's forest gold. Stakepole Books, Mechanicsburgh, PA. 
Radeloff, V. C., R. B. Hammer, and S. I. Stewart. 2005. Rural and suburban sprawl in the U.S. midwest from 1940 to 2000 and its relation to forest fragmentation. Conservation Biology 19:793-805.

Rasker, R. 1993. Rural development, conservation, and public policy in the greater Yellowstone ecosystem. Society and Natural Resources. 6:109-126.

Robbins, C. S. 2000. Comparative analysis of management regimes and medicinal plant trade monitoring. Conservation Biology 14:1422-1434.

Sala, O. E., F. S. Chapin, J. J. Armesto, E. Berlow, J. Bloomfield, R. Dirzo, E. HuberSanwald, L. F. Huenneke, R. B. Jackson, A. Kinzig, R. Leemans, D. M. Lodge, H. A. Mooney, M. Oesterheld, N. L. Poff, M. T. Sykes, B. H. Walker, M. Walker, and D. H. Wall. 2000. Global biodiversity scenarios for the year 2100. Science 287:1770-1774.

Skousen, J. G., C. D. Johnson, and K. Garbutt. 1994. Natural revegetation of 15 abandoned mine land sites in West Virginia. Journal of Environmental Quality 23:1224-1230.

Skousen, J., P. Ziemkiewicz, and C. Venable. 2006. Tree recruitment and growth on 20year-old , unreclaimed surface mined lands in West Virginia. International Journal of Mining, Reclamation, and the Environment 20:142-154.

Souther, S. and J. B. McGraw. 2014. Synergistic effects of climate change and harvest on extinction risk of American ginseng. Ecological Applications 24:1463-1477.

Ticktin, T., and C. Shackleton. 2011. Harvesting Non-timber Forest Products Sustainably: Opportunities and Challenges. Pages 149-169 in S. Shackleton, C. Shackleton, and P. Shanley, editors. Non-Timber Forest Products in the Global Context,Tropical Forestry. Springer Berlin Heidelberg. Berlin, Germany.

Townsend, P. A., D. P. Helmers, C. V. Kingdon, B. E. McNeil, K. M. de Beurs, and K. N. Eshleman. 2009. Changes in the extent of surface mining and reclamation in the Central Appalachians detected using a 1976 - 2006 Landsat time series. Remote Sensing of Environment 113:62-72.

Vaughan, G. L. 1979. Effects of stripmining on fish and diatoms in streams of the New River drainage basin. Journal of the Tennessee Academy of Science 54:110-115.

Vellend, M. 2005. Land-use history and plant performance in populations of Trillium grandiflorum. Biological Conservation 124:217-224.

Van der Voort, M. E. 1998. Thesis. An inventory of wild-harvested plants in the Otter Creek Wilderness Area of the Monongahela National Forest, West Virginia. West Virginia University. 
Van der Voort, M. E., and J. B. McGraw. 2006. Effects of harvester behavior on population growth rate affects sustainability of ginseng trade. Biological Conservation 130:505-516.

Wixted, K., and J. B. McGraw. 2009. A Panax-centric view of invasive species. Biological Invasions 11:883-893.

Yin, J., H. Zhang, and J. Ye. 2008. Traditional Chinese Medicine in treatment of metabolic syndrome. Endocrine, Metabolic \& Immune Disorders - Drug Targets 8:99-111.

Zipper, C. E., J. A. Burger, J. G. Skousen, P. N. Angel, C. D. Barton, V. Davis, and J. A. Franklin. 2011. Restoring forests and associated ecosystem services on Appalachian coal surface mines. Environmental Management 47:751-65. 
CHAPTER II: CONFLICTING VALUES ASSOCIATED WITH RENEWABLE VERSUS NON-RENEWABLE RESOURCE EXTRACTION IN APPALACHIA 


\begin{abstract}
Historically, the Appalachian economy is based on resource extraction, such as coal mining, timbering, and medicinal plant harvest, however these extractive activities may be in conflict with each other. Surface mining destroys forest habitat, and it is thereby reducing the land area supporting medicinal plant populations. The premier medicinal plant in Appalachia is the internationally valuable herb, American ginseng (Panax quinquefolius L.). While medicinal plant harvest is potentially sustainable, some harvesting practices can be detrimental to the performance of this long-lived herb. Little is known about how individuals in West Virginia view the relationship between surface mining and ginseng harvest, including whether they recognize the conflict, how they prioritize conservation, and whether harvesters engage in sustainable harvesting practices or alternatively, conclude that stewardship-oriented harvest practices are useless in the face of habitat loss. In order to study this relationship, we used a purposeful, communitybased participatory research methodology. As Appalachian communities, and especially ginseng harvesters, are considered distrustful of outsiders, student volunteers in an after school science program (Health Science and Technology Academy; HSTA) distributed surveys throughout West Virginia to people based on two sample frames: harvesters and non-harvesters. Questions in the surveys were organized into five concepts central to our objectives. Reliability of survey data was analyzed with Cronbach's alpha statistic, and comparisons between harvesters and the community at large were made using likelihoodratio $\chi^{2}$ or ANOVAs. As expected, harvesters had greater knowledge about ginseng, and a stronger positive opinion about conservation, when compared to nonharvesters. However, there was an apparent disconnect between environmental beliefs and actions with respect to harvest. Roughly $83 \%$ of harvesters surveyed admitted to illegal and detrimental harvesting activities, yet as a group, they were far more likely to advocate for ginseng conservation. Addressing how individuals in Appalachia can be empowered to translate beliefs into action will help ensure that ginseng harvest remains a sustainable activity for Appalachia. This research has the potential to aid in the development of effective environmental education and conservation outreach regarding medicinal plant harvest.
\end{abstract}




\section{Introduction}

Many communities worldwide embrace varying forms of resource extraction as an important component of their livelihood and lifestyle (Peluso, 1992; Shackleton, Shackleton, \& Cousins, 2001; Thomas \& Twyman, 2005). Even economies built on industries that have waned can have lasting impacts on the identity of the community (Bell \& York, 2010). In the Appalachian region, hunting, fishing, and gathering nontimber forest products (NTFP) are often important hobbies and traditions (Bailey, 1999; Edwards, 2011; Hufford, 2002, 2003). Appalachia historically has low levels of employment and high levels of poverty (Bailey, 1999; Chenoweth \& Galliher, 2004), so activities such as these can provide individuals from this region with valuable supplementary income or food supply (Bailey, 1999; Edwards, 2011). While these activities may have low environmental impact, other forms of high-impact resource extraction, such as surface mining, are also integrated into the cultural identity of this region, specifically West Virginia (Bell \& York, 2010; Blaacker, Woods, \& Oliver, 2012), potentially creating a conflict between values related to land-use and resource conservation.

Surface mining for coal is one of the principle drivers of habitat loss in Appalachia (Townsend et al., 2009), with an estimated 604,955 hectares of eastern forest being converted to mine sites between 1973 and 2000 (Drummond \& Loveland, 2010). In 1977, the Surface Mining Control and Reclamation Act (SMCRA) was established to reclaim mined sites (Sullivan \& Amacher, 2009), yet current evidence suggests that these sites do not return to pre-mining conditions after reclamation (Palmer et al., 2010). Even when sites are reclaimed, the process of surface mining can have numerous negative 
lasting impacts on the health of neighboring ecosystems (Bernhardt \& Palmer, 2011; Lindberg et al., 2011; Palmer et al., 2010; Pond et al., 2008). By definition, coal mining is unsustainable, as there are finite reserves of coal that are being depleted (as defined in Brown, Hanson, Liverman, \& Merideth, 1987). While West Virginia is rural, the economy has been based primarily on industry (Lewis, 1993); as such, while its economic contribution is waning (Bell \& York, 2010), surface mining is still an economic force in the Appalachian region, especially in West Virginia (BBER \& CBER, 2010). However, despite the belief that surface mining provides numerous jobs for the region, a previous study found that there was no relationship between employment and proximity to mountaintop removal mines, a form of surface mining (Woods \& Gordon, 2011). The conversion of deciduous forest to a post-mining landscape, ranging from grassland to an unusual early successional forest consisting of invasive native or exotic trees and shrubs, has long-lasting implications for the productivity and biodiversity of the ecosystem, as well as the cultural heritage of this region.

The premier wild-harvested herb in North America is American ginseng (McGraw et al., 2013; Robbins, 2000), hereafter referred to as ginseng. The range of ginseng as a resource in Appalachia overlaps directly with the concentrated area of coal surface mining. This small, herbaceous plant is harvested and sold for hundreds of dollars per kilogram on the international market where it is used in traditional Chinese medicine (Burkhart \& Jacobson, 2009; Schlag \& Mcintosh, 2006; Yin, Zhang, \& Ye, 2008). Ginseng has been harvested extensively since the 1700 s, one factor among several causing this once common species to become rare (McGraw et al., 2013); therefore, it is 
now listed on the Convention on International Trade in Endangered Species of Wild Fauna and Flora, Appendix II (CITES Secretariat). When a medicinal plant is overharvested, the species can become critically endangered (Rana \& Samant, 2011); species may be overharvested because the traditional ecological knowledge of a region may be lacking in areas that are essential for the survival of a rare species (Biró et al., 2014). However, when ginseng is sustainably harvested and stewarded, population sizes can increase, benefitting conservation management of this species (Van der Voort \& McGraw, 2006). While sustainability of the ginseng trade in Appalachia can be reduced because of illegal or unsustainable harvesting practices, sustainable trade is irrelevant if ginseng's habitat is being continually lost to surface mining practices; this will extinguish ginseng populations for the long-term.

American ginseng harvest is integrated into the Appalachian community and culture (Hufford, 2003), and the connection to this plant extends beyond ginseng harvesters. Previous survey work has focused on the 'top-down' harvest regulation of ginseng (Burkhart, Jacobson, \& Finley, 2012), harvest motivation and culture (Bailey, 1999), and opinions about ginseng poaching with various stakeholders (Pokladnik, 2008). In these previous studies, the concern among the ginseng community for habitat loss due to surface mining was expressed (Burkhart, Jacobson, \& Finley, 2012; Pokladnik, 2008), but land-use change and individual conservation knowledge were not the focus. West Virginia University students' perceptions about 'big coal' were investigated through surveys by Blaacker et al.(2012). The participants overestimated the size and importance of the coal industry in the state of West Virginia. From a social standpoint, 
the relationship between surface mining and ginseng has been studied (Hufford, 2002, 2003). Hufford (2003) argued that coal mining is overshadowing, and destroying, the cultural connection of ginseng in Appalachia, especially in the Coal River area of West Virginia, but that sustainable ginseng harvest is a viable option for a strong economy for this region (Hufford, 2002).

In a sociology thesis, Edwards (2011) studied, through qualitative interviews, how ginseng stewards perceive themselves in the context of a larger society, and how they negatively view the coal industry's impact on their livelihoods and lives. This thesis focused on interviewing individuals, all male and unemployed, who prioritize conservation; Edwards interviewed only one harvester who did not practice stewardship. Most ginseng harvesters are not strictly following harvest laws in some respect (McGraw, Souther, \& Lubbers, 2010), and so the narrow sample frame included in his research may not represent the at-large harvester community. Edward's work illustrated that harvesters (both stewards and non-steward) were distrustful of the government. Additionally, as his focus was to understand a small sub-group of the Appalachian community, we do not know how the Appalachian community at large views the relationship between ginseng harvest and surface mining.

To understand the most effective methods of environmental outreach and landmanagement protocols for a region, the culture, value systems, and traditional ecological knowledge of its residents must be understood (Berkes, Colding, \& Folke, 2000; Bowcutt, 1999; Hunter \& Brehm, 2004; Turner et al., 2008; Turner, Ignace, \& Ignace, 
2000). While all constituencies may recognize a tradeoff between alternative types of resource extraction, the human response to this tradeoff is not necessarily obvious. Responding to the perceived threat of surface mining for sustainable resource extraction such as ginseng harvest, individuals may feel as if they are 'invested' in the sustainability of the region. Even though surface mining is occurring at such a large-scale, and mining provides economic benefits to the region, these residents of Appalachia may feel that renewable resources are an important component of sustainable development for the region. Invested individuals would be future oriented, and believe that conservation of renewable resources should be prioritized, despite the environmental degradation that is occurring. Alternatively individuals may feel 'divested' in the sustainability of the region. Since surface mining is occurring, individuals may feel inclined to give little or no effort to defend or conserve renewable natural resources, as they feel they lack power to make positive change. Therefore, they exploit resources in a non-sustainable way, not concerned about future use.

This led us to ask the following questions about people who live in West Virginia: (1) While other studies have demonstrated that harvesters understand how surface mining is impacting ginseng, how far has this knowledge penetrated the community at large? (2) As such, do factors, such as employment, gender, and education influence the beliefs and perceptions differently among sample frames? (3) Will harvesters admit to illegal harvest practices observed in prior studies of natural populations? (4) How does the sense of individual empowerment influence opinions of conservation for the sample frames? 


\section{Methods \\ Sample and Procedure}

To address the questions above, a survey study was implemented with two sample frames targeted: individuals currently living in West Virginia that do not harvest ginseng (nonharvesters) and ginseng harvesters living in West Virginia (harvesters). Working with the Health Sciences and Technology Academy (HSTA), through West Virginia University (WVU), was an integral asset to this research. HSTA is an afterschool science and math enrichment program that serves, on average, 800 underserved and minority high school students in 26 rural counties across WV and has proven value in aiding community-based participatory research (Branch et al., 2011). Students are required to complete annual research projects and are encouraged to work with scientists. Our survey distribution was non-random and purposeful. This survey was considered community-based participatory research as it used a bottom-up assistance sampling protocol (Branch et al., 2011; Fowler, 2009; Kelley et al., 2003) by having a proportion of HSTA students distribute surveys to participants from the two sample frames in their communities.

Traditional random or stratified techniques, as well as interviews, can be ineffective at obtaining honest answers from survey participants, as this requires substantial trust in the interviewer (Bailey, 1999; Edwards, 2011). The benefit of our non-traditional methodology was that it could potentially provide additional anonymity to survey participants. Since we were investigating harvesting behavior that had the potential to be illegal, and questions dealt with opinions about the government, survey participants could feel additional security in answering genuinely. Additionally, because individuals in 
Appalachia, especially ginseng harvesters (Edwards, 2011), are distrustful of outsiders (Behringer \& Friedell, 2006; Boyer, 2006; Katz et al., 2009), a student from the community administering the survey would be more likely to obtain honest answers from participants. Since the surveys were associated with members of the West Virginian community (HSTA students) rather than a scientist, and the surveys are selfadministered, there was also likely to be a lower response bias (Fowler, 2009).

All participants involved with the development and dispersal of the survey instruments were trained in the Social/Behavioral Research Training and Human Subject Research tests through the Collaborative Institutional Training Initiative in accordance with West Virginia University's Institutional Review Board (IRB) protocol, and each student had direct access to a Community Research Associate (CRA) if they had any questions about survey work. HSTA CRA(s) are former science educators and public health experts that play an integral role in assisting HSTA students in preparing for their community-based research projects (ethics training, recruitment plans, reviewing IRB protocols, etc.) and in explaining the purpose of research to community members. The CRAs focus much of their attention on listening to the community and their needs so they can better guide the research of the students in the program (Morton-McSwain, 2013). Survey participants were required to be currently living in West Virginia and over the age of 15. The surveys had a waiver of signed consent for increased anonymity; each survey was handed to the participant in an unmarked white envelope. Surveys were self-administered, but the CRAs, research leads, or the HSTA students were available for questions or assistance in understanding the surveys. Upon completion, the survey was sealed in the envelope to 
ensure confidentiality and returned to WVU for analysis. West Virginia University's IRB approved the sampling protocols and the survey instruments in fall 2013 and fall 2014. Surveys were distributed from December 2013 through February 2015, with analysis occurring in 2015 (Appendix A, B).

\section{Measures}

Surveys for both harvesters (Appendix A) and non-harvesters (Appendix B) were comprised of questions that included Likert-items with five order response levels (Likert, 1974), yes or no questions, ranking items on a list, and quantifiable fill-in-the-blank questions (e.g. How many people do you know that harvest ginseng and sell it?). Questions were designed so numeric values could be assigned to each answer. If a participant left a question incomplete, or if they answered in a way that was impossible to code, their response was marked as blank. In order to determine readability of the survey instruments, the developed survey instruments were evaluated using the Flesh-Kincaid grade scale (Stockmeyer, 2009), and they were ranked at a grade of 6.5 or lower. This grade implies that someone with an elementary school education could understand the wording used in the surveys.

Questions in the survey corresponded to several overarching concepts that quantify individual preferences, activities, and beliefs in relation to surface mining and ginseng. Organized by concept, the numeric values of related questions were added and used as that participant's index score for that concept. This allowed us to investigate the relationships between concepts for non-harvesters, as well as harvesters. Additional 
questions were asked of both harvesters and non-harvesters that did not fall into these categories. Additionally, the ginseng conservation concept also included questions relating surface mining to ginseng. Harvesters were also given questions relating to harvest practices and culture.

Cronbach's alpha was used to test the internal reliability of the concepts (with a threshold set at $\alpha=0.7)$. Both harvesters and non-harvesters were evaluated with respect to the following concepts: ginseng conservation (seven questions, possible score range: 7-35; harvesters: $\alpha=0.83$; non-harvesters: $\alpha=0.71$ ), ginseng knowledge (eight questions, possible score range: $8-40$; harvesters: $\alpha=0.76$; non-harvesters: $\alpha=0.74)$, surface mining support (six questions, possible score range: 6-30; harvesters: $\alpha=0.86$; nonharvesters: $\alpha=0.85$ ), opinion of conservation (eleven questions, possible score range: 11-55; harvesters: $\alpha=0.81$; non-harvesters: $\alpha=0.78$ ), and trust of environmental experts (eight questions, possible score range: 8-40; harvesters: $\alpha=0.86$; non-harvesters: $\alpha=0.68$ ). The following are example survey items from each concept, and the answers for each question was a five-order response ranging from strongly disagree to strongly agree: Ginseng Conservation: Ginseng could go extinct with how people currently harvest ginseng; Ginseng Knowledge: Ginseng is an internationally important plant; Trust of Environmental Experts: The Environmental Protection Agency protects the Appalachian region; Surface Mining Support: I trust the mining companies to properly reclaim the land; Opinion of Conservation: Conservation of natural resources is important to my everyday life. 


\section{Analyses}

Normality of the residuals was evaluated with a Shapiro-Wilk W test. Harvesters and community members were asked to rank the trustworthiness of seven groups. The responses were collapsed into three categories: highest (rank 1 and 2), neutral (rank 3 and 4), and lowest (rank 5-7) levels of trust. Concept scores were treated as continuous variables, whereas responses to individual questions (which typically only had five possible answers) were treated as nominal variables. A likelihood-ratio (L-R) $\chi^{2}$ analysis was conducted to compare how harvesters and non-harvesters answered each question. To determine if harvesters and non-harvesters had similar mean scores for each concept, a one-way ANOVA was used. Two-way ANOVAs were used to determine if the effect of certain variables (employment status, gender, and education) on mean concept scores depended on sample frame (a variable x sample frame interaction).

For each harvester, depending on how they answered harvest related questions, their practices were classified as 'legal' or 'illegal' in accordance with West Virginia harvest laws. Finally, two-way ANOVAs were used to evaluate whether the difference between harvesters and non-harvesters in total concept score, depended on the level of agreement the participant had (a) that individuals can make a difference and (b) that they have a say in environmental issues in Appalachia. For these questions, there were four categories, low (if participants strongly disagreed or disagreed), neutral (if the participant was neutral on the subject), high (if participant agreed), and very high (if the participant strongly agreed). We were interested in the interaction, but if this term was not significant, we focused on the main effect of agreement with personal empowerment. 
When applicable, the conservative Tukey's HSD a posteriori test was used to determine differences among groups. Data were analyzed using SAS JMP Pro $11(\alpha=0.05$; SAS JMP, 2013).

\section{Results}

\section{Survey Participants}

A total of 35 harvesters and 304 non-harvesters participated in this research (Table 2.1), from a total of twenty counties in West Virginia. Among survey participants, more male harvesters than females responded, however the population was ca. 2:1 female:male in the non-harvester group. A wide range of ages were surveyed, with the non-harvester group biased somewhat toward the younger age-classes. Both harvesters and community members frequently had close friends or family members who were coal miners (Table 2.2). However, community members were less likely to know someone who was a ginseng harvester, while ginseng harvesters often knew other harvesters (Table 2.2). Harvesters and non-harvesters were most likely to rate pastors, followed by teachers, as being the most trustworthy (Table 2.3). Similarly, for harvesters and non-harvesters, the lowest levels of trust were assigned to radio or television and city mayors. Harvesters showed a stronger preference for outdoor activities: $71.4 \%$ of harvesters said that outdoor activities were extremely important to them, as compared to $31.6 \%$ of non-harvesters.

\section{Perceptions of surface mining and ginseng for harvesters and non-harvesters}

Harvesters were 56\% more likely to answer that they knew about ginseng's international importance than non-harvesters (Fig. 2.1a; L-R $\chi^{2}=37.07, \mathrm{p}<0.0001$ ). Additionally, harvesters were $78 \%$ more likely to claim they knew a lot about the environment (Fig. 
2.1a; $\mathrm{L}-\mathrm{R} \chi^{2}=23.34, \mathrm{p}=0.0001$ ), and $43 \%$ more likely to agree that ginseng could go extinct the way it is currently harvested (Fig. 2.1a; L-R $\chi^{2}=32.15$, p<0.0001). Of all harvesters, $65.7 \%$ strongly disagreed with the statement that it does not matter if ginseng is around for future generations, as compared to $24.7 \%$ of non-harvesters (Fig. 2.1b; L-R $\left.\chi^{2}=29.79, \mathrm{p}<0.0001\right)$.

There were also differences between harvesters and non-harvesters in questions related to resource and land-management. Harvesters were $91 \%$ more likely to agree with the statements that surface mining reduces the amount of ginseng in Appalachia (Fig. 2.1a; L-R $\left.\chi^{2}=28.97, \mathrm{p}<0.0001\right)$, and $65 \%$ more likely to agree that surface mining reduces the habitat for native animals and plants (Fig. 2.1a; $\mathrm{L}-\mathrm{R} \chi^{2}=19.75$, $\mathrm{p}=0.0006$ ). They were $47 \%$ more likely to answer that they did not trust mining companies to have the best interest of the public in mind (Fig. 2.1b; L-R $\chi^{2}=10.63, \mathrm{p}=0.0311$ ), and harvesters were $30 \%$ more likely to agree that there should be more conservation management of resources in Appalachia (Fig. 2.1a; L-R $\chi^{2}=12.48, \mathrm{p}=0.0141$ ). Harvesters were 150\% more likely to strongly disagree that their land/property is a short-term investment only (Fig. 2.1b; L-R $\chi^{2}=14.93, \mathrm{p}=0.005$ ). Ginseng harvesters were $32 \%$ more likely than non-harvesters to disagree that they appreciated the forest only because of its monetary value (Fig. 2.1b; L-R $\chi^{2}=15.31, \mathrm{p}=0.0041$ ), and harvesters were $107 \%$ more likely to disagree that parks and preserves are owned by everyone (Fig. 2.1b; L-R $\chi^{2}=17.93$, $\mathrm{p}=0.0013$ ). While harvesters were $48 \%$ more likely than non-harvesters to trust scientists to be honest (Fig. 2.1a; L-R $\chi^{2}=13.33$, $\mathrm{p}=0.0098$ ), harvesters were $90 \%$ more likely to 
disagree that the EPA protects the Appalachian Region (Fig. 2.1b; L-R $\chi^{2}=12.91$, $\mathrm{p}=0.0117)$.

Harvesters were more likely than non-harvesters to support ginseng conservation, and understand environmental threats for this species (Fig. 2.2a; $F=32.95, \mathrm{p}<0.0001$ ), with a mean concept score being approximately $15.5 \%$ higher than a non-harvester. When compared to non-harvesters, harvesters scored $29.1 \%$ higher on the ginseng knowledge concept (Fig. 2.2b; F=45.02, p<0.0001). Harvesters also held a stronger positive opinion of conservation (7.6\% higher) than non-harvesters (Fig. 2.2c; $F=10.20, p=0.0015)$.

\section{Influence of social variables}

The effect of sample frame on understanding ginseng conservation depended on if individuals were employed full-time; while harvesters understood ginseng conservation better than non-harvesters, non-harvesters that were not full-time employed had lower levels of understanding ginseng conservation than employed non-harvesters (Fig. 2.3a; $\mathrm{F}_{\text {sample frame } \mathrm{x} \text { employment }}=3.93, \mathrm{p}=0.0483$ ). The effect of employment status on support for surface mining differed for the two sample frames, with employed harvesters tending to support surface mining more than unemployed harvesters, but the reverse was seen for

non-harvesters (Fig 2.3b; $\left.\mathrm{F}_{\text {sample frame } \mathrm{x} \text { employment }}=4.64, \mathrm{p}=0.0319\right)$. Additionally, there was a trend that the effect of sample frame on the opinion of conservation depended on employment status: non-harvesters that were not employed full-time had the lowest opinion of conservation relative to harvesters or full-time employed non-harvesters (Fig. $2.3 \mathrm{c} ; \mathrm{F}_{\text {sample frame } \mathrm{x} \mathrm{employment}}=3.78, \mathrm{p}=0.0527$ ). 
Two other social variables, gender and education, also may impact how individuals from different sample frames scored in certain concepts. The effect of sample frame on the support for surface mining score depended on education level; non-harvesters with higher levels of education had lower support for surface mining compared to non-harvesters with a high school degree or below, while the opposite was seen for harvesters (Fig. 2.3d; $\mathrm{F}_{\text {sample frame x education }}=6.33, \mathrm{p}=0.0123$ ). The effect of sample frame on the participant's trust of environmental experts depended on the participant's gender, as all groups had similar levels of trust in environmental experts, except female harvesters (Fig. 2.3e; $\mathrm{F}_{\text {sample frame } \mathrm{x}}$ gender $=8.60, p=0.0036)$. Female harvesters trusted environmental experts more than male harvesters, and non-harvesters of either gender.

\section{Harvester response}

Harvesters readily admitted to illegal activity. The law most harvesters admitted to breaking was the size limit law, as $64.7 \%$ of harvesters admitted to taking plants that were too small (Table 2.4). Since $2010,25.7 \%$ of harvesters admitted to harvesting out of season. Also, $28.5 \%$ of harvesters admitted to harvesting on land illegally (private property without permission, state forests, national parks, etc.) (Table 2.4). Out of all harvesters, $82.9 \%$ admitted to at least one form of illegal harvest (e.g., harvesting out of season, in illegal locations, or taking plants that were too small, etc.) (Table 2.4). 


\section{Sense of empowerment}

Between harvesters and non-harvesters, there was a difference in scores on certain concepts, depending on the level of personal empowerment that participants felt. The effect of sample frame on the mean ginseng conservation concept depended on whether survey participants believed that individuals could make a difference (Fig. 2.4a; $\mathrm{F}_{\text {sample frame }}$ $\mathrm{x}$ agreement $=3.31, \mathrm{p}=0.0203$ ). Harvesters had a higher understanding of ginseng conservation than non-harvesters, but harvesters had scores similar to non-harvesters when the survey participant felt neutral to the idea that an individual can make a difference. Notably, harvesters who very strongly agreed that individuals can make a difference and harvesters who felt like individuals could not make a difference had similar high scores.

The effect of sample frame on mean trust in environmental experts score depended on whether survey participants felt they had a say in environmental issues in Appalachia (Fig. 2.4b; $\mathrm{F}_{\text {sample frame } \mathrm{X} \text { agreement }}=5.61, \mathrm{p}=0.0009$ ). Harvesters' trust in environmental experts increased more with increasing perception of having a say, than non-harvesters. The groups with the lowest trust in environmental experts were the survey participants that did not feel that they have a voice in the issues concerning conservation in Appalachia.

Individuals who strongly agreed with the statement "I believe I have a say in environmental issues in Appalachia" scored 13.0\% higher in understanding ginseng conservation than individuals with low levels of agreement (Fig. 2.5a; $\mathrm{F}_{\text {agreement }=} 4.11$, 
$\mathrm{p}=0.0070$ ). Additionally, individuals who strongly agreed that they have a voice in the environmental issues of Appalachia were more likely to have a higher opinion of conservation than individuals with neutral or low agreement (Fig. $2.5 \mathrm{~b} ; \mathrm{F}_{\text {agreement }}=5.10$, $\mathrm{p}=0.0019)$. In fact, they were more likely to have, on average, a $13.0 \%$ higher opinion of conservation than individuals with a low or neutral agreement. 
Table 2.1. Demographic overview of survey respondents, organized by sample frame.

\begin{tabular}{|c|c|c|c|c|}
\hline & Harvesters & $\%(\mathrm{~N}=35)$ & Non-Harvesters & $\%(\mathrm{~N}=304)$ \\
\hline \multicolumn{5}{|l|}{ Gender } \\
\hline Female & 10 & $28.6 \%$ & 196 & $64.5 \%$ \\
\hline Male & 25 & $71.4 \%$ & 101 & $33.2 \%$ \\
\hline (blank) & 0 & $0.0 \%$ & 7 & $2.3 \%$ \\
\hline \multicolumn{5}{|l|}{ Age } \\
\hline $15-20$ & 5 & $14.3 \%$ & 106 & $34.9 \%$ \\
\hline $21-30$ & 5 & $14.3 \%$ & 17 & $5.6 \%$ \\
\hline $31-40$ & 10 & $28.6 \%$ & 50 & $16.4 \%$ \\
\hline $41-50$ & 5 & $14.3 \%$ & 68 & $22.4 \%$ \\
\hline $51-60$ & 4 & $11.4 \%$ & 38 & $12.5 \%$ \\
\hline $61-70$ & 5 & $14.3 \%$ & 19 & $6.3 \%$ \\
\hline $71-80$ & 1 & $2.9 \%$ & 4 & $1.3 \%$ \\
\hline over 100 & 0 & $0.0 \%$ & 1 & $0.3 \%$ \\
\hline (blank) & 0 & $0.0 \%$ & 1 & $0.3 \%$ \\
\hline \multicolumn{5}{|l|}{ Employment } \\
\hline Full-time & 16 & $45.7 \%$ & 131 & $43.1 \%$ \\
\hline Part-time & 2 & $5.7 \%$ & 36 & $11.8 \%$ \\
\hline Retired & 7 & $20.0 \%$ & 26 & $8.6 \%$ \\
\hline Unemployed & 10 & $28.6 \%$ & 107 & $35.2 \%$ \\
\hline (blank) & 0 & $0.0 \%$ & 4 & $1.3 \%$ \\
\hline \multicolumn{5}{|l|}{ Highest Level of Education } \\
\hline Elementary school & 0 & $0.0 \%$ & 2 & $0.7 \%$ \\
\hline Middle school & 2 & $5.7 \%$ & 7 & $2.3 \%$ \\
\hline High school & 16 & $45.7 \%$ & 143 & $47.0 \%$ \\
\hline Trade school & 6 & $17.1 \%$ & 8 & $2.6 \%$ \\
\hline Some college classes & 3 & $8.6 \%$ & 48 & $15.8 \%$ \\
\hline College degree & 5 & $14.3 \%$ & 45 & $14.8 \%$ \\
\hline Graduate degree & 3 & $8.6 \%$ & 50 & $16.4 \%$ \\
\hline (blank) & 0 & $0.0 \%$ & 1 & $0.3 \%$ \\
\hline \multicolumn{5}{|l|}{ Household Income } \\
\hline less than $\$ 15,000$ & 4 & $11.4 \%$ & 38 & $12.5 \%$ \\
\hline$\$ 15,001-\$ 30,000$ & 4 & $11.4 \%$ & 60 & $19.7 \%$ \\
\hline$\$ 30,001-\$ 45,000$ & 8 & $22.9 \%$ & 51 & $16.8 \%$ \\
\hline$\$ 45,001-\$ 60,000$ & 6 & $17.1 \%$ & 53 & $17.4 \%$ \\
\hline$\$ 60,001-\$ 75,000$ & 4 & $11.4 \%$ & 25 & $8.2 \%$ \\
\hline over $\$ 75,000$ & 6 & $17.1 \%$ & 61 & $20.1 \%$ \\
\hline (blank) & 3 & $8.6 \%$ & 16 & $5.3 \%$ \\
\hline
\end{tabular}


Table 2.2. Community relationship between ginseng and coal mining among survey participants, organized by sample frame.

\begin{tabular}{lcccc}
\hline & Harvesters & $\%(\mathbf{N}=\mathbf{3 5})$ & Non-Harvesters & $\%$ (N=304) \\
\hline Personally Use Ginseng Medicinally & & & & \\
$\quad$ Yes & 5 & $14.3 \%$ & 42 & $13.8 \%$ \\
$\quad$ No & 30 & $85.7 \%$ & 261 & $85.9 \%$ \\
$\quad$ (blank) & 0 & $0.0 \%$ & 1 & $0.3 \%$ \\
\hline $\begin{array}{l}\text { Know Individuals Who Use Ginseng } \\
\text { Medicinally }\end{array}$ & & & \\
$\quad$ Yes & 22 & $62.9 \%$ & 86 & $28.3 \%$ \\
$\quad$ No & 12 & $34.3 \%$ & 217 & $71.4 \%$ \\
$\quad$ (blank) & 1 & $2.9 \%$ & 1 & $0.3 \%$ \\
\hline Know People Who Harvest Ginseng for & & & & \\
Profit & 32 & $91.4 \%$ & 177 & $58.2 \%$ \\
$\quad$ Yes & 2 & $5.7 \%$ & 126 & $41.4 \%$ \\
$\quad$ No & 1 & $2.9 \%$ & 1 & $0.3 \%$ \\
$\quad$ (blank) & & & & \\
\hline Friend/Family is a Coal Miner & & & & \\
$\quad$ Yes & 33 & $94.3 \%$ & 252 & $82.9 \%$ \\
$\quad$ No & 2 & $5.7 \%$ & 52 & $17.1 \%$ \\
$\quad$ (blank) & 0 & $0.0 \%$ & 0 & $0.0 \%$ \\
\hline
\end{tabular}


Table 2.3. Rank of how harvesters and non-harvesters view the trustworthiness of certain groups (organized by harvester trust).

\begin{tabular}{|c|c|c|c|c|}
\hline & Harvesters & $\%$ & Non-Harvesters & $\%$ \\
\hline \multicolumn{5}{|l|}{ Highest Level of Trust } \\
\hline Pastor & 23 & $32.9 \%$ & 193 & $31.7 \%$ \\
\hline Teacher & 18 & $25.7 \%$ & 162 & $26.6 \%$ \\
\hline Scientist & 11 & $15.7 \%$ & 54 & $8.9 \%$ \\
\hline Forestry Official & 10 & $14.3 \%$ & 62 & $10.2 \%$ \\
\hline Nonprofit Agency & 3 & $4.3 \%$ & 21 & $3.5 \%$ \\
\hline Radio or Television & 2 & $2.9 \%$ & 12 & $2.0 \%$ \\
\hline City Mayor & 0 & $0.0 \%$ & 9 & $1.5 \%$ \\
\hline \multirow[t]{2}{*}{ (blank) } & 3 & $4.3 \%$ & 95 & $15.6 \%$ \\
\hline & $\mathrm{N}=70$ & & $\mathrm{~N}=608$ & \\
\hline \multicolumn{5}{|l|}{ Neutral Level of Trust } \\
\hline Forestry Official & 14 & $20.0 \%$ & 118 & $19.4 \%$ \\
\hline Scientist & 13 & $18.6 \%$ & 97 & $16.0 \%$ \\
\hline Teacher & 13 & $18.6 \%$ & 69 & $11.3 \%$ \\
\hline Nonprofit Agency & 9 & $12.9 \%$ & 89 & $14.6 \%$ \\
\hline City Mayor & 8 & $11.4 \%$ & 51 & $8.4 \%$ \\
\hline Pastor & 4 & $5.7 \%$ & 28 & $4.6 \%$ \\
\hline Radio or Television & 3 & $4.3 \%$ & 36 & $5.9 \%$ \\
\hline \multirow{2}{*}{ (blank) } & 6 & $8.6 \%$ & 120 & $19.7 \%$ \\
\hline & $\mathrm{N}=70$ & & $\mathrm{~N}=608$ & \\
\hline \multicolumn{5}{|l|}{ Lowest Level of Trust } \\
\hline Radio or Television & 27 & $25.7 \%$ & 201 & $22.0 \%$ \\
\hline City Mayor & 22 & $21.0 \%$ & 184 & $20.2 \%$ \\
\hline Nonprofit Agency & 20 & $19.0 \%$ & 136 & $14.9 \%$ \\
\hline Scientist & 9 & $8.6 \%$ & 98 & $10.7 \%$ \\
\hline Forestry Official & 8 & $7.6 \%$ & 70 & $7.7 \%$ \\
\hline Pastor & 7 & $6.7 \%$ & 26 & $2.9 \%$ \\
\hline Teacher & 2 & $1.9 \%$ & 15 & $1.6 \%$ \\
\hline \multirow[t]{2}{*}{ (blank) } & 10 & $9.5 \%$ & 182 & $20.0 \%$ \\
\hline & $\mathrm{N}=105$ & & $\mathrm{~N}=912$ & \\
\hline
\end{tabular}


Table 2.4. Percentage of harvesters who participated in illegal ginseng harvesting practices.

\begin{tabular}{|c|c|c|c|}
\hline & Harvesters & $\%(\mathrm{~N}=35)$ & Legal Status \\
\hline \multicolumn{4}{|l|}{ Harvest Season (from 2010 to present) } \\
\hline July & 2 & $5.7 \%$ & Illegal \\
\hline August & 7 & $20.0 \%$ & Illegal \\
\hline September & 22 & $62.9 \%$ & Legal \\
\hline N/A & 2 & $5.7 \%$ & \\
\hline (blank) & 2 & $5.7 \%$ & \\
\hline \multicolumn{4}{|l|}{ Size of Smallest Plant Ever Harvested } \\
\hline One prong & 5 & $14.3 \%$ & Illegal \\
\hline Two prong & 17 & $48.6 \%$ & Illegal \\
\hline Three prong & 12 & $34.3 \%$ & Legal \\
\hline (blank) & 1 & $2.9 \%$ & \\
\hline \multicolumn{4}{|l|}{ Individuals Legally Harvesting Ginseng } \\
\hline No & 29 & $82.9 \%$ & Illegal \\
\hline Yes & 6 & $17.1 \%$ & Legal \\
\hline & \multicolumn{2}{|c|}{$\begin{array}{l}\text { Number of Individuals } \\
\text { Who Have Harvested at } \\
\text { the Following Locations }\end{array}$} & \\
\hline Legal & Harvesters & $\%(\mathrm{~N}=35)$ & \\
\hline Personal Private Property & 32 & $91.4 \%$ & \\
\hline Property of a Friend or Family Member (Invited) & 26 & $74.3 \%$ & \\
\hline National Forests* & 2 & $5.7 \%$ & \\
\hline \multicolumn{4}{|l|}{ Illegal } \\
\hline National Parks & 3 & $8.6 \%$ & \\
\hline Private Property (Without Owner's Knowledge) & 5 & $14.3 \%$ & \\
\hline State Forests & 5 & $14.3 \%$ & \\
\hline State Parks & 1 & $2.9 \%$ & \\
\hline Nature Preserves & 1 & $2.9 \%$ & \\
\hline
\end{tabular}


Figure 2.1. Frequencies of select Likert-item question responses between harvesters and non-harvesters. Compass charts are organized using collapsed responses of (A) strongly agree/agree and (B) strongly disagree/disagree. *indicates only strongly disagree responses.

\section{Strongly Agree/Agree}

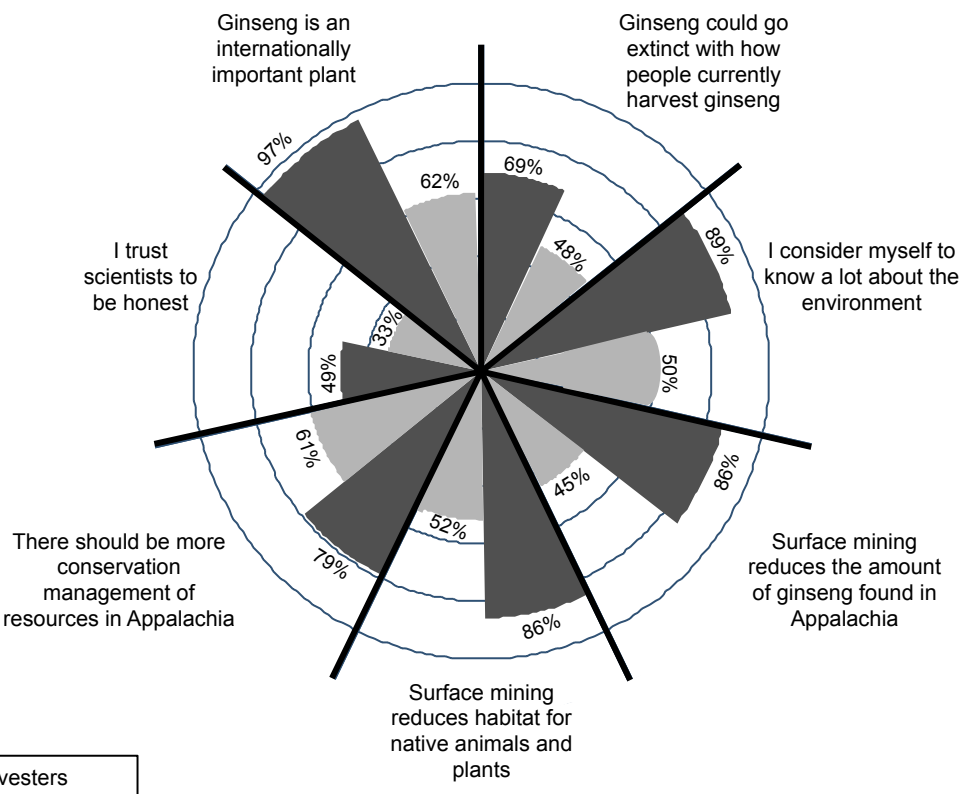

Non-Harvesters

\section{Strongly Disagree/Disagree}

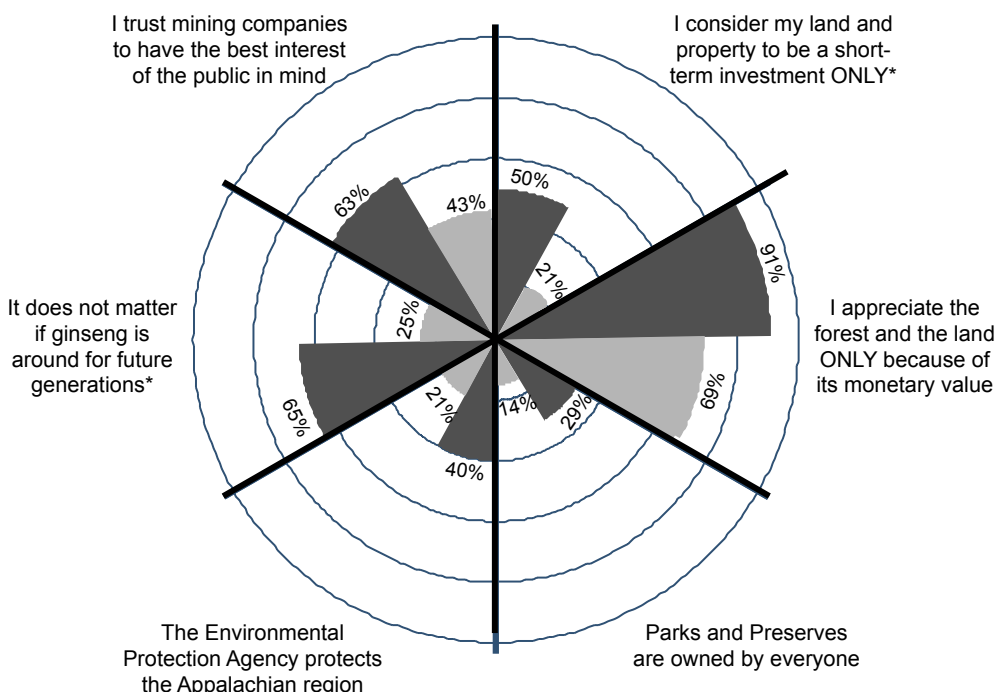


Figure 2.2. Effect of sample frame on participants' scores in three concepts: (A) ginseng conservation, (B) ginseng knowledge, and (C) opinion of conservation.
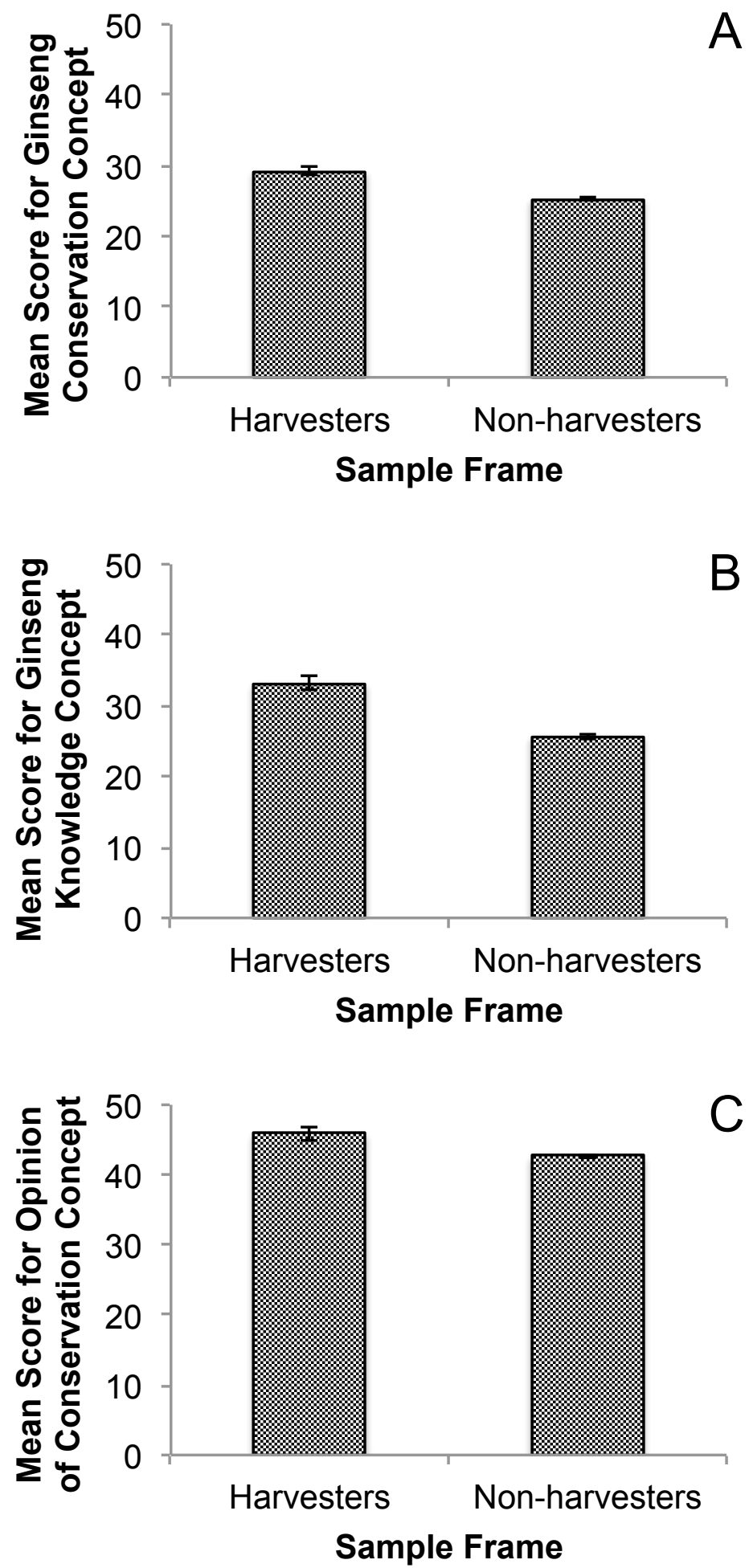
Figure 2.3. Effect of (A, B, C) employment, (D) education, and (E) gender on participants' concept scores, depending on sample frame.
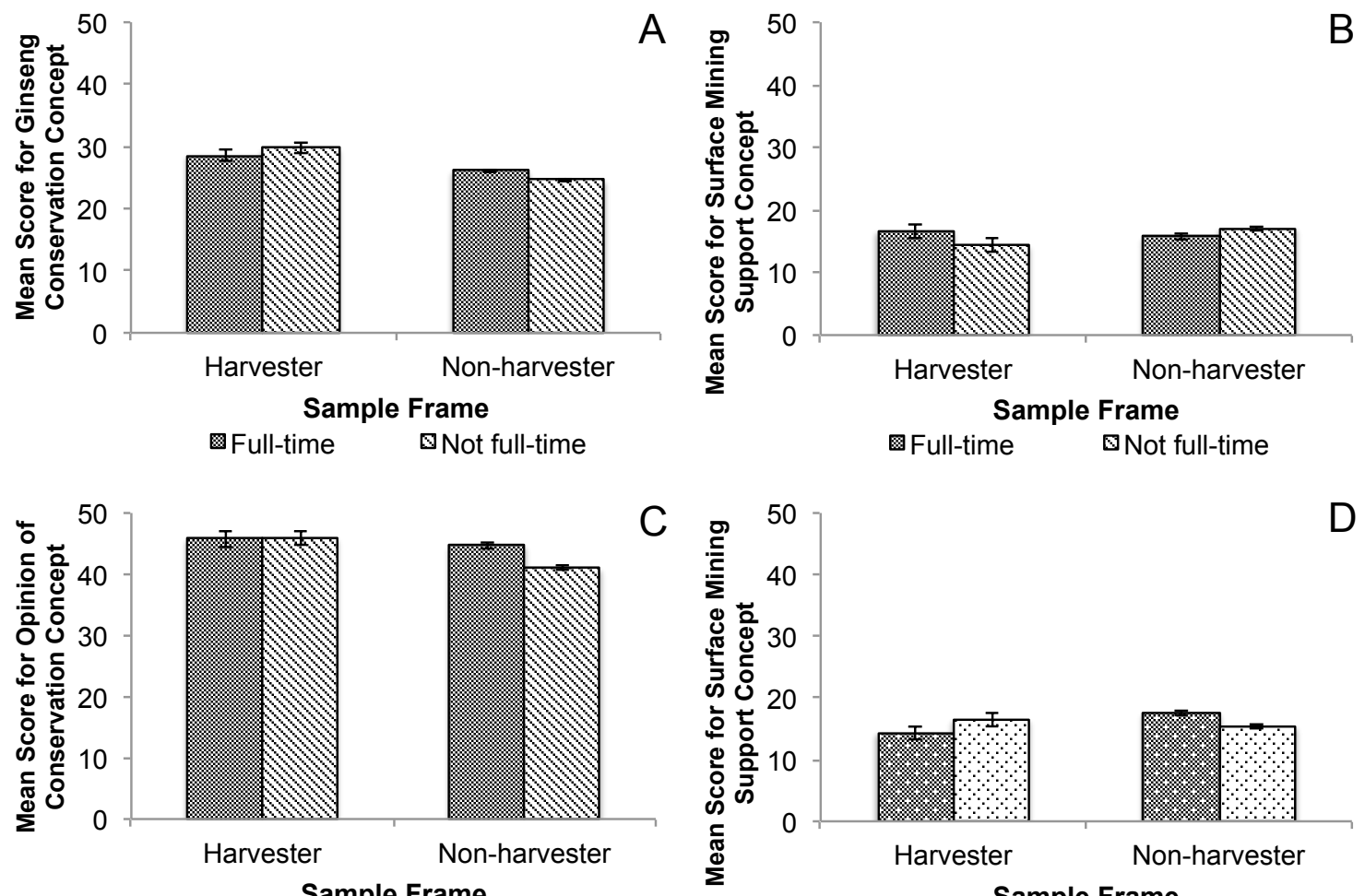

Sample Frame

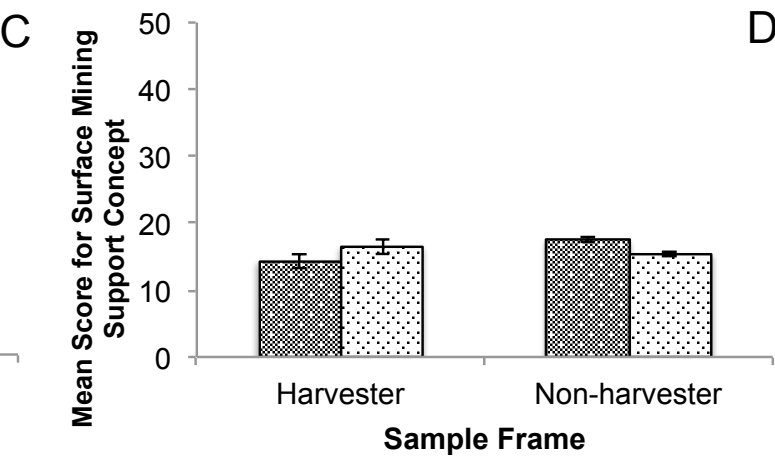

圈Full-time $\quad$ Not full-time
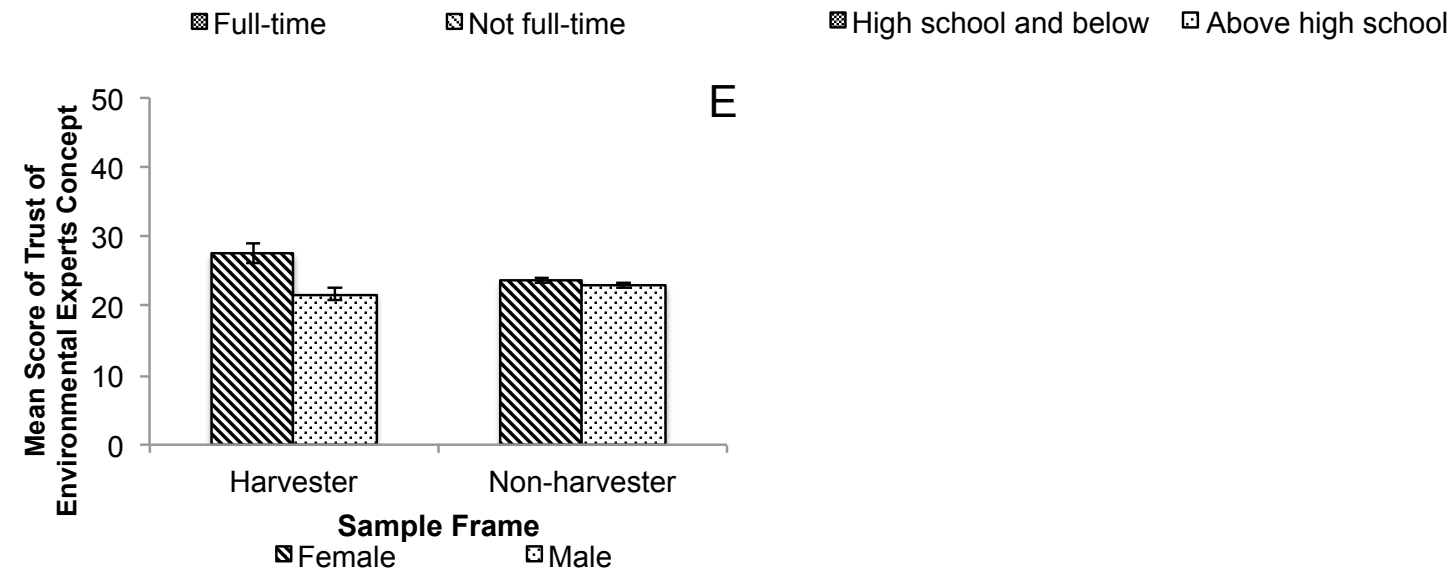
Figure 2.4. Effects of sample frame on concept scores for (A) ginseng conservation, and (B) trust in environmental experts depended on the level of agreement involving personal empowerment in Appalachia.

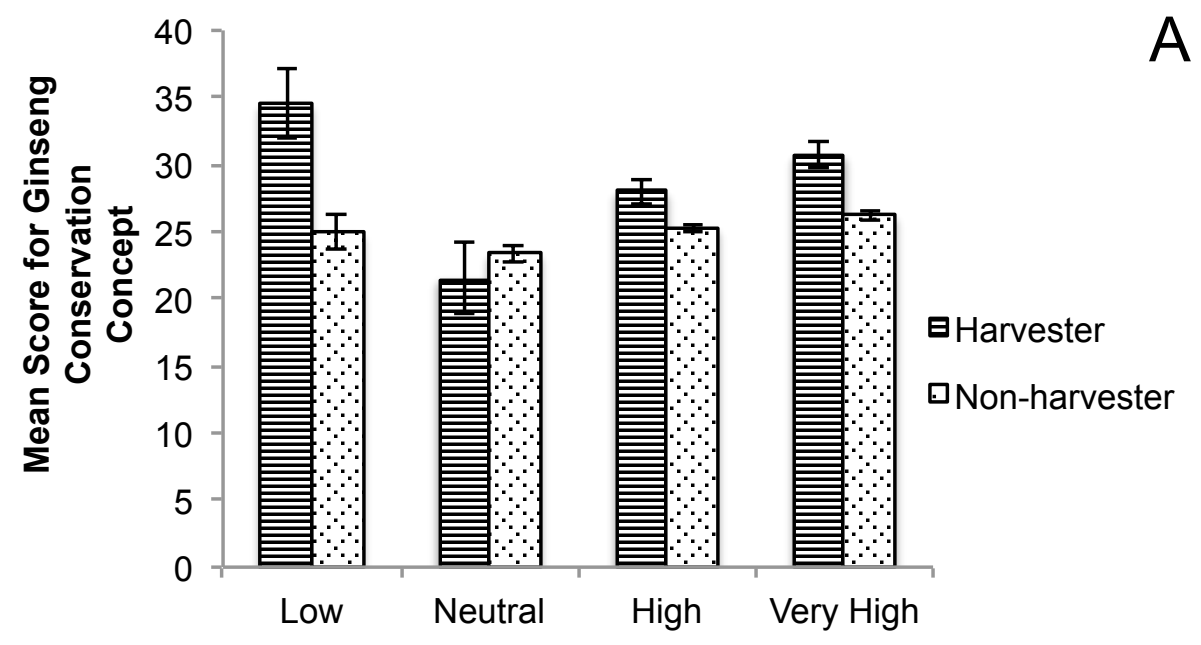

Level of Agreement for: I feel like individuals can make a difference

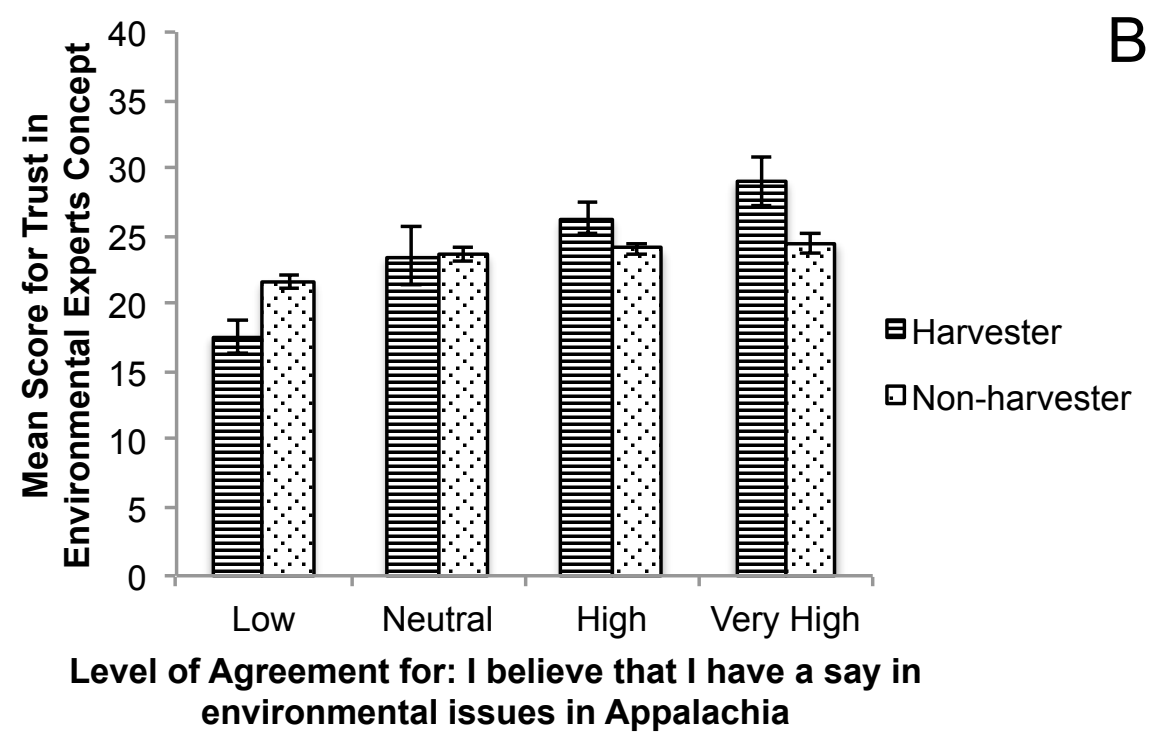


Figure 2.5. The effect of participant's level of agreement that "they have a say in environmental issues in Appalachia" on the concepts of (A) ginseng conservation and (B) opinion of conservation.
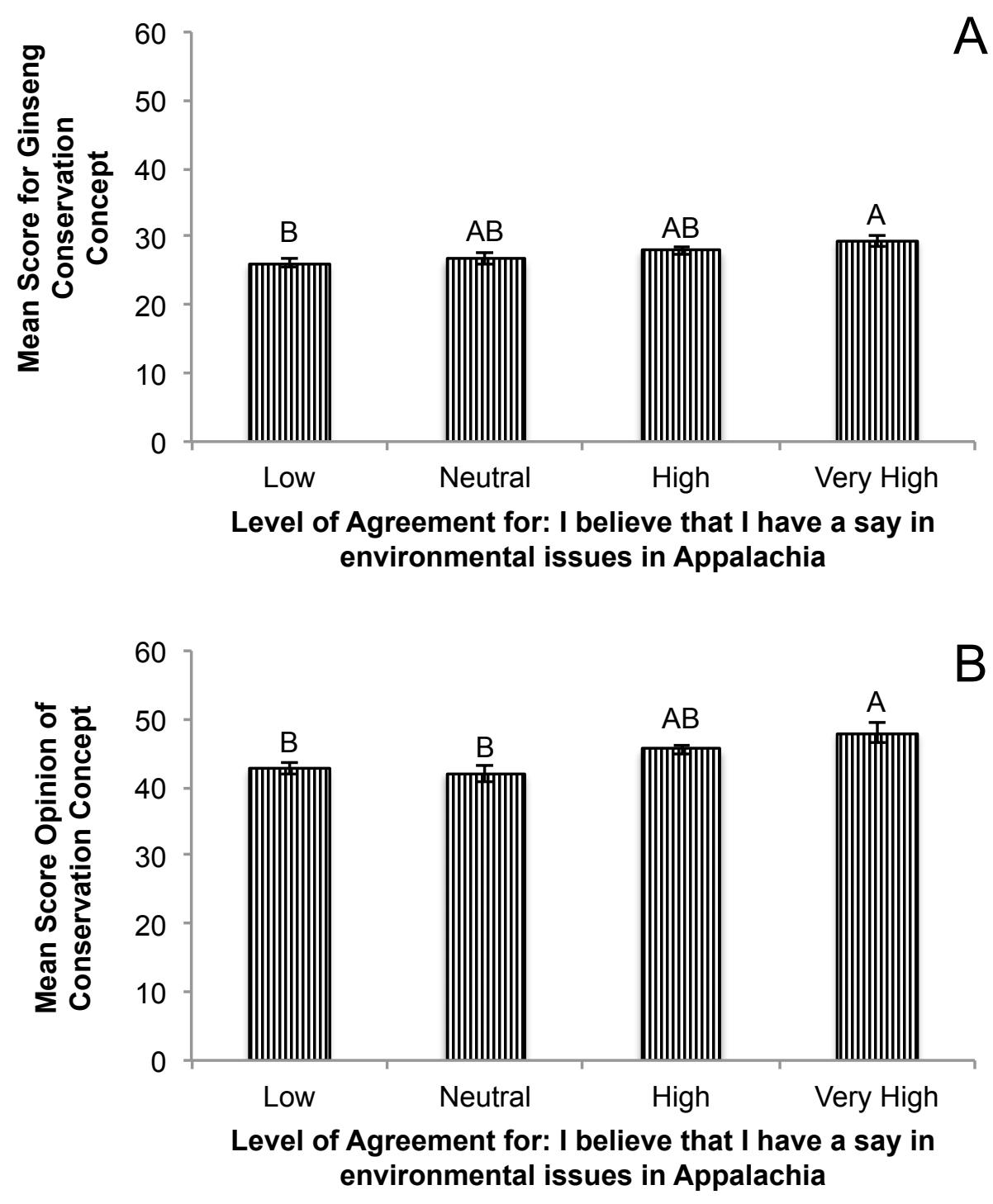


\section{Discussion}

The cultural connection between surface mining and ginseng is a deeply rooted, multifaceted relationship for harvesters and the community at large alike. Because nonrandom methodology was used, we were unable to calculate return rates, and so it is unclear how representative our results were relative to the total population. In support of our findings, many responses mirrored those of previous ginseng harvester research (Bailey, 1999; Burkhart et al., 2012; Edwards, 2011). In addition, partnering with HSTA has been shown to be effective in earlier community-based participatory research (Branch et al., 2011).

\section{Perceptions of surface mining and ginseng for harvesters and non-harvesters} While previous studies have focused on harvester perceptions and beliefs, we cannot assume harvester views mirror those of the community at large. Between harvesters and non-harvesters, there was a difference in basic knowledge of ginseng biology, understanding of conservation concerns, and the general opinion of conservation. As expected, when compared to non-harvesters, harvesters responded that they understood the international importance of ginseng, and that they strongly felt that ginseng needs to be conserved for future generations. As harvesters likely have a greater connection with this plant than the general community, and they are more likely acutely aware of conservation threats for this plant, these results were not surprising.

Harvesters were more likely to understand the negative impacts surface mining has on native plants and animals, including ginseng, and they were less likely to trust mining companies than non-harvesters. However, overall, when the numeric value of all 
questions regarding surface mining support were totaled and compared, there were no differences between sample frames in the value scored on this concept. Beyond surface mining, harvesters were not as supportive of sacrificing the integrity of the Appalachian ecosystem for economic reasons as their non-harvester counterparts. Bailey (1999) found that, while economic potential for ginseng harvest was considered an important aspect of the harvesting experience, harvesters were also motivated by non-economic, cultural reasons. This was echoed by the work of Edwards (2011), as well as the results of this survey. Harvesters demonstrated that they appreciated the forest beyond a short-term investment, or for its monetary value alone, whereas non-harvesters did not share this sentiment as strongly. If harvesters were purely economically driven for immediate gains, they would likely practice unsustainable harvest to maximize monetary value and not feel any sense of priority to conserve the forest and the resources within. There is value in preserving harvest culture from a sustainability standpoint, as the harvesters' motivations were less about the intrinsic worth of the forest and more about preserving the lifestyle associated with outdoor activities. Additionally, they had a greater understanding of the negative impacts of surface mining on native plants and animals than the larger community. In this sense, preservation of a ginseng harvest culture has conservation value that goes beyond preservation of a single species.

While harvesters felt there needed to be greater conservation management of resources in Appalachia, they were less likely to trust the Environmental Protection Agency (EPA) to help the region. Previous research demonstrated that harvesters did not trust the government (Burkhart et al., 2012; Edwards, 2011). Contrasting with the lack of trust of 
government, harvesters were more likely to trust scientists to be honest than the general community. Harvesters may have greater motivation to preserve the Appalachian landscape, but due to the lack of trust in the organizations that are responsible for maintaining the health of an ecosystem after mining, they are unlikely to tap the appropriate resources to aid their cause. Finding ways to engage these stakeholders in active ginseng conservation will be important for the long-term sustainability of renewable resources in Appalachia.

While ginseng harvest is a popular activity, there are more non-harvesters than ginseng harvesters in the state of West Virginia. Understanding how the community at large views the relationship between surface mining and ginseng is essential in terms of future conservation of renewable resources in this region. As such, these individuals are a larger voting block, electing the officials that represent the interests of the region. There is a positive correlation between an individual's environmental attitude and environmental education (Arcury, 1990). Educating the general community about conservation in an area with historically low scientific literacy (Haight \& GonzálezEspada, 2009) has the potential to encourage sustainability by the citizens of this region. Public opinion often influences policy (Page \& Shapiro, 1983), thus, if individuals are not vocal about their opinions about the environment through the government, there will not be reprioritization based on the long-term benefits of an intact ecosystem to the people. 


\section{Influence of social variables}

The reason that harvesters may have higher levels of support for ginseng conservation than non-harvesters could be that harvesters typically have a deep connection to the outdoors: Our results showed that over two-thirds of all harvesters said that outdoor activities were extremely important to them, whereas less than one-third of community members prioritized the same sorts of activities. Gragson and Bolstat (2006) found that communities in Appalachia prioritized conservation at a higher level when they were in closer proximity to recreation land, and when they had greater knowledge about conservation. Non-harvesters that are not employed full-time may not spend as much time outdoors as other groups, therefore they may have a lower understanding about ginseng conservation.

The pro-mining preferences of non-harvesters that are not employed full-time could be directly impacted by the presumed economic benefits that surface mining brings for the region (Blaacker et al., 2012). There are limited economic opportunities in Appalachia (Chenoweth \& Galliher, 2004). While harvesters, regardless of employment, can benefit economically from conservation practices (especially if they practice sustainable ginseng harvest), non-harvesters who are not employed full-time may see conservation as a luxury. This may be especially true as, historically, there has been a perceived trade-off between economic growth and environmental protection (MacDonald, 2010; Rasker, 1993). These individuals may be in 'survival mode' in this area, as it is economically disadvantaged (Chenoweth \& Galliher, 2004). 'Survival mode' means that these individuals may place emphasis on perceived short-term monetary gain over long-term 
sustainability of the region. All of the stewarding harvesters that participated in Edwards (2011) research were not employed full-time, and it is unclear why harvesters who are employed full-time have greater support of mining. Perhaps this select group is more likely to work as an employee for mining companies, and thus, these individuals may have a greater vested interest in mining.

The last two social variables that showed differential perceptions among sample frames included education and gender. Non-harvesters who had an education above the high school level had lower support for surface mining. As there is a correlation between environmental knowledge and environmental attitude (Arcury, 1990), increased levels of education may relate to the individual having increased knowledge about how surface mining can cause health problems (Ahern et al., 2011; Hendryx, 2008) and environmental degradation (Bernhardt \& Palmer, 2011; Palmer et al., 2010). Education is important for regions that want to effectively work towards sustainable development, as it provides employment opportunities beyond industries that focus on resource extraction (Tilbury et al., 2002). Female harvesters had the highest trust in environmental experts as compared to male harvesters, or community members of either gender; while women tend to be more trusting than men (Feingold, 1995), it is unclear why non-harvester women had lower levels of trust as compared to harvester females. Nevertheless, as females represented a small subgroup of harvesters, they are often not included, or they are a minority, in research about ginseng harvest (Bailey, 1999; Burkhart et al., 2012; Edwards, 2011). This may be a valuable group to work with to develop conservation outreach material to the larger harvesting public. As female harvesters are more trusting 
of experts, they may be more willing to work with government agencies developing environmental educational material and distribute it to the community.

\section{Harvester response}

Harvesters who recognized how surface mining was detrimental to ginseng were less likely to support the process of mining. Burkhart et al. (2012) found that in Pennsylvania, $48 \%$ of collectors, planters, and buyers of ginseng surveyed said that surface mining reduced ginseng populations, as compared to the $85.7 \%$ of West Virginia harvesters in our study. These responses may be different because West Virginia has a more dominant 'coal culture' (Bell \& York, 2010), with higher rates of coal production than Pennsylvania (BBER \& CBER, 2010), and harvesters may be more likely to witness the conversion from forest to surface mine firsthand.

In previous survey research, harvesters readily admitted to illegal harvest, in an unquantifiable manner, or they knew others who harvest illegally (Bailey, 1999; Burkhart et al., 2012; Edwards, 2011). Many harvesters felt that ginseng should be sustainably harvested so it is conserved for future generations. These beliefs did not stop a majority $(82.9 \%)$ of harvesters from participating in illegal harvest: These results mirrored a study that examined the illegal nature of harvest across seven states. McGraw et al. (2010) found that, in thirty natural populations of American ginseng, $94.1 \%$ of any harvest activity that occurred was illegal in nature. Additionally, in that study the observed rates of out of season harvest (21\%) were comparable to the admitted rates from survey participants (25.7\%). A large portion of survey participants (64.7\%) admitted to 
harvesting plants below the legal size limit, which was established to protect ginseng. These harvesters, while they are generally supportive of ginseng conservation, may not understand that the laws were implemented based on the biology of ginseng.

Harvesting illegally on property without permission (e.g., from state forests, national and state parks, and nature preserves) has been documented in another study (Bailey, 1999). McGraw et al. (2010) found that $65 \%$ of harvest activities occur on protected property, yet only $28.5 \%$ of our survey participants admitted to harvesting on these lands. This could mean that the harvesters were unwilling to fully admit where they have harvested, or, those harvesters who admitted to this activity harvest ginseng in greater amounts in these areas. Nevertheless, illegal harvesting, or poaching, occurs for numerous species and for a variety of reasons (Muth \& Bowe, 1998). For some communities the poaching of resources by individuals, such as fishing for salmon, is accepted (Gezelius, 2004). The motivations for poaching can include disagreeing with regulations, recreation, or poaching as a traditional right of use (Muth \& Bowe, 1998).

The idea of property rights in Appalachia may be convoluted, as much of the property in Appalachia is owned by a few large outside landowners, quite often coal company owners or the companies themselves (Gaventa, 1995). Individuals often feel they have a historic 'right' to use land they may not own, especially if they had family that previously owned the land generations back (Pokladnik, 2008). Harvesters readily admit to harvesting on other people's lands, sometimes with the justification that the owner would never know the plants were missing (Bailey, 1999). 
The reason many harvesters do not practice legal harvest is largely because they feel the laws were designed by individuals 'out of touch' with ginseng culture or they do not agree with the laws themselves (Burkhart et al., 2012; Edwards, 2011). For future ginseng conservation efforts, educational material should be developed with harvesters about why harvest laws are beneficial for the species, as this may help reduce illegal harvest activity. As harvesters and non-harvesters alike trust pastors and teachers, perhaps scientists and policy makers should work with religious support systems and the education system alongside harvesters to distribute information about why these laws are important. Working with clergy can be effective for scientific outreach; case studies of scientists working alongside leaders of faith communities have shown great potential for creatively educating the public about conservation issues, such as climate change and inspiring civic action (Hitzhusen, 2012).

\section{Sense of empowerment}

By studying whether individuals feel empowered in Appalachia, we can understand how people reconcile their beliefs and practices with respect to ginseng and surface mining. Sustainable development is often driven when individuals feel empowered (Tilbury et al., 2002). Interestingly, in our research, belief that an individual can make a difference and that people have a say in environmental issues, had no relationship with either sample frame's support for surface mining. Nevertheless, the relationship between individual empowerment and other concepts suggest that certain groups feel empowered to engage in sustainability and others may feel conservation practices are pointless. 
Harvesters who understood environmental threats for ginseng were more likely to have divergent viewpoints on the idea that individuals can make a difference, effectively classifying harvesters as 'invested' or 'divested.' These two parties possibly have different perspectives on how, or if, ginseng can be conserved for future generations. A majority of harvesters $(88.6 \%)$ either agreed or strongly agreed that individuals can make a difference. These invested harvesters are likely akin to the stewarding harvesters featured in Edwards' research (2011), as they work individually to preserve the species and they feel that a single person can impact the species. Harvesters who are divested, while they may understand the conservation concerns for this medicinal plant, may feel powerless, i.e., that there is nothing an individual can do to conserve the plant for future generations. This way of thinking is similar to the non-stewarding harvester featured in Edwards (2011) who was highly-educated about ginseng biology and conservation, yet did not practice sustainable harvest. One of his reasons for practicing unsustainable harvest was if he did not harvest the plants, someone else would. Divested harvesters act for immediate gains rather than engage in long-term conservation. Harvesters and nonharvesters that were 'neutral' about the ability of individuals to make a difference scored lower on ginseng conservation concept. They may not fully understand ginseng conservation or they may be apathetic about the sustainability of ginseng. These divested and neutral harvesters may be likely to contribute to the 'tragedy of the commons' for this species (Hardin, 1968; Hufford, 2002), as they may be more likely to harvest without thinking, or caring, about the long-term consequences for the species. 
If individuals, harvesters, or non-harvesters felt like they had a say in environmental issues in Appalachia, they were more likely to have higher levels of trust in environmental experts. Therefore, if harvesters feel empowered, they may be more willing to listen to environmental experts. Edwards (2011) and Burkhart et al. (2012) described how harvesters had lower levels of trust for anyone associated with ginseng regulation (the government, Division of Natural Resources, etc.). A distrust of experts may be observed because individuals feel frustrated about the known environmental hazards (Palmer et al., 2010) or health problems (Ahern et al., 2011; Hendryx, 2008) associated with surface mining, yet this process continues. Interestingly, of the six legal harvesters that were classified as invested (felt like individuals can make a difference), four felt they did not have a say in environmental issues in Appalachia. Hufford (2002) interviewed a man who was upset over the amount of harvest regulations, as there are no regulations that prevent mountaintop removal from destroying ginseng. This sentiment of individuals being upset that ginseng harvest is over-regulated, and land-use change is under-regulated, was echoed in Burkhart et al. (2012). As historic evidence suggests that the coal industry has a large influence on the political process of the region, divested individuals may feel they are powerless and that, with the political force of the coal company throughout West Virginia, the future sustainability of ginseng may not matter.

People who felt like they have a say in deciding the fate of the environment in Appalachia were more likely to understand environmental threats to ginseng and have a higher opinion of conservation in general. This could be that the more empowered an individual felt, the more likely they paid attention to sustainability issues in the region. If 
people in Appalachia thought they had influence in the region, they may be more likely to pay attention to environmental consequences in this area and to take action to preserve long-term sustainable resource extraction.

One way to increase empowerment and improve opinion of conservation from an early age in Appalachian citizens is to incorporate critical place-based education as a component of the curriculum in the public schools (McInerney, Smyth, \& Down, 2011). Appalachia is an area with a strong sense of localism (Chenoweth \& Galliher, 2004) and place-based learning would likely be supported. As Appalachia is a biodiversity hotspot (Stein et al., 2000) with a rich cultural history of using plants for medicine (Cavender, 2006), this area provides a wealth of opportunity to teach about native ecosystems and ethnobotany. Furthering conservation education in the classroom, students could learn restoration ecology skills. Students could learn about conservation theory and practices by reintroducing medicinal plants, such as ginseng, to the forest ecosystem, thus countering the loss of ginseng that occurs because of land-use change. This would be beneficial as long as they are planted in sites that maximize success (Turner \& McGraw, 2015). Teaching in the local schools would also target the large, critical demographic of surface mining supporters that only had a high school education or below. A benefit of place-based education is that it empowers individuals, especially in rural communities, as they are actively involved in the pursuit of knowledge that is relevant to them (McInerney et al., 2011). Previous work has documented that place-based education can increase community participation in the political process (as cited in McInerney et al., 2011). By organizing the community through the trusted educators of the public school system and 
educating individuals about the ecology of the region, people can feel empowered to make change and support biodiversity.

\section{Acknowledgments}

Without the guidance and support of survey-expert Dr. A. Kristjansson, this work would not have been possible. We would like to thank all of the HSTA students, and the survey participants, who contributed their time, opinions, and knowledge. Thank you to J. Chandler, M. Burnham, C. Walter, L. Papadimitriou, and M. Elza for their comments on the manuscript. These surveys were approved by WVU's IRB, protocols numbers: 1309086683 and 1310109052 . Our research was supported by a National Science Foundation Long Term Research in Environmental Biology Grant to J.B. McGraw (DEB-0613611 and DEB-1118702), the Botany in Action Fellowship, through Phipps Conservatory in Pittsburgh, PA, to J.B. Turner, and by the National Institute of General Medical Sciences, U54GM104942. The content is solely the responsibility of the authors and does not necessarily represent the official views of the funding sources. 


\section{References}

Ahern, M. M., Hendryx, M., Conley, J., Fedorko, E., Ducatman, A., \& Zullig, K. J. (2011). The association between mountaintop mining and birth defects among live births in central Appalachia, 1996-2003. Environmental Research, 111(6), 838-46. doi:10.1016/j.envres.2011.05.019

Arcury, T. A. (1990). Environmental attitude and environmental knowledge. Human Organization, 49(4), 300-304.

Bailey, B. (1999). Social and economic impacts of wild harvested products. Dissertation. West Virginia University.

Behringer, B., \& Friedell, G. H. (2006). Appalachia: Where place matters in Health. Preventing Chronic Disease, 3(4).

Bell, S. E., \& York, R. (2010). Community economic identity: The coal industry and ideology construction in West Virginia. Rural Sociology, 75(1), 111-143.

Berkes, F., Colding, J., \& Folke, C. (2000). Rediscovery of traditional ecological knowledge as adaptive management. Ecological Applications, 10(5), 1251-1262.

Bernhardt, E. S., \& Palmer, M. A. (2011). The environmental costs of mountaintop mining valley fill operations for aquatic ecosystems of the Central Appalachians. New York, 1223, 39-57. doi:10.1111/j.1749-6632.2011.05986.x

Biró, É., Babai, D., Bódis, J., \& Molnár, Z. (2014). Lack of knowledge or loss of knowledge? Traditional ecological knowledge of population dynamics of threatened plant species in East-Central Europe. Journal for Nature Conservation, 22(4), 318325. doi:10.1016/j.jnc.2014.02.006

Blaacker, D., Woods, J., \& Oliver, C. (2012). How big is big coal? Public perceptions of the coal industry's economic impact in West Virginia. Organization \& Environment, 25(4), 385-401. doi:10.1177/1086026612464766

Bowcutt, F. (1999). Ecological restoration and local communities: A case study from Sinkyone Wilderness State Park, Mendocino County, California. Ecological Restoration, 27(2), 359-368. doi:10.1023/A:1018733529690

Boyer, J. C. (2006). Reinventing the Appalachian commons. Social Analysis, 50(3), 217-232. 
Branch, R. A., Chester, A., Morton-McSwain, C., Udin Al Ayubi, S., Bhat Schelbert, K., Brimson, P., Buch, S., Cannon, Y., Groark, S., Hanks, S., Nukui, T., Pancoska, P., Parmanto, B., Paulsen, S., \& Wahl, E. (2011). A novel approach to adolescent obesity in rural Appalachia of West Virginia: Educating adolescents as family health coaches and research investigators. In M. B. Zimering (Ed.), Topics in the Prevention, Treatment and Complications of Type 2 Diabetes (pp. 309-340).

Brown, B. J., Hanson, M. E., Liverman, D. M., \& Merideth, R. W. (1987). Global Sustainability: Toward Definition. Environmental Management, 11(6), 713-719. doi:10.1007/BF01867238

Bureau of Business and Economic Research and Center for Business and Economic Research. (2010). The West Virginia Coal Economy 2008. A report published by Bureau of Business and Economic Research, West Virginia University, and Center for Business and Economic Research, Marshall University.

Burkhart, E., \& Jacobson, M. (2009). Transitioning from wild collection to forest cultivation of indigenous medicinal forest plants in eastern North America is constrained by lack of profitability. Agroforestry Systems, 76, 437-453. doi:10.1007/s10457-008-9173-y

Burkhart, E. P., Jacobson, M. G., \& Finley, J. (2012). A case study of stakeholder perspective and experience with wild American ginseng (Panax quinquefolius) conservation efforts in Pennsylvania, U.S.A .: limitations to a CITES driven, topdown regulatory approach. Biodiversity \& Conservation, 21(14), 3657-3679. doi:10.1007/s10531-012-0389-9

Cavender, A. (2006). Folk medical uses of plant foods in southern Appalachia, United States. Journal of Ethnopharmacology, 108, 74-84. doi:10.1016/j.jep.2006.04.008

Chenoweth, E., \& Galliher, R. V. (2004). Factors influencing college aspirations of rural West Virginia high school students. Journal of Research in Rural Education, 19(2), $1-14$.

CITES Secretariat. Convention on International Trade in Endangered Species of Wild Fauna and Flora (CITES) (n.d.) www.cites.org (accessed April 15, 2015).

Drummond, M. A., \& Loveland, T. R. (2010). Land-use pressure and a transition to forest-cover loss in the eastern United States. BioScience, 60(4), 286-298. doi:10.1525/bio.2010.60.4.7 
Edwards, E. A. (2011). Stewards of the Forest: An analysis of ginseng harvesters and the communal boundaries that define their identity in an area of environmental degradation. Thesis. Marshall University.

Feingold, A. (1995). Gender differences in personality: A meta-analysis. Psychological Bulletin, 116(3), 429-456. doi:10.1037/0033-2909.116.3.429

Fowler, F. J. (2009). Survey Research Methods. (L. Bickman \& D. J. Rog, Eds.) (4th ed.). Thousand Oaks, California: SAGE publications, Inc.

Gaventa, J. (1995). The political economy of land tenure: Appalachia and the southwest. In Who owns America? Land and natural resource tenure issues in a changing environment (pp. 71-98). University of Wisconsin-Madison: Land Tenure Center. doi:10.1353/nas.1995.0031

Gezelius, S. S. (2004). Food, money, and morals: Compliance among natural resource harvesters. Human Ecology, 32(5), 615-634. doi:10.1007/s10745-004-6099-5

Gragson, T. L., \& Bolstad, P. V. (2006). Land use legacies and the future of southern Appalachia. Society and Natural Resources, 19, 175-190. doi:10.1080/08941920500394857

Haight, A. D., \& González-Espada, W. J. (2009). Scientific literacy in central Appalachia through contextually relevant experiences: The "Reading the River" Project. International Journal of Environmental and Science Education, 4(3), 215-230.

Hardin, G. (1968). The tragedy of the commons. Science, 162(3859), 1243-1248.

Hendryx, M. (2008). Mortality rates in Appalachian coal mining counties : 24 years behind the nation. Environmental Justice, 1(1), 5-11. doi:10.1089/env.2008.0500

Hitzhusen, G. E. (2012). Going green and renewing life: Environmental education in faith communities. In New Directions for Adult and Continuing Education (Vol. 2012, pp. 35-44). doi:10.1002/ace

Hufford, M. (2002). Reclaiming the commons: Narratives of progress, preservation, and ginseng. In B. J. Howell (Ed.), Culture, Environment, and Conservation in the Appalachian South (pp. 100-120). Chicago, IL.

Hufford, M. (2003). Knowing ginseng: The social life of an Appalachian root. Cahiers de Littérature Orale, 53-54, 265-295. 
Hunter, L. M., \& Brehm, J. M. (2004). A qualitative examination of value orientations toward wildlife and biodiversity by rural residents of the intermountain region. Human Ecology, 11(1), 13-26.

Katz, M. L., Reiter, P. L., Heaner, S., Ruffin, M. T., Post, D. M., \& Paskett, E. D. (2009). Acceptance of the HPV vaccine among women, parents, community leaders, and healthcare providers in Ohio Appalachia. Vaccine, 27, 3945-3952.

doi:10.1016/j.vaccine.2009.04.040

Kelley, K., Clark, B., Brown, V., \& Sitzia, J. (2003). Good practice in the conduct and reporting of survey research. International Journal for Quality in Health Care, 15(3), 261-266. doi:10.1093/intqhe/mzg031

Lewis, R. L. (1993). Appalachian restructuring in historical perspective: Coal, culture and social change in West Virginia. Urban Studies, 30(2), 299-308. doi:10.1080/00420989320080301

Likert, R. (1974). A method of constructing an attitude scale. In Scaling: a sourcebook for behavioral scientists (pp. 233-243). Chicago, IL.

Lindberg, T. T., Bernhardt, E. S., Bier, R., Helton, A. M., Merola, R. B., Vengosh, A., \& Di Giulio, R. T. (2011). Cumulative impacts of mountaintop mining on an Appalachian watershed. Proceedings of the National Academy of Sciences, 108(52), 20929-20934. doi:10.1073/pnas.1112381108

MacDonald, K. I. (2010). The devil is in the (bio)diversity: Private sector "engagement" and the restructuring of biodiversity conservation. Antipode, 42(3), 513-550. doi:10.1111/j.1467-8330.2010.00762.x

McGraw, J. B., Lubbers, A. E., Van der Voort, M. E., Mooney, E. H., Furedi, M. A., Souther, S., Turner, J. B, \& Chandler, J. (2013). Ecology and conservation of ginseng (Panax quinquefolius) in a changing world. Annals of the New York Academy of Sciences: The Year in Ecology and Conservation Biology, 1286, 62-91. doi:10.1111/nyas.12032

McGraw, J. B., Souther, S., \& Lubbers, A. E. (2010). Rates of harvest and compliance with regulations in natural populations of American ginseng (Panax quinquefolius L.). Natural Areas Journal, 30(2), 202-210. doi:10.3375/043.030.0207

McInerney, P., Smyth, J., \& Down, B. (2011). "Coming to a place near you?" The politics and possibilities of a critical pedagogy of place-based education. AsiaPacific Journal of Teacher Education, 39(1), 3-16. doi:10.1080/1359866X.2010.540894 
Morton-McSwain, C. (2013). HSTA: A case study. An examination of community perception of a 9th-12th grade after school pipeline program. Doctoral dissertation. West Virginia University.

Muth, R. M., \& Bowe, J. F. (1998). Illegal harvest of renewable natural resources in North America: Toward a typology of the motivations for poaching. Society \& Natural Resources, 11(1), 9-24.

Page, B. I., \& Shapiro, R. Y. (1983). Effects of public opinion on policy. American Political Science Review, 77(1), 175-190. doi:10.2307/1956018

Palmer, M. A., Bernhardt, E. S., Schlesinger, W. H., Eshleman, K. N., FoufoulaGeorgiou, E., Hendryx, M. S., Lemly, A.D., Likens, G.E., Loucks, O.L., Power, M.E., White, P.S., Wilcock, P. R. (2010). Mountaintop mining consequences. Science, 327, 148-149. doi: 10.1126/science.1180543

Peluso, N. L. (1992). The rock, the beach, and the tidal pool: People and poverty in natural resource-dependent areas. Society and Natural Resources, 7(1), 23-38. Retrieved from http://www.ncbi.nlm.nih.gov/pubmed/8822306

Pokladnik, R. J. (2008). Roots and remedies of ginseng poaching in central Appalachia. Antioch University New England, Kenne, New Hampshire.

Pond, G. J., Passmore, M. E., Borsuk, F. A., Reynolds, L., \& Rose, C. J. (2008). Downstream effects of mountaintop coal mining: comparing biological conditions using family-and genus-level macroinvertebrate bioassessment tools. Journal of the North American Benthological Society, 27(3), 717-737. doi:10.1899/08-015.1

Rasker, R. (1993). Rural development, conservation, and public policy in the greater Yellowstone ecosystem. Society and Natural Resources, 6(2), 109-126.

Rana, M. S., \& Samant, S. S. (2011). Population biology of Lilium polyphyllum D. Don ex Royle-A critically endangered medicinal plant in a protected area of Northwestern Himalaya. Journal for Nature Conservation, 19(3), 137-142. doi:10.1016/j.jnc.2010.08.001

Robbins, C. S. (2000). Comparative analysis of management regimes and medicinal plant trade monitoring. Conservation Biology, 14(5), 1422-1434. doi:10.1046/j.15231739.2000.99100.x

SAS JMP Pro 11. (2013). SAS Campus Drive, Cary, NC, USA 27513.

Schlag, E. M., \& Mcintosh, M. S. (2006). Ginsenoside content and variation among and within American ginseng (Panax quinquefolius L .) populations. Phytochemistry, $67,1510-1519$. 
Shackleton, C. M., Shackleton, S. E., \& Cousins, B. (2001). The role of land-based strategies in rural livelihoods: The contribution of arable production, animal husbandry and natural resource harvesting in communal areas in South Africa. Development Southern Africa, 18(5), 581-604. doi:10.1080/03768350120097441

Stein, B. A., Kutner, L. S., \& Adams, J. S. (Eds.). (2000). Precious Heritage: The status of biodiversity in the United States. Cary, NC: Oxford University Press, USA.

Stockmeyer, N. O. (2009). Using Microsoft Word's readability program. Michigan Bar Journal, 88, 46-47.

Sullivan, J., \& Amacher, G.S. (2009). The social costs of mineland restoration. Land Economics, 85(4), 712-726.

Thomas, D. S. G., \& Twyman, C. (2005). Equity and justice in climate change adaptation amongst natural-resource-dependent societies. Global Environmental Change, 15, 115-124. doi:10.1016/j.gloenvcha.2004.10.001

Tilbury, D., Stevenson, R. B., Fien, J., \& Schreuder, D. (Eds.). (2002). Education and sustainability responding to the global challenge. Gland, Switzerland and Cambridge, UK.

Townsend, P. A., Helmers, D. P., Kingdon, C. V., McNeil, B. E., de Beurs, K. M., \& Eshleman, K. N. (2009). Changes in the extent of surface mining and reclamation in the Central Appalachians detected using a 1976 - 2006 Landsat time series. Remote Sensing of Environment, 113, 62-72. doi:10.1016/j.rse.2008.08.012

Turner, J. B., \& McGraw, J. B. (2015) Ecological Indicators. Accepted.

Turner, N. J., Gregory, R., Brooks, C., Failing, L., \& Satterfield, T. (2008). From invisibility to transparency: Identifying the implications. Ecology And Society, 13(2), 7.

Turner, N. J., Ignace, M. B., \& Ignace, R. (2000). Traditional ecological knowledge and wisdom of aboriginal peoples in British Columbia. Ecological Applications, 10(5), 1275-1287. doi: 10.1890/1051-0761(2000)010[1275:TEKAWO]2.0.CO;2

Van der Voort, M. E., \& McGraw, J. B. (2006). Effects of harvester behavior on population growth rate affects sustainability of ginseng trade. Population (English Edition), 130, 505-516. doi:10.1016/j.biocon.2006.01.010

Woods, B. R., \& Gordon, J. S. (2011). Mountaintop removal and job creation: Exploring the relationship using spatial regression. Annals of the Association of American Geographers, 101(February 2015), 806-815. doi:10.1080/00045608.2011.567947 
Yin, J., Zhang, H., \& Ye, J. (2008). Traditional Chinese Medicine in treatment of metabolic syndrome. Endocrine, Metabolic \& Immune Disorders - Drug Targets, 8(2), 99-111. doi:10.1016/j.biotechadv.2011.08.021 
CHAPTER III: GREEN VERSUS BLACK GOLD: AN ECONOMIC COMPARISON OF LAND-USE IN APPALACHIA 


\begin{abstract}
Appalachia's economy has been historically industrial, and largely dominated by coal mining. However, harvest of the economically valuable medicinal plant, American ginseng, provides many individuals with an important secondary source of income. Both ginseng harvest and surface mining provide great economic returns for the Appalachian community: wild ginseng harvest, if done properly, has the potential to be a sustainable resource, whereas coal is non-renewable. Ginseng has become increasingly rare, and surface mining reduces its habitat. To evaluate the financial viability of these two resources, we analyzed the economics for a landowner under three land-use scenarios for a hypothetical 100 hectares of eastern deciduous forest: (1) coal royalties received through surface mining; (2) stewarded harvest of ginseng; (3) establishment of a largescale ginseng farm. Our analysis includes detailed cash flow projection models, valuation sensitivity analyses based on key factors, and evaluation of relevant risks, opportunities, and market conditions. While coal royalties provide a more certain source of income, ginseng farming and stewarded harvest can provide meaningful economic value to the landowner. This research has the potential to help landowners make educated decisions about land-use, as well as inform policy makers of the economic opportunities of an intact, healthy forest.
\end{abstract}




\section{Introduction}

The postulate that there is a trade-off between conservation and economic growth and security has been a predominant aspect of modern western beliefs (MacDonald, 2010; Rasker, 1993), especially in the resource-extraction driven nature of the Appalachia economy (Nesbitt and Weiner, 2001). In this area of the United States, timbering (Chandler and McGraw, 2015; Nesbitt and Weiner, 2001), coal mining, and Non-timber Forest Product (NTFP) harvest (Bailey, 1999) are important sources of income for individuals. Arguably, two important historic forms of resource extraction in the state of West Virginia are surface mining (BBER and CBER, 2010) and the harvest of American ginseng (Panax quinquefolius L.), hereafter referred to as ginseng (Hufford, 2003).

Surface mining has existed in Appalachia since the early 1900's (Montrie, 2003), with West Virginia's coal industry being responsible for $32 \%$ of the nation's coal exports (Hammond, 2011), making West Virginia a leading producer of coal in the United States (BBER and CBER, 2010). Despite this, in 2010, West Virginia employed only 6,300 individuals with surface mining jobs (as cited in Epstein et al., 2011). In contrast to the often-made claim that mining equates jobs (Woods and Gordon, 2011), which has led to the popular misconception that mining is a main employment opportunity in the state (Blaacker et al., 2012), surface mining jobs represent less than one percent of the state's working employment (as cited in Epstein et al., 2011). The current cultural connection with coal in Appalachia, and the current misconception of coal's economic dominance, is a legacy of the historical importance of this resource (Bell and York, 2010). 
While surface mining is often considered an economic driver of West Virginia (Blaacker et al., 2012; Woods and Gordon, 2011), ginseng harvest remains an important source of income (Bailey, 1999). Ginseng can be found throughout eastern North America, and it has been harvested since the 1700's; because of concerns about the effects of harvest, ginseng is listed on the CITES Appendix II (CITES Secretariat, 2015). Due to the economic value of ginseng, it is North America's premier herbal product (McGraw et al., 2013). The majority of harvested ginseng is exported into the international market (US FWS, 2012), where it is used in Traditional Chinese Medicine (TCM) (Schlag and Mcintosh, 2006; Wang et al., 2009; Yin et al., 2008). When ginseng is exported from the United States, most of the roots end up in Hong Kong to be consumed by individuals in the Asian market (US FWS, 2012).

The end market and demand for ginseng is highly stable and growing. Ginseng is one of the most commonly used herbs in TCM (Schlag and Mcintosh, 2006; Yin et al., 2008). The dried root can be consumed as an extract, in a pill, in foodstuff and drinks, dried, or raw (FAO UN and WHO, 2012). Despite Asian countries having increased availability of western medicine and technology, there remains a consistent demand for ginseng and other forms of TCM. To illustrate, in China, individuals with higher levels of education routinely used TCM, and there is a rise in the use of TCM with higher socioeconomic groups (Chung et al., 2007). Further, there are numerous undergraduate degrees and clinics established by the government that support the use of TCM (Chung et al., 2007). Within Korea, the younger generation is consuming ginseng at the same rate as the older generations (Baeg and So, 2013). While there remains little detailed information on the 
end market of ginseng, the current growth of the Chinese middle class and the aging of populations in Asian countries indicate that this market will likely continue to grow. For example, experts expect that the amount of money spent on healthcare in China will experience one of the largest increases by expenditure category by 2025 (Farrell et al., 2006).

The market strength for wild ginseng is further supported by a lack of substitution risk. Wild harvested, or wild simulated, ginseng is considered by end users to be much more effective than cultivated ginseng, which is reflected in the significant price premium wild ginseng commands in the marketplace relative to cultivated (Burkhart and Jacobson, 2009). The closest substitution for American ginseng is Asian ginseng (Panax ginseng C. A. Mey.), however, this has medicinal benefits that do not completely overlap with the benefits of American ginseng (Schlag and Mcintosh, 2006). Additionally, Asian ginseng is on the verge of extinction in the wild, and is a State-Protected Rare and Endangered Plant (Li et al., 2011), rendering it difficult to acquire wild Asian ginseng. In sum, the long-term strength and stability of the international ginseng market is supported by the large, multi-billion dollar size of TCM (Williamson et al., 2013), lack of viable substitutes, and beneficial demographic and medical trends within Asian countries.

In southern West Virginia, over sixty percent of all ginseng harvested in the state comes from eight counties (Bailey, 1999). For this region in the southern Appalachians, surface mining is a dominant form of industry, and household incomes are among the lowest (Bailey, 1999; Barry 2001). While ginseng harvest is monitored by the state, there has 
been no effort to monitor the amount of ginseng that is lost through the process of surface mining, which by its nature destroys the habitat for ginseng (Hufford, 2002). There is also little information on the economic opportunities that are lost from the local extirpation of this NTFP.

Assuming ginseng is planted in areas that maximize performance (Turner and McGraw, 2015), ginseng can be an economically viable agroforestry product (Burkhart and Jacobson, 2009). Both ginseng and surface mining can provide economic returns for the Appalachian region: Wild ginseng harvest, if done correctly, has the potential to be a sustainable resource. This is especially true if populations are not harvested regularly (Sverdlove, 1981). Counter to the potential renewable resource of ginseng harvest, coal mining, by definition, can be considered a non-renewable resource (as defined in Brown et al., Due to the environmental implications and mutually exclusive nature of these two types of resource extraction, does ginseng harvest yield a comparable relative economic return to surface mining, over time? We will evaluate the value of 100 hypothetical hectares (247.1 acres) of land with three scenarios for land-use: (1) surface mining, assuming the landowner owns mineral rights; (2) stewarded ginseng harvest; and (3) the establishment of a commercial-scale ginseng farm.

\section{Methods and Results}

\section{Land and General Assumptions}

We assumed the 100 hectares are completely forested with deciduous trees, and all land is suitable for ginseng growth. Given the wide distribution of ginseng across aspects and 
elevational gradients (McGraw et al. 2003), this assumption does not exclude a significant fraction of forests in Appalachia. Additionally, we assume the land has a consistent coal seam across the 100 hectares, and the landowner has implemented a successful deer management plan on the property that reduces deer browse to insignificant levels. The land is financed with $100 \%$ equity, and we do not include any value from timber sales. All scenarios are established in 2014, and when appropriate, numeric values discussed in this article, and in the models, are rounded. The final assumption is that the individual owns mineral rights to their private property, and that all appropriate permits have been filed and accepted before the process of mining begins.

\section{Value from Surface Mining}

The monetary value of the land to the owner under a surface mining scenario is based on the royalties earned on the value of the coal recovered from the property. To determine the amount of coal under the 100 hectare land plot, we used a seam depth average, approximately 1.87 meters, for the Pittsburgh Coal Seam, which runs through a significant portion of West Virginia (PA DEP and DEDGT, 2001). Over the 100 hectares of land, assuming a bulk density of $793 \mathrm{~kg} / \mathrm{m}^{3}$ (Pirraglia et al., 2012), the total coal available is $1,484,457$ metric tons (Appendix C).

To determine gross coal revenue from the mining operation, we used coal prices from the U.S. Energy Information Administration (2015) and assumed zero price growth through the lifetime of the operation. Coal prices have fluctuated historically and commodity prices are notoriously hard to predict on a long-term basis. However, coal prices have 
been very stable over the past five years (US EIA, 2015), and we assume they will remain relatively flat in the medium term. We assume that the factors driving coal prices over the long term will be economic output, industrial and residential energy efficiency, regulations, and supply effects of potential energy substitutes such as natural gas, wind, nuclear, and solar. Given the long-term uncertainty and recent stability of prices, a flat price growth assumption was used. The US Energy Information Administration projects a slight coal price decline of less than 1.0\% through 2016 (US EIA, 2015), which corroborates this assumption. From a valuation standpoint, a risk of future price decline is considered in the application of a discount rate. Note that in all modeling scenarios the effect of future inflation is ignored due to the current low inflationary environment and an assumption that any material inflation should affect both revenues and costs, thus mitigating the effect. Also, the potential future negative impact from inflation is factored into the discount rates applied to the valuations.

To determine the cash received by the landowner, we used the typical royalty rate per ton of coal for a surface mine of 15\% (Skousen, personal communication, 2015). This percentage was multiplied by the total market value of the coal extracted, as this is how royalty agreements are typically structured. We applied a tax rate of $12.5 \%$ to all royalty income, which is the typical statutory rate for surface mining royalties (US DOI, 2013). As mining is an investment with potential risks, including operational execution risk and coal market price fluctuations, a discount rate of $15 \%$ was used to determine the present value of the cash flows (Pratt and Grabowski, 2011). Assuming that it takes 20 years to mine a 100 hectare site (Gray, personal communication, 2015) with a consistent annual 
extraction, the total cash flow received by the landowner would be $\$ 10.3$ million (Table 3.1.), and a present value to the owner of $\$ 3.1$ million.

\section{Value from Stewarded Ginseng Harvest}

\section{Natural Sustainable Harvest Densities}

In order to determine the natural densities of ginseng for the general region, we studied five natural ginseng populations. These five populations, found across three states, were selected as they are located within $70 \mathrm{~km}$ of active mining sites. Exact locations are withheld due to conservation concern. The ginseng populations at the sites have been monitored by the McGraw laboratory, at West Virginia University, since, at least 2004, as part of a National Science Foundation Long Term Research in Environmental Biology Grant (McGraw et al., 2013). The perimeter of each population was mapped using Google Earth (Google Earth, 2012), and all five populations were smaller than a hectare (ranging in size from 0.25 hectare to 0.8 hectare).

The demography data were pooled, by year, at each of these sites for nine years (20042012), except for one site that was timbered in 2011 (2004-2010). The average total number of ginseng plants per population per year was calculated, the number of mature plants, or plants that had three or four leaves (often referred to as prongs), and the number of plants that produced seeds were also averaged. The densities of these plants were extrapolated to the size of a hectare. However, in terms of both the ginseng stewardship model and the ginseng farm model, due to the need for access roads and space between plots, $10 \%$ of the land will not be harvested, nor will it be stewarded. On average, of the 
plants that produced seeds, the average number of seeds produced from a mature plant was rounded to the even number of 5 seeds, with a range from 1 to 49 seeds per plant. Previous research has shown that a stewardship method of harvest, removing only $25 \%$ of all mature plants with seeds, can increase the population size (Van der Voort and McGraw, 2006). Because of this definition, at this density, only 8 plants should be harvested per hectare (2.3\% of the population) in the first year and will grow as the population density increases through the projection period. Under our stewarded harvest scenario, we assume that the seeds from the plants are collected and planted to maximize population growth and thus ginseng yield. Our projection model, which assumes harvesting at this rate of $2.3 \%$, projects the number of plants to increase from 32,000 to 163,400 in the land plot over the 32-year projection period. In our model, 700 plants are harvested in the first year and 3,500 are harvested in the $32^{\text {nd }}$ year as the germinated plants from the collected seeds outpace the harvest rate.

\section{Ginseng Root Value under Sustainable Harvest}

Revenue is earned by the landowner through harvesting, drying, and selling the roots into the marketplace. The cash received each year is a function of roots harvested and the wholesale market price for the roots in the given year. Drivers of root value include (i) age, (ii) mass, and (iii) supply and demand. Each of these factors are considered in the projection model. 


\section{Determination of Root Mass}

We modeled root mass as a function of the age of a plant, through two data sets: (1) leaf area to dry root mass; and (2) age to leaf area. Combining these two datasets, of mass to leaf area and leaf area to age, allowed us to create a model for dry root mass based on age. Age was determined as number of years from germination.

To determine the relationship between leaf area and dry root mass, two trained ginseng harvesters measured leaf area and collected roots in fall of 2012. Before the plants were harvested, each plant was given a unique identification number, and the length and width of the longest leaflet on each leaf was recorded. Any plants that were missing a leaf were not included in this study. Once the roots were harvested, they were dried for seven weeks at room temperature. Each root was individually weighed (g) and using a previously derived allometric relationship, the total leaf area of each plant was calculated. A total of 98 ginseng roots were included in the analysis. All statistical analysis in this study was completed using SAS JMP Pro 11 (SAS JMP, 2013). Data were tested for normality. The data were natural log-transformed and a linear regression was used to determine the relationship between leaf area and dry root mass $(\mathrm{g})\left(\mathrm{r}^{2}=0.335\right)$. This equation serves as a baseline for the variation that is found in nature.

$$
\text { Dry Root Mass }(\mathrm{g})=e^{(-0.2278+(0.0023 * \text { Leaf Area }))}
$$

Using a dataset of the leaf area of aged roots from $2009(\mathrm{~N}=161)$, we used the previously listed equation to establish a predicted relationship between age and dry root mass $(\mathrm{g})$. 
The data were transformed using a Box Cox transformation $(\lambda=-2)$ and a quadratic regression was used, as older ginseng plants have smaller leaf area (McGraw, personal communication, 2015) to determine the relationship between age and the predicted dry $\operatorname{root} \operatorname{mass}(\mathrm{g})\left(\mathrm{r}^{2}=0.538\right)$.

$$
\text { Predicted Root Mass }(\mathrm{g})=\sqrt{\frac{1}{1-1.5823\left(-0.2749+0.0338 \mathrm{Age}-0.0009(\mathrm{Age}-8.5155)^{2}\right)}}
$$

The values established from these equations serve as a baseline for natural variation, and can be used as an estimate in a financial model to calculate mean mass in grams by age, especially given the large volumes of roots we are assuming in the model. We ignore values predicted for roots under five years old, due to unusual growth patterns associated with early years of life, and that it is illegal to harvest roots at this age (WV Division of Forestry, 2015). The sample of roots in a given year should approximate the average of the population, and the resultant root mass affects the market price as buyers pay per gram rather than per root.

\section{Determination of Root Age and Price}

As roots age and grow, if they are in the right conditions, they can become more 'gnarled,' which is more attractive to buyers as this attribute is associated with increased medicinal efficacy (Obae and West, 2012). The age of the plants harvested in a given year is calculated on an average basis. Average age at the beginning of the projection is assumed to be 8.5 years, which is the average projected age of plants in the 2009 dataset. Each plant harvested in the first year is assumed to be 8.5 years. For subsequent years, 
average age is determined based on the aging of the initial base of plants and the age of new plants introduced during the projection years.

The current price per age of ginseng root was obtained from a commercial operation website and the price after aging dried ginseng roots from two stores in Chicago's Chinatown during December 2014, reduced by $20 \%$ to account for the spread between retail and wholesale pricing. While the retail price in Asian markets is significantly higher than those reported in this study, the profit to the seller is approximately the same given the higher costs of delivery to Asia. We observed that each additional year of root age contributed, on average, an additional 22.1 cents per gram to the market price. Based on our observations, we assume this price is for wild cultivated roots, however, we assume wild ginseng roots will command a $25 \%$ premium due to the more desirable qualitative factors. Given the increase in mass as the plant ages and value of qualitative age factors, older plants are significantly more valuable than younger plants and reach a maximum value around 39 years of age (Fig. 3.1). For older roots, this pricing data is extrapolated from market price trend for younger roots. Therefore, given the lack of market data points, real world pricing for older roots could be significantly different. After the age of 39 years, the price begins to decline as the incremental increases in value are offset by the incremental decline in mass as the plant gets older.

\section{$\underline{\text { Influence of Supply and Demand }}$}

By its nature as a commodity, ginseng pricing is largely determined by levels of supply and demand. While its current prices can be observed, future changes in supply and 
demand can significantly affect its market price, and thus the value of ginseng harvest to the landowner. Over its long-term history, ginseng has experienced both a significant decline in supply and an increase in demand. Supply has declined, for many reasons, including the over-harvest of wild ginseng (McGraw et al., 2013), and demand has increased due to the economic development and population growth of key Asia Pacific countries, most notably China (Farrell et al., 2006; Wang et al., 2009). As such, the average price per gram has increased from 31.5 cents per gram in 1983 to $\$ 1.82$ per gram in 2013 , an average annual growth rate of $6.0 \%$, and a more recent growth rate of $10.6 \%$ since 2006 (Davis and Persons, 2014). While historic growth rates averaged $6.0 \%$ and there is an expectation for the supply and demand trends to continue, in order to develop a more conservative model, we assume that the average price of ginseng grows at a rate of $3.0 \%$ per year through the next 15 years. We assume a zero growth rate for years 16 and beyond, due to the uncertainty of long-term supply and demand factors. Also, a significant increase in ginseng prices would potentially drive the proliferation of ginseng farms, therefore increasing supply and price stability.

\section{Revenue for Stewarded Harvest}

In the first year of harvest, the landowner harvests $\$ 1,800$ worth of ginseng. However, as time progresses in the projections, ginseng harvest value increases due to the increase in number of plants, higher price of ginseng, and increased age of plants. Annual revenue grows to $\$ 68,100$ by 2047 and cumulative revenue through the end of the projection (2015-2047) period is $\$ 803,400$ (Appendix D). 


\section{Expenses for Stewarded Harvest}

Expenses incurred in a stewarded scenario are limited. We assume that it would take an individual approximately 250 person-hours of work for our plot of land in the first year (McGraw, personal communication, 2015). Person-hours increase over time, proportionately to the number of plants harvested. In 2047, person-hours total 1,217 hours. At a rate of $\$ 9.00$ per hour, which is a slight decrease from the average labor wage for US agriculture workers of $\$ 9.09$ per hour (US DL, 2014) due to lower labor rates in West Virginia, this translates to an annual expense, or opportunity cost, ranging from $\$ 2,300$ in the first year to $\$ 11,000$ in 2047 .

\section{Stewarded Harvest Valuation}

We valued the stewarded harvest using the discounted cash flow method. In the first year of harvest (2015), the landowner harvests $\$ 1,800$ worth of ginseng but has $\$ 2,300$ of expenses, yielding a net loss of $\$ 400$. The harvest operation becomes profitable in 2018, and revenue by the end of the projection period (2047) is $\$ 68,100$ for a net profit of $\$ 44,100$ after taxes. As the ginseng harvest is indefinitely renewable, we assume a sale of the harvest rights at the end of the projection period for $80 \%$ of the calculated terminal value, or $\$ 740,300$. The $20 \%$ discount is applied to account for transaction expenses, taxes, and a liquidity premium, which is the implied price paid by a seller for receiving cash for the enterprise up front. Over the entire projection period the landowner receives $\$ 1.1$ million of net cash flow ( $\$ 500,000$ of cash from harvest operations and $\$ 600,000$ from sale of the harvest rights) (Table 3.1.). To value this stream of cash flows on a present value basis, we use a discount rate $12 \%$, used for other agriculture financial 
analysis (Kalikander and Hoekstra, 1990), for the risk of decline in ginseng prices and the time value of money. On a discounted basis, the stewarded harvest is worth $\$ 63,000$.

\section{Ginseng Farm}

\section{Determination of Length of Harvest Cycle}

Ginseng farming is a viable industry, with a range of work intensity of cultivation practices: 1) field cultivation with shade cloth, requiring a large investment of time and capital; 2) wild cultivated in forest-shaded beds, requiring an intermediate level of investment of resources; 3 ) wild simulated in the woods, where seeds are planted at low densities (Davis and Persons, 2014). The value of ginseng roots decline as cultivation intensities increase, as often the roots have less qualitative desirable forms. Our model assumes a wild cultivated approach for the ginseng farm (Appendix E), and maintains that only 90 hectares will be used for farming, due to the need for access roads and space between plots.

A key decision in operating a commercial ginseng farm is deciding at what age to harvest the plants. Waiting longer allows the roots to grow in size and age, which demands a higher market price. Additionally, given the long-term supply and demand dynamics, the landowner may see prices go higher. However, an increase in the harvest cycle length results in more spending on maintenance and a delay in receiving revenue, which greatly affects the present value of the cash flow given the time value of money. To determine optimal timing, we performed a sensitivity analysis, which calculates the present value of the farm based on length of harvest cycle. While the value of a ginseng farm is slightly 
higher if harvest occurs when the roots are five years old, we chose to harvest plants when they are six years of age to insulate the operation from the risks of illegal harvest, as harvested plants need to be older than five years (WV Division of Forestry, 2015). We model a harvest cycle of eight years given ginseng seeds need a period of time for stratification, and seeds germinate between 18 and 22 months (Proctor and Louttit, 1995).

\section{Investment Sources and Uses of Cash}

A landowner would require a cash investment to establish a ginseng farm. In the case we modeled, the landowner would need to provide a $\$ 9.8$ million investment to fund initial operating losses ( $\$ 9.3$ million), purchase of seeds ( $\$ 0.2$ million), and fit our assumptions about costs associated with buildings and equipment ( $\$ 0.3$ million), and other various setup expenses such as legal expenses (\$0.1 million.) The significant need to fund operating losses is driven by the long harvest cycle and amount of labor, overhead, and other expenses incurred prior to the first sizeable harvest. The farm does not become cash flow positive until the first meaningful harvest in the ninth year, or 2023.

\section{Revenue}

Revenue to the landowner under this scenario is derived from sales of roots and seed surpluses. To target densities that are typically found in agroforestry projects, this farm will establish 10 plants per $\mathrm{m}^{2}$ (Burkhart and Jacobson, 2009). This means that there will be a total of 9 million plants across 90 hectares. From density calculations mentioned above, the 90 hectares will have 700 sustainably harvest-ready ginseng plants at year 
2015. We assume that all of these plants produce the average number of 5 seeds per plant, and these seeds have a 65\% germination rate (Davis and Persons, 2014).

While germination rates for our model start at 65\% (Davis and Persons, 2014), we incorporated a diminishing yield effect of 3.8\% per harvest cycle (Nkonya et al., 2008). This reduction in yield accommodates problems associated with reduced ginseng performance in the same tract of land over time, often seen in large-scale ginseng farms (Davis and Persons, 2014). The model assumes that each plant produces five seeds each year; these seeds are planted to replace the harvested plant, with the remaining seeds sold to contribute to ginseng agroforestry projects elsewhere. In the first year, the harvested seeds do not provide the volume to reach targeted densities. As such, we assume the requisite numbers of seeds, 13.8 million, are purchased. Seeds are valued at $\$ 0.017$ per seed, based on 2014 commercial operations prices and are expected to grow in lock-step with ginseng prices.

Per the eight year harvest cycle discussed previously, we modeled harvests in years 2015, 2023, 2031, 2039, and 2047. Root pricing was determined based on the factors discussed under the stewarded harvest scenario, with wild cultivated roots being worth less than wild harvested roots. Revenue is de minimus in the first harvest (2015) as the farm is not at commercial volume. Sales in the first harvest year of planted roots (2023) are approximately $\$ 16.0$ million and increase to $\$ 16.4$ million in the final harvest year, driven by the increase in ginseng prices. Approximately 95\% of the revenue is from root sales with the remainder from surplus seed sales. 


\section{Expenses}

The Cost of Goods Sold (COGS) was determined largely by using information from Burkhart and Jacobson (2009); they completed an economic analysis of the viability of agroforestry of medicinal herbs, including ginseng. Cost of labor is assumed to be at a rate of $\$ 9$ per hour, 9 cents lower than the average salary data for agricultural workers through the Bureau of Labor Statistics (US DL, 2014). Labor rates from planting, maintenance, and harvesting, as well as soil and pest management costs, were adapted from Burkhart and Jacobson (2009) and scaled for the size of 90 hectares. Due to economies of scale, however, we made an assumption that there will be a $25 \%$ percent reduction in costs, due to the significantly larger size of the operation and the use of equipment. Annual costs vary from period to period, as the labor needs change relative to the stage in the harvest cycle. The Selling, General, and Administration (SG\&A) costs were established for hiring four overhead employees at a fully loaded cost of $\$ 50,000$ per year. The annual cost is reduced during non-harvest years, as there is less need of overhead expenses. Average annual expenses for harvest years and non-harvest years were approximately $\$ 3.6$ million and $\$ 0.9$ million, respectively. Given there are eight years between harvests, total operating costs for each harvest cycle total \$10.2 million. US corporate tax rates (based on the level of taxable income) were used (IRS, 2014), and we accounted for the roll-forward of any net operating losses per IRS rules on determining taxable income. We also assumed the company would be structured as a flow-through entity and thus not be subject to both corporate and personal income taxes. 


\section{Valuation}

We valued the farm harvest using the discounted cash flow method. The cash flows to the landowner are significantly negative in the early stages of the investment given the long harvest cycle and cash needed to plant and maintain the ginseng crops. The farm requires $\$ 9.8$ million of cash prior to the first meaningful harvest in year 8 . The first harvest yields $\$ 11.1$ million, thus yielding a cumulative net operating cash flow of $\$ 1.9$ million to the investor. The value of each harvest cycle declines in successive years as the projected increase in ginseng prices rolls off, and yields diminish. As with the stewarded model, we assume the business is sold at $80 \%$ of the terminal value of the cash flows. The terminal value is calculated using a long-term growth rate of $-1.3 \%$, which is the decrease in cash flows from the harvest cycle ending in 2039 to the harvest cycle ending in 2047. A discount rate of $25 \%$ was used, as this rate is typical for investments of moderate risks (Kodukula and Papudesu, 2006). With the discount factor applied, the total present value of a ginseng farm is negative $\$ 3.4$ million. The negative value implies that the cash flow provided by the business does not provide a return on investment above the $25 \%$ discount rate (also considered a "hurdle rate" in financial decisionmaking) and should not be pursued.

\section{Rate of Return for Investors}

The commercial ginseng farm can also be viewed from a return on investment (ROI) perspective. On the investor's $\$ 9.8$ million investment in 2014 , the investor earns $\$ 23.3$ million of dividends through 2047 (assuming excess cash is disbursed as a dividend) and $\$ 1.4$ million through the sale of the business, which is assumed to be $80 \%$ of the terminal 
value to account for capital gains taxes, fees, and a liquidity premium. These cash flows result in the investor earning 2.5 times the initial investment and an ROI of $6.7 \%$. As mentioned previously, this is below our targeted hurdle rate, and therefore the farm should not be pursued as an investment. 
Table 3.1. Total cash flow to the land-owner, post taxes, at three time-points. To establish the value in 2047 for the surface mining scenario, the total cash value of coal royalties in 2035 was invested with an annual $3.5 \%$ interest.

\begin{tabular}{lrrr} 
Scenario & 2015 & 2035 & 2047 \\
\hline Surface Mining & $\$ 490,335$ & $\$ 10,297,031$ & $\$ 10,502,972$ \\
Ginseng Farm & $(\$ 3,270,315)$ & $\$ 1,991,326$ & $\$ 14,878,029$ \\
Stewarded & $(\$ 440,295)$ & $\$ 281,756$ & $\$ 1,078,500$
\end{tabular}


Figure 3.1. Illustration of the mass of an average root through its life cycle, and the projected price by age.

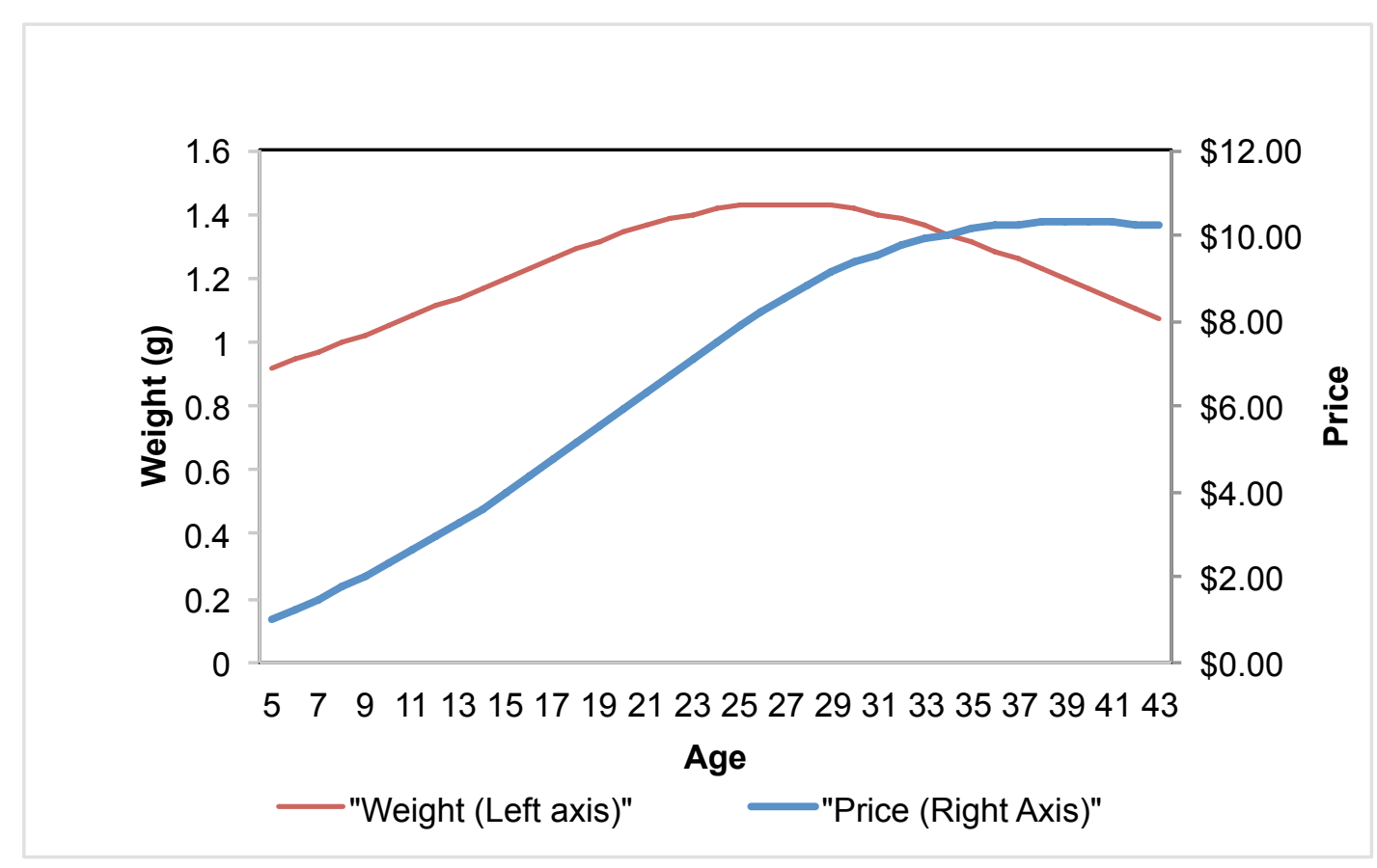


Figure 3.2. Investor rate of return for a ginseng farm, based on average price per root.

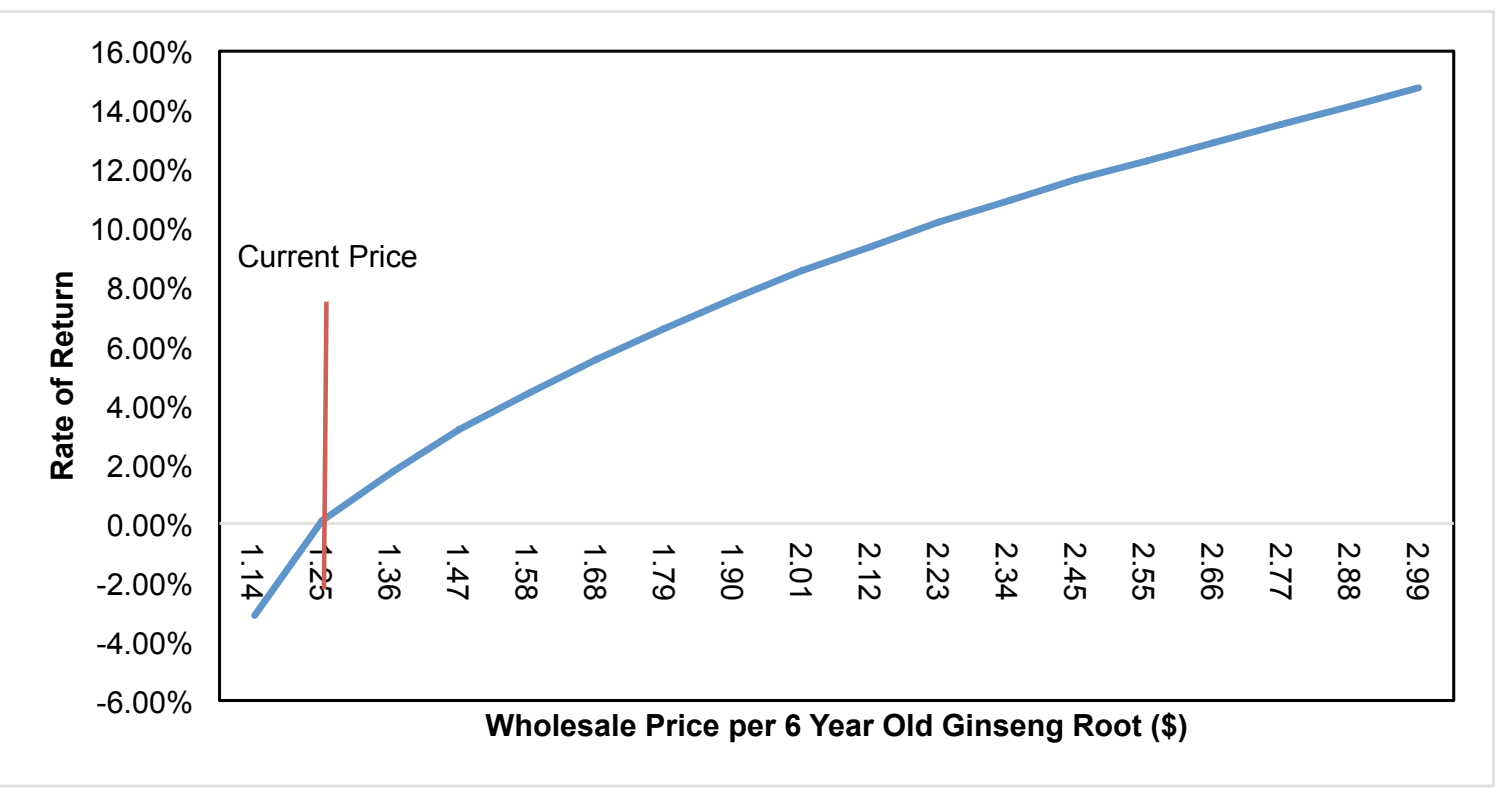




\section{Discussion}

Harvest and resource extraction are components of the Appalachian identity, be it potentially sustainable, such as medicinal plant harvest (Bailey, 1999), or the unsustainable process of coal mining, as there are limited reserves that are being depleted (as reviewed in Brown, Hanson, Liverman, \& Merideth, 1987). From a valuation perspective, ginseng harvest is not as valuable relative to the royalties received by coal mining. In our 100 hectare example, the present value of the coal royalties, as compared to the ginseng farm, is greater by approximately $\$ 6.5$ million ( $\$ 3.1$ million for the coal royalty stream and negative $\$ 3.4$ million for the commercial ginseng farm). However, the present value of a stewarded population of ginseng is $\$ 63,000$.

While there is a significant valuation chasm between ginseng harvest and coal, the total cash value from a ginseng farm exceeds the value of surface mining royalties (Table 3.1.). Further, there are certain compelling reasons for landowners to pursue ginseng harvest. As illustrated, ginseng farm or sustainable harvest operation would be able to provide substantial economic value to 100 hectares of land. Note that while the present value of a ginseng farm is negative, the investment still yields a meaningful $6.7 \%$ annual return. The benefits of the other alternative, stewardship harvest of ginseng, is that it can provide revenue immediately, with minimum costs and risk. Although this method of resource extraction is not as valuable as coal royalties or a large-scale farm, sustainable harvest can provide an immediate, and long term, important secondary source of income to a household. 
A ginseng farm is a riskier investment opportunity due to the long harvest cycle, significant up-front investment, and meaningful operational risks. The long time required for the crop to become significantly valuable (in excess of five years) drives a significant up-front investment (\$9.8 million in our example). In turn, the long-dated positive cash flows (it takes nine years to become cash-flow positive) is highly detrimental to value given the time-value of money and necessary hurdle rate for this type of an investment. From a practical perspective, the landowner may not have access to such a magnitude of capital or be able to find a willing investor. Additionally, uncertainty regarding the future price of ginseng and existence of various operational hazards (e.g., drought, fire, unemployment in the region, etc.), which can influence the volume of ginseng harvest (Bailey, 1999), can decrease the value to an investor or landowner. These risks are reflected in the high discount rate of $25 \%$, which is inversely proportional to the value. There are solutions to reduce the risks associated with starting a woods-grown ginseng farm. First, as illegal harvest could cause massive losses of profit at a large-scale ginseng farm, finding ways to reduce the risk of poaching can lower the discount rate. Additionally, if crop protection permits could be purchased, the barrier to start a ginseng farm may be reduced.

A key assumption in our valuation model is that ginseng will grow in price at an inflation-adjusted annual rate of $3 \%$ until 2029. While grounded in historical price trends and supply/demand dynamics, this assumption is inherently speculative. If the price of ginseng were to increase, the value of ginseng could be much higher than what is projected in the models. The failure for ginseng prices to grow affects the value 
proposition to the landowner significantly. In fact, if ginseng prices were to stay flat with 2014 prices in perpetuity, the ginseng farm would operate slightly above break-even profitability (Fig. 3.2).

Overall, the economics of a ginseng farm offers an explanation of the lack of commercial wild-simulated ginseng farms in Appalachia today. In the same vein, we can utilize this model as a predictive tool to project that such farms may be established in greater magnitude once prices get sufficiently high, and with increased public interest in ginseng harvest. Per our model, the farm begins to yield a reasonably strong rate of return of $10 \%$ at approximately $\$ 2.20$ per root, which is $80 \%$ above the value in today's market (Fig. 3.2.). While these are a significant increase over today's prices, historical price trends and the supply/demand dynamics could make this a reality in the near future.

While a large-scale ginseng farm does not provide significant immediate revenue, the long-term cash received exceeds the value of surface mining royalties in our modeling scenario (\$14.9 million for farmed ginseng harvest compared to $\$ 10.3$ million for surface mining) (Table 3.1.). If the value from coal royalties were invested in 2035 with an interest rate of $3.5 \%$, coal-mining royalties would still not exceed the value of the ginseng farm (Table 3.1.) The ginseng farm scenario benefits from providing revenue in perpetuity versus the limited revenues received by coal mining driven by finite coal reserves. In the future, a ginseng farm may become more economically competitive with coal mining as ginseng prices are likely to go up for reasons previously discussed, and coal prices could potentially go down due to increased renewable energy and natural gas 
volumes. Additionally, the pursuit of a ginseng farm preserves the option value of surface mining while surface mining destroys the ability to pursue ginseng harvest.

An overall caveat to this analysis is that individuals rarely own mineral rights to their property (Bailey, 1999; Peluso, 1992), and a landowner without mineral rights would likely be unable to stop a surface mine operation from occurring. However, this exercise was undertaken to illustrate the potential value and show that renewable resource extraction is a viable option for this area. Additionally, it may be possible in some situations to buy the mineral rights, which would make this analysis relevant to more landowners, but create more upfront costs.

Since the community-at-large is more likely to prioritize the economic value of nature, as compared to ginseng harvesters (Chap 1), this research can be beneficial to educate the general public about alternative economic land-uses in Appalachia. Ginseng harvest can provide potential revenue for an individual, and the results from this study should be used as a framework to help land managers and the owners of mineral-rights to make educated decisions about future land-use of forested property. While this paper attempts to demonstrate the economic viability of growing and harvesting ginseng in lieu of surface mining, this is only one type of NTFP that can be grown in a shaded forest. Economic opportunities that couple with sustainable NTFP harvest, and maintain the integrity of the forest, would be selling the carbon credits of the property to interested industry members. 
There are a numerous economic opportunities from wild harvested products from a rich and diverse forest. As Bailey (1999) explored, forest harvesters typically collect a range of NTFPs that can be sold: ramps, wild mushrooms, goldenseal, walnuts, fur trapping, etc. An additional use of the forest, in conjunction with potential ginseng harvest, is maple syrup production (Nadeau et al., 1999). West Virginia has the potential to be the seventh largest maple syrup producer in the United States, with the large number of maples growing in the forests, and especially on privately owned lands (Farrell and Chabot, 2012). There is a growing demand for syrup, as America's consumption of syrup has risen by $155 \%$ since the 1970's (Farrell and Chabot, 2012). From a sustainable forestry standpoint, sap can only be harvested from trees that are older than 30 years (Farrell and Chabot, 2012). Sap is collected before ephemerals and sensitive seedlings emerge, allowing a diverse understory, typical of older forests, to grow in the warmer months. It is important to note, however, that ginseng may not have maximized performance under red maple trees (Turner and McGraw, 2015), and so, agroforestry may be more successful if ginseng is planted under sugar maple trees. While syrup production coupled with ginseng harvest can be a strong economic opportunity for the state of West Virginia, as Farrell and Chabot (2012) suggest, West Virginia currently does not have the syrup 'culture' that is found in other states. A paradigm shift, focusing the culture away from the 'coal or bust' mentality, and focusing instead on renewable resource extraction, is one that could create a larger source of economic and environmental sustainability for the individuals of this state. 
While extracting coal may provide large, immediate, economic incentives for a landowner, there are long-term costs associated with surface mining (Epstein et al., 2011). Additionally, the current cultural connection with coal is a legacy of the historical importance of this resource (Bell and York, 2010). Extracting coal has become increasingly difficult due to greater regulation of the industry to protect human and environmental health (Hammond, 2011). In addition to coal being harder to extract, advances in technology and methods of coal extraction, i.e., the controversial practice of mountain top removal, have dramatically decreased the number of individuals employed in the mining industry (Blaacker et al., 2012; Epstein et al., 2011). For example, Woods and Gordon (2011) found no evidence that mountain top removal (a form of surface mining) increased the employment in communities neighboring a mountain top removal site.

Despite the conception that coal mining is an economic driver of the region (Bell and York, 2010), the environmental impacts are large and costly (Epstein et al., 2011). As coal mining is a private industry, the externalities to the community are disproportional to the community benefits (Randall et al., 1978). Therefore, focusing on long-term land-use that promotes sustainability and biodiversity in the Appalachian region should be prioritized. As demonstrated in this article, agroforestry can yield profitable returns, and can be a competitor to an industrial enterprise. Natural gas is set to replace coal as the primary source of energy in America (US EIA, 2013). As such, the total value of coal, and the future demand of coal, should be considered before converting the land from forest to surface mine. Land-use change is one of the greatest drivers for loss of 
biodiversity (Sala et al., 2000) and, therefore finding economically viable alternatives can help maintain the integrity of the eastern deciduous forest and preserve the habitat of other plant and animal species. By harvesting NTFPs in a sustainable manner, rather than drastically altering the landscape, ginseng may act as a vehicle for conservation for numerous other, less charismatic species.

\section{Acknowledgments}

Thanks to J.B. McGraw for his constant help throughout the study. Thank you to J. Skousen for your advice and suggestions. Additionally, thanks to our ginseng harvesters, D.W. Turner and Z. Zacavish, for being meticulous about harvesting sustainably and for measuring leaflets. A very special thanks to E.H. Mooney for her previous, timeconsuming work of aging ginseng roots and recording their leaf area. Our research was supported by a National Science Foundation Long Term Research in Environmental Biology Grant to J.B. McGraw (DEB-0613611 and DEB-1118702), a Huyck Preserve travel grant to E.H. Mooney, and the Botany in Action Fellowship, through Phipps Conservatory in Pittsburgh, PA, to E.H. Mooney and J.B. Turner. 


\section{References}

Baeg, I., So, S.H., 2013. The world ginseng market and the ginseng (Korea). J. Ginseng Res. 37, 1-7. doi: 10.5142/jgr.2013.37.1

Bailey, B., 1999. Social and economic impacts of wild harvested products. Dissertation. West Virginia University.

Barry, J. 2001. Mountaineers are always free? An examination of the effects of mountaintop removal in West Virginia. Women's Stud. Q. 29, 116-130.

Bureau of Business and Economic Research (BBER) and Center for Business and Economic Research (CBER) 2010. The West Virginia Coal Economy 2008. A report published by Bureau of Business and Economic Research, West Virginia University, and Center for Business and Economic Research, Marshall University.

Bell, S.E., York, R., 2010. Community economic identity: The coal industry and ideology construction in West Virginia. Rural Sociol. 75, 111-143. doi: 10.1111/j.15490831.2009.00004.x

Blaacker, D., Woods, J., Oliver, C., 2012. How big is big coal? Public perceptions of the coal industry's economic impact in West Virginia. Organ. Environ. 25, 385-401. doi:10.1177/1086026612464766

Brown, B.J., Hanson, M.E., Liverman, D.M., Merideth, R.W., 1987. Global Sustainability: Toward Definition. Environ. Manage. 11, 713-719. doi: 10.1007/BF01867238

Burkhart, E., Jacobson, M., 2009. Transitioning from wild collection to forest cultivation of indigenous medicinal forest plants in eastern North America is constrained by lack of profitability. Agrofor. Syst. 76, 437-453. doi:10.1007/s10457-008-9173-y

CITES Secretariat. Convention on International Trade in Endangered Species of Wild Fauna and Flora (CITES) (n.d.) [WWW Document]. URL www.cites.org (accessed 4.15.2015).

Chandler, J.L., McGraw, J.B., 2015. Variable effects of timber harvest on the survival, growth, and reproduction of American ginseng (Panax quinquefolius L.). For. Ecol. Manage. 344, 1-9. doi:10.1016/j.foreco.2015.02.007

Chung, V., B.C.M., R.C.M.P, (HK), Wong, E., M.A., Woo, J., F.R.C.P., M.D., M.B.B.Chir, Vi Lo, S., M.B.B.C.H., F.F.P.H.M., Griffiths, S., 2007. Use of Traditional Chinese Medicine in the Hong Kong special administrative region of China. J. Altern. Complement. Med. 13, 361-367. doi:10.1089/acm.2006.6152 
Davis, J.M., Persons, W.S., 2014. Growing and marketing ginseng, goldenseal and other woodland medicinals, Revised ed. New Society Publishers, Gabriola Island, BC, Canada.

Epstein, P.R., Buonocore, J.J., Eckerle, K., Hendryx, M., Stout, B.M., Heinberg, R., Clapp, R.W., May, B., Reinhart, N.L., Ahern, M.M., Doshi, S.K., Glustrom, L., 2011. Full cost accounting for the life cycle of coal. Ann. N. Y. Acad. Sci. 1219, 73 98. doi:10.1111/j.1749-6632.2010.05890.x

Farrell, D., Gersch, U.A., Stephenson, E., 2006. The value of China' s emerging middle class. McKinsey Q. Special ed. 60-69.

Farrell, M., Chabot, B., 2012. Assessing the growth potential and economic impact of the U.S. maple syrup industry. J. Agric. Food Syst. Community Dev. doi:10.5304/jafscd.2012.022.009

Food and Agriculture Organization of the United Nations (FAO UN), World Health Organization (WHO), 2012. Discussion paper on the possible extension of the territorial application of the codex regional standard for ginseng products into a worldwide standard, in: Codex Committee on Processed Fruits and Vegetables.

Google Earth, 2012. Exact location withheld due to conservation concerns. URL http://www.google.com/earth/index.html (accessed 1.23.2012).

Hammond, G.W., 2011. Consensus coal production and price forecast for West Virginia: 2011 Update, West Virginia Department of Environmental Protection; Office of Special Reclamation.

Hufford, M., 2002. Reclaiming the commons: Narratives of progress, preservation, and ginseng, in: Howell, B.J. (Ed.), Culture, Environment, and Conservation in the Appalachian South. Chicago, IL, pp. 100-120.

Hufford, M., 2003. Knowing ginseng: The social life of an Appalachian root. Cah. Littérature Orale 265-295.

IRS, 2014. Instructions for Form 1120 (2014) [WWW Document]. URL http://www.irs.gov/instructions/i1120/ch02.html\#d0e2731 (accessed 5.19.15).

Kalikander, F., Hoekstra, D.A., 1990. Dryland Management: The Machokos District, Kenya, in: Dixon, J.A., James, D.E., Sherman, P.B. (Eds.), Dryland Management: Economic Case Studies. Earthscan, Oxon.

Kodukula, P., Papudesu, C., 2006. Project Valuation Using Real Options: A Practitioner's Guide. J. Ross Publishing, Inc. 
Li, S., Li, J., Yang, X.-L., Cheng, Z., Zhang, W.-J., 2011. Genetic diversity and differentiation of cultivated ginseng (Panax ginseng C. A . Meyer) populations in North-east China revealed by inter-simple sequence repeat (ISSR) markers. Hortscience 5, 815-824. doi:10.1007/s10722-010-9618-9

MacDonald, K.I., 2010. The devil is in the (bio)diversity: Private sector "engagement" and the restructuring of biodiversity conservation. Antipode 42, 513-550. doi:10.1111/j.1467-8330.2010.00762.x

McGraw, J., Sanders, S., Van der Voort, M., 2003. Distribution and abundance of Hydrastis canadensis L . (Ranunculaceae) and Panax quinquefolius L . (Araliaceae) in the Central Appalachian Region. J. Torrey Bot. Soc. 130, 62-69.

McGraw, J.B., Lubbers, A.E., Van der Voort, M., Mooney, E.H., Furedi, M.A., Souther, S., Turner, J.B., Chandler, J., 2013. Ecology and conservation of ginseng (Panax quinquefolius) in a changing world. Ann. New York Acad. Sci. Year Ecol. Conserv. Biol. 1286, 62-91. doi:10.1111/nyas.12032

Montrie, C., 2003. To Save the Land and People: A history of opposition to surface coal mining in Appalachia. University of North Carolina Press.

Nadeau, I., Olivier, A., Simard, R.R., Coulombe, J., 1999. Growing American ginseng in maple forests as an alternative landuse system in Québec, Canada. Agrofor. Syst. 44, 345-353. doi:10.1023/A:1006275316779

Nesbitt, J.T., Weiner, D., 2001. Conflicting environmental imaginaries and the politics of nature in Central Appalachia. Geoforum 32, 333-349. doi: 10.1016/S00167185(00)00047-6

Nkonya, E., Gicheru, P., Woelcke, J., Okoba, B., Kilambya, D., Gachimbi, L.N., 2008. On-site and off-site long-term economic impacts of soil fertility management practices. Int. Food Policy Res. Inst. 1-32.

Obae, S.G., West, T.P., 2012. Variation of phytochemical profiles and content among root morphotypes of American ginseng: Economic implications for the grower. J. Med. Plants Res. 6, 3889-3897. doi:10.5897/JMPR12.418

PA Department of Environmental Protection (PA DEP) and D'Appolonia Engineering Division of Ground Technology (DEDGT), 2001. Remote sensing of forestland above longwall mines [WWW Document]. URL http://www.dep.state.pa.us/dep/deputate/minres/longwallforestlandstudy/forestlandh ome.htm (accessed 5.21.15).

Peluso, N.L., 1992. The rock, the beach, and the tidal pool: People and poverty in natural resource-dependent areas. Soc. Nat. Resour. 7, 23-38. doi: $10.1080 / 08941929409380842$. 
Pirraglia, A., Gonzalez, R., Denig, J., Saloni, D., Wright, J., 2012. Assessment of the most adequate pre-treatments and woody biomass sources intended for direct cofiring in the U.S. BioResources 7, 4817-4842. doi: 10.15376/biores.7.4.4817-4842

Pratt, S.P., Grabowski, R.J., 2011. Cost of Capital in Litigation: Applications and Examples. John Wiley \& Sons, Inc., Hoboken, NJ.

Proctor, J.T., Louttit, D., 1995. Stratification of American ginseng seed: embryo growth and temperature. Korean J. Ginseng Sci. 19, 171-174.

Randall, A., Grunewald, O., Johnson, S., Ausness, R., Pagoulatos, A., 1978. Reclaiming coal surface mines in central Appalachia: A case study of the benefits and costs. Land Econ. 54, 472-489. doi: 10.2307/3146172

Rasker, R., 1993. Rural development, conservation, and public policy in the greater Yellowstone ecosystem. Soc. Nat. Resour. 6, 109-126. doi: 10.1080/08941929309380814

Sala, O.E., Chapin, F.S., Armesto, J.J., Berlow, E., Bloomfield, J., Dirzo, R., HuberSanwald, E., Huenneke, L.F., Jackson, R.B., Kinzig, A., Leemans, R., Lodge, D.M., Mooney, H.A., Oesterheld, M., Poff, N.L., Sykes, M.T., Walker, B.H., Walker, M., Wall, D.H., 2000. Global biodiversity scenarios for the year 2100. Science. 287, 1770-1774. doi: 10.1126/science.287.5459.1770

SAS JMP Pro 11. (2013). SAS Campus Drive, Cary, NC, USA 27513.

Schlag, E.M., Mcintosh, M.S., 2006. Ginsenoside content and variation among and within American ginseng (Panax quinquefolius L .) populations. Phytochemistry 67, 1510-1519. doi:10.1016/j.phytochem.2006.05.028

Sverdlove, R., 1981. Leslie models with input. SIAM J. Appl. Math. 41, 324-330. doi:10.1137/0141028

Turner, J.B., McGraw, J.B., 2015. Can putative indicator species predict habitat quality for American ginseng? Ecol. Indic. 57, 110-117. doi:10.1016/j.ecolind.2015.04.010

US Department of Labor (US DL), 2014. Occupational outlook handbook: agricultural workers [WWW Document]. URL http://www.bls.gov/ooh/farming-fishing-andforestry/agricultural-workers.htm (accessed 5.19.15).

US Department of the Interior (US DOI), 2013. Coal management program. Washington, D.C. [WWW Document]. URL http://www.doi.gov/oig/reports/upload/CR-EVBLM-0001-2012Public.pdf (accessed 5.20.15). 
US Energy and Information Administration (US EIA), 2013. AEO2014 Early release overview [WWW Document]. URL

http://www .eia.gov/forecasts/aeo/er/pdf/0383er(2014).pdf (accessed 5.21.15).

US Energy and Information Administration (US EIA), 2015. Coal News and Markets [WWW Document]. URL http://www.eia.gov/coal/news_markets/ (accessed $5.19 .15)$

US Fish and Wildlife Service (US FWS), 2012. U.S. exports of American ginseng. Dep. Inter. 1-22.

Van der Voort, M.E., McGraw, J.B., 2006. Effects of harvester behavior on population growth rate affects sustainability of ginseng trade. Biol. Conserv. 130, 505-516. doi:10.1016/j.biocon.2006.01.010

Wang, H., Peng, D., Xie, J., 2009. Ginseng leaf-stem: bioactive constituents and pharmacological functions. Chin. Med. 4. doi:10.1186/1749-8546-4-20

Williamson, E.M., Lorenc, A., Booker, A., Robinson, N., 2013. The rise of traditional Chinese medicine and its materia medica: A comparison of the frequency and safety of materials and species used in Europe and China. J. Ethnopharmacol. doi:10.1016/j.jep.2013.06.050

Woods, B.R., Gordon, J.S., 2011. Mountaintop removal and job creation: Exploring the relationship using spatial regression. Ann. Assoc. Am. Geogr. 101, 806-815. doi:10.1080/00045608.2011.567947

WV Division of Forestry, 2015. Ginseng digging season September 1 through November 30 [WWW Document]. URL http://www.wvforestry.com/ginseng.cfm?menucall=ginseng (accessed 5.26.15).

Yin, J., Zhang, H., Ye, J., 2008. Traditional Chinese Medicine in treatment of metabolic syndrome. Endocrine, Metab. Immune Disord. - Drug Targets 8, 99-111. doi:10.1016/j.biotechadv.2011.08.021. 


\section{CHAPTER IV: CAN PUTATIVE INDICATOR SPECIES PREDICT HABITAT QUALITY FOR A RARE UNDERSTORY HERB?}

(Turner and McGraw, 2015, Ecological Indicators 57:110-117) 


\begin{abstract}
American ginseng, P. quinquefolius, is a long-lived medicinal understory herb, which has been heavily harvested since the 1700's. Because of the economic value of the root and the increasing rarity of this plant, Panax quinquefolius L._is often reintroduced across its range. Land managers and hobby growers recommend using 'associate species' as a way to determine ideal site conditions for reintroduction. However, the accuracy of these putative indicator species in identifying sites that will maximize growth of this rare herb has not been tested. Using a long-term ecological dataset of 26 populations, we evaluated whether 20 putative indicators (herbs, shrubs, and trees) could predict $P$. quinquefolius performance, as measured by the relative growth rate of the leaf area, at the population and microsite level. Of the indicators, only one tree species was able to predict positive performance. If a $P$. quinquefolius was within 10 meters of a Liriodendron tulipifera $\mathrm{L}$. tree, the plant would have increased growth, as compared to plants that were not within 10 meters of this tree. Surprisingly, the presence of most putative indicator species was found to be unreliable as a site quality measure. At the population level, four putative indicators, Aralia nudicaulis L., Acer rubrum L., Betula lenta L., and Lindera benzoin (L.) Blume, were actually contra-indicators, as their presence at a site implied lower $P$. quinquefolius performance. If Podophyllum peltatum L. was absent from a site, but $B$. lenta present, $P$. quinquefolius had reduced growth. The results from this study have important implications for in situ conservation strategies of this rare medicinal plant. If $P$. quinquefolius is planted in sites that do not maximize performance, reintroduction projects may be unsuccessful, which will result in a waste of time, money, and resources.
\end{abstract}




\section{Introduction}

The understory is responsible for $90 \%$ of the biodiversity of the eastern deciduous forest (Gilliam, 2007). These species in the forest understory are ecologically significant; many of these species are economically and medicinally important (Burkhart and Jacobson, 2009; Chamberlain et al., 2013). Often, rare understory forbs are the most sensitive to disturbance and their abundance is likely to decrease as disturbance events occur over time (Wiegmann and Waller, 2006). Knowing the most effective ways to implement conservation, by assessing habitat quickly and effectually for reintroduction of these sensitive species, can be vital to preserve diversity.

Analysis of indicator species within a habitat can be used to assess ecosystem health or determine habitat quality (Landres et al., 1988). This technique can be particularly useful in predicting habitat suitability for a single rare or endangered plant species (Gregory et al., 2010; Ren et al., 2010; Vittoz et al., 2006). Species' niches, in general, are multidimensional in ways that are difficult to quantify (Pulliam, 2000). If indicator species could be found that respond to environmental variation in space and time in a similar manner to a rare species, knowing the detailed niche requirements of the rare species would not be necessary to determine where that species might be found, or where that species could be successfully reintroduced (Ren et al., 2010).

One example where indicator species analysis could be used to support reintroduction would be the efforts to restore populations of the uncommon to rare species, American ginseng (Panax quinquefolius L.). P. quinquefolius is often reintroduced, as this species is a valuable medicinal plant that is harvested by individuals in North America and sold 
into the international market (Burkhart, 2013; Burkhart et al., 2012). In addition to being economically valuable, $P$. quinquefolius is ecologically important as a food source as wood thrushes (Hylocichla mustelina) consume the flesh from the berries (Hruska et al., 2014), whitetail deer (Odocoileus virginianus) browse the leaves (McGraw and Furedi, 2005), and rodents eat the roots (Davis and Persons, 2014).

Reintroduction, or woods grown cultivation, of $P$. quinquefolius is an in situ strategy for conservation (Burkhart, 2013). This process can be difficult as the niche of this species is broad, ginseng can be found on a variety of slopes, aspects, elevations, over a vast latitudinal and longitudinal breadth (McGraw et al., 2003, 2013), and under a wide array of overstory species (McGraw et al., 2013). The ideal indicator species would be a plant whose niche would overlap completely with the portion of this niche where $P$. quinquefolius has rapid growth rate and high reproductive success (Fig. 4.1a).

Experienced cultivators have already adopted the indicator species approach to make recommendations to others wanting to produce 'wild simulated' or 'woods grown' roots (Burkhart, 2013). P. quinquefolius habitat indicators are frequently listed in the popular literature (Pritts, 1995), in anthropological studies (Hufford, 2003), and in ecological studies (Burkhart, 2013). Examples of several putative indicator species include Jack-inthe-pulpit (Arisaema triphyllum (L.) Schott), rattlesnake fern (Botrychium virginianum (L.) Sw.), and sugar maple (Acer saccharum Marshall) (Anderson et al., 1993; Fountain, 1986). Previous research on indicators and $P$. quinquefolius involved visiting sites with this herb present, and cataloguing the species in the adjacent area (Anderson et al., 1993; 
Burkhart, 2013; Fountain, 1986). While there has been extensive work to determine these associated species, there is no research on their ability to predict sites that maximize performance. Reintroduction can be a valuable tool in rare plant conservation (Guerrant, 2012), but there are risks in planting cultivated, woods grown, or wild simulated $P$. quinquefolius (Apsley and Carroll, 2004; Davis and Persons, 2014; Punja, 2011). Often, because of this potential failure, individuals who are interested in agroforestry of this species are given the recommendation of introducing a few plants or seeds to test the site before starting a large scale reintroduction project (Beyfuss, 1992; Carroll and Apsley, 2004; Davis and Persons, 2014). However, as this understory herb matures slowly (McGraw et al., 2013), this time frame may be ill-suited for a species that needs conservation priority.

The use of association analysis alone to guide $P$. quinquefolius' planting could be flawed for several reasons. As an economically valuable plant that has been harvested since the 1700's (McGraw et al., 2013), plants may be found now primarily in fringe habitats (Burkhart, 2013; McGraw et al., 2003) (Fig. 4.1b). Due to localized extirpation, remaining populations could be 'sink populations' (Pulliam, 1988). Second, this plant's niche is large (McGraw et al., 2003), but the likelihood is low that the niches of these indicator species overlap neatly within the niche of this rare herb. Instead, the niche of an indicator species might be smaller in some dimension, and therefore, only a good indicator in a part of its range (Fig. 4.1c). Finally, the niche of the putative indicator could be larger, such that its presence is not a good indicator of suitable habitat everywhere it is found (Fig. 4.1d). The validity of indicator species in predicting quality 
habitat needs to be rigorously tested so time, money, effort, and plants are not wasted on unsuccessful reintroduction projects.

Understanding whether the use of indicator species can signal if a site is within the optimum niche will be beneficial for future reintroduction projects. The existence of a suite of indicators for P. quinquefolius pre-supposes a Clementsian ecological niche, in which groups of species share a common set of environmental requirements (Clements, 1916). Given that research more generally supports the Gleasonian individualistic niche (Denslow, 2014), and communities do not respond in a unified fashion to temporal or spatial environmental gradients (Davis, 1984), the more likely scenario is that there will be different indicators for quality P. quinquefolius habitat in different parts of its range. Using a new methodology that investigates whether the presence of indicator species indicates positive performance, while the absence indicates poor performance, will help us understand if these species are, in fact, universal indicators of prime habitat.

In this study, we investigated the potential use of indicator species in a new way: we determined, based on the presence or absence of neighboring companion species, if we could predict a rare species' performance, at varying scales across its range. Our questions were: (1) Do populations of $P$. quinquefolius with putative indicator species present at the site have higher levels of performance than those populations that do not have those indicator species? (2) Do individual $P$. quinquefolius plants located near putative indicator species have higher levels of performance than plants that are not near 
indicator species, suggesting certain indicator species represent an ideal microsite environment?

\section{Methods}

\section{Study Species}

P. quinquefolius is a representative herbaceous species of the eastern deciduous forest due to its life history traits, long-lived nature, and wide geographic range in North America (McGraw et al., 2013). Further, this plant can be found on a variety of slopes, aspects and elevations (McGraw et al., 2003). A single population of plants can range in physical size from .04 to 4 hectares. Each population is made up of smaller groups of individuals we refer to as "clusters." Populations of $P$. quinquefolius often have fewer than 200 individuals, but, within the population, cluster size can range from 1 plant to more than 100 plants $/ \mathrm{m}^{2}$ (McGraw et al., 2013; Wagner and McGraw, 2013).

\section{Census}

Twenty-six natural populations of $P$. quinquefolius, found across seven states, were used for this research during the summer of 2013. The plants included in this study were visited twice each year, to measure size and reproductive output. Each individual plant was cryptically tagged with a numbered aluminum nail. During the spring census, we measured the length and width of the longest leaflet on each leaf. These populations were censused every year since at least 2004 with the same methodology. Using this geographically and temporally extensive data set, we were able to analyze $P$.

quinquefolius growth over time. Growth is a strong metric for plant performance, as the size of the plant corresponds with reproductive effort (McGraw, 2001). For each year, 
total plant leaf area was calculated using a previously derived allometric relationship using the length and width of the longest leaflet on each of the leaves.

$$
\begin{aligned}
& \text { Leaf Area }=-49.66+(6.87 * \text { Leaf Length })+(12.63 * \text { Leaf Width })+(1.96 *(\text { Leaf Length } \\
& -7.51) *(\text { Leaf Width-3.64) })
\end{aligned}
$$

At each population, P. quinquefolius plants were selected using a stratified-random method: From 20 randomly selected clusters at each population, one plant per cluster was randomly selected from the dataset, given that the plant was present in 2012. However, if the population had fewer than 20 clusters, at least one plant was selected randomly from each cluster, and additional plants were randomly selected from previously used clusters to a maintain comparable sample size among populations. Plants that were not independent of each other (within two, five, or 10 meters, depending on the analysis) were removed from the dataset to avoid pseudoreplication (Sokal and Rohlf, 2012). However, any indicator species present in the microsite of these plants were marked as also present in the population. If the randomly selected plant did not emerge in 2013, or if the plant was browsed, the plant in closest proximity to the selected plant was used instead. For two large, spatially expansive populations, additional individuals were sampled.

\section{Putative Indicator Species}

The putative indicator species used for this research were selected from literature reviews (Anderson et al., 1993; Burkhart, 2013; Davis and Persons, 2014; Fountain, 1986; 
Roberts and Richardson, 1981), initial surveys of the overstory at each site, as well as unpublished opinions of an individual with extensive planting experience (Beyfuss, personal communication, 2013). Additionally, these species were selected based on ease of identification, which is important in indicator research, as this allows scientists, landmanagers, and the general public to understand and use this research (Coote et al., 2013; Schiller et al., 2001). The indicator species list included herbaceous plants, shrubs, and trees (Table 4.1).

To determine if indicator species were able to predict $P$. quinquefolius performance, a modified 'Panax-centric' approach was used (Wixted and McGraw, 2009). Wixted and McGraw (2009) used this methodology to study the impact of invasive herbs, shrubs, and trees on P. quinquefolius plants. A research team identified the indicator species in the vicinity the $P$. quinquefolius plant at three different scales for herbaceous, shrub, and tree species. Understory indicator herbaceous species were counted as present if the putative indicators were found within two meters of the selected plant. Indicator shrubs were counted as present if the shrub was within five meters of the selected plant, and tree species were counted as present if the tree was within 10 meters of the selected plant (Table 4.1).

\section{Data Analysis}

For each year, any plants that were identified as new seedlings were removed from the analysis for that year only, due to atypical growth rates associated with the first year. Plants included in the analysis had to be present for at least three years between the years 
of 2004 to 2013, to ensure that there were sufficient data points for a regression. The number of $P$. quinquefolius plants that met the criteria for independence, at the scale for herbs $(2 \mathrm{~m})$, shrubs $(5 \mathrm{~m})$, and trees $(10 \mathrm{~m})$ were as follows: $\mathrm{N}=367$ for herbs; $\mathrm{N}=310$ for shrubs; and $\mathrm{N}=236$ for trees. Based on equations of Hunt (1990) and McGraw and Garbutt (1990), we calculated relative growth rate $\left(\mathrm{RGR}_{\mathrm{LA}}\right)$ from 2004 to 2013 by finding the slope of the regression of natural log of leaf area on year for each plant.

To determine if there was a difference in P. quinquefolius $\mathrm{RGR}_{\mathrm{LA}}$ among populations where indicator species were present or absent (population level analysis), a nested oneway ANOVA was used. Indicator species presence or absence at the population was the main effect, and population was nested within indicator species presence or absence class. Restricted maximum likelihood was used to estimate the variance components (SAS JMP, 2013).

Additionally, we asked if the presence or absence of a single indicator species affected $P$. quinquefolius performance, depending on the presence or absence of another indicator species. By selecting a combination of species of interest at the population level, based on the other analyses, we completed an "and/or" analysis to investigate if two indicator species were better at predicting plant performance, rather than an individual indicator. This analysis used a two-way nested ANOVA with the terms: Species 1 (levels: present/absent), Species 2 (present/absent), Species 1 X Species 2, and the nested term Population (Species 1 x Species 2). 
For populations in which an indicator species was present, we asked if plant growth was greater in the microsite of the indicator, as compared to P. quinquefolius plants that were not within the microsite at the two, five, and 10 meter scale (for herbs, shrubs, and trees, respectively). A two-way ANOVA was used for only the subset of populations having an indicator species of interest at the population level, but also having microsites within the same population that both had and did not have the indicator species of interest (Table 4.1). The two factors were population and indicator species (present/absent). We used the same dependent variable that was used in the population level analysis: relative growth rate. For all analyses in this study, if the residuals were not normally distributed, data were log transformed. Data were analyzed using SAS JMP Pro 11 (SAS JMP, 2013).

\section{Results}

In the 26 populations studied, only one population did not have $A$. saccharum present, and similarly, only one did not have A. triphyllum present (Table 4.1). These were therefore excluded from population-level analyses. The next most common species present were Polystichum acrostichoides (Michx.) Schott and Liriodendron tulipifera L., at 22 and 20 populations, respectively. Due to limited replication, population level analysis of these two species may not be the most accurate.

\section{Population Level Analysis}

At the population level, for 14 of the 18 species examined, there was no difference in growth of $P$. quinquefolius when the putative indicator was absent vs. present $(\mathrm{p}>0.05)$.

Of the indicator species that were able to successfully predict $P$. quinquefolius 
performance, a majority of these could be considered 'contra-indicators,' as their presence at a population resulted in lower growth rates. Growth in populations where Aralia nudicaulis L. was absent was 5.16-fold higher than growth in the populations having A. nudicaulis (Fig. 4.2a; $\mathrm{F}=11.12, \mathrm{p}=0.0067$ ). At populations that had $A$. nudicaulis present, the $\mathrm{RGR}_{\mathrm{LA}}$ was no different from zero using a two-tailed t-test $(\mathrm{t}=0.66, \mathrm{p}=0.5135)$, i.e., the plant was neither growing nor shrinking in size. Populations of P. quinquefolius had lower RGR $\mathrm{LA}_{\text {A }}$ when Acer rubrum L. was present (Fig. 4.2b; $\mathrm{F}=19.57, \mathrm{p}=0.0007)$. If $A$. rubrum was absent from a population, $P$. quinquefolius grew 11.48-fold faster relative to sites where this species was present. Populations with $A$. rubrum present had a mean $\mathrm{RGR}_{\mathrm{LA}}$ that was not different from zero using a two-tailed ttest $(\mathrm{t}=0.15, \mathrm{p}=0.8849)$. At populations with Betula lenta $\mathrm{L}$. absent, $P$. quinquefolius had higher RGR $\mathrm{LA}_{\mathrm{L}}$ than P. quinquefolius that had B. lenta present at the population (Fig. 4.2c; $\mathrm{F}=8.81, \mathrm{p}=0.0055)$. However, the $\mathrm{RGR}_{\mathrm{LA}}$ of $P$. quinquefolius at populations with $B$. lenta was greater than zero using a two-tailed $\mathrm{t}$-test $(\mathrm{t}=2.57, \mathrm{p}=0.0115)$. There was a trend that there was an increase in performance if Lindera benzoin (L.) Blume was absent from the population (Fig. 4.2d; $F=2.98, p=0.092$ ), but the mean $R_{G R}$ was greater than zero using a two-tailed $\mathrm{t}$-test when the shrub was present at the population $(\mathrm{t}=5.51$, $\mathrm{p}<0.0001)$.

Effects of multiple species on P. quinquefolius growth were not always additive. For example, there was a trend that the effect of $B$. lenta presence on the growth rate of $P$. quinquefolius depended on the presence or absence of Podophyllum peltatum L. (Fig.

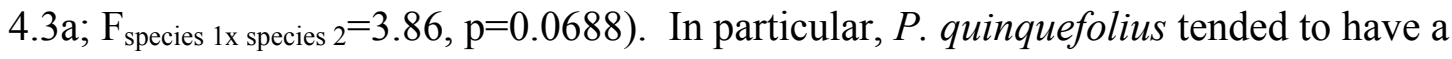


lower RGR $\mathrm{LA}_{\mathrm{LA}}$ if a population had B. lenta present and $P$. peltatum absent. The $\mathrm{RGR}_{\mathrm{LA}}$ of this combination was not different from zero using a two-tailed $t$-test $(\mathrm{t}=-0.75, \mathrm{p}=0.4547)$, whereas all of the other means were greater than zero (P. peltatum present, B. lenta present: $\mathrm{t}=4.38, \mathrm{p}<0.0001 ;$. peltatum present, $B$. lenta absent: $\mathrm{t}=7.66, \mathrm{p}<0.0001 ; P$. peltatum absent, $B$. lenta absent: $\mathrm{t}=4.696, \mathrm{p}<0.0001)$.

There was also a trend for the effect of Botrychium virginianum presence on the growth rate to depend on the presence or absence of Tilia americana $\mathrm{L}$. (Fig. 4.3b; $\mathrm{F}_{\text {species } 1 \mathrm{x} \text { species }}$ $\left.{ }_{2}=4.01, \mathrm{p}=0.0529\right)$. If the population had only one of the species present, there was a tendency for there to be a higher $P$. quinquefolius growth rate, but if both, or neither, species were present, there was reduced $\mathrm{RGR}_{\mathrm{LA}}$. All of the means differed from zero using a two-tailed t-test ( $T$. americana present, $B$. virginianum present: $\mathrm{t}=3.26, \mathrm{p}=0.0015$; T. americana present, $B$. virginianum absent: $\mathrm{t}=5.96, \mathrm{p}<0.0001 ; T$. americana absent, $B$. virginianum present: $\mathrm{t}=4.53, \mathrm{p}<0.0001 ; T$. americana absent, $B$. virginianum absent: $\mathrm{t}=3.53, \mathrm{p}=0.0011)$.

\section{Microsite Level Analysis}

In total there were 19 putative indicator species included in the microsite analysis, as Juglans nigra L. was omitted from the study due to lack of replication within sites. If there was a high density of a single species within the site, where every plant was within a microsite of the indicator of interest, we excluded that population from the analysis, resulting in a smaller sample size. There was a lack of differences in the growth effects of 18 out of 19 indicator species examined at the microsite level. L. tulipifera was a 
positive indicator for $P$. quinquefolius growth. If a P. quinquefolius plant was within 10 m of $L$. tulipifera, $\mathrm{RGR}_{\mathrm{LA}}$ was $43.8 \%$ higher than for plants that were not near $L$. tulipifera (Fig. 4.4; $\left.\mathrm{F}_{\text {presence }}=6.60, \mathrm{p}=0.0114\right)$. The effect of $L$. tulipifera proximity on $P$. quinquefolius growth did not vary among populations $\left(\mathrm{F}_{\mathrm{pop} \times \text { presence }}=1.44, \mathrm{p}=0.1701\right)$. 
Table 4.1. List of indicator species along with number of populations in which they were found, as well as percent of those populations included in microsite analysis.

\begin{tabular}{|c|c|c|c|c|}
\hline & Indicator Species & Common Name & $\begin{array}{l}\text { Number of } \\
\text { populations } \\
\text { with indicator } \\
\text { species } \\
\text { present }\end{array}$ & $\begin{array}{l}\text { Percent of those } \\
\text { populations that } \\
\text { were included in } \\
\text { microsite analysis }\end{array}$ \\
\hline \multirow{9}{*}{ Herbaceous } & $\overline{\text { Adiantum pedatum }}$ & northern maidenhair fern & 8 & $38 \%$ \\
\hline & Aralia nudicaulis & wild sarsaparilla & 3 & $67 \%$ \\
\hline & Arisaema triphyllum & jack-in-the-pulpit & 25 & $40 \%$ \\
\hline & Asarum canadense & Canada wild ginger & 9 & $22 \%$ \\
\hline & Botrychium virginianum & rattlesnake fern & 15 & $73 \%$ \\
\hline & Caulophyllum thalictroides & blue cohosh & 8 & $75 \%$ \\
\hline & Podophyllum peltatum & mayapple & 18 & $72 \%$ \\
\hline & Polystichum acrostichoides & christmas fern & 22 & $59 \%$ \\
\hline & Actaea sp. & Black Cohosh or Doll's eyes & 19 & $58 \%$ \\
\hline \multirow{2}{*}{ Shrub } & Hamamelis virginiana & American witch-hazel & 4 & $50 \%$ \\
\hline & Lindera benzoin & northern spicebush & 13 & $23 \%$ \\
\hline \multirow{9}{*}{ Tree } & Acer rubrum & red maple & 4 & $75 \%$ \\
\hline & Acer saccharum & sugar maple & 25 & $20 \%$ \\
\hline & Betula lenta & black birch & 10 & $40 \%$ \\
\hline & Fagus grandifolia & American beech & 14 & $21 \%$ \\
\hline & Juglans nigra & eastern black walnut & 5 & $0 \%$ \\
\hline & Liriodendron tulipifera & tulip poplar & 20 & $55 \%$ \\
\hline & Prunus serotina & black cherry & 14 & $64 \%$ \\
\hline & Quercus rubra & northern red oak & 16 & $63 \%$ \\
\hline & Tilia americana & American basswood & 16 & $31 \%$ \\
\hline
\end{tabular}


Figure 4.1. Graphical scenarios of the relationship between the niche of $P$. quinquefolius and several key 'putative indicator' species niches.

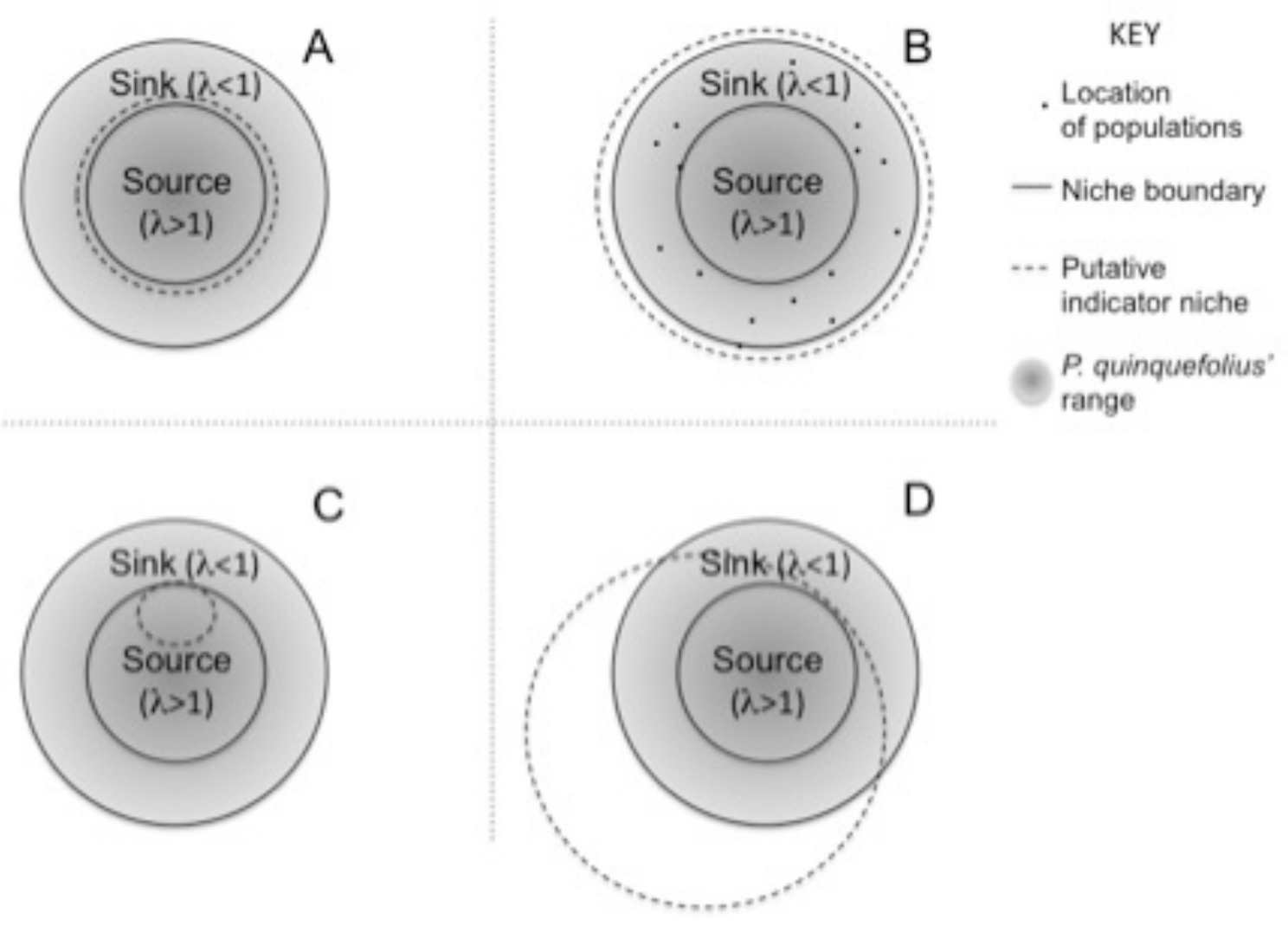


Figure 4.2. Effect of putative indicator species presence in the population on relative growth rate $\left(\mathrm{RGR}_{\mathrm{LA}}\right)$ of $P$. quinquefolius plants over a 10 -year period.

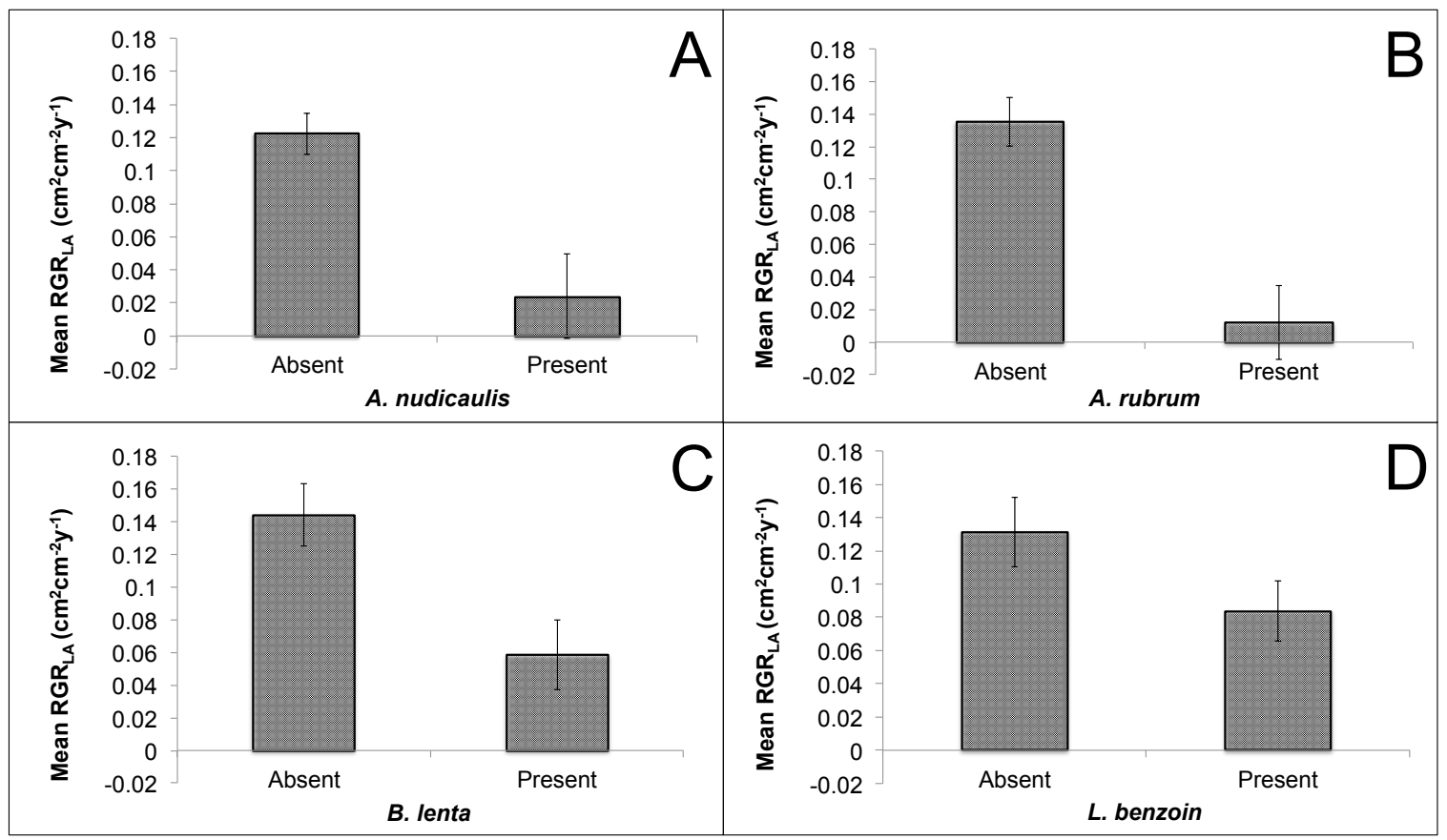


Figure 4.3. Effect of the presence or absence of two putative indicator species on relative growth rate (RGR $\left.\mathrm{RA}_{\mathrm{LA}}\right)$ of $P$. quinquefolius plants over a 10 -year period.

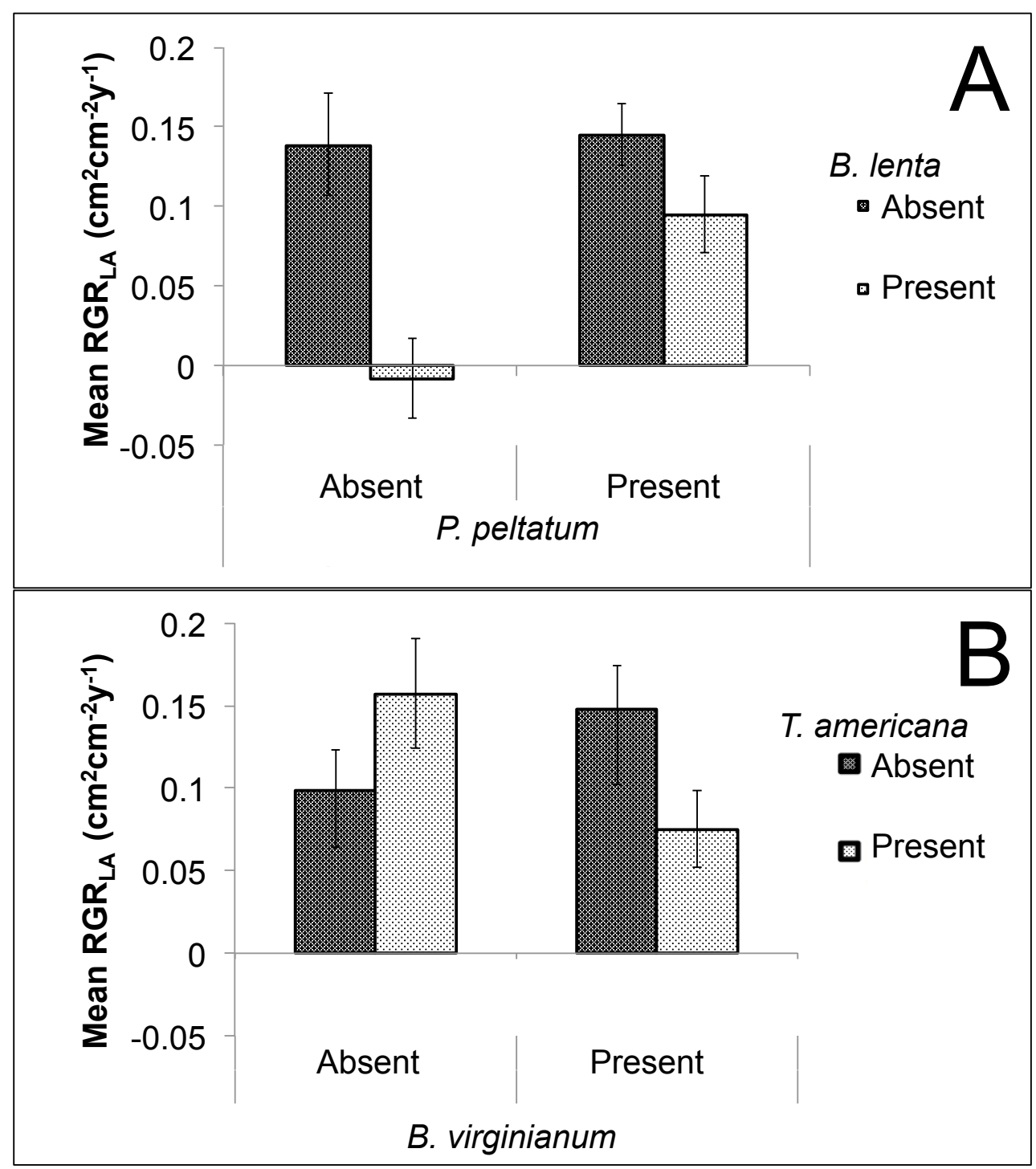


Figure 4.4. The effect of the putative indicator species L. tulipifera presence in the microsite of $P$. quinquefolius on relative growth rate $\left(\mathrm{RGR}_{\mathrm{LA}}\right)$ of $P$. quinquefolius plants over a 10 -year period.

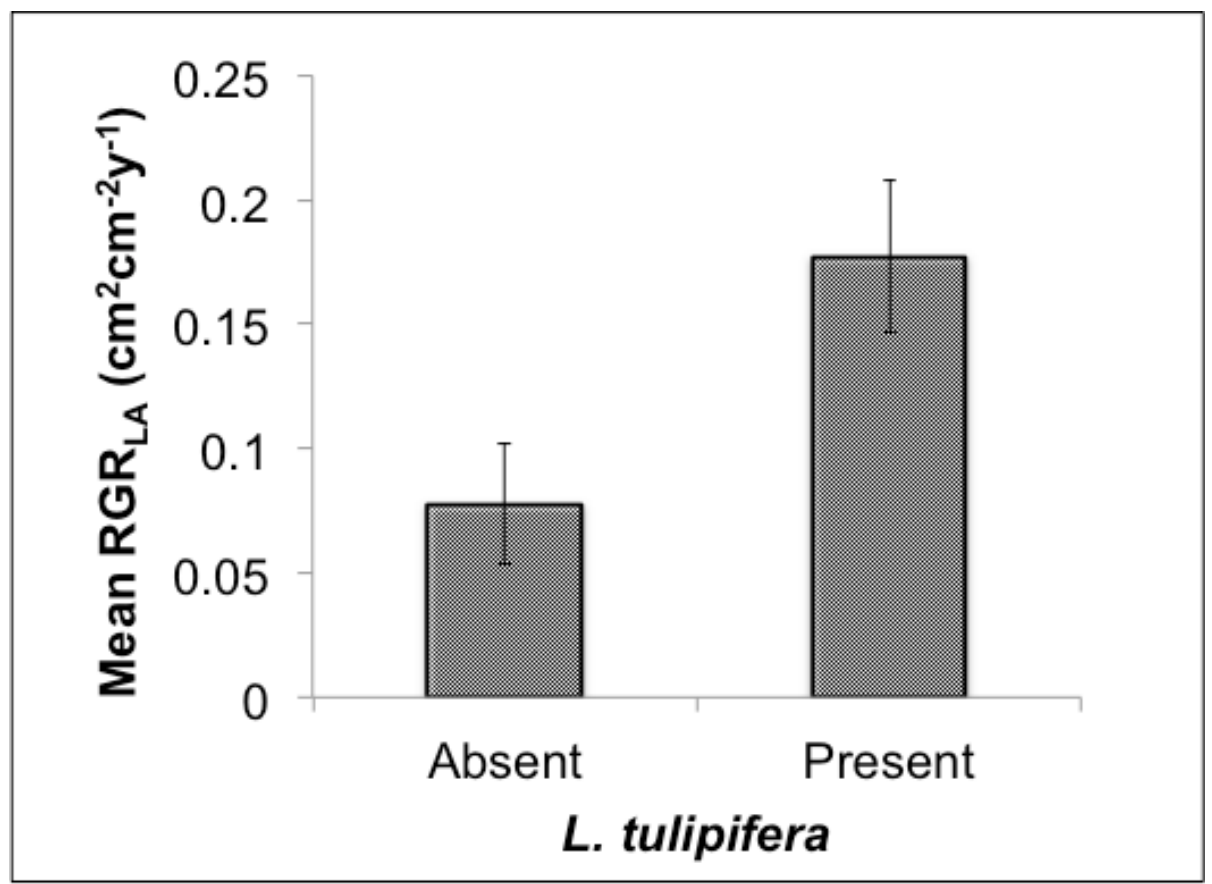




\section{Discussion}

\section{Population Level}

Two of the species, A. saccharum and A. triphyllum, were common among populations, and because of this, they were unable to be included in any population level analysis. The presences of A. saccharum and A. triphyllum have been observed in other indicator studies, and these species are often associated with $P$. quinquefolius habitat (Anderson et al., 1993; Burkhart, 2013). Both of these species have a large range, and are rather common throughout eastern North America (Bierzychudek, 1982; Lovett and Mitchell, 2004). The niche of these species could overlap the total range of $P$. quinquefolius, but perhaps still encompassing poor sites as well as good sites (Fig. 4.1b). An experimental study is needed to determine if these two species can predict performance at the population level or if their broad niches encompass the niche of this species entirely.

At the population level, the presence of four indicator species was able to predict reduced performance. These species are contra-indicators of high quality sites, even if their range extends into where $P$. quinquefolius might be found. One of these contra-indicators, $A$. nudicaulis, was present at only three of the 26 populations. This understory herb can be found in mesic or dry-mesic forests (Roberts and Gilliam, 1995). Whitman et al. (1998) found that older ramets of $A$. nudicaulis can survive on well-shaded sites with drier soils, whereas, P. quinquefolius grows best in moist, but well-drained soils (Li, 1995). As $A$. nudicaulis was only found at three sites, and can survive in drier conditions, the niche of A. nudicaulis may overlap a small section of the niche of $P$. quinquefolius and not the area of the niche that represents maximized growth. 
Another contra-indicator species whose niche likely does not mirror the niche of $P$. quinquefolius is A. rubrum. As reviewed in Burns and Honkala (1990), A. rubrum is a 'super-generalist' with a dense canopy, and the niche of A. rubrum may be one of the broadest of any native tree in North America. This hardy tree can grow on moisture extremes, from xeric to mesic soils, in a variety of elevations, $\mathrm{pH}$ levels, and soil textures. Wagner and McGraw (2013) determined that lower exposure to sunflecks is beneficial for the emergence of $P$. quinquefolius seedlings but it decreases the performance of adult plants. Therefore, the dense canopy of A. rubrum, and the propensity of this species to grow in soil moisture extremes, may be detrimental for the growth of this herb.

Betula lenta was another contra-indicator. This species prefers well-drained, moist soils, but can grow in rockier and shallower soils (as reviewed in Burns and Honkala, 1990). As this species is associated with recently disturbed sites (as reviewed in Nowacki and Abrams, 1991) and is considered an intermediate successional species (Marks, 1975), the habitat is likely to be ill-suited for $P$. quinquefolius for several reasons. The canopies of a mature forest often have minor breaks in the canopy, allowing for scattered, yet predictable, patterns of sunflecks (Wagner and McGraw, 2013). The canopy structure of a secondary forest may not mirror the proper light requirements for maximized growth of the study species. Sites that have B. lenta present may represent neither an ideal soil nor light environment for $P$. quinquefolius.

In addition to tree species, we identified $L$. benzoin as a shrub with a tendency to be a contra-indicator. When L. benzoin is present at a site, the shrub is often a dominant 
species; only $23 \%$ of sites with $L$. benzoin present could be included in the microsite analysis due to the density of the shrubs at the population. Practical guides and experts often recommend planting/transplanting seeds or roots under or near $L$. benzoin because that is often where P. quinquefolius can be found (Carroll and Apsley, 2004; Davis and Persons, 2014). However, P. quinquefolius may be growing under L. benzoin, not because the habitat supports optimum performance, but because birds, e.g., H. mustelina, dispersed the seeds in this location (Hruska et al., 2014). Wood thrush (H. mustelina) is a primary disperser of $P$. quinquefolius seeds (Hruska et al., 2014). As this species tends to take shelter in shrubs (Vega Rivera et al., 1998), it could drop the seeds underneath the branches. Additionally, P. quinquefolius may be found under the dense, low branches of L. benzoin because the branches may prevent harvesters from seeing the plant, or these branches may discourage browse from whitetail deer (O. virginianus). Browse can be detrimental to P. quinquefolius performance (McGraw and Furedi, 2005). Further, $L$. benzoin has a dense canopy; while this cover may be beneficial for seedling germination, fewer sunflecks may reduce mature plant performance (Wagner and McGraw, 2013). While the growth rate was low, yet greater than zero, the benefits of $P$. quinquefolius being under spicebush (low deer browse and less likely to be found by harvesters) could outweigh the low growth problem when considering it as a planting spot.

While we identified four single-species contra-indicators, we also identified combinations of species absence and presence that could predict $P$. quinquefolius performance. At sites that had B. lenta present and P. peltatum absent, there was a trend of reduced performance. Notably, P. peltatum grows best in moist soils and often in shady forest 
environments (Krochmal et al., 1974). Betula lenta prefers moist, well-drained soils (as reviewed in Burns and Honkala, 1990) but it has been found in xeric environments (Nowacki and Abrams, 1991), as well as recently disturbed sites (as reviewed in Nowacki and Abrams, 1991). The sites that have $B$. lenta present and $P$. peltatum absent could be more xeric, which could explain the reduced performance. Further, these forests may be younger; $P$. peltatum comes into the understory slowly after succession, since seed dispersal is often limited in clonal plants (Eriksson, 1993). Sites that have B. lenta, but are missing $P$. peltatum, may be too young to support maximized herbaceous species performance.

Our research indicated that $P$. quinquefolius exhibited higher levels of growth in a population with either $B$. virginianum or $T$. americana, but not both. In the eastern deciduous forest, $B$. virginianum is often considered a positive indicator species for $P$. quinquefolius (Anderson et al., 1993; Burkhart, 2013). Both T. americana and B. virginianum are associated with high calcium soils (Burkhart, 2013; Burns and Honkala, 1990; Greer et al., 1997), as is P. quinquefolius (Burkhart, 2013). We posit that this result could reflect chance, and indeed, statistically the 2-way interaction was only a 'trend'.

\section{Microsite Level Analysis}

While we had several population level contra-indicators, we had only one indicator at the microsite level. L. tulipifera has a large range, and grows in moist, well-drained soils (as reviewed in Burns and Honkala, 1990; McCarthy, 1933); these soil conditions may be 
ideal for the growth of $P$. quinquefolius $(\mathrm{Li}, 1995)$. The crown of $L$. tulipifera is of medium density (McCarthy, 1933), which may provide a light environment that is suitable for mature plant growth (Wagner and McGraw, 2013). Additionally, $L$. tulipifera is a species that is associated with high levels of organic matter and deep topsoil (as reviewed in Burns and Honkala, 1990; Elliott et al., 1999). These conditions associated with L. tulipifera suggest a nutrient rich environment that may be beneficial for $P$. quinquefolius. Our results should not be interpreted to mean that any site with $L$. tulipifera trees would represent quality habitat for reintroducing this rare plant. Since all the forested sites used in this study were $>50$ years old, the $L$. tulipifera trees growing in this forest were typically large. We are unable to conclude that sites with L. tulipifera are always beneficial (i.e., sites that are early successional forests of dense, young saplings); rather, we can conclude that sites with mature $L$. tulipifera may be beneficial for $P$. quinquefolius performance. With the other putative indicator species, some lack of significance of our microsite analysis may represent Type II error, as our small sample sizes could have resulted in incorrectly accepting the null hypothesis by chance.

\section{General}

The goal of this study was to critically evaluate putative indicator species for high-quality P. quinquefolius habitat across its range, in order to guide in situ conservation. As extension agents and hobby growers alike use indicator species for reintroduction of $P$. quinquefolius, the quality of the indicator species used needs to be tested (Jørgensen et al., 2013). Surprisingly, only one of the putative indicator species had a positive relationship to P. quinquefolius performance, while the rest predicted poorer 
performance. A limitation to all indicator research with this species, so far, is that it does not account for if indicator species are found in similar abundances at sites without $P$. quinquefolius present. However, a strength of our study is that, while we followed this traditional methodology, we quantified the performance of $P$. quinquefolius at these sites. By incorporating growth and the presence and absence of indicators, we were able to evaluate the quality of the indicator species used.

Reintroduction projects frequently fail (Godefroid et al., 2011), and there can also be failure in agroforestry of $P$. quinquefolius (Davis and Persons, 2014). Most of this failure is associated with planting the reintroduced species in an ill-suited habitat (Godefroid et al., 2011). By understanding what species might be effective indicators of high quality habitat, we can reduce the waste of resources, time, and effort associated with unsuccessful reintroduction projects. How should we use indicator species if they predict negative growth of $P$. quinquefolius? The presence of contra-indicators at a site may suggest that reintroduction will not be successful.

A caveat to our research is that the climate is changing (Parmesan, 2006; Souther and McGraw, 2011), and now an important aspect of in situ conservation and forest management could be assisted migration (Millar et al., 2007). Some of the putative indicator species may have once represented an ideal habitat, but the current climate conditions could generate incompatibility between indicators and P. quinquefolius. The species that are able to predict $P$. quinquefolius habitat may change as the climate changes. 
Extrapolating from our results, there should be a hierarchical process to evaluate site quality for $P$. quinquefolius reintroduction. First, the forest should be mature with a mostly closed canopy, mid-layer, and understory. The soil should be moist, but not wet, and there should be adequate, but not too dense shade (Wagner and McGraw, 2013). Second, due to widespread poaching (McGraw et al., 2010), P. quinquefolius should be planted in areas that are isolated and generally protected from trespassers (Davis and Persons, 2014). These sites should also be protected from future anthropogenic disturbances (Guerrant and Kaye, 2007), such as timbering (Chandler and McGraw, 2015) or surface mining. Finally, when planting roots or seeds, sites with contraindicators should be avoided (A. nudicaulis, A. rubrum, B. lenta, or L. benzoin), while planting $P$. quinquefolius close to large L. tulipifera. This may help in producing a successful reintroduction project to counteract the loss of $P$. quinquefolius populations, especially in an environment that is shifting.

\section{Conclusion}

As changes to the environment are occurring, reintroduction of species to maintain or increase biodiversity may help species from becoming extinct (Bontrager et al., 2014). $P$. quinquefolius populations continue to decline from illegal harvesting (McGraw et al., 2010), deer browse (McGraw and Furedi, 2005), climate change (Souther and McGraw, 2011), and land-use change (McGraw et al., 2013). Reintroduction is a valuable, albeit high-stakes, method to return biodiversity to habitats (Maunder, 1992). By understanding which indicator species are the best predictors of suitable habitats for rare and valuable 
plants, land managers may be able to optimize reintroduction practices. Reintroductions of rare species need to occur in areas of high likelihood of success to ensure that species, such as $P$. quinquefolius, exist for future generations.

\section{Acknowledgements}

We thank J.L. Chandler, A.M. Hruska, A. Wagner, M. Elza, C. Mallow, Z. Zacavish, K. Gregory, and a plethora of previous undergraduate and graduate students, for their help with the field component of this research. This work would have been impossible without the many landowners who let us study their plants. Thank you to M. Burnham, J.L. Chandler, and C. Walter for their insightful comments on the manuscript. This research was supported by a National Science Foundation Long Term Research in Environmental Biology Grant to J.B. McGraw (DEB-0613611 and DEB-1118702), and the Botany in Action Fellowship, through Phipps Conservatory in Pittsburgh, PA, to J.B. Turner. 


\section{References}

Anderson, R.C., Fralish, J.S., Armstrong, J.E., Benjamin, P.K., 1993. The ecology and biology of Panax quinquefolium L. (Araliaceae) in Illinois. Am. Midl. Nat. 129, 357-372. doi: 10.2307/2426517

Apsley, D., Carroll, C., 2004. Growing American ginseng in Ohio: Selecting a Site. Ohio State Univ. Ext. Fact Sheet F-58-04, 1-4.

Beyfuss, R., 1992. American ginseng production in woodlots. Agrofor. Notes. (USDANAC).1-4.

Bierzychudek, P., 1982. The demography of jack-in-the-pulpit, a forest perennial that changes sex. Ecol. Monogr. 52, 335-351. doi: 10.2307/2937350

Bontrager, M., Webster, K., Elvin, M., Parker, I.M., 2014. The effects of habitat and competitive/facilitative interactions on reintroduction success of the endangered wetland herb, Arenaria paludicola. Plant Ecol. 215, 467-478. doi:10.1007/s11258014-0317-z

Burkhart, E.P., 2013. American ginseng (Panax quinquefolius L .) floristic associations in Pennsylvania : guidance for identifying calcium-rich forest farming sites. Agrofor. Syst. 87,1157-1172. doi:10.1007/s10457-013-9627-8

Burkhart, E.P., Jacobson, M.G., 2009. Transitioning from wild collection to forest cultivation of indigenous medicinal forest plants in eastern North America is constrained by lack of profitability. Agrofor. Syst. 76, 437-453.

doi:10.1007/s10457-008-9173-y

Burkhart, E.P., Jacobson, M.G., Finley, J., 2012. A case study of stakeholder perspective and experience with wild American ginseng (Panax quinquefolius) conservation efforts in Pennsylvania, U.S.A .: limitations to a CITES driven, top-down regulatory approach. Biodivers. Conserv. doi:10.1007/s10531-012-0389-9

Burns, R.M., Honkala, B., 1990. Silvics of North America. US Dep. Agric. 2, 1-891.

Carroll, C., Apsley, D., 2004. Growing American ginseng in Ohio: an introduction. Ohio State Univ. Ext. Fact Sheet F-56-04, 1-4.

Chamberlain, J.L., Prisley, S., McGuffin, M., 2013. Understanding the relationships between American ginseng harvest and hardwood forests inventory and timber harvest to improve co-management of the forests of eastern United States. J. Sustain. For. 32, 605-624. doi:10.1080/10549811.2013.798828 
Chandler, J.L, McGraw, J.B., 2015. Variable effects of timber harvest on the survival, growth, and reproduction of American ginseng (Panax quinquefolius L.). For Ecol Manage 344:1-9. doi:10.1016/j.foreco.2015.02.007

Clements, F.E. 1916. Plant succession: an analysis of the development of vegetation. Carnegie, Institution of Washington, Washington.

Coote, L., Dietzsch, A.C., Wilson, M.W., Graham, C.T., Fuller, L., Walsh, A.T., Irwin, S., Kelly, D.L., Mitchell, F.J.G., Kelly, T.C., Halloran, J.O., 2013. Testing indicators of biodiversity for plantation forests. Ecol. Indic. 32, 107-115. doi:10.1016/j.ecolind.2013.03.020

Davis, J.M., Persons, W.S., 2014. Growing and marketing ginseng, goldenseal and other woodland medicinals, Revised ed. New Society Publishers, Gabriola Island, BC, Canada. pp. 1- 508.

Davis, M.B., 1984. Climatic instability, time lags, and community disequilibrium, in: Diamond, J., Case, T.J. (Eds.), Community Ecology. Harper and Row, pp. 269- 284.

Denslow, J.S., 2014. Plant Community Assembly. Bull. Ecol. Soc. Am. 95, 334-336. doi: $0.1890 / 0012-9623-95.4 .334$

Elliott, K.J., Vose, J.M., Swank, W.T., Bolstad, P.V., 1999. Long-term patterns in vegetation-site relationships in a southern Appalachian forest. J. Torrey Bot. Soc. 126, 320-334. doi: 10.2307/2997316

Eriksson, O., 1993. Dynamics of genets in clonal plants. Trends Ecol. Evol. 8, 313-316.

Fountain, M., 1986. Vegetation associated with natural populations of ginseng (Panax quinquefolium) in Arkansas. Castanea 51, 42-48.

Gilliam, F.S., 2007. The ecological significance of the herbaceous layer in temperate forest ecosystems. Bioscience 57, 845-858. doi:10.1641/B571007

Godefroid, S., Piazza, C., Rossi, G., Buord, S., Stevens, A., Aguraiuja, R., Cowell, C., Weekley, C.W., Vogg, G., Iriondo, J.M., Johnson, I., Dixon, B., Gordon, D., Magnanon, S., Valentin, B., Bjureke, K., Koopman, R., Vicens, M., Virevaire, M., Vanderborght, T., 2011. How successful are plant species reintroductions? Biol. Conserv. 144, 672-682. doi:10.1016/j.biocon.2010.10.003

Greer, G.K., Lloyd, R.M., McCarthy, B.C., 1997. Factors influencing the distribution of Pteridophytes in a southeastern Ohio hardwood forest. J. Torrey Bot. Soc. 123, 1121. doi: $10.2307 / 2996594$ 
Gregory, C., Braham, R., Blank, G., Stucky, J., 2010. Habitat and search criteria of the rare sandhills lily, Lilium pyrophilum M.W. Skinner and Sorrie. Castanea 75, 198204.

Guerrant, E.O.J., 2012. Characterizing two decades of rare plant reintroductions, in: Maschinski, J., Haskins, K.E. (Eds.), Plant Reintroduction in a Changing Climate. pp. 9-30. doi:10.5822/978-1-

Guerrant, E.O.J., Kaye, T.N., 2007. Reintroduction of rare and endangered plants: common factors, questions and approaches. Aust. J. Bot. 362-370. doi: 10.1071/BT06033

Hruska, A.M., Souther, S., McGraw, J.B., 2014. Songbird dispersal of American ginseng (Panax quinquefolius). Ecoscience 21, 46-55. doi:10.2980/21-1-3679

Hufford, M., 2003. Reclaiming the commons: narratives of progress, preservation, and ginseng. In: Howell, B. (Ed.), Culture, Environment, and Conservation in the Appalachian South. University of Illinois Press, Urbana, pp. 100-120.

Hunt, R., 1990. Basic growth analysis. Unwin Hyman Ltd., London. pp. 1-112

Jørgensen, S., Burkhard, B., Müller, F., 2013. Twenty volumes of ecological indicators An accounting short review. Ecol. Indic. 28, 4-9. doi:10.1016/j.ecolind.2012.12.018

Krochmal, A., Wilkins, L., Van Lear, D., Chien, M., 1974. Mayapple (Podophyllum peltatum L.). USDA For. Serv. Res. Pap. NE-296, 1-12.

Landres, P., Verner, J., Thomas, J., 1988. Ecological uses of vertebrate indicator species: A critique. Conserv. Biol. 2, 316-328. doi: 10.1111/j.1523-1739.1988.tb00195.x

Li, T.S.C., 1995. Asian and American ginseng-A review. Horttechnology 5, 27-34.

Lovett, G.M., Mitchell, M.J., 2004. Sugar maple and nitrogen cycling in the forests of eastern North America. Front. Ecol. Environ. 2, 81-88.

Marks, P.L., 1975. On the relation between extension and growth successional status of deciduous trees of the northeastern United States. Bull. Torrey Bot. Club 102, 172 177. doi: $10.2307 / 2484938$

Maunder, M., 1992. Plant reintroduction: an overview. Biodivers. Conserv. 1, 51-61. doi: 10.1007/BF00700250

McCarthy, E.F., 1933. Yellow poplar characteristics, growth and management. USDA Tech. Bull. No. 356, 1-64. 
McGraw, J.B., 2001. Evidence for decline in stature of American ginseng plants from herbarium specimens. Biol. Conserv. 98, 25-32. doi:10.1016/S00063207(00)00138-5

McGraw, J., Furedi, M., 2005. Deer browsing and population viability of a forest understory plant. Science 307, 10-13. doi:10.1126/science.1107036

McGraw, J.B., Garbutt, K., 1990. The analysis of plant growth in ecological and evolutionary studies. Trends Ecol. Evol. 5, 251-254. doi: 10.1016/01695347(90)90065-L

McGraw, J.B., Lubbers, A.E., Van der Voort, M., Mooney, E.H., Furedi, M.A., Souther, S., Turner, J.B., Chandler, J., 2013. Ecology and conservation of ginseng (Panax quinquefolius) in a changing world. Ann. New York Acad. Sci. Year Ecol. Conserv. Biol. 1-30. doi:10.1111/nyas.12032

McGraw, J., Sanders, S., Van der Voort, M., 2003. Distribution and abundance of Hydrastis canadensis L. (Ranunculaceae) and Panax quinquefolius L. (Araliaceae) in the Central Appalachian Region. J. Torrey Bot. Soc. 130, 62-69. doi: $10.2307 / 3557530$

McGraw, J.B., Souther, S., Lubbers, A.E., 2010. Rates of harvest and compliance with regulations in natural populations of American ginseng (Panax quinquefolius L.). Nat. Areas J. 30, 202-210. doi:10.3375/043.030.0207

Millar, C.I., Stephenson, N.L., Stephens, S.L., 2007. Climate change and forests of the future: managing in the face of uncertainty. Ecol. Appl. 17, 2145-2151. doi: $10.1890 / 06-1715.1$

Nowacki, G.J., Abrams, M.D., 1991. Community and edaphic analysis of mixed oak forests in the ridge and valley province of central Pennsylvania, in: 8th Central Hardwood Forest Conference. pp. 247-260.

Parmesan, C., 2006. Ecological and evolutionary responses to recent climate change. Annu. Rev. Ecol. Evol. Syst. 37, 637-669. doi:10.1146/annurev.ecolsys.37.091305.110100

Pritts, K.D., 1995. Ginseng: How to find, grow, and use America's forest gold. Stakepole Books, Mechanicsburgh, PA.

Pulliam, H.R., 1988. Sources, sinks, and population regulation. Am. Nat. 132, 652-661.

Pulliam, H.R., 2000. On the relationship between niche and distribution. Ecol. Lett. 349361. doi:10.1046/j.1461-0248.2000.00143.x 
Punja, Z.K., 2011. American ginseng: research developments, opportunities, and challenges. J. Ginseng Res. 35, 368-74. doi:10.5142/jgr.2011.35.3.368

Ren, H., Zhang, Q., Wang, Z., Guo, Q., Wang, J., Liu, N. Liang, K., 2010. Conservation and possible reintroduction of an endangered plant based on an analysis of community ecology: a case study of Primulina tabacum Hance in China. Plant Species Biol. 25, 43-50. doi:10.1111/j.1442-1984.2009.00261.x

Roberts, C.R., Richardson, J., 1981. Wild ginseng monitoring program in Kentucky: A three-year summary. Univ. Kentucky, Coll. Agric. 256, 1-20.

Roberts, M.R., Gilliam, F.S., 1995. Disturbance effects on herbaceous layer vegetation and soil nutrients in Populus forests of northern lower Michigan. J. Veg. Sci. 6, 903-912.

SAS JMP Pro 11, 2013. SAS Campus Drive, Cary, NC, USA.

Schiller, A., Hunsaker, C.T., Kane, M.A., Wolfe, A.K., Dale, V.H., Suter, G.W., Russell, S., Pion, G., Jensen, M.H., Konar, V.C., 2001. Communicating ecological indicators to decision makers and the public. Ecol. Soc. 5, 19.

Sokal, R.R., Rohlf, F.J., 2012. Biometry: the principles and practice of statistics in biological research. 4th edition. W. H. Freeman and Co.: New York.

Souther, S., McGraw, J.B., 2011. Evidence of local adaptation in the demographic response of American ginseng to interannual temperature variation. Conserv. Biol. 25, 922-931. doi:10.1111/j.1523-1739.2011.01695.x

Vega Rivera, J.H., Rappole, J.H., McShea, W.J., Haas, C.A., 1998. Wood thrush postfledging movements and habitat use in northern Virginia. Condor 100, 69-78.

Vittoz, P., Wyss, T., Gobat, J., 2006. Ecological conditions for Saxifraga hirculus in Central Europe : A better understanding for a good protection. Biol. Conserv. 131, 599-608. doi:10.1016/j.biocon.2006.03.006

Wagner, A., McGraw, J.B., 2013. Sunfleck effects on physiology, growth, and local demography of American ginseng (Panax quinquefolius L .). For. Ecol. Manage. 291, 220-227. doi:10.1016/j.foreco.2012.11.038

Whitman, A.A., Hunter, M.L.J., Witham, J.W., 1998. Age distribution of ramets of a forest herb, Wild Sarsaparilla, Aralia nudicaulis (Araliaceae). Can. Field-Naturalist $112,37-44$.

Wiegmann, S.M., Waller, D.M., 2006. Fifty years of change in northern upland forest understories: Identity and traits of "winner" and "loser" plant species. Biol. Conserv. 129, 109-123. doi:10.1016/j.biocon.2005.10.027 
Wixted, K., McGraw, J.B., 2009. A Panax-centric view of invasive species. Biol. Invasions 11, 883-893. doi:10.1007/s10530-008-9301-7 
CHAPTER V: DOES LAND-USE HISTORY INFLUENCE REINTRODUCTION SUCCESS OF MEDICINAL PLANTS IN APPALACHIA? 


\begin{abstract}
Appalachia was historically virgin forest, but there has been significant land-use change in this region for centuries. One dominant driver of land-use change has been surface mining for coal. While coal mining is an economically significant form of resource extraction, many Appalachian residents also obtain a valuable secondary source of income from the forest harvest of medicinal plants, specifically American ginseng and goldenseal. These medicinal plants have become increasingly rare, due to a host of environmental stressors, including habitat loss. Because of their high economic and cultural value, reintroduction of medicinal plants is a desirable in situ conservation practice in this region. Previous land-use can influence plant performance for centuries; however, the magnitude of those effects is likely to vary greatly. Abandoned agricultural land may have relatively small residual effects, whereas surface mining, which may remove live soil completely, is likely to have much stronger effects. In order to determine if medicinal plant performance will be influenced by previous land-use history, a reintroduction study was implemented. Goldenseal and ginseng were reintroduced to two sites in West Virginia and in Ohio, each containing forested areas with three types of land-use history: (1) Plots previously used for agriculture; (2) plots along the bench of a highwall; (3) plots of $>80$ year old second growth forest, hereafter considered a mature forest. Highwall plots had the lowest persistence of reintroduced plants, and this was likely due to standing water, acidic soils, and low calcium levels. All plots with reintroduced plants were growing in size, except for West Virginia highwall and secondary plots. Ginseng had higher levels of performance at plots that had soil conditions (e.g., $\mathrm{pH}$ and calcium) similar to levels found at 27 populations of wild ginseng. This work can inform future medicinal plant reintroduction projects.
\end{abstract}




\section{Introduction}

Appalachia is a temperate region that has high levels of biodiversity (Stein et al. 2000). Within the eastern deciduous forest, the herbaceous understory can be responsible for $90 \%$ of the plant diversity (Gilliam 2007). These plant species perform important ecosystem functions (e.g., nutrient cycling, Gilliam 2007), provide food for animals (Roberts \& Gilliam 2003), and a select subgroup of them are important Non-Timber Forest Products (NTFP) for humans (Bailey 1999). However, throughout the eastern deciduous forest, the herbaceous understory has been negatively impacted by direct and indirect influences of anthropogenic activity, including land-use change (Gilliam 2007).

Since the early $19^{\text {th }}$ century, timbering, agriculture, and surface mining have been drivers of forest clearing in Appalachia (Gragson \& Bolstad 2006). A source of change for this region, surface mining, has occurred since the early 1900's (Yarnell 1998). Before 1977, when the Surface Mine Control and Reclamation Act was enforced on a national scale requiring sites to be reclaimed, some states had reclamation laws, but roughly $40 \%$ of all sites disturbed by mining were left abandoned (Emerson et al. 2009). Despite abandonment, biodiversity can return to these sites over time via natural succession (Skousen et al. 1994; Gorman et al. 2001; Skousen et al. 2006). However, these newly regenerated forests do not resemble the original forest as early successional species such as Acer rubrum or Betula lenta dominate, or alternatively, grasses cover the landscape, effectively preventing tree growth (Skousen et al. 1994; Skousen et al. 2006). Even if the site is reclaimed, the long-term environmental impacts of mining can alter both aquatic and terrestrial ecosystems, and the eastern deciduous forest may be permanently altered (Palmer et al. 2010). Holl (2002) determined that reclaimed coal mines could have a 
similar diversity to previously logged sites, yet rarer species were less likely to be found on reclaimed mined sites.

Agriculture, like surface mining, also has legacy effects. Dupouey et al. (2002) found that agriculture type and intensity affected the plant community and species richness in forests centuries later. Brown and Boutin (2009) discovered that sites cleared for agriculture within the past 70 years had a larger presence of invasive species and species associated with disturbed sites than other woodlots. Vellend (2005) established that secondary forests after agriculture were not as suitable for Trillium grandiflorum (Michaux) Salisb. when compared to primary forests. The differences in performance of T. grandiflorum between sites could not be attributed to soil quality or canopy openness; rather, the differences were likely due to a biotic limitation. There is a variety of economically valuable herbaceous species that may be reintroduced for agroforestry purposes (Burkhart \& Jacobson 2009). Understanding how to select appropriate sites is essential in order to avoid a reintroduction project failure (Godefroid et al. 2011).

The two plants that are often the most valuable NTFPs in Appalachia are American ginseng (Panax quinquefolius L.), hereafter referred to as ginseng, and goldenseal (Hydrastis canadensis L.) (Robbins 2000). Ginseng is often considered the premier wildharvested medicinal plant in the United States (McGraw et al. 2013). However, both plants are herbaceous species that are found across a wide range of temperate forests in eastern North America (McGraw et al. 2003). Ginseng can be found on numerous slopes and aspects, whereas, due to its rarity, classifying the distribution of goldenseal is more 
difficult (McGraw et al. 2003). Harvesting the root of ginseng and the rhizome of goldenseal provide a source of income for individuals within rural communities, as they are sold as medicinal plants (Bailey 1999; Robbins 2000; Van der Voort et al. 2003).

Overexploitation of both ginseng and goldenseal have caused these species to be listed on Appendix II of the Convention on International Trade in Endangered Species of Wild Fauna and Flora, (CITES Secretariat; Robbins 2000). As ginseng and goldenseal are economically valuable medicinal plants, they are being harvested from the forest, often at an unsustainable rate (Sanders 2004; Van der Voort \& McGraw 2006). Harvest pressure and land-use change are two stressors that can impact the long-term survival of a rare species, such as ginseng (McGraw et al. 2013). Burkhart et al. (2012) suggested that planting medicinal plants might be more effective than increased government regulation to counter unsustainable harvest and conversion of forest habitat.

In order to supplement the loss of these valuable, medicinal species due to the pressures of land-use change and overharvest, medicinal plants can be reintroduced into the eastern deciduous forest. While there is a variety of terms used to describe the process of reintroduction based on the scope of the project (Dalrymple et al. 2012), the term here is broadly defined as planting these medicinal plants within their natural range. As medicinal plants such as ginseng and goldenseal are culturally significant, as well as economically valuable NTFPs, planting populations of medicinal plants is already a popular practice (Burkhart \& Jacobson 2009). However, how will these species respond to a previously disturbed landscape? There is evidence that goldenseal has higher levels 
of performance following disturbance (Sinclair \& Catling 2003; Sinclair \& Catling 2004), or along a cline of disturbance (Sanders \& McGraw 2002). In contrast, ginseng is pre-adapted to the environment of old growth forests (Wagner \& McGraw 2013; Chandler \& McGraw 2015) and therefore may be less able to cope with the legacy effects of disturbance on soils and tree canopies. Additionally, goldenseal and ginseng have contrasting growth forms, as goldenseal expands by clonal growth and ginseng by sexual reproduction (Van der Voort et al. 2003), and growth forms may impact the performance of species in different land-use histories. The clonal growth form of goldenseal may help this species have higher levels of performance in a degraded landscape. While planting procedures and reintroduction studies have been conducted for medicinal plants (Li 1995; Sinclair \& Catling 2003; Sanders \& McGraw 2005), land-use history has not been the focus of these studies.

A main reason that past reintroduction projects have failed is that plants were reintroduced to an ill-suited habitat (Godefroid et al. 2011), and since land-use history can influence the performance of plants, this is an important consideration for reintroduction projects. Since people often want to reintroduce ginseng and goldenseal for agroforestry reasons (Davis \& Persons 2014) or ecological benefits, knowing what might increase the project's success is imperative to optimize the use of the limited resources of time, money, and effort. This research will address the following questions: (1) Do reintroduced medicinal plants have differential rates of performance on sites that were previously surface mined, rather than sites with different land-use histories? Since previous research has shown that land-use legacies can impact which species grow in an 
area, we predict that there will be lower medicinal plant performance on sites that were previously surface mined, due to the scale of disturbance. (2) Is there a differential growth rate between goldenseal, a clonal plant, and ginseng, an aclonal plant that propagates via sexual reproduction? If there is a differential growth rate between species, will species performance depend on the land-use history? As ginseng is pre-adapted to the light conditions associated with old-growth forests, and goldenseal responds positively to disturbance, we hypothesize that goldenseal will have increased performance as compared to ginseng on plots that were previously disturbed. (3) The existence of an extensive database on natural populations of ginseng allowed us to also ask whether reintroduced ginseng had similar levels of performance as natural populations, allowing us to assess the success of the reintroductions. We hypothesize that ginseng reintroduced to mature sites will have performance similar to ginseng found in natural populations. Ginseng reintroduced to sites that experienced greater disturbance (agriculture and surface mining) will have lower performance than ginseng found in natural populations.

\section{Methods}

The goldenseal and ginseng reintroduction study was initiated in fall, 2012. Two sites with diverse land-use histories were selected (locations withheld for conservation purposes): one site in southeastern Ohio $(\mathrm{OH})$, and one site in north-central West Virginia (WV). The Pittsburgh coal seam was present at the WV site, and the Meigs Creek \#9 coal seam was present at the $\mathrm{OH}$ site (Skousen, personal communication, 2015). Within each site, there were three common land-use histories: secondary forests over 80 years old, hereafter referred to as mature forests (Ripple et al. 1991), post-agriculture second- 
growth forest, and post-mining second-growth forest (along the bench of a highwall)

(Fig. 5.1). At each site, within each of the land-use histories, three $25 \mathrm{~m} \mathrm{X} 25 \mathrm{~m}$ plots were randomly established. The plots along the bench of the highwall, hereafter referred to as highwall plots, were unreclaimed. Soil samples were collected from at least three locations within each plot; these samples were analyzed at West Virginia University Soil Testing Lab in 2012. In order to determine differences in site quality, soil $\mathrm{pH}$ and calcium levels were each analyzed with a two-way nested ANOVA, with the terms landuse, site, land-use*site, and plot(land-use*site). The range of age of the forest was inferred from tree cores at each plot (Table 5.1). At each site, the dominant trees were identified, and the diameter at breast height was recorded $(\mathrm{cm})$ of the two largest trees that were of different species (Table 5.2).

In each of the plots, three quasi-randomly selected subplots of goldenseal $(n=25$ ramets in each) and four quasi-randomly selected subplots of ginseng ( $\mathrm{n}=18$ roots in each) were planted. Subplots were established within each plot by using tapes to establish distance along each plot edge, and using random numbers to determine the location of the subplot; however, the subplot was moved to avoid obstacles such as trees, rocks, or other objects that would prevent planting. Both ginseng and goldenseal were recently derived from wild Maryland stock, and purchased two weeks before planting in early October. The ginseng roots were between one and three years old, and the goldenseal rhizomes were of varying size. The roots and rhizomes were dipped in a 3\% sodium hypochlorite solution to suppress pathogenic fungi and mold that could have been growing, and held at $4 \mathrm{deg}$ C. After dipping each plant, 18 ginseng roots of varying ages and 25 goldenseal rhizomes of varying sizes were wrapped in moist paper towels and placed in open plastic 
bags that were numbered for each individual subplot.

In mid-October, plants were reintroduced to the plots. Every subplot of goldenseal had five rows of five goldenseal rhizomes, planted $20 \mathrm{~cm}(+/-5 \mathrm{~cm})$ apart, whereas each subplot of ginseng had three rows of six ginseng roots, planted $20 \mathrm{~cm}(+/-5 \mathrm{~cm})$ apart (Fig. 5.1). Each ginseng root was planted at a 45-degree angle, with the rhizome of the root three centimeters $(+/-1 \mathrm{~cm})$ from the surface. Goldenseal rhizomes were planted 2.5 centimeters deep $(+/-1 \mathrm{~cm})$. Each plant was labeled with a numbered nail. After a large tree fell in one mature plot in $\mathrm{OH}$ in late 2012, we removed the plot from analysis, as it no longer had the same canopy cover as the other mature plots. For $\mathrm{OH}, 574$ ginseng plants and 598 goldenseal plants were included from the eight plots used for this study. In WV, across nine plots, a total of 648 ginseng plants and 675 goldenseal plants were included in the study. A total of 1,273 goldenseal plants and 1,222 ginseng plants were included in the whole experiment.

Sites were visited annually; in mid June and early August in 2013, 2014, and 2015. Leaf length and width for ginseng, and the leaf length for goldenseal was measured in the first census in order to estimate leaf area from regression relationships (Sanders 2004; Souther \& McGraw 2011a). Reproductive status was assessed on goldenseal ramets and ginseng plants. At each subplot in 2015, we looked for seedlings that were germinated from seeds produced by the reintroduced plants. While we recorded seed production in each fall census, as the plants were young and had low rates of reproductive output, we did not include this dependent variable in any analysis. 
If there was any vegetative material of the plant aboveground, the plant was recorded as present, as the presence of plants is a good indicator that the plants are surviving. There are many reasons why a plant may be absent from the aboveground cohort each year, including browse by deer prior to censusing (McGraw \& Furedi 2005) and rodent browse (Davis \& Persons 2014). Our study recorded the presence of plants over four years, with the initial year being the year of planting. In order to address our first question, and track the proportion of plants that were aboveground over time, hereafter referred to as persistence rate, we calculated the natural $\log$ of the proportion of plants that were present in each plot, each year. The slope of these values was then calculated for each plot, and a two-way ANOVA was used to determine any differences for each of the species between land-use history, site, land-use history*site, by using slope of decline in extant numbers in each plot as the dependent variable.

We calculated relative growth rate $\left(\mathrm{RGR}_{\mathrm{LA}}\right)$ by using leaf area of the plants from 2013 to 2015. This was done by finding, for each plant, the slope of the regression of natural log of leaf area on year (Turner \& McGraw 2015), based on the principles of Hunt (1990) and McGraw and Garbutt (1990). Plants needed to be present for at least two years to be included in the analysis. One ginseng plant in a mature plot in $\mathrm{OH}$ was determined an outlier (Mahalanobis outlier test) and was therefore removed from the dataset for the $\mathrm{RGR}_{\mathrm{LA}}$ analysis. A total of 424 ginseng plants and 425 goldenseal plants were included in this analysis. 
Independent variables in the $\mathrm{RGR}_{\mathrm{LA}}$ analysis included site (two levels: $\mathrm{OH}$ and WV), land-use history (three levels: mature, secondary due to agriculture, and secondary due to mining), and plant species (two levels: ginseng and goldenseal). We also included all possible interactions among variables (Fig. 5.1). While interaction terms are often the interest in multi-way factorial designs, we designed this experiment to use site as a replicate. However, the results of the other terms were directly relevant to our reintroduction questions. Data were analyzed using a three-way nested ANOVA, weighted by the number of plants present in each subplot. To answer our first question asking if medicinal plants reintroduced to sites that were previously disturbed had reduced performance, we were interested in the main effect of land-use history. To address our question evaluating if there was a difference in goldenseal and ginseng performance, we evaluated the main effect of species, and species*land-use history. Due to the low persistence rate of plants, the mean $\mathrm{RGR}_{\mathrm{LA}}$ for each subplot was calculated and used as the dependent variable. In order to determine if the reintroductions could be considered a success, we used a one-tailed t-test (Sokal \& Rohlf 2012) to determine if the mean $\mathrm{RGR}_{\mathrm{LA}}$ of each subplot, weighted by the number of plants present in each subplot, of each land-use history*site for both goldenseal and ginseng. If the $\mathrm{RGR}_{\mathrm{LA}}$ was greater than zero, the plants were growing at these plots.

Of the plants that were present each year, the reproductive status was recorded. For each plot, across all three years, we calculated the mean proportion of reproductive plants, the number of goldenseal with two or three leaves present (Sanders \& McGraw 2005) or ginseng plants that had inflorescences present. Due to the low persistence rate of plants, 
we used plot as a replicate. To address if previously mined-lands resulted in reduced medicinal plant performance, a two-way ANOVA by species was used for both ginseng and goldenseal, with the terms being land-use history, site, and land-use history*site.

To determine if land-use history influenced viability of ginseng seeds, as well as germination, a seed-cage study was conducted. We did not include a seed study for goldenseal, as research suggests that goldenseal propagates primarily through vegetative clones (Van der Voort et al. 2003). In each plot, $8.5 \mathrm{~cm}$ diameter x $8 \mathrm{~cm}$ deep seed cages made from polyvinyl-chloride sections of pipe were used to test germination rates of seeds (Souther \& McGraw 2011b). Within each plot, six seed cages holding 25 nonstratified ginseng seeds in each cage were inserted into the soil. The seed cages were buried at random coordinates within plots, and seeds were mixed with the local soil. Each year, the number of germinated seedlings was recorded, and two of the ginseng seed cages were removed from each plot. The seeds were sieved from the soil present in the seed cages and the seeds were tested for viability using tetrazolium chloride staining (Baskin \& Baskin 1998). Ginseng seeds from a recently derived cultivated Maryland source were used for the seed cage study. We calculated the probability of the seeds surviving the first winter, and the probability that the seeds would germinate. These values were calculated for each plot. As plot served as the replicate, data were analyzed with a two-way ANOVA with the terms land-use history, site, and land-use history*site.

To address our third question, if the reintroduced ginseng had performance comparable to wild populations, we compared $\mathrm{RGR}_{\mathrm{LA}}$ between wild populations and the ginseng planted 
in each land-use history for each site (OH and WV). Across seven states, twenty-seven populations of American ginseng have been visited twice annually for at least ten years. In addition to measuring ginseng growth, soil samples from each of the 27 populations were collected in 2010 and analyzed by the West Virginia University Soil Testing Laboratory (Table 5.3). Each ginseng plant in these populations has a unique identification number. For each plant, the length and width of the longest leaflet on each leaf has been measured in order to calculate leaf area using the same method as the reintroduction study. New seedlings were marked annually, and followed in subsequent years, providing a record of growth from age 1 to age 6 (comparable to the reintroduction study). The $\mathrm{RGR}_{\mathrm{LA}}$ for this subset of plants was calculated, as long as the plant was present for at least two years. By finding the $\mathrm{RGR}_{\mathrm{LA}}$ of wild ginseng roots that were between one and six years old, we were able to compare the $\mathrm{RGR}_{\mathrm{LA}}$ of similarly aged reintroduced roots. To determine if the reintroduced ginseng populations had reduced performance relative to wild ginseng populations, a one tailed t-test (Sokal \& Rohlf 2012) was performed comparing the mean $\mathrm{RGR}_{\mathrm{LA}}$ subplot values, of reintroduced plants in each land-use history by site, weighted by the number of plants present in each subplot, to the $\mathrm{RGR}_{\mathrm{LA}}$ of the 27 wild populations.

In order to determine if there were differences between the performance of recently derived Maryland source ginseng plants and Wisconsin source ginseng plants, a lineage plot was established at a highwall site at the nature preserve in WV. Sixty plants were from the Wisconsin source and 60 plants were from the Maryland source. Each ginseng plant was planted randomly within a grid pattern, $20 \mathrm{~cm}$ apart from any other plant, for a 
total of 120 plants. The data were analyzed using a one-way ANOVA, with source as the independent variable.

For all analyses, the normality of the residuals was tested using a Shapiro-Wilk W test. An a posteriori Tukey's HSD test was used, when appropriate, to determine differences between groups (Sokal \& Rohlf 2012). All analyses were completed with SAS JMP Pro 11 (2013), and the critical value was set at $\alpha=0.05$.

\section{Results}

\section{Soil Test Results:}

The effect of land-use history on the soil $\mathrm{pH}$ of plots where ginseng and goldenseal were reintroduced depended on site (Table 5.4; $\mathrm{F}=4.186, \mathrm{p}=0.0415$ ), with WV highwall and secondary plots having the most acidic soils. The $\mathrm{OH}$ site was less acidic than the WV site, but the WV mature plot had $\mathrm{pH}$ levels similar to the $\mathrm{OH}$ site. There was a trend that the effect of land-use history on the amount of calcium in the soil differed for $\mathrm{OH}$ and WV sites (Table 5.4; $\mathrm{F}=3.7684, \mathrm{p}=0.0566$ ). The WV highwall and secondary plots had the lowest levels of calcium in the soil, and the $\mathrm{OH}$ sites and the WV mature plot had higher levels of calcium in the soil.

\section{Persistence:}

Goldenseal and ginseng both had low persistence at the highwall plots. Ginseng at the highwall plots had the lowest level of persistence relative to ginseng plants at other landuse history plots (Fig. 5.2.a; F=5.9373, p=0.0178). Ginseng planted at secondary plots was more likely to persist than those planted along the bench of a highwall, and the plants 
at mature plots had a persistence level between plants reintroduced to secondary and highwall plots. The effect of land-use history on the persistence of goldenseal depended on site (Fig. 5.3.; $\mathrm{F}=6.2198, \mathrm{p}=0.0156$ ). Goldenseal had low persistence at the highwall plots in both $\mathrm{WV}$ and $\mathrm{OH}$, and increased persistence at the $\mathrm{OH}$ secondary plot. However, goldenseal's persistence also depended on the main effects of site (Fig. 5.3.; F=5.8818, $\mathrm{p}=0.0337$ ) with greater persistence in $\mathrm{OH}$. Goldenseal had lower persistence along the bench of highwall plots relative to other land-use history plots (Fig. 5.2b F=10.2771, $\mathrm{p}=0.003$ ). To help in interpreting persistence rates, we calculated the percent of plants that would be remaining after four years as a consequence of those rates. The percent of reintroduced ginseng and goldenseal still remaining at highwall sites would be only $19.4 \%$ and $23.3 \%$, respectively. At mature plots, the percent of reintroduced ginseng and goldenseal still present after four years would be $38.0 \%$ and $52.1 \%$, and at secondary plots, the percent of reintroduced ginseng and goldenseal persisting would be $26.5 \%$ and $37 \%$.

$$
R G R_{L A}
$$

Individual plants showed a high degree of variation in leaf area growth rate. As a result, there was no difference in mean growth rates between species or as a function of land-use history. In addition, the effect of land use history did not differ for the two species. There was a trend suggesting that plants at the $\mathrm{OH}$ site had nearly 3 -fold greater $\mathrm{RGR}_{\mathrm{LA}}$ than plants reintroduced into WV (Fig. 5.4; F=3.7747, $\mathrm{p}=0.0773$ ).

Goldenseal and ginseng at the WV highwall and secondary plots did not increase in leaf area over the course of the experiment (Table 5.5). Consistent with this pattern, there 
was a trend that the ginseng found at the WV highwall and secondary plots had a $\mathrm{RGR}_{\mathrm{LA}}$ that was less than the $\mathrm{RGR}_{\mathrm{LA}}$ of ginseng found at 27 wild populations of ginseng (Table 5.6). However, in all plots in $\mathrm{OH}$, and in the mature plot in $\mathrm{WV}$, reintroduced plants increased in leaf area over the course of the experiment (Table 5.5).

\section{Reproduction:}

There was a trend that land-use history influenced the proportion of reproductive ginseng plants (Fig. 5.5; $\mathrm{F}=3.7556, \mathrm{p}=0.0571$ ), with ginseng plants present at highwall plots having a higher rate of inflorescence initiation. Goldenseal was ca. $10 \%$ more likely to be reproductive at plots in $\mathrm{OH}$ than plots in WV (Fig. 5.6; $\mathrm{F}=5.5349, \mathrm{p}=0.0383$ ).

Natural seedling establishment of ginseng was documented in both WV and OH in 2015 . In $\mathrm{OH}$ secondary plots, three new seedlings emerged, and in an $\mathrm{OH}$ highwall plot, two new seedlings were documented. In WV, three seedlings emerged in two mature plots, and two seedlings emerged at a highwall plot. The data were natural log transformed, and a two-way ANOVA showed no difference in the seedling germination from reintroduced plants among land-use histories $(\mathrm{F}=0.0341, \mathrm{p}=0.9666)$ or between sites $(\mathrm{F}=0, \mathrm{p}=1)$, and no differential response to land use history between sites $(\mathrm{F}=1.8479$, $\mathrm{p}=0.2033)$.

\section{Seed Cage Studies:}

The probability that ginseng seeds would survive the first winter did not depend on site $(\mathrm{F}=0.6521, \mathrm{p}=0.4365)$, land-use history $(\mathrm{F}=0.3834, \mathrm{p}=0.6903)$, and the effect of site 
ginseng seeds surviving did not depend on land-use history $(\mathrm{F}=1.1084, \mathrm{p}=0.3643)$.

Further, the probability that ginseng seeds would germinate did not depend on site $(\mathrm{F}=0.2551, \mathrm{p}=0.6235)$ and land-use history $(\mathrm{F}=0.1621, \mathrm{p}=0.8524)$, and the effect of site on seeds germinating did not depend on land-use history $(\mathrm{F}=0.8847, \mathrm{p}=0.4403)$.

\section{Source:}

There was no difference in $\mathrm{RGR}_{\mathrm{LA}}$ between the ginseng of Maryland source or Wisconsin source $(\mathrm{F}=1.9357, \mathrm{p}=0.1732)$. The source of ginseng did not impact the persistence of the plant over the four-year experimental period $(\mathrm{F}=0.1677, \mathrm{p}=0.7219)$. 
Table 5.1. Mean age range of plots as determined by tree ring analysis.

\begin{tabular}{|c|c|c|c|}
\hline Site & Land-use & Plot & $\begin{array}{l}\text { Years since } \\
\text { disturbance }\end{array}$ \\
\hline WV & Highwall & 1 & $30-40$ \\
\hline WV & Highwall & 2 & $30-40$ \\
\hline WV & Highwall & 3 & $30-40$ \\
\hline WV & Secondary & 1 & $50-60$ \\
\hline WV & Secondary & 2 & $50-60$ \\
\hline WV & Secondary & 3 & $40-50$ \\
\hline WV & Mature (>80yo) & 1 & $>80$ \\
\hline WV & Mature (>80yo) & 2 & $>80$ \\
\hline WV & Mature (>80yo) & 3 & $>80$ \\
\hline $\mathrm{OH}$ & Highwall & 1 & $50-60$ \\
\hline $\mathrm{OH}$ & Highwall & 2 & $50-60$ \\
\hline $\mathrm{OH}$ & Highwall & 3 & $50-60$ \\
\hline $\mathrm{OH}$ & Mature (>80yo) & 2 & $>80$ \\
\hline $\mathrm{OH}$ & Mature (>80yo) & 3 & $>80$ \\
\hline $\mathrm{OH}$ & Secondary & 1 & $50-60$ \\
\hline $\mathrm{OH}$ & Secondary & 2 & $30-40$ \\
\hline $\mathrm{OH}$ & Secondary & 3 & $30-40$ \\
\hline
\end{tabular}


Table 5.2. Composition and size of dominant trees at each plot, as measured by the diameter at breast height $(\mathrm{cm})$. The two largest trees of different species were listed. Land-use history (LUH) types are abbreviated: Highwall plots $(\mathrm{H})$, Secondary Plots (S), and Mature Plots $(\mathrm{M})$.

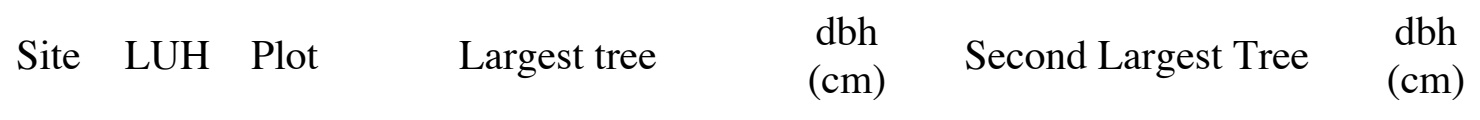

\begin{tabular}{lllllll}
\hline WV & H & 1 & Prunus serotina & 34.53 & Betula lenta & 32.97 \\
WV & H & 2 & Acer saccharum & 62.95 & Betula lenta & 45.29 \\
WV & H & 3 & Acer saccharum & 46.28 & Betula lenta & 26.10 \\
WV & S & 1 & Liriodendron tulipifera & 87.97 & Acer saccharum & 20.81 \\
WV & S & 2 & Liriodendron tulipifera & 72.25 & Prunus serotina & 40.80 \\
WV & S & 3 & Quercus alba & 93.89 & Liriodendron tulipifera & 37.33 \\
WV & M & 1 & Acer saccharum & 60.12 & Carya ovata & 58.43 \\
WV & M & 2 & Liriodendron tulipifera & 92.87 & Quercus rubra & 74.41 \\
WV & M & 3 & Liriodendron tulipifera & 79.34 & Acer saccharum & 28.20 \\
OH & H & 1 & Liriodendron tulipifera & 53.91 & Platanus occidentalis & 52.83 \\
OH & H & 2 & Platanus occidentalis & 60.79 & Acer negundo & 46.79 \\
OH & H & 3 & Populus deltoides & 62.25 & Platanus occidentalis & 51.50 \\
OH & M & 2 & Prunus serotina & 44.56 & Fraxinus americana & 44.18 \\
OH & M & 3 & Liriodendron tulipifera & 63.05 & Acer saccharum & 57.26 \\
OH & S & 1 & Liriodendron tulipifera & 56.40 & Juglans nigra & 51.62 \\
OH & S & 2 & Quercus rubra & 45.83 & Acer negundo & 36.60 \\
OH & S & 3 & Populus deltoides & 50.60 & Quercus rubra & 48.38
\end{tabular}


Table 5.3. Soil test results from 27 wild populations of American ginseng.

\begin{tabular}{lccc} 
& Mean & Minimum & Maximum \\
\hline $\mathrm{pH}$ & 5.0 & 3.9 & 6.6 \\
$\mathrm{Ca}(\mathrm{meq} / 100 \mathrm{~g})$ & 9.7 & 0.7 & 25.0
\end{tabular}


Table 5.4. Soil test results from all plots organized by sites.

\begin{tabular}{llcc}
\hline Site & Land-use History & $\mathrm{pH}$ & $\begin{array}{c}\text { Calcium } \\
\text { level } \\
(\mathrm{meq} / 100 \mathrm{~g})\end{array}$ \\
\hline WV & Highwall & 3.8 & 1.0 \\
WV & Secondary & 4.6 & 2.2 \\
WV & Mature (>80 yo) & 5.6 & 7.2 \\
OH & Highwall & 5.9 & 9.8 \\
OH & Secondary & 7.0 & 16.6 \\
OH & Mature $(>80$ yo) & 6.1 & 13.1
\end{tabular}


Table 5.5. Compilation of the results of one-tailed t-tests of $\mathrm{RGR}_{\mathrm{LA}}$, determining if the mean $\mathrm{RGR}_{\mathrm{LA}}$ was greater than zero, for each plant species for each site in each land-use history and weighted by the number of plants in each subplot. Asterisks indicate statistical significance $(\mathrm{p}<0.05)$.

\begin{tabular}{llcc} 
& & \multicolumn{2}{c}{ Plant Species } \\
\cline { 3 - 4 } Site & Land-use History & \multicolumn{1}{c}{ Goldenseal } & Ginseng \\
\hline WV & Highwall & $\mathrm{t}=0.6131, \mathrm{p}=0.2812$ & $\mathrm{t}=0.4068, \mathrm{p}=0.3481$ \\
& Secondary & $\mathrm{t}=0.3173, \mathrm{p}=0.3796$ & $\mathrm{t}=0.0538, \mathrm{p}=0.4790$ \\
& Mature (>80yo) & $\mathrm{t}=2.6222, \mathrm{p}=0.0153^{*}$ & $\mathrm{t}=3.5041, \mathrm{p}=0.0025^{*}$ \\
\hline \multirow{2}{*}{ OH } & Highwall & $\mathrm{t}=2.7462, \mathrm{p}=0.0126^{*}$ & $\mathrm{t}=3.0192, \mathrm{p}=0.0058^{*}$ \\
& $\begin{array}{l}\text { Secondary } \\
\text { Mature }(>80 \mathrm{yo})\end{array}$ & $\mathrm{t}=4.0911, \mathrm{p}=0.0075^{*}$ & $\mathrm{t}=5.1617, \mathrm{p}=0.0002^{*}$ \\
& & $\mathrm{t}=4.8524, \mathrm{p}=0.0009^{*}$ & $\mathrm{t}=3.5440, \mathrm{p}=0.0061^{*}$ \\
\hline
\end{tabular}


Table 5.6. The results of a t-test comparing the mean $\mathrm{RGR}_{\mathrm{LA}}$ of ginseng from each landuse history* site to the mean $\mathrm{RGR}_{\mathrm{LA}}$ of 27 wild populations of ginseng. A superscript ' $\mathrm{t}$ ' $\left({ }^{\mathrm{t}}\right)$ indicate a trend $(\alpha<0.10)$.

\begin{tabular}{llc} 
Site & Land-use History & $\begin{array}{c}\mathrm{RGR}_{\mathrm{LA}} \text { reintroduced } \\
<\mathrm{RGR}_{\mathrm{LA}} \text { native }\end{array}$ \\
\hline $\mathrm{WV}$ & Highwall & $\mathrm{t}=-1.6624, \mathrm{p}=0.0702^{\mathrm{t}}$ \\
& Secondary & $\mathrm{t}=-1.4925, \mathrm{p}=0.0818^{\mathrm{t}}$ \\
& Mature (>80yo) & $\mathrm{t}=1.4577, \mathrm{p}=0.9136$ \\
\hline $\mathrm{OH}$ & Highwall & $\mathrm{t}=0.7687, \mathrm{p}=0.7709$ \\
& Secondary & $\mathrm{t}=1.9680, \mathrm{p}=0.9626$ \\
& Mature $(>80 \mathrm{yo})$ & $\mathrm{t}=2.2559, \mathrm{p}=0.9675$ \\
\hline
\end{tabular}


Figure 5.1. Statistical layout of the design of the reintroduction experiment. Plots are the columns. Subplots are the small clouds nested within the plots.

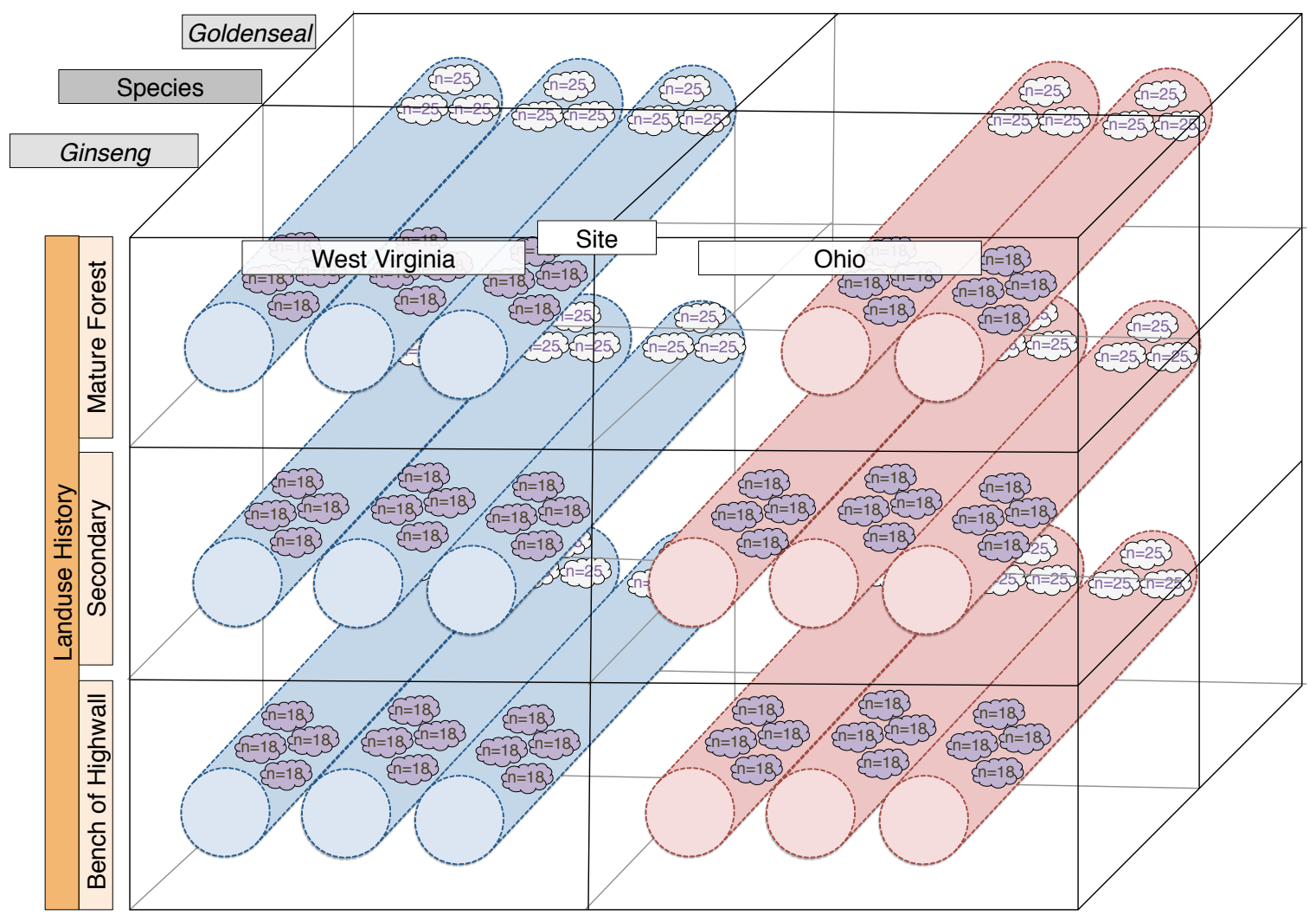


Figure 5.2. Effect of land-use history on the persistence of (A) ginseng and (B) goldenseal over four years.

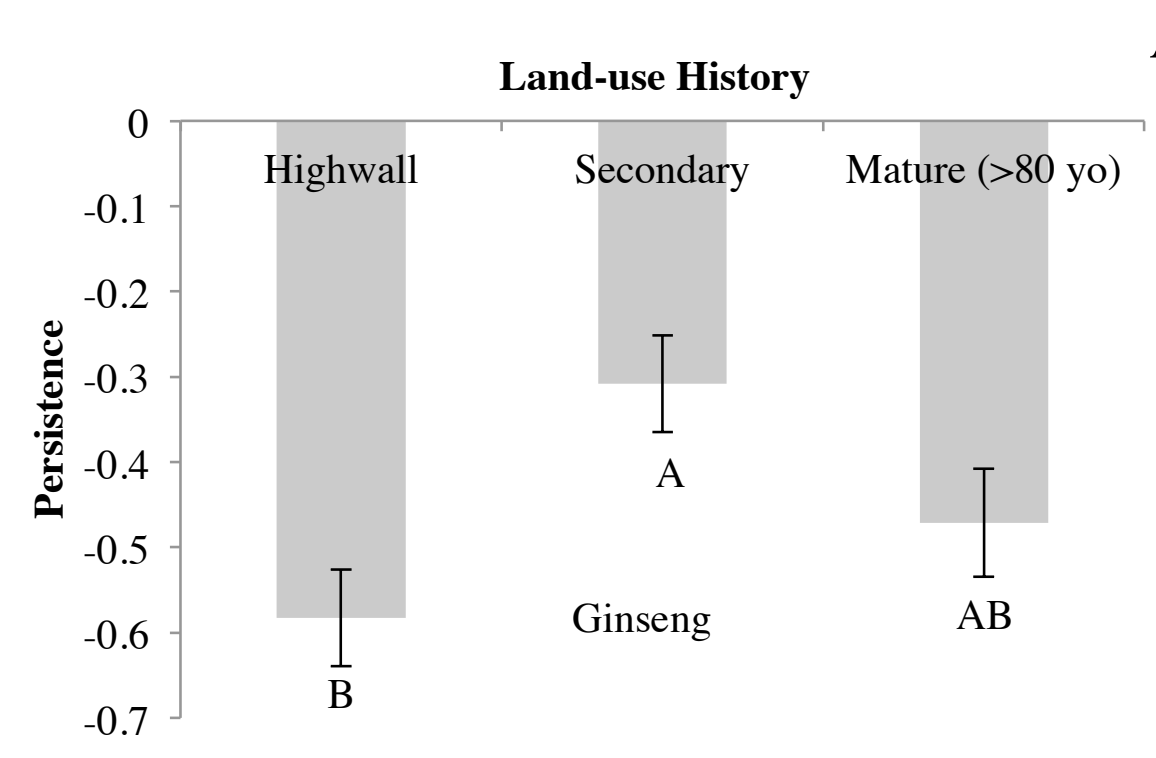

A

B

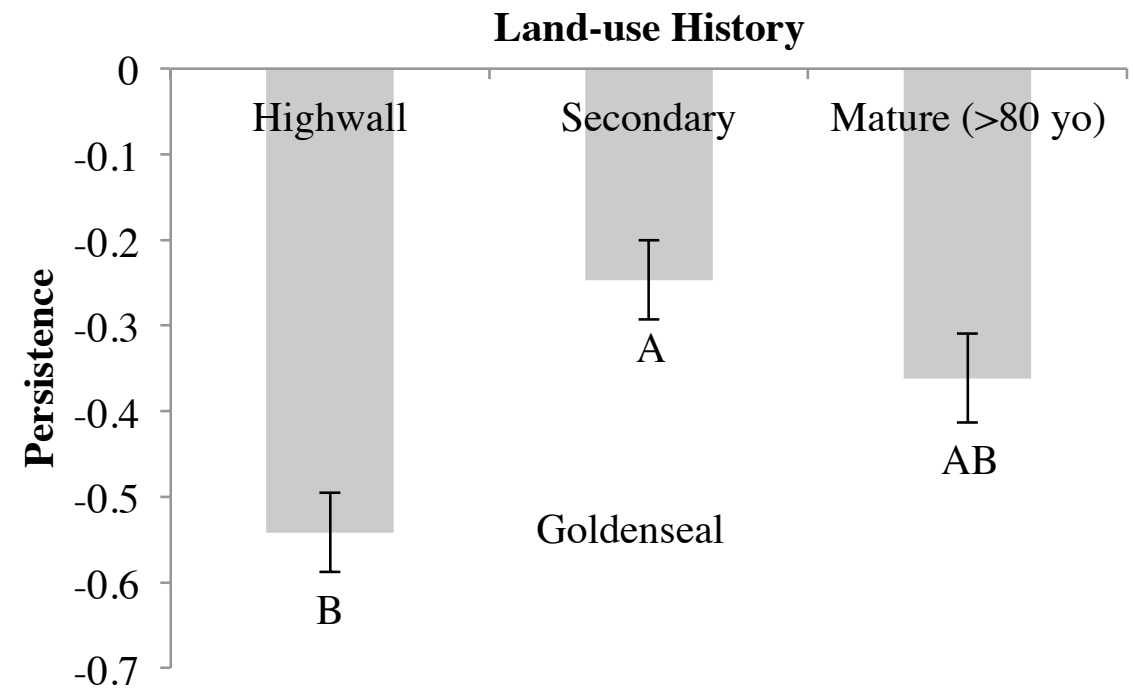


Figure 5.3. Effect of land-use history on the persistence rate of goldenseal depended on site over four years.

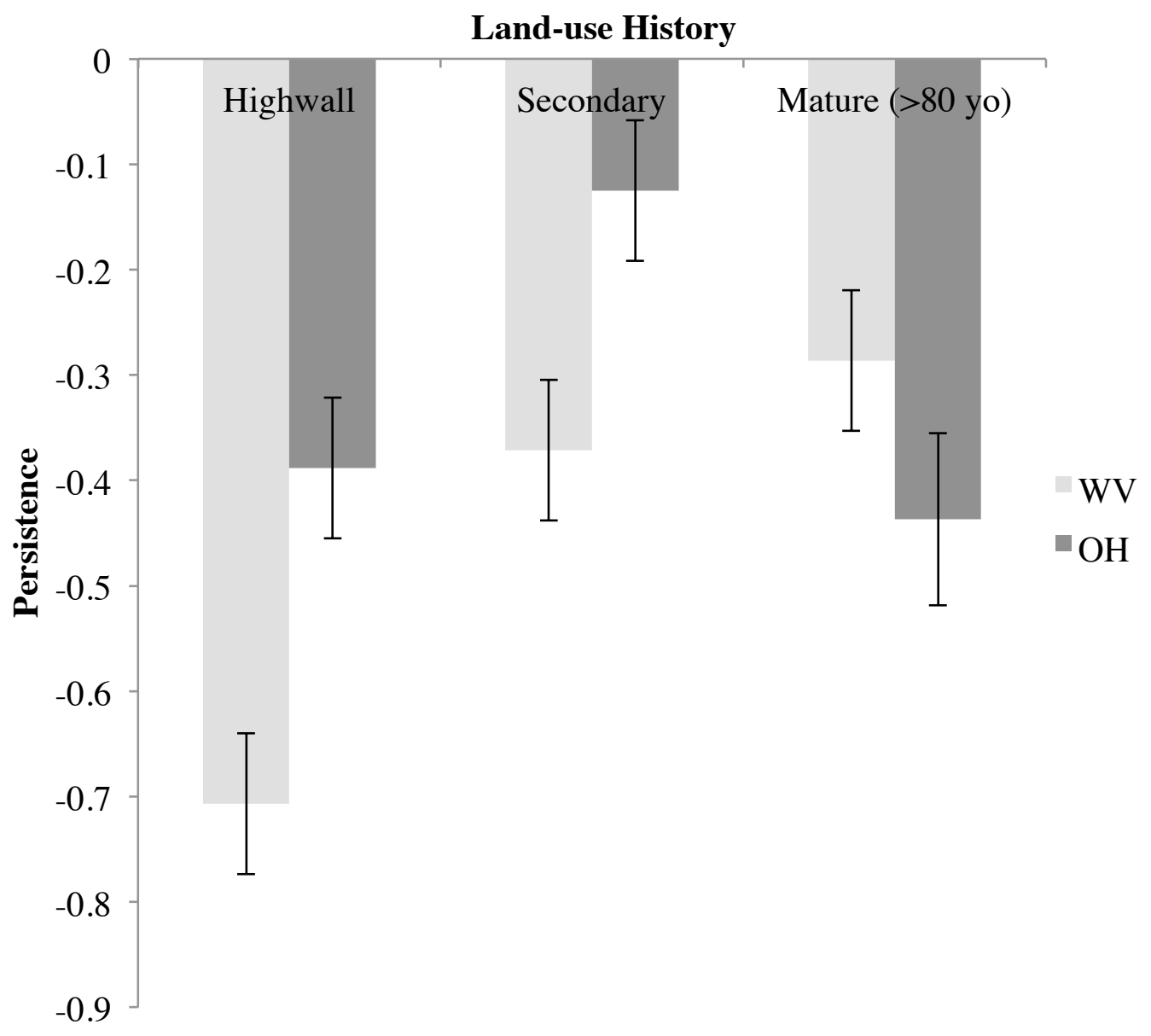


Figure 5.4. Effect of site on the Mean $\mathrm{RGR}_{\mathrm{LA}}$ across both species. Land-use history $(\mathrm{LUH})$ types are abbreviated: Highwall plots $(\mathrm{H})$, Secondary Plots $(\mathrm{S})$, and Mature Plots (M).

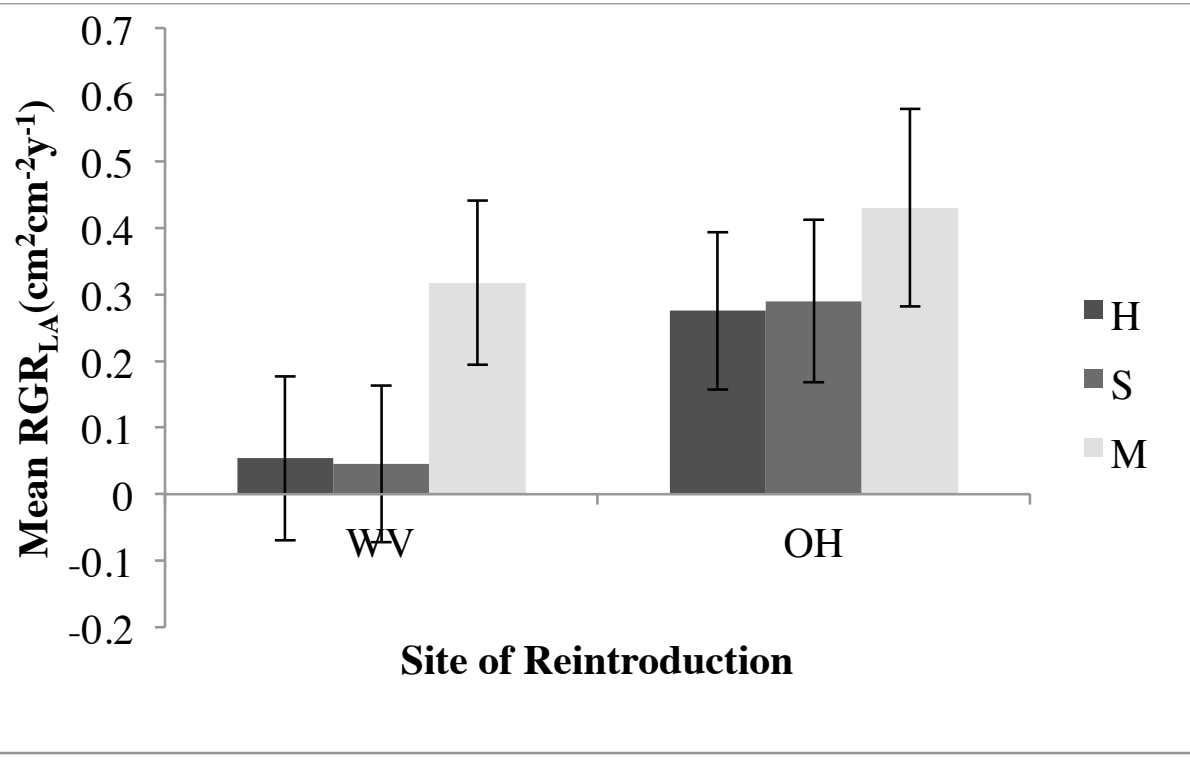


Figure 5.5. Effect of land-use history on the percent of reproductive ginseng plants.

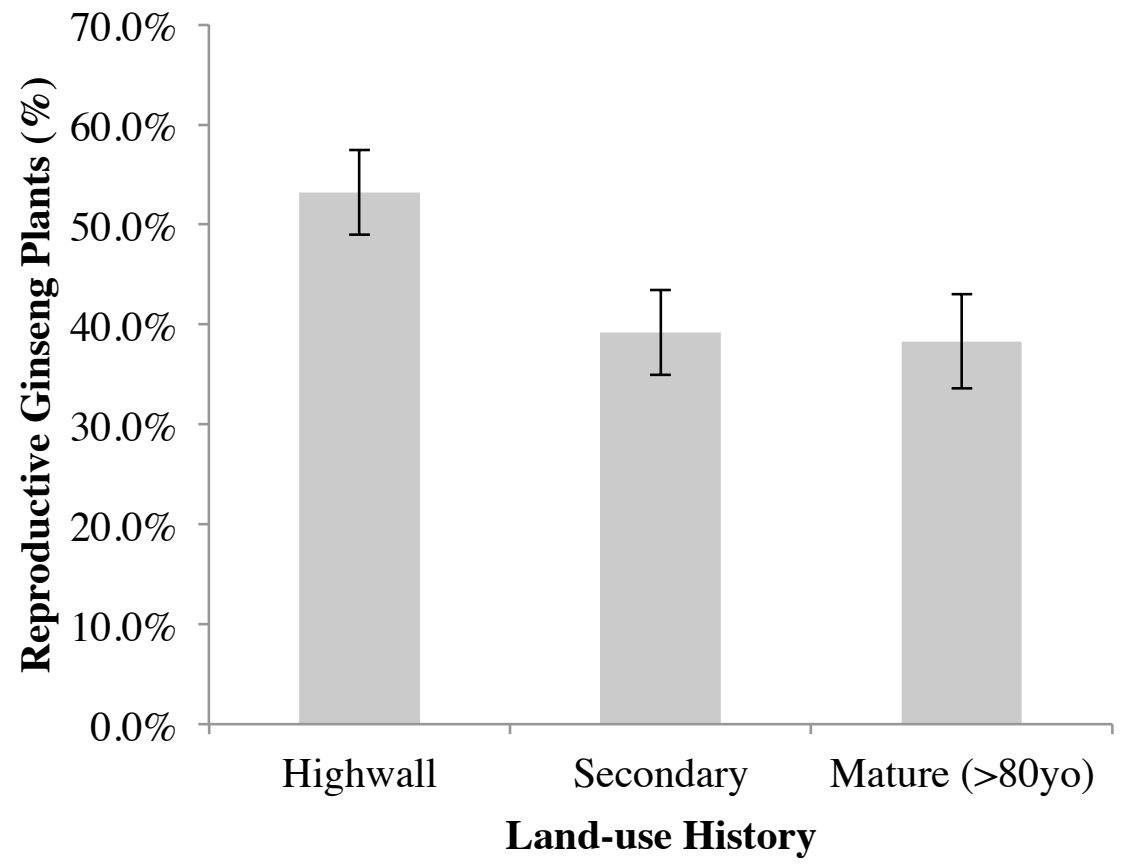


Figure 5.6. Effect of site on the percent of reproductive goldenseal plants.

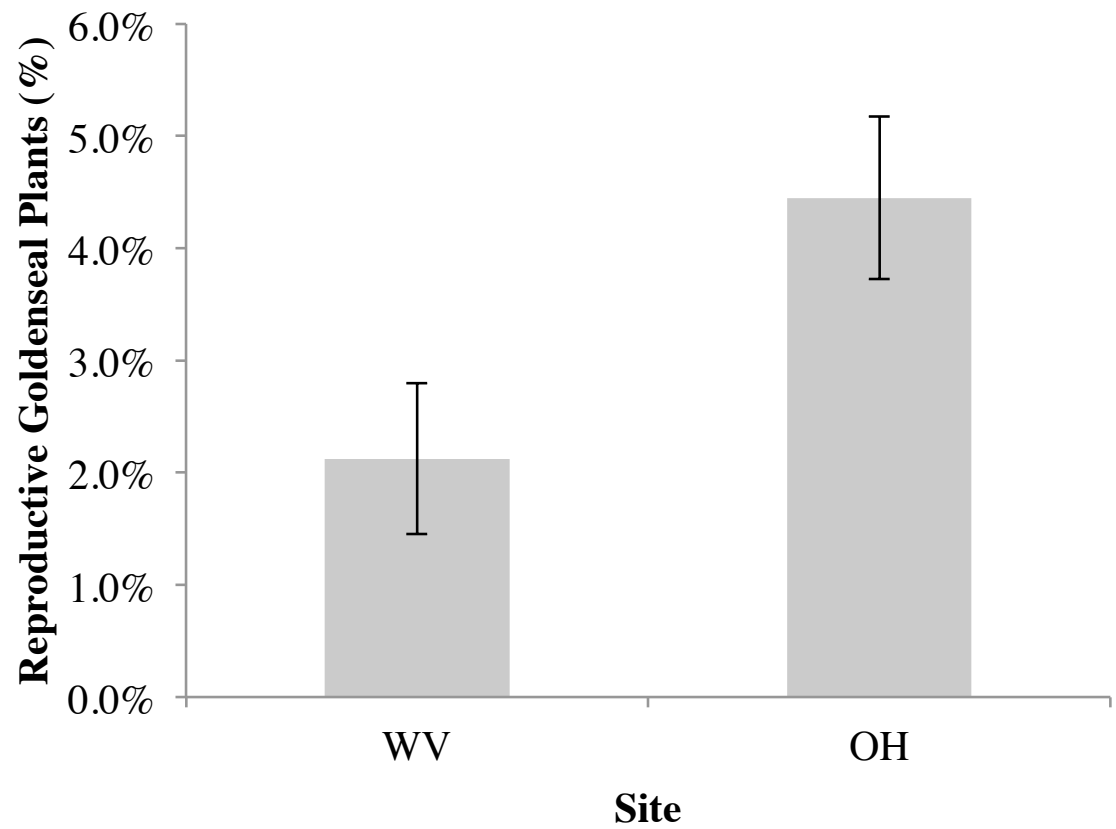




\section{Discussion}

The failure of medicinal plants to persist on the bench of a highwall may be due to several reasons. Both ginseng and goldenseal's poor performance at highwall plots could be due to the standing water that was observed in early summer at many of the plots within this type of land-use history. Plants were reintroduced to the sites in mid-fall, without knowing how the microsite would change in the course of a year. The bench of a highwall can have compressed substrates that prevent drainage (Haering et al. 2004), however ginseng and goldenseal both grow best in moist, well-drained soils (Van der Voort et al. 2003). If medicinal plants, such as ginseng, grow in poorly drained soils, the plant's root may be more susceptible to root rot (Davis \& Persons 2014). The poor performance on highwall plots could be due to a biotic constraint that we were unable to precisely identify, such as the presence of pathogens (Vellend 2005; Davis \& Persons 2014). However, there was a trend that, if ginseng plants were able to persist on a highwall site, the extant plants were more likely to be reproductive. This higher rate of reproduction could be explained by the fact that reproduction can be a response to stress in plants - an attempt by the plant to produce offspring before it dies (Karlsson and Méndez 2005).

The persistence and growth of both goldenseal and ginseng may be strongly influenced by soil $\mathrm{pH}$ and calcium levels. Calcium is considered to be an important mineral for ginseng growth (Burkhart 2013). Both plant species had higher $\mathrm{RGR}_{\mathrm{LA}}$ in $\mathrm{OH}$ than $\mathrm{WV}$, and soil from $\mathrm{OH}$ had a higher average level of calcium and less acidity than soils from WV. Additionally, goldenseal had greater persistence, and was more likely to be reproductive at the $\mathrm{OH}$ site. A study involving 21 natural populations of goldenseal in 
the northern part of goldenseal's range showed that the $\mathrm{pH}$ of the soil at these populations ranged between 5.7 to 6.3 (Sinclair and Catling 2001). This range is closer to the soil pH of the $\mathrm{OH}$ site than the WV site. By averaging soil test results from the 27 wild populations, we were able to determine that the wild ginseng plants in this study were found in soils with a mean $\mathrm{pH}$ of 5.04 and with a mean high level of calcium, 9.7 meq/100g. This importance of $\mathrm{pH}$ and calcium was also seen at the WV highwall and secondary plots as these plots had acidic soils and low calcium levels. At WV highwall and secondary plots, the $\mathrm{RGR}_{\mathrm{LA}}$ of goldenseal and ginseng was not different from zero, thus the plants that persisted were just maintaining their size and not growing.

The comparable $\mathrm{pH}$ and calcium levels could explain why wild ginseng plants had similar $\mathrm{RGR}_{\mathrm{LA}}$ to all of the reintroduced ginseng plants in $\mathrm{OH}$ and to the ginseng reintroduced into the mature plots in WV. As the WV highwall and secondary sites had a $\mathrm{pH} \leq 5$, the poorer performance of plants may be explained by bacterial disease or fungal infections. In contrast, previous research with goldenseal demonstrates that supplementing the soils with gypsum to increase calcium levels can be detrimental to root growth and reduce the aboveground size of the plant, but increasing the $\mathrm{pH}$ can increase root growth (Davis \& Persons 2014). However, as the $\mathrm{pH}$ of the soil becomes greater, there is an increase in the available calcium in the soil (Fernández \& Hoeft 2009), and this research shows that calcium may be beneficial for goldenseal growth.

While seedlings germinated at some of the plots, this does not indicate that these sites are appropriate for reintroducing medicinal plants. Seedlings germinated in highwall plots in 
$\mathrm{OH}$ and in WV, however, adult persistence was low at these plots. Most likely, these seedlings would not persist, and eventually the seedlings would experience mortality. Although the seed cage experiments showed no difference among plots, the environmental conditions associated with land use history and site impact the performance of reintroduced ginseng plants after a seed germinates. Thus, selecting site conditions that will increase adult performance should be prioritized.

There was no differential growth rate between a clonal plant, goldenseal, and a plant with a taproot, ginseng, in this study. As goldenseal responds positively to disturbance (Sanders \& McGraw 2002), and ginseng is pre-adapted to old growth forests (Wagner \& McGraw 2013; Chandler \& McGraw 2015), this result was surprising. Reintroductions often focus on rare plants with more specific habitat requirements or a narrow range (Rowland \& Maun 2001; Dalrymple et al. 2012), and work has shown that reintroductions of species with wide distributions may not be as successful as reintroductions of species with narrower ranges (Dalrymple et al. 2012). As goldenseal is rarer than ginseng, the distribution of goldenseal has been harder to quantify (McGraw et al. 2003). Goldenseal may have a narrower niche than ginseng, and this could explain the variable response shown. As ginseng's performance was more consistent among sites and plots than goldenseal, this research may suggest that ginseng's broader niche may render this species a better plant to reintroduce.

Site conditions are not the only concern when planning a reintroduction project. There was no difference in $\mathrm{RGR}_{\mathrm{LA}}$ between ginseng plants of Wisconsin and Maryland source, 
and the source of the ginseng plants did not impact persistence. Nevertheless, the genetic material used for plant reintroductions should be evaluated to preserve genetic diversity, and reduce inbreeding or outbreeding depression (Neale 2012). Not only is genetic diversity important to consider, but also the mixture of plants from different sources can impact reintroduction success. While this part of the research focused on ginseng, previous work has demonstrated that plots of reintroduced goldenseal will have higher performance if the goldenseal is planted in clumps that came from a single source (Sanders \& McGraw 2005). Further, genetic material has the potential to influence the performance of future crosses between native and cultivated types (Mooney \& McGraw 2007). As natural populations are genetically different from cultivated ginseng (Schluter $\&$ Punja 2002), if land-managers are supplementing wild populations with ginseng plants from Wisconsin source, outbreeding depression may occur in the resulting crosses over time (Mooney \& McGraw 2007), reducing the performance of the native populations. While our study showed no difference in performance between Maryland and Wisconsin source ginseng plants, genetic material must be considered for reintroduction practices in order to maximize future success.

Reintroducing medicinal plants is an important and valuable in situ conservation practice (Guerrant 2012). Due to the variation in plant performance based on site and land-use history, our results reflect the multi-dimensional nature of reintroductions. Our project shows that mature plots have higher rates of persistence than plots along the bench of a highwall; project success may be defined as long-term persistence (Menges 2008). However, a population that is self-sustaining is indicative of a successful reintroduction 
(Godefroid et al. 2011). For plots found in WV within the land-use history of highwall and secondary forests, this reintroduction project can most likely already be classified as a failure, as the $\mathrm{RGR}_{\mathrm{LA}}$ of both species were no different from zero, meaning the plants were not growing in size.

Our results demonstrate that land-use history can impact the performance of ginseng and goldenseal, and that the history of the land should strongly influence in situ conservation management plans. Land-managers should select reintroduction sites first based on macrosite qualities, such as land-use history, soil $\mathrm{pH}$, and soil calcium levels. Within the site, microsite conditions, such as canopy openness and water flow patterns, should be evaluated before reintroducing medicinal plants to the site. If these steps of evaluating macrosite and microsite quality are followed, there could be widespread successful medicinal plant reintroductions.

Successful in situ conservation of medicinal plants may halt, and eventually reverse, the loss of medicinal plants to environmental stressors, such as surface mining and overharvest. There could be an increase the amount of medicinal plants that could be sustainably harvested. If medicinal plants were no longer considered rare, stakeholders, such as the Asian medicinal market and medicinal plant harvesters, would ultimately benefit in the long-term as these species will not go extinct. While the natural process of succession is occurring throughout Appalachia, the long-term nature of habitat loss due to mining and agriculture reduces habitat for medicinal plants. The clearing of forest for agriculture can have long-lasting effects on medicinal plant persistence and growth, thus 
re-introductions should focus on sites where the physical characteristics are closer to ideal for the species.

\section{Acknowledgements}

This work would have been impossible without the help of D.W. Turner, M.B. Turner, and A. Wagner. A special thanks to the field crew who helped census and set up these experiments, including, but not limited to: Muskingum University's and West Virginia University's Tri-Beta club, J. Chandler, A. Hruska, W. Bailey, Z. Zacavish, P. Crim, Q. Doyle, A. Jarrell, M. Elza, C. Mallow, M. Arbuiso, J.D. Skoff, and J.W. Turner. Further, thank you to the Wilds Conservation Center, and the Nature Preserve in WV for providing a unique location for this research. Our research was supported by a Doctoral Research Grant from WVU, a National Science Foundation Long Term Research in Environmental Biology Grant to J.B. McGraw (DEB-0613611 and DEB-1118702), and the Botany in Action Fellowship, through Phipps Conservatory in Pittsburgh, PA, to J.B. Turner. 


\section{References}

Bailey B (1999) Social and economic impacts of wild harvested products. $\mathrm{PhD}$ Dissertation, West Virginia University, Morgantown

Baskin CC, Baskin JM (1998) Seeds: ecology, biogeography, and evolution of dormancy and germination, 1st edn. Academic Press, San Diego, California

Brown CD, Boutin C (2009) Linking past land use, recent disturbance, and dispersal mechanism to forest composition. Biological Conservation 142:1647-1656

Burkhart E, Jacobson M (2009) Transitioning from wild collection to forest cultivation of indigenous medicinal forest plants in eastern North America is constrained by lack of profitability. Agroforestry Systems 76:437-453

Burkhart EP, Jacobson MG, Finley J (2012) A case study of stakeholder perspective and experience with wild American ginseng (Panax quinquefolius) conservation efforts in Pennsylvania, U.S.A : limitations to a CITES driven, top-down regulatory approach. Biodiversity Conservation 21:3657-3679

Burkhart EP (2013) American ginseng (Panax quinquefolius L.) floristic associations in Pennsylvania: guidance for identifying calcium-rich forest farming sites. Agroforestry Systems 87:1157-1172

CITES Secretariat Convention on International Trade in Endangered Species of Wild Fauna and Flora (CITES). www.cites.org (accessed 15 April 2015)

Chandler JL, McGraw JB (2015) Variable effects of timber harvest on the survival, growth, and reproduction of American ginseng (Panax quinquefolius L.). Forest Ecology and Management 344:1-9

Dalrymple SE, Banks E, Stewart GB, Pullin AS (2012) A meta-analysis of threatened plant reintroductions from across the globe. Pages 31-50 In: Maschinski J, Haskins KE (eds) Plant reintroduction a changing climate. Promises and perils. Island Press, Washington, D.C.

Davis JM, Persons WS (2014) Growing and marketing ginseng, goldenseal and other woodland medicinals, Revised ed. New Society Publishers, Gabriola Island, BC, Canada

Dupouey JL, Dambrine E, Laffite JD, Moares C (2002) Irreversible impact of past land use on forest soils and biodiversity. Ecology 83:2978-2984

Emerson P, Skousen J, Ziemkiewicz P (2009) Survival and growth of hardwoods in brown versus gray sandstone on a surface mine in West Virginia. Journal of Environmental Quality 38:1821-1829 
Fernández FG, Hoeft RG (2009) Managing soil pH and crop nutrients. Pages91-112 In: Illinois Agronomy Handbook 24th edn. University of Illinois, Urbana, Illinois

Gilliam FS (2007) The ecological significance of the herbaceous layer in temperate forest ecosystems. Bioscience 57:845-858

Godefroid S, Piazza C, Rossi G, et al (2011) How successful are plant species reintroductions? Biological Conservation 144:672-682

Gorman JM, Skousen JG, Sencindiver J, Ziemkiewicz P (2001) Forest productivity and minesoil development under a white pine plantation versus natural vegetation after 30 years. Pages 103-111 In:2001 National Meeting of the American Society for Surface Mining and Reclamation, Lexington, Kentucky

Gragson TL, Bolstad PV (2006) Land use legacies and the future of southern Appalachia. Society of Natural Resources 19:175-190

Guerrant EOJ (2012) Characterizing two decades of rare plant reintroductions. Pages9-30 In: Maschinski J, Haskins KE (eds) Plant reintroduction a changing climate. Promises and perils. Island Press, Washington, D.C.,

Haering KC, Daniels WL, Galbraith JM (2004) Appalachian mine soil morphology and properties: effects of weathering and mining method. Soil Science Society of America Journal 68:1315-1325

Holl KD (2002) Long-term vegetation recovery on reclaimed coal surface mines in the eastern USA. Journal of Applied Ecology 39:960-970

Hunt R (1990) Basic growth analysis. Unwin Hyman Ltd., London

Karlsson PS, Mendez M (2005) The Resource Economy of Plant Reproduction. Pages149 In: Reekie EG, Bazzaz FA (eds) Reprouctive allocation in plants. Elsevier Academic Press, Burlington, MA

Li TSC (1995) Asian and American ginseng-A review. Horttechnology 5:27-34

McGraw J, Furedi M (2005) Deer browsing and population viability of a forest understory plant. Science 307:10-13

McGraw J, Sanders S, Van der Voort M (2003) Distribution and abundance of Hydrastis canadensis L . (Ranunculaceae) and Panax quinquefolius L . (Araliaceae) in the Central Appalachian Region. Journal of the Torrey Botanical Society 130:62-69

McGraw JB, Garbutt K (1990) The analysis of plant growth in ecological and evolutionary studies. Trends in Ecology and Evolution 5:251-254 
McGraw JB, Lubbers AE, Van Der Voort M, et al (2013) Ecology and conservation of ginseng (Panax quinquefolius) in a changing world. The Year in Ecology and Conservation Biology. Pages1-30 In: Annals of the New York Academy of Sciences, New York, New York

Menges ES (2008) Turner Review No . 16 Restoration demography and genetics of plants : when is a translocation successful ? Australian Journal of Botany 187-196

Mooney EH, McGraw JB (2007) Effects of self-pollination and outcrossing with cultivated plants in small natural populations of American ginseng, Panax quinquefolius (Araliaceae). American Journal of Botany 94:1677-1687

Neale JR (2012) Genetic considerations in rare plant reintroduction: Practical applications (or How are we doing?). Pages71-88 In: Maschinski J, Haskins KE (eds) Plant reintroduction a changing climate. Promises and perils. Island Press, Washington, D.C.

Palmer MA, Bernhardt ES, Schlesinger WH, et al (2010) Mountaintop mining consequences. Science 327:148-149

Roberts MR, Gilliam FS (2003) Response of the herbaceous layer to disturbance in eastern forests. Pages302-320 In: Roberts MR, Gilliam FS (eds) The herbaceous layer of the eastern North America Oxford University Press, USA, Oxford

Ripple WJ, Johnson DH, Hershey KT, Meslow EC (1991) Old-growth and mature forests near spotted owl nests in western Oregon. Journal of Wildlife Management $55: 316-318$

Robbins CS (2000) Comparative analysis of management regimes and medicinal plant trade monitoring. Conservation Biology 14:1422-1434

Rowland J, Maun MA (2001) Restoration Ecology of an Endangered Plant Species: Establishment of New Populations of Cirsium pitcheri. Restoration Ecology 9:60-70

Sanders S (2004) Tests for causes of rarity in goldenseal (Hydrastis canadensis L.). PhD Dissertation, West Virginia University, Morgantown

Sanders S, McGraw JB (2005) Population differentiation of a threatened plant: variation in response to local environment and implications for restoration. Journal of the Torrey Botanical Society 132:561-572

Sanders SM, McGraw JB (2002) Distribution, abundance, and population dynamics of Goldenseal (Hydrastis canadensis L.) in an Indiana Nature Preserve, USA. Natural Areas Journal 22:129-134. 
SAS JMP Pro 11. (2013). SAS Campus Drive, Cary, NC, USA 27513

Schluter C, Punja ZK (2002) Genetic diversity among natural and cultivated field populations and seed lots of American Ginseng (Panax quinquefolius L.) in Canada. International Journal of Plant Science 163:427-439

Sinclair A, Catling PM (2004) Restoration of Hydrastis canadensis: Experimental test of a disturbance hypothesis after two growing seasons. Restoration Ecology 12:184189

Sinclair A, Catling PM (2003) Restoration of Hydrastis canadensis by transplanting with disturbance simulation: Results of one growing season. Restoration Ecology $11: 217-222$

Sinclair A, Catling PM (2001) Cultivating the increasingly popular medicinal plant, goldenseal: Review and update. American Journal of Alternative Agriculture 16:131-140

Skousen JG, Johnson CD, Garbutt K (1994) Natural revegetation of 15 abandoned mine land sites in West Virginia. Journal of Environmental Quality 23:1224-1230

Skousen J, Ziemkiewicz P, Venable C (2006) Tree recruitment and growth on 20-yearold , unreclaimed surface mined lands in West Virginia. International Journal of Mining, Reclamation and Environment 20:142-154. doi:10.1080/17480930600589833

Sokal RR, Rohlf FJ (2012) Biometry: the principles and practice of statistics in biological research, 4th edition. W. H. Freeman and Co., New York, New York

Souther S, McGraw JB (2011a) Vulnerability of wild American ginseng to an extreme early spring temperature fluctuation. Population Ecology 53:119-129.

Souther S, McGraw JB (2011b) Evidence of local adaptation in the demographic response of American ginseng to interannual temperature variation. Conservation Biology 25:922-931

Stein BA, Kutner LS, Adams JS (eds) (2000) Precious Heritage: The status of biodiversity in the United States. Oxford University Press, USA, Cary, North Carolina

Turner JB, McGraw JB (2015) Can putative indicator species predict habitat quality for American ginseng? Ecological Indicators 57:110-117

Van der Voort ME, Bailey B, Samuel DE, McGraw JB (2003) Recovery of populations of goldenseal (Hydrastis canadensis L.) and American ginseng (Panax

quinquefolius L.) following harvest. American Midland Naturalist 149:282-292 
Vellend M (2005) Land-use history and plant performance in populations of Trillium grandiflorum. Biological Conservation 124:217-224

Wagner A, McGraw JB (2013) Sunfleck effects on physiology, growth, and local demography of American ginseng (Panax quinquefolius L .). Forest Ecology and Management 291:220-227

Wixted K, McGraw JB (2009) A Panax-centric view of invasive species. Biological Invasions 11:883-893

Yarnell SL (1998) The Southern Appalachians: A history of the landscape. General Technical Report SRS-18. Ashville, North Carolina 
CHAPTER VI: OVERALL CONCLUSIONS OF THE DISSERTATION 
Due to the plethora of stressors in Appalachia that negatively affect medicinal plants, such as ginseng (McGraw et al. 2013), conservation action must be taken to ensure that these valuable plants survive for future generations. As medicinal plant species, especially ginseng, are of cultural and economic importance in Appalachia (Hufford 2002) they can be used to focus land management strategies. Indeed, ginseng can be described as a 'cultural keystone species' (Garibaldi \& Turner 2004) as this plant is an economically valuable resource in Appalachia (Turner and Skoff, Chap 3) and a large component of the culture of NTFPs harvest in this region (Turner et al., Chap 2). Additionally, ginseng is an important link in the food chain of the eastern deciduous forest, as it is consumed by birds and mammals (Hruska et al. 2014). Scientists and the general public alike care about this native species; as Appalachia is an area that has been impacted by habitat loss and degradation (Gragson \& Bolstad 2006), returning medicinal plants into the eastern deciduous forest can be part of a component of a comprehensive ecological restoration plan.

This dissertation was designed to study the relationships that pertain to the sustainability of ginseng in relation to surface mining. As such, the results from every chapter can aid in the interpretation of the other three chapters. Cohesively, the results from this dissertation can help inform non-profit organizations and government agencies as they develop conservation strategies for ginseng. This research addresses the root of sustainability for ginseng on three levels: (1) understanding the cultural integration of surface mining and ginseng, (2) completing an analysis of the economics of ginseng and surface mining, and (3) developing in situ conservation strategies for ginseng. 
Interpreting the results from Chapter 2, environmental outreach material can be developed to focus on what ginseng harvesters and the broader Appalachian community prioritize and value. The results from Chapter 2 indicate that harvest culture is one worth saving, as harvesters prioritize the forest beyond economic reasons, specifically as they enjoy time outdoors. This was also seen in Bailey's dissertation (1999). Chapter 2 determined that the general (non-harvester) West Virginia community is more likely to value the forest for economic reasons. Since there is a difference in the priorities of harvesters and the general West Virginian community, non-profit organizations or government agencies can use the results of Chapter 2 to develop effective educational outreach materials for land-managers about how a diverse forest can be financially profitable, as seen in the results of Chapter 3.

Chapter 3 shows that sustainable harvest of stewarded wild ginseng, or the harvest of cultivated ginseng from a farm, can provide substantial economic value to a plot of land. While starting a ginseng farm would require an upfront investment, the monetary value from the renewable resource of medicinal plant harvest can succeed the value a landowner would obtain from surface mining royalties. However, developing outreach about the economic benefits of ginseng conservation to the West Virginia community may be easier than connecting with and reaching the secretive harvesting community. Reaching harvesters and encouraging positive change and sustainable legal harvest may be more difficult. 
Harvesters understand that ginseng could go extinct with how ginseng is currently being harvested. Despite this, illegal harvesting behavior is common in the harvester community. If non-profit organizations and government agencies want to empower harvesters to actively participate in the conservation of ginseng, these groups need to educate harvesters about the importance of stewardship and harvest laws. However, Burkhart et al. (2012) demonstrated that ginseng harvesters do not appreciate a top-down regulatory approach. Further, the results from Chapter 2 determined that if harvesters are divested in the future of ginseng, they are less likely to trust environmental experts. As female harvesters are more likely to trust environmental experts, and most ginseng harvesters know other people who harvest ginseng, government agencies and non-profit groups may want to collaborate with female harvesters. Working with this group may encourage the effective development and distribution of conservation information about responsible medicinal plant harvest and appropriate site selection for agroforestry, as demonstrated by the results of Chapter 4 and Chapter 5 .

Using the site selection criteria as outlined in Chapters 4 and 5, land-managers who may have been inspired by the potential value of their land, as determined by Chapter 3 , can evaluate if their property is a suitable candidate for agroforestry. The purpose of these chapters was to identify site conditions that could maximize reintroduced medicinal plant performance. Chapter 4 results illustrate that the majority of ginseng indicator species, as they have traditionally been used, are not effective at predicating site quality. Of the species that could predict ginseng performance, most were contra-indicators; ginseng has reduced performance at sites with these indicators present (Turner and McGraw, 2015). 
The traditional method of determining site quality for ginseng is generally ineffective. This research illustrates that avoiding sites with contra-indicators, and planting ginseng in a mature forest, within 10 meters of a large L. tulipifera, can help maximize the use of limited resources, such as time, money, and effort, and may result in a more successful reintroduction project.

As determined by Chapter 5, the success of a reintroduction project can be influenced by land-use history. By comparing the performance of the medicinal plants, ginseng and goldenseal, that have been reintroduced to secondary forested sites that were along the bench of a highwall, previously used for agriculture, and an older secondary forest, I was able to determine that ginseng and goldenseal had lower persistence on sites that were previously surface mined. Sites that had soils with a more neutral $\mathrm{pH}$ and higher levels of calcium were the sites where medicinal plant performance was the highest. The results of Chapter 4 and 5 can be used to guide agroforestry and in situ conservation of ginseng to counter the loss of ginseng that occurs due to the process of surface mining.

Understanding the relationship between harvest and land-use change are important to conserve species. Ticktin (2005) found that the conservation of wild populations of the valuable NTFP, Aechmea magdalenae, depended on a combination of harvester behavior and land-use decisions (e.g., deciding to burn the land), but planting populations of $A$. magdalenae is a valuable conservation strategy. To address problems associated with unsustainable NTFP harvest, harvesters must be examining current harvest regimes while working with key stakeholders; these groups should be developing management practices 
and effective harvest strategies that will ultimately lead to conservation (Ticktin 2004). These statements echo the results of my research and the importance of a multidisciplinary approach to sustainability.

By evaluating the relationship between a potentially renewable resource versus a nonrenewable resource in Appalachia, I was able to determine that harvest culture is worth saving and sustainably harvested NTFPs can provide a substantial source of income for a land-manager. Further, my work shows that in order to develop protocol for in situ conservation, scientists must evaluate site-conditions, land-use history, and common folklore strategies. The conclusions from these chapters are applicable for other areas with a similar resource conflict. For example, South America is biologically diverse; however, the countries within Latin America have extreme poverty, especially in rural areas, and, often, major industries are based on resource extraction (Pulgar-Vidal et al. 2010). South America is home to many medicinal plant species (Roth and Lindorf 2002), some which may be able to be classified as 'cultural keystone species' (Garibaldi and Turner 2004). Or, species may be identified as an 'inter-cultural keystone species,' not unlike ginseng. The presence of local plant species that are medicinally, ecologically, and culturally valuable could drive conservation efforts and potentially encourage government agencies to increase the protection of habitat. Commercially valuable plants can be a positive incentive to encourage local communities to protect forests (Pennisi 2015). 
A paradigm shift needs to occur culturally, in which all individuals in Appalachia remain 'invested' (Turner et al., Chap 2) in the future of ginseng; individuals who own forested land need to champion the protection of natural resources. As $87 \%$ of all forested land in West Virginia is privately owned (Smith et al. 2004), empowering individuals to support conservation efforts for ginseng is vital for the survival of this rare species. This research will aid individual landowners and land-managers in participating in 'point-source conservation.' Point-source conservation is the idea that by empowering individuals to harvest sustainably, to plant medicinal plants, or to steward medicinal plant populations in their own woodlots, conservation ethics can become part of a community modus operandi. Ultimately, a conglomeration of individuals practicing positive conservation can create a greater worldwide impact. Ginseng could thrive in the vast majority of the forests across West Virginia if individuals are educated about ginseng biology and the economic benefits of sustainability. Implementing in situ conservation strategies on private land should be incentivized and encouraged. 


\section{Specific Recommendations for Stakeholders}

The following section outlines specific recommendations to various stakeholders based

on the outcome of my studies. These are actions that stakeholders should take in order to

further ginseng conservation as forest cover in Appalachia is lost due to surface mining.

1) To reach ginseng harvesters:

a. Work with female ginseng harvesters to develop and distribute outreach material that will be the most effective at creating positive conservation action within the harvester community.

b. Develop educational material that outlines harvest laws and stewardship practices, and why these laws and suggestions have been developed based on ginseng biology. This outreach should include information about how stewarding ginseng populations can result in the population tripling in size in six years (McGraw, personal communication, 2015). Every harvester should obtain this information prior to the ginseng harvest season.

2) To reach the general community of West Virginia:

a. Develop outreach material focusing on the economic opportunities available through ginseng stewardship and agroforestry.

3) To reach both groups:

a. Implement place-based learning in schools so students can learn about the cultural heritage of ginseng harvest, the history of ethnobotany in Appalachia, and the ecology of the region. Future generations may prioritize the conservation of this valuable species, and become advocates for ginseng, if they are encouraged to learn about the environment and the harvest culture.

b. Non-profit organizations and government agencies should work with teachers and religious groups to share information about ginseng stewardship and medicinal plant agroforestry to the general public.

c. Provide all interested individuals, and all ginseng harvesters, the following information about evaluating site quality for reintroductions or agroforestry:

i. Determine the land-use history of the forest as this may influence the success of the reintroduction project. Older sites with less historic disturbance may be a better location to reintroduce ginseng.

ii. Choose a site that will not experience land-use change in the near future, such as timbering and surface mining.

iii. Select reintroduction sites that are isolated to avoid poaching. Do not talk about the location of your ginseng patch after planting.

iv. Develop a deer management plan to protect the sites from deer browse.

$\mathrm{v}$. The forest should be mature with a mostly closed canopy in the overstory, a developed mid-story, and understory. If the understory is mostly invasive plant species, grass, or weedy plants, 
ginseng may not grow as well. Conduct yearlong monitoring of the site, and mark locations that hold water or that have ephemeral springs. Ginseng grows best in moist, but not wet soils.

vi. Evaluate soil quality by getting the soil professionally tested. Soil $\mathrm{pH}$ and calcium levels are important to evaluate before reintroducing ginseng. Soil $\mathrm{pH}$ should range between 5 to 7 , and higher levels of calcium (over 4,000 kg/hectare) may result in the project success.

vii. Use ginseng roots, rather than seeds, if possible. Use ginseng that is genetically similar to the ginseng growing in the area.

viii. When planting ginseng roots, avoid sites with 'contra-indicators': wild sarsaparilla (Aralia nudicaulis), red maple (Acer rubrum), black birch (Betula lenta), or spicebush (Liriodendron benzoin). If $B$. lenta is present, make sure mayapple (Podophyllum peltatum) is present at the site, as well. Otherwise, choose a different location to introduce your roots.

ix. If possible, plant ginseng roots within 10 meters of a large tulip poplar tree (Liriodendron tulipifera.)

x. In late August, plant all of the seeds that the introduced ginseng plants produce $(2 \mathrm{~cm}$ down) near the parent plant, and cut the tops off all of your plants. This will reduce poaching and increase the number of plants in the long-term. 


\section{References}

Bailey, B. 1999. Social and economic impacts of wild harvested products. West Virginia University.

Burkhart, E. P., M. G. Jacobson, and J. Finley. 2012. A case study of stakeholder perspective and experience with wild American ginseng (Panax quinquefolius) conservation efforts in Pennsylvania, U.S.A .: limitations to a CITES driven, topdown regulatory approach. Biodiversity \& Conservation.

Garibaldi, A., and N. Turner. 2004. Cultural Keystone Species : Implications for Ecological Conservation and Restoration. Ecology And Society 9.

Gragson, T. L., and P. V. Bolstad. 2006. Land use legacies and the future of southern Appalachia. Society and Natural Resources 19:175-190.

Hruska, A. M., S. Souther, and J. B. McGraw. 2014. Songbird Dispersal of American ginseng (Panax quinquefolius). Ecoscience 21:46-55.

Hufford, M. 2002. Reclaiming the commons: Narratives of progress, preservation, and ginseng. Pages 100-120 in B. J. Howell, editor. Culture, Environment, and Conservation in the Appalachian South. Chicago, IL.

McGraw, J. B., A. E. Lubbers, M. Van der Voort, E. H. Mooney, M. A. Furedi, S. Souther, J. B. Turner, and J. Chandler. 2013. Ecology and conservation of ginseng (Panax quinquefolius) in a changing world. Annals of the New York Academy of Sciences: The Year in Ecology and Conservation Biology:1-30.

Pennisi, E. 2015. Second act. Science 349:810-813.

Pulgar-Vidal, M., B. Monteferri, and J. L. Dammert. 2010. Trade-offs between conservation and extractive industries. Pages 233-252 in N. Leader-Williams, W. M. Adams, and R. J. Smith, editors. Trade-offs in Conservation: Deciding what to save. 1st edition. Blackwell Publishing Ltd, Somerset, NJ.

Roth, I., and H. Lindorf. 2002. South American medicinal plants: Botany, remedial properties and general use. Springer Science \& Business Media.

Smith, W. B., P. D. Miles, J. S. Vissage, and S. A. Pugh. 2004. Forest resources of the United States, 2002. St. Paul, Minnesota.

Ticktin, T. 2004. The ecological implications of harvesting non-timber forest products. Journal of Ecology 41:11-21.

Ticktin, T. 2005. Applying a metapopulation framework to the management and conservation of a non-timber forest species. Forest Ecology and Management 206:249-261. 
Turner, J. B., and J. B. McGraw. 2015. Can putative indicator species predict habitat quality for American ginseng? Ecological Indicators 57:110-117. 


\section{Appendix: A. Ginseng Harvester Survey}

The number of survey participants that selected a certain answer is shown in the parentheses.

What is your employment status?:

unemployed (10)

part-time (less than 40 hours a week) (2)

full-time (40 hours a week) (16)

retired (7)

What is your Gender?:

male (25)

female (10)

What is your highest level of education?:

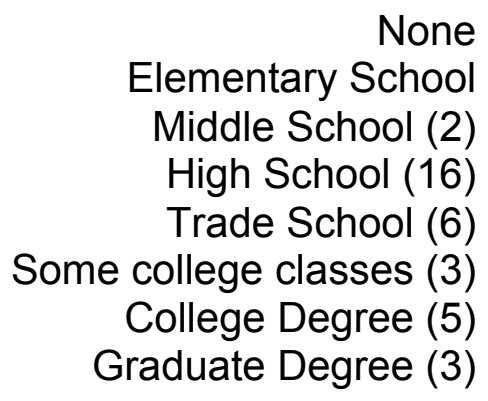

What Political Party do you agree with?:

\footnotetext{
Democrat (12)

Mountain Party

Republican (10)

Libertarian

Tea Party

Independent (2)

None (11)
}

What is your age group?: 
What county and state did you spend a majority of your childhood?:

County:

State:

Which county and state do you currently live?:

County:

State:

What is your household income level?:

$$
\begin{array}{r}
\text { less than } \$ 15,000(4) \\
\$ 15,001-\$ 30,000(4) \\
\$ 30,001-\$ 45,000(8) \\
\$ 45,001-\$ 60,000(6) \\
\$ 60,001-\$ 75,000(4) \\
\text { over } \$ 75,000(6)
\end{array}
$$

How important are outdoor activities (hunting, fishing, hiking, etc) to you?:

Extremely Important (25)

Important (8)

Neutral (1)

Not Important (1)

Extremely Not Important

Please rank the following political issues in order of importance to you (with 1 being most important and 7 being the least important):

$$
\begin{array}{r}
\text { Foreign policy } \\
\text { Climate change } \\
\text { Sustainable Use of Resources } \\
\text { Energy Independence } \\
\text { Unemployment } \\
\text { Conservation of habitat } \\
\text { National Security }
\end{array}
$$

I appreciate the forest because I enjoy it with my family and friends:

Strongly Agree (26) Agree (8) Neutral (1)

Disagree

Strongly Disagree 
Please rank the reasons you like the forest (1 as your top reason, 3 as your last reason):

Economic Value

Natural Beauty

Recreation

Have you used, or are you currently using, ginseng for medicinal purposes?:

Yes (5)

No (30)

How many people do you know that use ginseng for medicinal purposes?:

How many people do you know that harvest ginseng and sell it?:

How many people do you know that harvest ginseng and use it for medicine?:

I am aware of environmental issues:

I consider myself to know a lot about the environment:

Strongly Agree (15)

Agree (14)

Neutral (5)

Disagree (1)

Strongly Disagree

Strongly Agree (11)

Agree (20)

Neutral (3)

Disagree (1)

Strongly Disagree

I know about ginseng's economic value:

I know about ginseng's cultural value:

Yes (31)

No (4)

Yes (30)

No (5)

How would you rate your ability at identifying ginseng?:

\author{
Very strong (15) \\ Strong (12) \\ Okay (6) \\ Weak (2) \\ Very weak
}


Please identify Ginseng out of the following four plants: (28 correctly identified ginseng as ' $\mathrm{C}$ ')
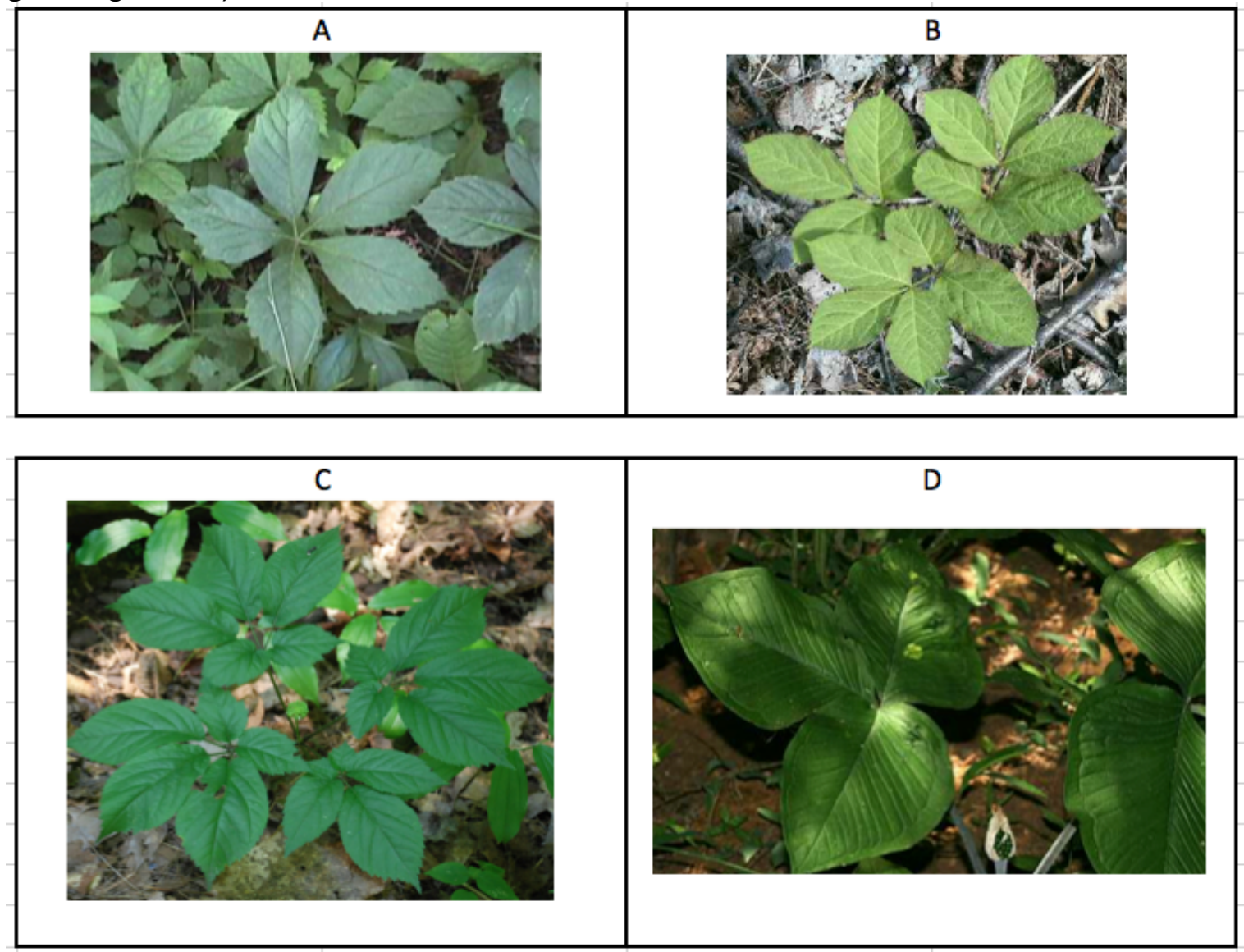

Ginseng is an internationally important plant:

$$
\begin{array}{r}
\text { Strongly Agree (21) } \\
\text { Agree (13) } \\
\text { Neutral (1) } \\
\text { Disagree } \\
\text { Strongly Disagree } \\
\text { Strongly Agree (21) } \\
\text { Agree (12) } \\
\text { Neutral (2) } \\
\text { Disagree } \\
\text { Strongly Disagree }
\end{array}
$$

Ginseng is valuable for Asian Medicine:

Ginseng could go extinct with how people currently harvest ginseng:

Strongly Agree (18)

Agree (6)

Neutral (8)

Disagree (2)

Strongly Disagree (1) 
Ginseng should be conserved for future generations:

Strongly Agree (17)

Agree (10) Neutral (7)

Disagree (1)

Strongly Disagree

Ginseng should be sustainably harvested, so it will be available for future generations:

Strongly Agree (17)

Agree (12)

Neutral (5)

Disagree (1)

Strongly Disagree

It does not matter if ginseng is around for future generations:

Strongly Agree
Agree (2)
Neutral (6)
Disagree (4)
Strongly Disagree (23)

Surface mining reduces the amount of ginseng found in Appalachia:

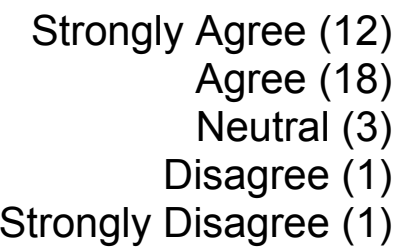

Surface mining reduces habitat for native animals and plants:

Strongly Agree (14)
Agree (16)
Neutral (3)
Disagree (1)
Strongly Disagree (1)

Surface mines should be reclaimed into forests, rather than pasture:

Strongly Agree (12)

Agree (11)

Neutral (11)

Disagree (1)

Strongly Disagree 
I am concerned about health problems that arise due to surface mining:

Strongly Agree (6)

Agree (11)

Neutral (7)

Disagree (7)

Strongly Disagree (3)

It is more important to having surface mining jobs now, than having medicinal plants around in the future:

Strongly Agree (1)

Agree (8)

Neutral (11)

Disagree (12)

Strongly Disagree (2)

The process of surface mining should continue without any changes in policy or regulation:

Strongly Agree (1)
Agree (4)
Neutral (8)
Disagree (15)
Strongly Disagree (6)

I trust the mining companies to properly reclaim the land:

Strongly Agree (3)

Agree (7)

Neutral (9)

Disagree (6)

Strongly Disagree (10)

I trust mining companies to have the best interest of the public in mind:

Strongly Agree (3) Agree (6) Neutral (4)

Disagree (10)

Strongly Disagree (12)

If there is an environmental problem, I know the mining companies will fix it:

Strongly Agree (3)

Agree (4)

Neutral (7)

Disagree (11)

Strongly Disagree (10) 
Members of my immediate family are coal miners and work/have worked at a surface mine:

Members of my extended family are coal miners and work/have worked at a surface mine:

Close friends are coal miners and they work/have worked at a surface mine:

Yes (31)

No (4)

Conserving resources is only good when it is useful to me:

Strongly Agree

Agree (2)

Neutral (4)

Disagree (12)

Strongly Disagree (17)

Conservation of natural resources is important to my everyday life:

Strongly Agree (12)

Agree (19)

Neutral (4)

Disagree

Strongly Disagree

There should be more conservation management of resources in Appalachia:

Strongly Agree (13)

Agree (14)

Neutral (4)

Disagree (2)

Strongly Disagree (1)

Sustainable management of resources is important: 
I am concerned about the future of the forests:

\author{
Strongly Agree (16) \\ Agree (12) \\ Neutral (6) \\ Disagree (1) \\ Strongly Disagree
}

I appreciate the forest and the land ONLY because of its monetary value:

Strongly Agree (1) Agree (1) Neutral (1)

Disagree (15)

Strongly Disagree (17)

I appreciate the forest and the land because they exist, and are therefore important:

Strongly Agree (11) Agree (11) Neutral (7) Disagree (4) Strongly Disagree (2)

I consider my land and property to be a long-term investment:

Strongly Agree (22)

Agree (11)

Neutral (2)

Disagree

Strongly Disagree

I consider my land and my property to be a short-term investment ONLY:

Strongly Agree Agree (3) Neutral (3)

Disagree (11)

Strongly Disagree (17)

I trust the government to make the best policies for me:

\author{
Strongly Agree (2) \\ Agree (3) \\ Neutral (5) \\ Disagree (7) \\ Strongly Disagree (18)
}


The Environmental Protection Agency protects the Appalachian region:

Strongly Agree (4)

Agree (7)

Neutral (10)

Disagree (7)

Strongly Disagree (7)

I trust scientists to be honest:

Strongly Agree (7)

Agree (10)

Neutral (8)

Disagree (5)

Strongly Disagree (5)

Scientists cannot be trusted:

Strongly Agree (4)

Agree (5)

Neutral (9)

Disagree (13)

Strongly Disagree (4)

I believe scientists understand environmental issues:

Strongly Agree (7)

Agree (13)

Neutral (10)

Disagree (5)

Strongly Disagree

Environmentalists are people who want to protect and preserve the forest:

Strongly Agree (13)

Agree (13)

Neutral (5)

Disagree (3)

Strongly Disagree (1)

Environmentalists are people who have the best interest of society at heart:

Strongly Agree (5)

Agree (5)

Neutral (12)

Disagree (10)

Strongly Disagree (3) 
Conservationists are people who want to protect and preserve the forest:

Strongly Agree (16)

Agree (12)

Neutral (6)

Disagree (1)

Strongly Disagree

Conservationists are people who have society's best interest in mind:

Strongly Agree (5)

Agree (13)

Neutral (11)

Disagree (5)

Strongly Disagree (1)

Scientists are people who have society's best interest in mind:

\author{
Strongly Agree (4) \\ Agree (9) \\ Neutral (10) \\ Disagree (8) \\ Strongly Disagree (4)
}

Government Environmental officials are people who have society's best interest in mind:

Strongly Agree (1) Agree (10)

Neutral (10)

Disagree (5)

Strongly Disagree (8)

Government Environmental Officials cannot be trusted to make good decisions, based on science, for the environment:

Strongly Agree (3)

Agree (9)

Neutral (12)

Disagree (8)

Strongly Disagree (1) 
Please rank the following in order of how much you trust them (1 is the most trustworthy, 7 is the least trustworthy):

\author{
Forestry Official \\ Scientist \\ City Mayor \\ Teacher \\ Pastor \\ Radio or TV \\ Non Profit Agency
}

Parks and Preserves are owned by everyone:

\author{
Strongly Agree (3) \\ Agree (7) \\ Neutral (4) \\ Disagree (10) \\ Strongly Disagree (11)
}

I feel like individuals can make a difference:

$$
\begin{array}{r}
\text { Strongly Agree (16) } \\
\text { Agree (15) } \\
\text { Neutral (2) } \\
\text { Disagree (1) } \\
\text { Strongly Disagree (1) }
\end{array}
$$

I believe that I have a say in environmental issues in Appalachia:

Strongly Agree (5)

Agree (13)

Neutral (5)

Disagree (7)

Strongly Disagree (5)

I know where the ginseng goes when I sell it to the root dealer:

Strongly Agree (3)

Agree (16)

Neutral (7)

Disagree (7)

Strongly Disagree (2)

I care about where ginseng goes when I sell it to the root dealer.

Strongly Agree (4)

Agree (16)

Neutral (7)

Disagree (7)

Strongly Disagree (1) 
I would rather get money for ginseng harvest now, rather than ensuring that ginseng will be around for the future:

Strongly Agree

Agree (3)

Neutral (11)

Disagree (11)

Strongly Disagree (10)

I would rather ginseng be around for the future, over profiting from ginseng harvest now:

Always (17)

$75 \%$ of the time (2)

$50 \%$ of the time (13)

$25 \%$ of the time (1)

Never (2)

I plant the seeds when I harvest ginseng:

Always (29)

$75 \%$ of the time (2)

$50 \%$ of the time (2)

$25 \%$ of the time

Never (2)

From 1980 to 2010, what month is the earliest you have ever harvested ginseng?:

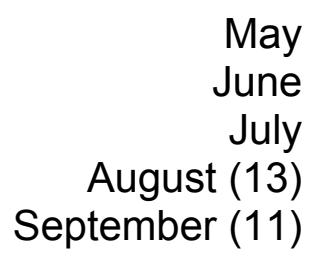

From 2010 to now, what month is the earliest you have ever harvested ginseng?:

May June July (7)

August (2)

September (22)

Would you still harvest ginseng if the government said you couldn't harvest ginseng?:

Yes (6)

Maybe (6)

No (23) 
I plant the seeds when I harvest ginseng, in the same area of the parent plant:

Always (30)

$75 \%$ of the time

$50 \%$ of the time (1)

$25 \%$ of the time (2)

Never (2)

I take the seeds when I harvest ginseng, and plant it in a different area, further away:

Always

$75 \%$ of the time (2)

$50 \%$ of the time (2)

$25 \%$ of the time (3)

Never (28)

I have harvested in the following places (circle all that apply):

Personal Private Land

Property of a friend or family member (invited)

State Parks

National Parks

State Forests

National Forests

Nature Preserves

Private property (without owner's knowledge)

What is the weight of the largest root you have ever harvested?:

How many prongs did the largest root you ever harvested have?:

One

Two (1)

Three (11)

Four (22)

How many prongs did the smallest plant you have ever harvested have?:

One (5)

Two (17)

Three (12)

Four 
I harvest ginseng every

Year (17)

two years (5)

three years (1)

four years

five or more years $(7)$

I no longer harvest ginseng (3)

How many people have you taught to harvest ginseng?:

How much money did you get per pound (on average) for your ginseng roots last year?:

There is __ ginseng present, as compared to levels from when you first started to harvest.:

a lot more (4) more (2)

the same (10) less (13)

a lot less (6)

How old were you when you started harvesting ginseng?:

Who taught you how to harvest ginseng, and in what county were you taught?:

family friend grandpa grandma mother father uncle aunt brother sister cousin self-taught Other 
Why do you harvest ginseng? (Rank in the order of importance, with 1 being most important and 5 being least important):

Extra money Time with family or friends Get outside Keep traditions alive The thrill of finding a big root

Think back to when you first started to harvest ginseng, and rank the order of importance. (Rank in the order of importance, with 1 being most important and 5 being least important):

Extra money Time with family or friends Get outside

Keep traditions alive The thrill of finding a big root

How much money did you make selling ginseng roots last year?:

How long have you harvested Ginseng? (circle the most appropriate time bracket):

Under 5 years

5 - 10 years

$10-15$ years

$16-20$ years

$21-30$ years

$31-40$ years

$41-50$ years

$51-60$ years

Do you harvest any other items from the forest? (circle):

Part 2: Rank them in order of your favorite (1 is favorite)

Blood Root
Yellow Root/Goldenseal
Ginger
Mayapple
Mushrooms
Moss
Walnuts
Black Cohosh
Ramps
Squirrels
Deer
Any sort of Trapping
Turkey




\section{Appendix: B. Ginseng Community Survey}

The number of survey participants that selected a certain answer is shown in the parentheses.

What is your employment status?:

unemployed (107)

part-time (less than 40 hours a week) (36)

full-time (40 hours a week) (131)

retired (26)

What is your Gender?:

male (101)

Female (196)

What is your highest level of education?:

None

Elementary School (2)

Middle School (7)

High School (143)

Trade School (8)

Some college classes (48)

College Degree (45)

Graduate Degree (50)

What Political Party do you agree with?:

What is your age group?:

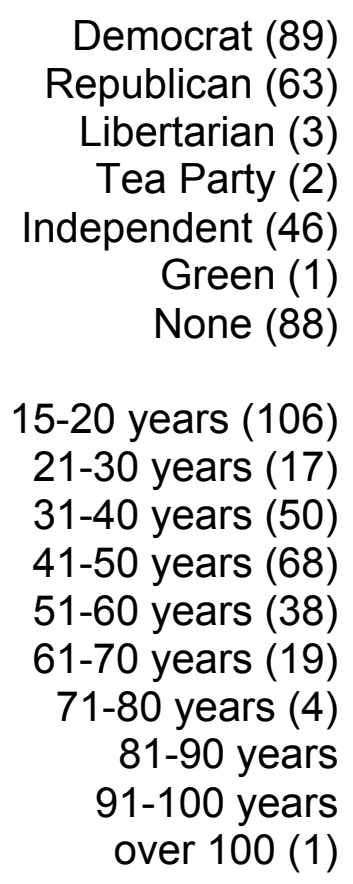


What county and state did you spend a majority of your childhood?:

County:

State:

Which county and state do you currently live?:

County:

State:

What is your household income level?:

$$
\begin{array}{r}
\text { less than } \$ 15,000(38) \\
\$ 15,001-\$ 30,000(60) \\
\$ 30,001-\$ 45,000(51) \\
\$ 45,001-\$ 60,000(53) \\
\$ 60,001-\$ 75,000(25) \\
\text { over } \$ 75,000(61)
\end{array}
$$

How important are outdoor activities (hunting, fishing, hiking, etc) to you?:

Extremely Important (96)

Important (126)

Neutral (59)

Not Important (17)

Extremely Not Important (6)

Please rank the following political issues in order of importance to you (with 1 being most important and 7 being the least important):

Foreign policy Climate change Sustainable Use of Resources

Energy Independence Unemployment Conservation of habitat National Security

I appreciate the forest because I enjoy it with my family and friends:

Strongly Agree (150)

Agree (103)

Neutral (41)

Disagree (8)

Strongly Disagree (2) 
Please rank the reasons you like the forest (1 as your top reason, 3 as your last reason):

Economic Value

Natural Beauty

Recreation

Have you used, or are you currently using, ginseng for medicinal purposes?:

Yes (42)

No (261)

How many people do you know that use ginseng for medicinal purposes?:

How many people do you know that harvest ginseng and sell it?:

How many people do you know that harvest ginseng and use it for medicine?:

I am aware of environmental issues:

I consider myself to know a lot about the environment:

$$
\begin{array}{r}
\text { Strongly Agree (50) } \\
\text { Agree (163) } \\
\text { Neutral (78) } \\
\text { Disagree (7) } \\
\text { Strongly Disagree (5) } \\
\text { Strongly Agree (37) } \\
\text { Agree (114) } \\
\text { Neutral (113) } \\
\text { Disagree (32) } \\
\text { Strongly Disagree (6) }
\end{array}
$$

I know about ginseng's economic value:

I know about ginseng's cultural value:

$$
\begin{array}{r}
\text { Yes (184) } \\
\text { No (119) } \\
\text { Yes (152) } \\
\text { No (149) }
\end{array}
$$

How would you rate your ability at identifying ginseng?: 
Please identify Ginseng out of the following four plants: (143 correctly identified ginseng as ' $C$ ')
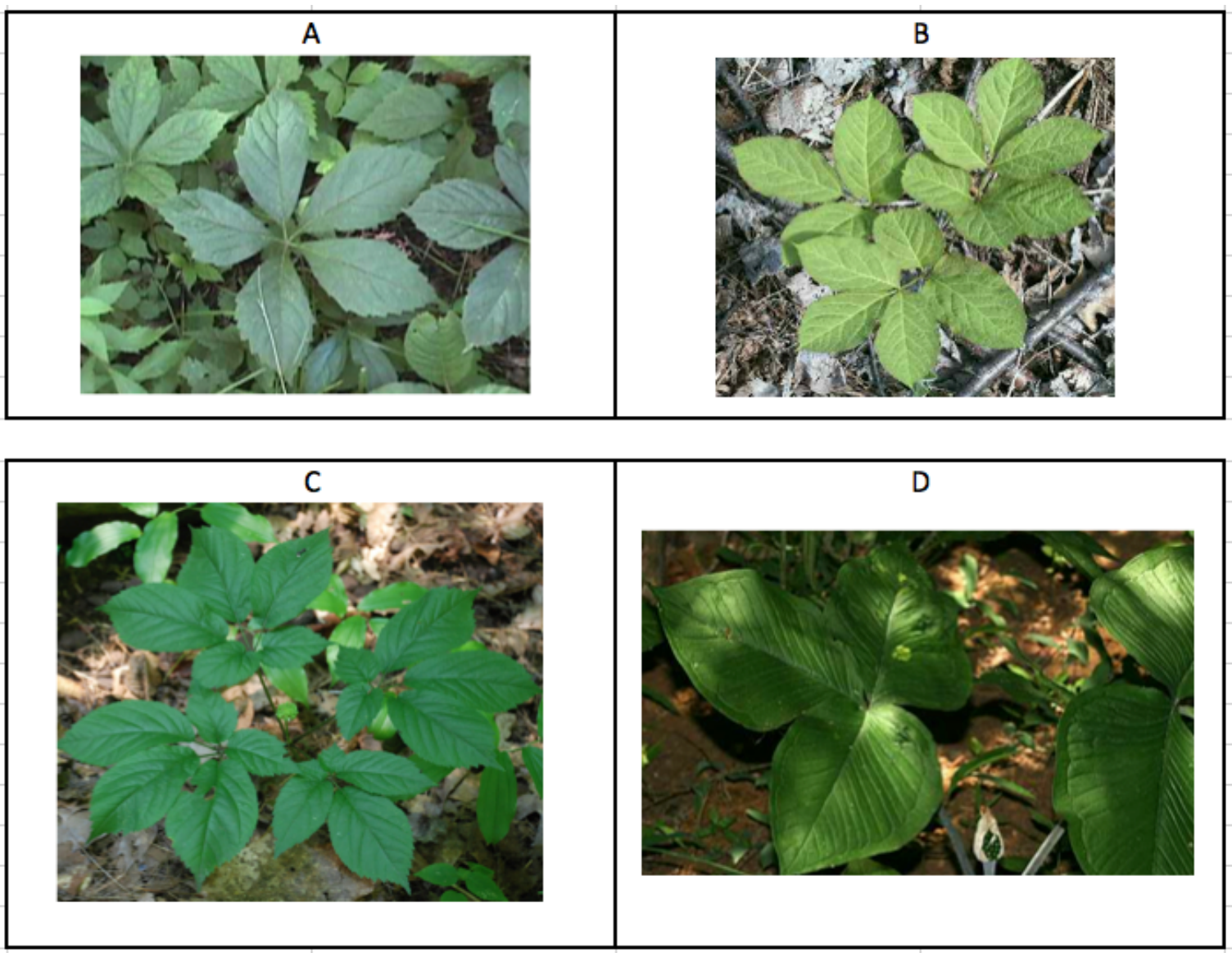

Ginseng is an internationally important plant:

Ginseng is valuable for Asian Medicine:

Strongly Agree (53) Agree (135) Neutral (107)

Disagree (7) Strongly Disagree

Strongly Agree (2) Agree (62) Neutral (122)

Disagree (114) Strongly Disagree (4) 
Ginseng should be conserved for future generations:

\author{
Strongly Agree (49) \\ Agree (158) \\ Neutral (86) \\ Disagree (7) \\ Strongly Disagree (3)
}

Ginseng could go extinct with how people currently harvest ginseng:

Strongly Agree (31)

Agree (112)

Neutral (128)

Disagree (25)

Strongly Disagree (5)

It does not matter if ginseng is around for future generations:

Strongly Agree (8)

Agree (10)

Neutral (62)

Disagree (148)

Strongly Disagree (75)

Ginseng should be sustainably harvested, so it will be available for future generations:

Strongly Agree (54)

Agree (154)

Neutral (84)

Disagree (6)

Strongly Disagree (3)

Surface mining reduces the amount of ginseng found in Appalachia:

Strongly Agree (27)

Agree (109)

Neutral (128)

Disagree (28)

Strongly Disagree (10)

Surface mining reduces habitat for native animals and plants:

Strongly Agree (46)

Agree (112)

Neutral (92)

Disagree (37)

Strongly Disagree (15) 
Surface Mines should be reclaimed into forests, rather than pasture:

Strongly Agree (35)

Agree (110)

Neutral (121)

Disagree (28)

Strongly Disagree (7)

I am concerned about health problems that arise due to surface mining:

Strongly Agree (40)

Agree (94)

Neutral (105)

Disagree (46)

Strongly Disagree (19)

It is more important to having surface mining jobs now, than having medicinal plants around in the future:

Strongly Agree (11) Agree (42)

Neutral (149)

Disagree (81)

Strongly Disagree (19)

The process of surface mining should continue without any changes in policy or regulation:

Strongly Agree (17)

Agree (35)

Neutral (120)

Disagree (107)

Strongly Disagree (24)

I trust the mining companies to properly reclaim the land:

Strongly Agree (28)

Agree (51)

Neutral (106)

Disagree (82)

Strongly Disagree (36)

I trust mining companies to have the best interest of the public in mind:

Strongly Agree (26)

Agree (56)

Neutral (92)

Disagree (85)

Strongly Disagree (45) 
If there is an environmental problem, I know the mining companies will fix it:

Strongly Agree (17)

Agree (46)

Neutral (106)

Disagree (93)

Strongly Disagree (41)

Members of my immediate family are coal miners and work/have worked at a surface mine:

Members of my extended family are coal miners and work/have worked at a surface mine:

Close friends are coal miners and they work/have worked at a surface mine:

Yes (215) No (85)

Conserving resources is only good when it is useful to me:

Strongly Agree (14) Agree (18) Neutral (64) Disagree (139) Strongly Disagree (68)

Conservation of natural resources is important to my everyday life:

Strongly Agree (69)

Agree (139)

Neutral (82)

Disagree (11)

Strongly Disagree

There should be more conservation management of resources in Appalachia:

Strongly Agree (53)

Agree (131)

Neutral (103)

Disagree (8)

Strongly Disagree (7) 
Sustainable management of resources is important:

Strongly Agree (68)

Agree (163)

Neutral (66)

Disagree (4)

Strongly Disagree

I am concerned about the future of the forests:

Strongly Agree (83)

Agree (137)

Neutral $(65)$

Disagree (14)

Strongly Disagree (4)

I appreciate the forest and the land ONLY because of its monetary value:

Strongly Agree (9)

Agree (25)

Neutral (59)

Disagree (139)

Strongly Disagree (70)

I appreciate the forest and the land because they exist, and are therefore important:

Strongly Agree (65)

Agree (158)

Neutral (58)

Disagree (16)

Strongly Disagree (6)

I consider my land and property to be a long-term investment:

Strongly Agree (95)

Agree (135)

Neutral (55)

Disagree (11)

Strongly Disagree (6)

I consider my land and my property to be a short-term investment ONLY:

Strongly Agree (6) Agree (16)

Neutral (58)

Disagree (158)

Strongly Disagree (65) 
I trust the government to make the best policies for me:

Strongly Agree (12)

Agree (24)

Neutral (71)

Disagree (106)

Strongly Disagree (89)

The Environmental Protection Agency protects the Appalachian region:

Strongly Agree (10) Agree (69) Neutral (157)

Disagree (42)

Strongly Disagree (22)

I trust scientists to be honest:

Strongly Agree (12)

Agree (88)

Neutral (105)

Disagree (72)

Strongly Disagree (25)

Scientists cannot be trusted:

Strongly Agree (19) Agree (33) Neutral (141) Disagree (95)

Strongly Disagree (14)

I believe scientists understand environmental issues:

Strongly Agree (19)

Agree (123)

Neutral (100)

Disagree (24)

Strongly Disagree (10)

Environmentalists are people who want to protect and preserve the forest:

Strongly Agree (36)

Agree (144)

Neutral (76)

Disagree (12)

Strongly Disagree (8) 
Environmentalists are people who have the best interest of society at heart:

Strongly Agree (18)

Agree (75)

Neutral (127)

Disagree (43)

Strongly Disagree (13)

Conservationists are people who want to protect and preserve the forest:

Strongly Agree (34)

Agree (140)

Neutral (83)

Disagree (17)

Strongly Disagree (2)

Conservationists are people who have society's best interest in mind:

Strongly Agree (22)

Agree (85)

Neutral (126)

Disagree (35)

Strongly Disagree (8)

Scientists are people who have society's best interest in mind:

Strongly Agree (16)

Agree (54)

Neutral (142)

Disagree (51)

Strongly Disagree (13)

Government Environmental officials are people who have society's best interest in mind:

Strongly Agree (2)

Agree (35)

Neutral (153)

Disagree (80)

Strongly Disagree (31)

Government Environmental Officials cannot be trusted to make good decisions, based on science, for the environment:

Strongly Agree (20)

Agree (52)

Neutral (177)

Disagree (43)

Strongly Disagree (9) 
Please rank the following in order of how much you trust them (1 is the most trustworthy, 7 is the least trustworthy):

\author{
Forestry Official \\ Scientist \\ City Mayor \\ Teacher \\ Pastor \\ Radio or TV \\ Non Profit Agency
}

Parks and Preserves are owned by everyone:

Strongly Agree (3)

Agree (39)

Neutral (95)

Disagree (120)

Strongly Disagree (44)

I feel like individuals can make a difference:

$$
\begin{array}{r}
\text { Strongly Agree (100) } \\
\text { Agree (154) } \\
\text { Neutral (40) } \\
\text { Disagree (7) } \\
\text { Strongly Disagree (1) }
\end{array}
$$

I believe that I have a say in environmental issues in Appalachia:

Strongly Agree (34)

Agree (105)

Neutral (90)

Disagree (60)

Strongly Disagree (13) 

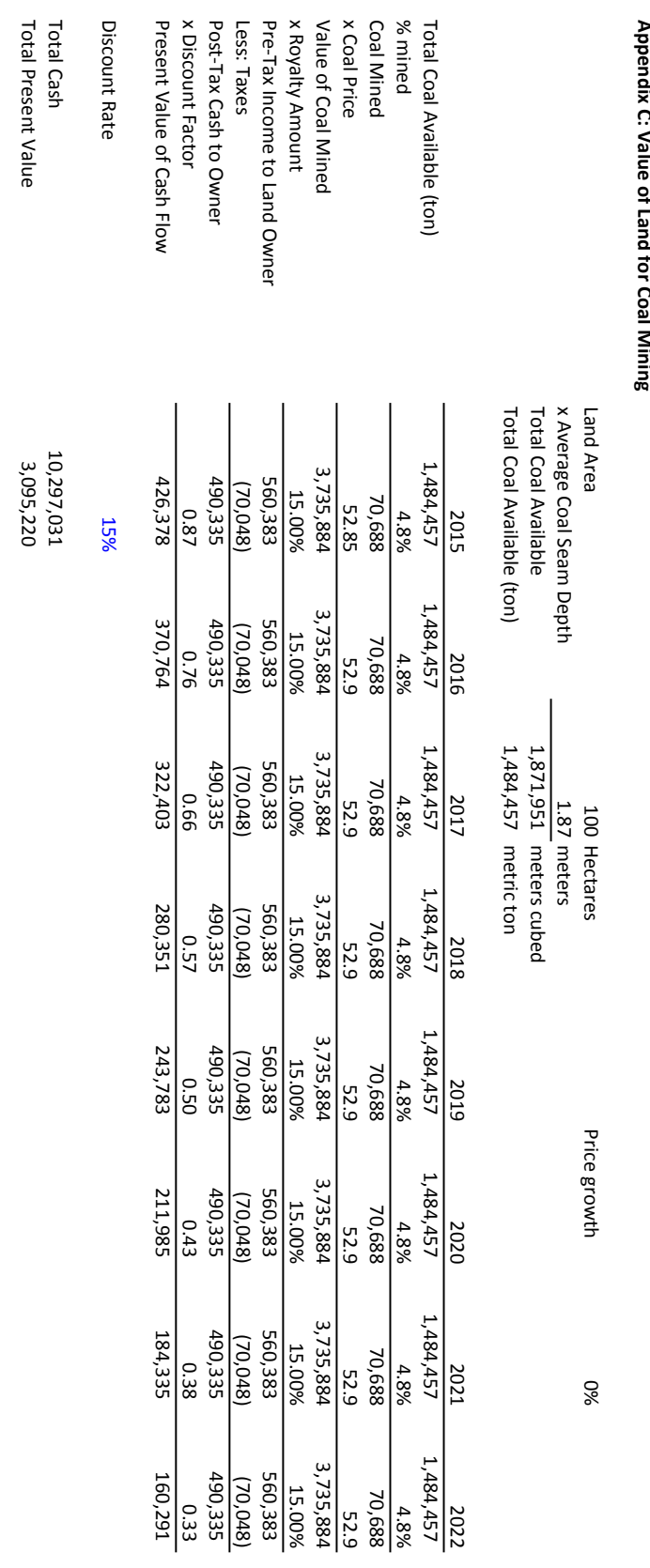

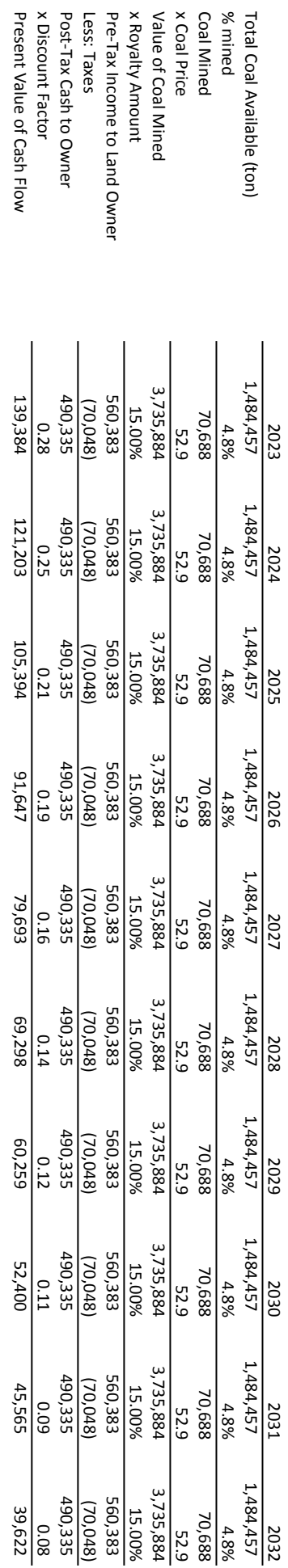

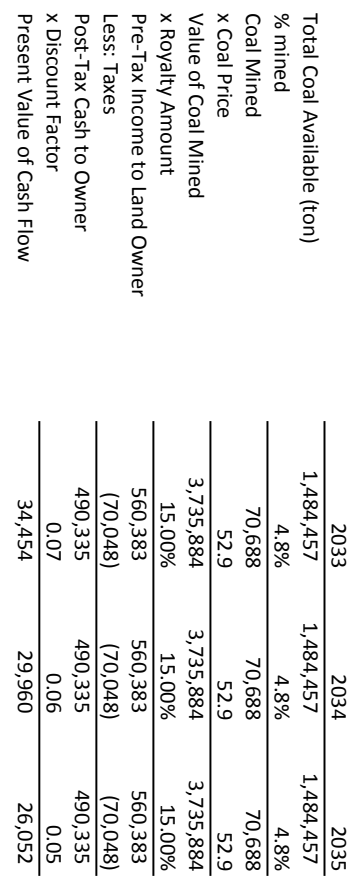


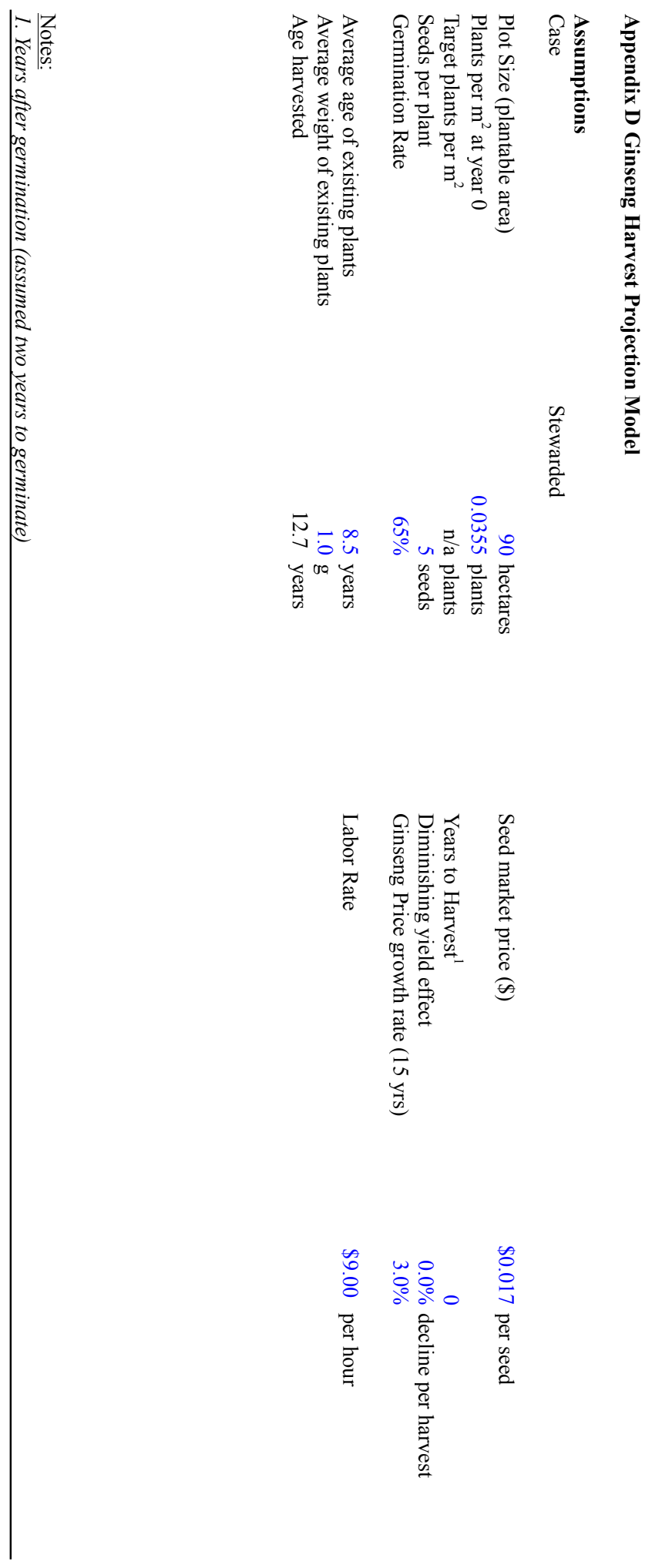




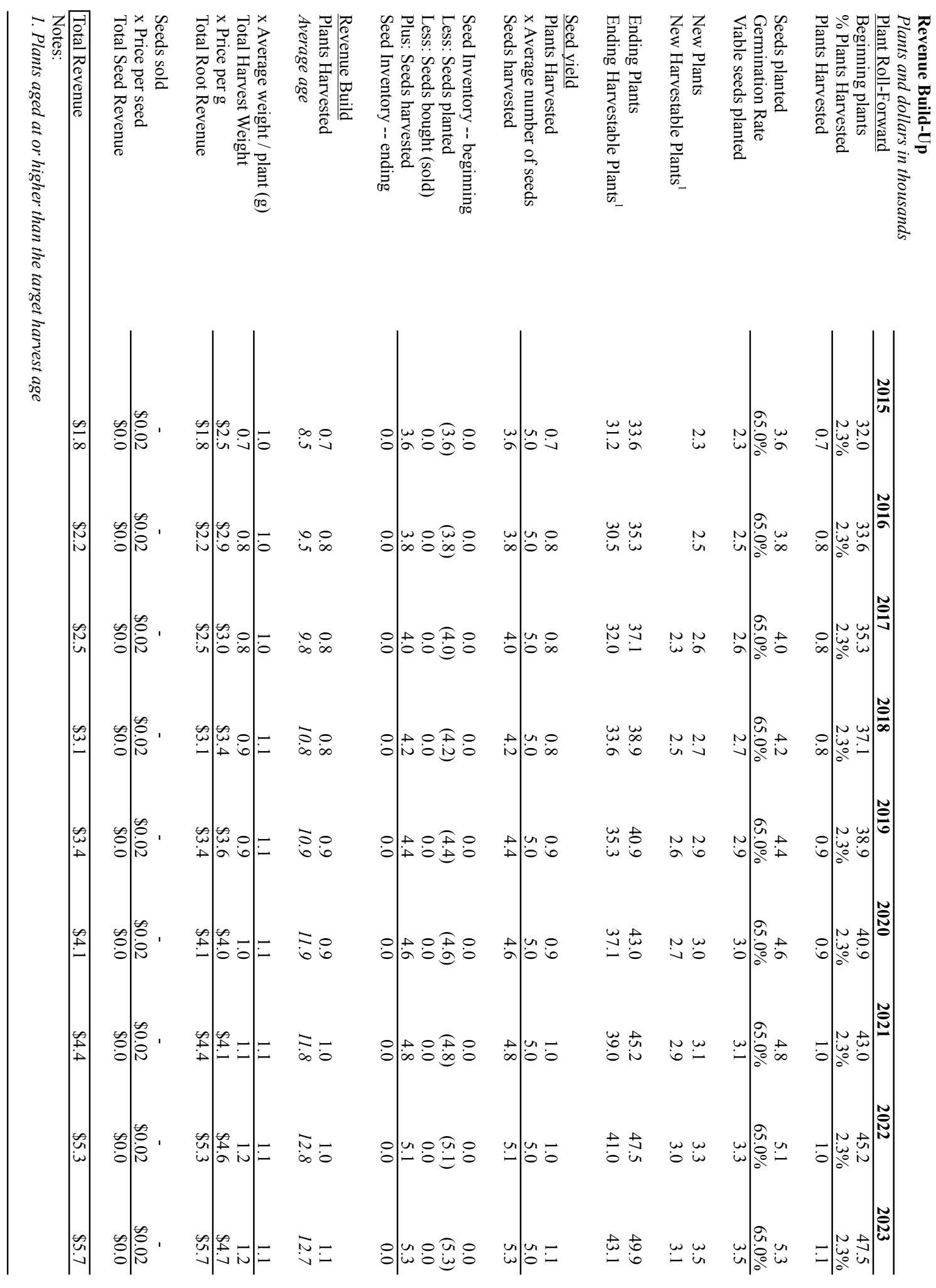




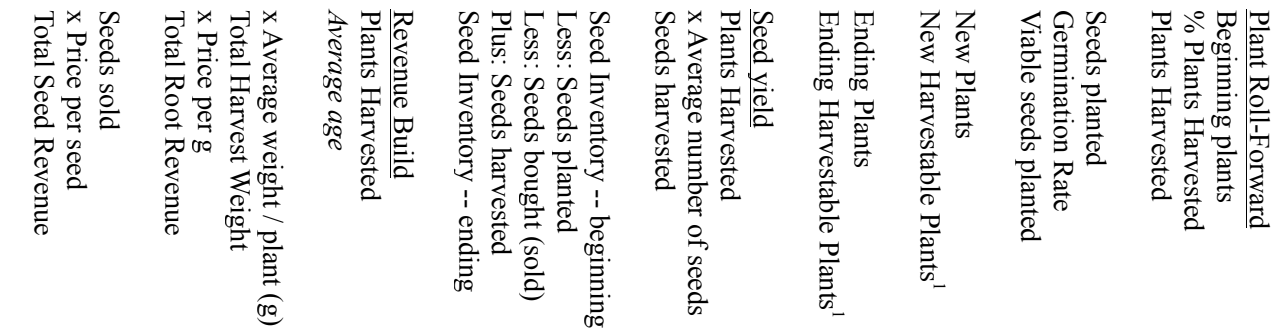

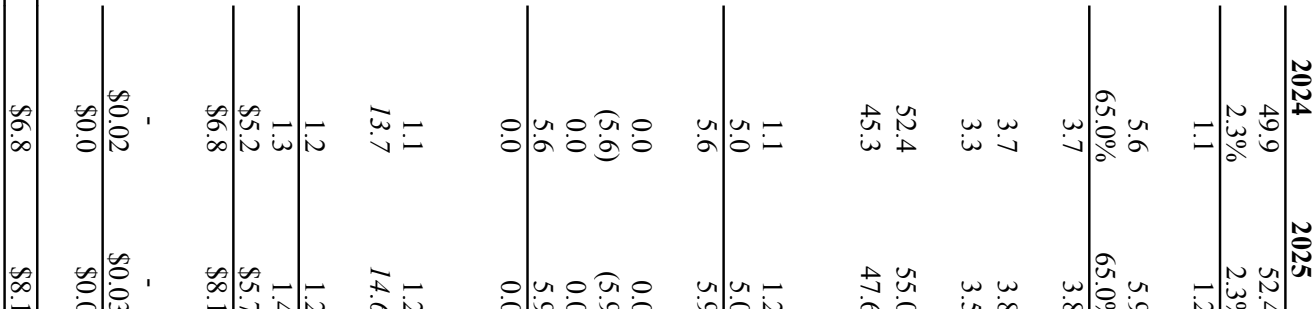

$\Rightarrow$ a

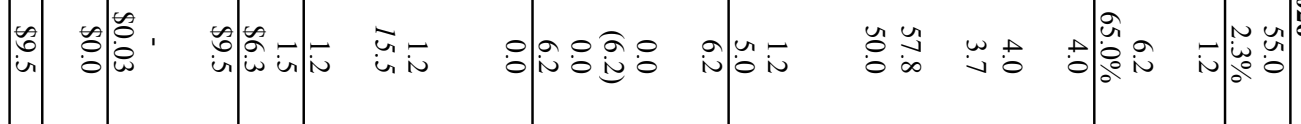

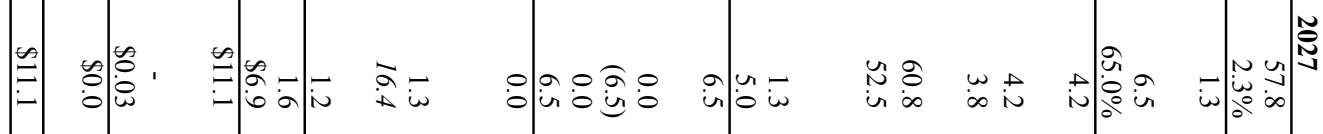

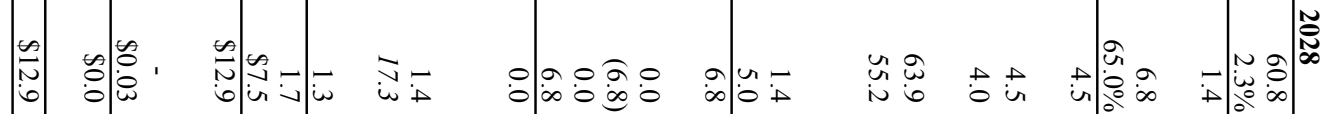

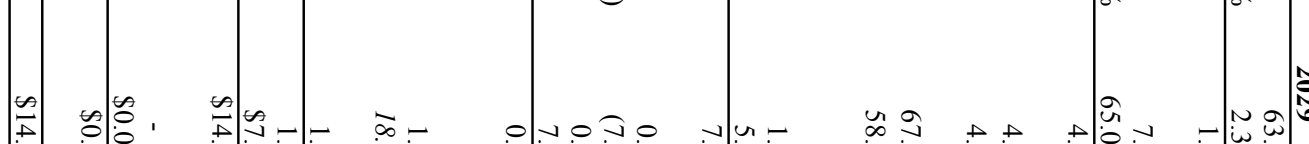

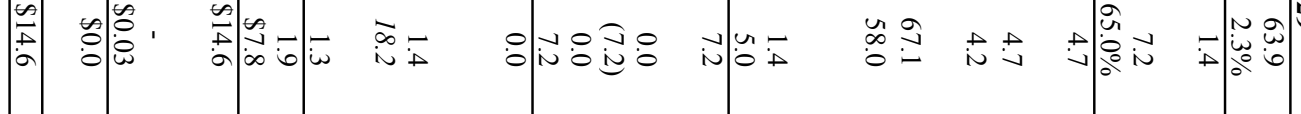

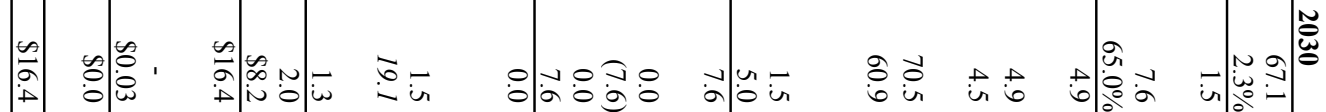

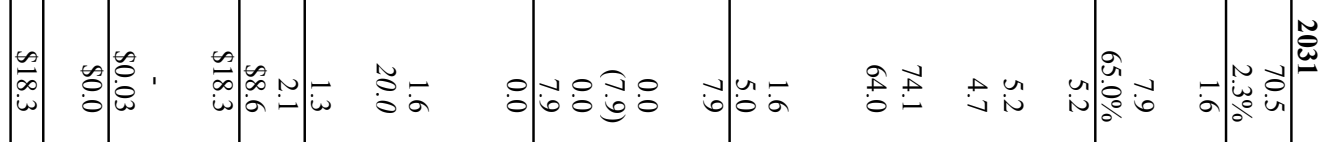

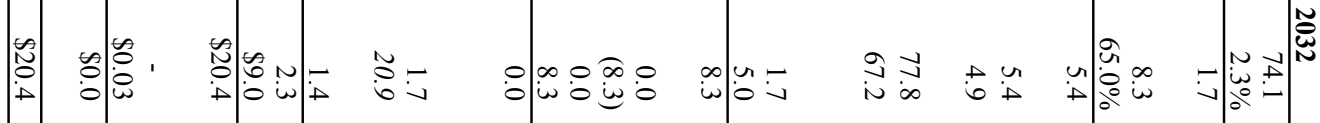

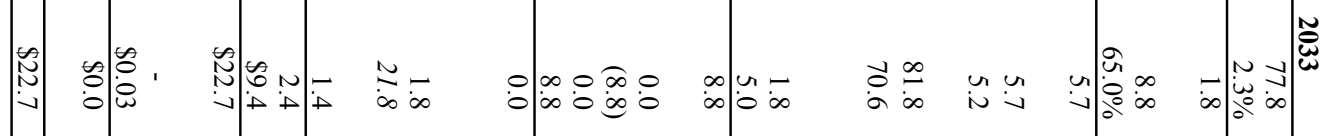

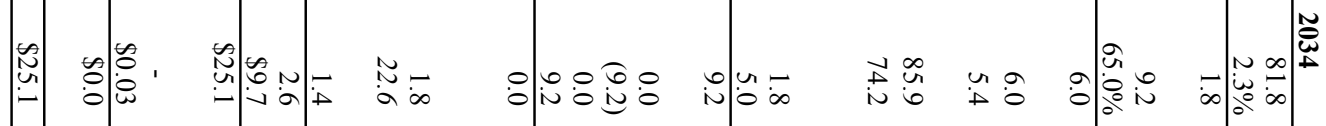

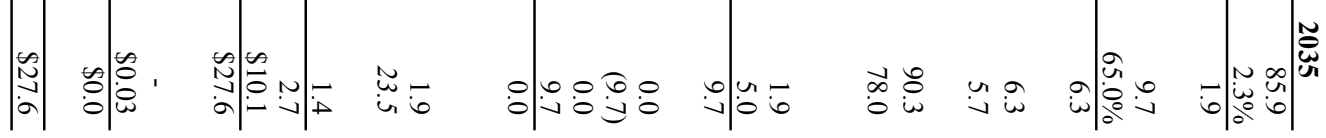




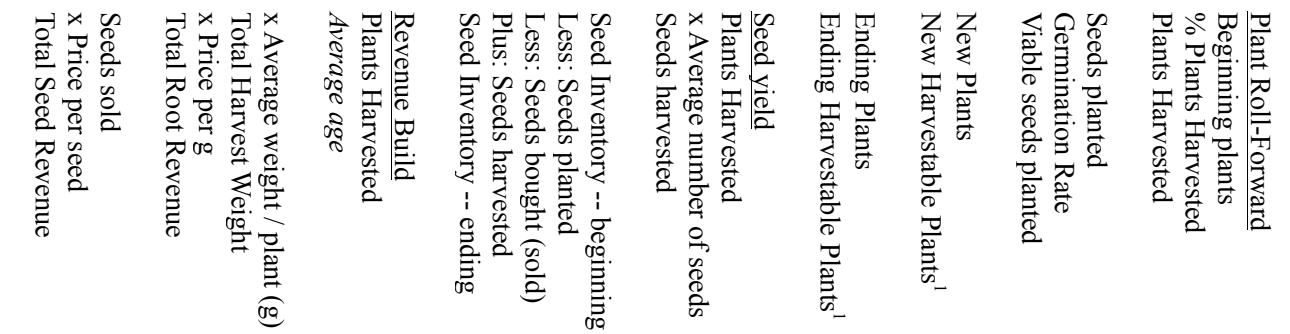

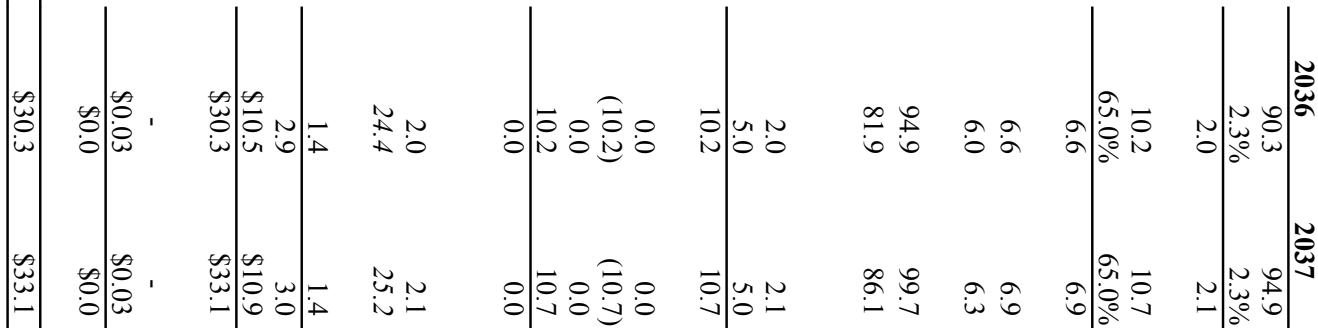

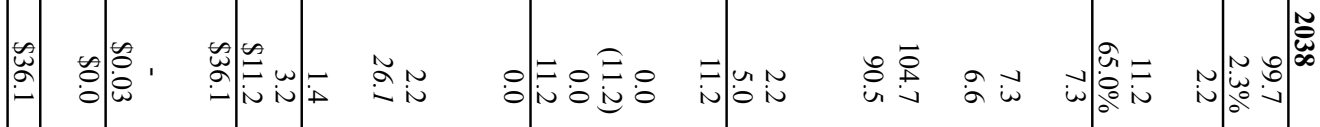

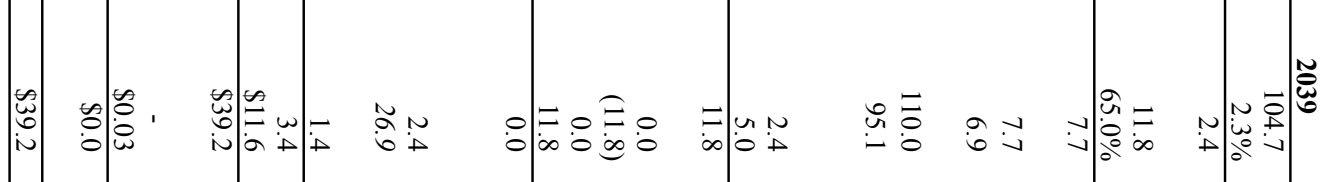

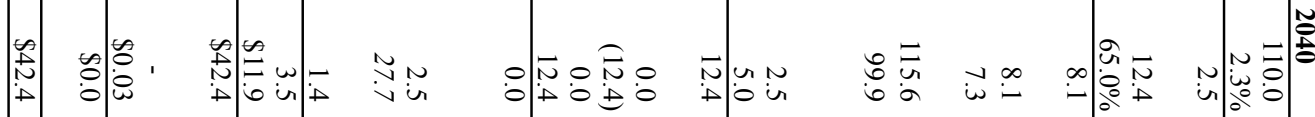

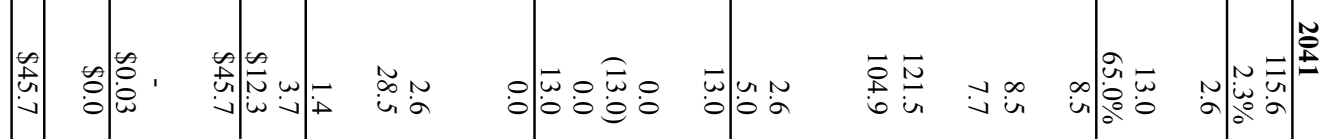

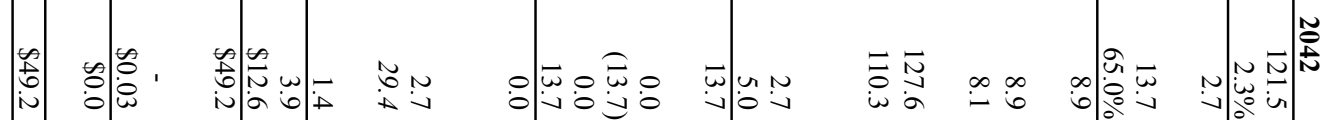

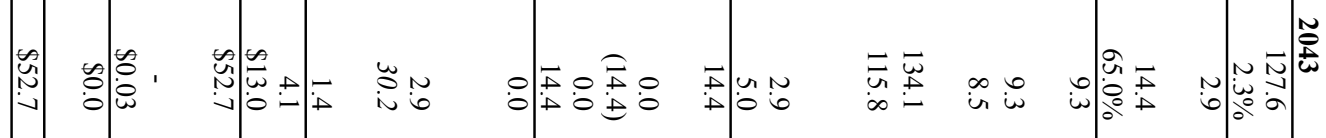

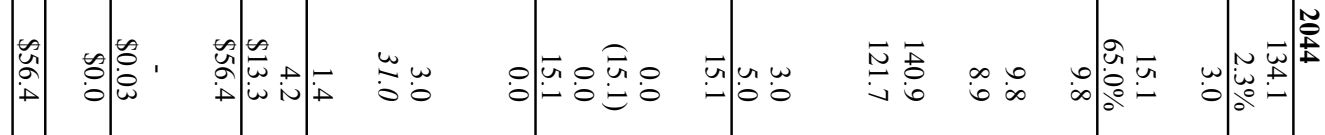

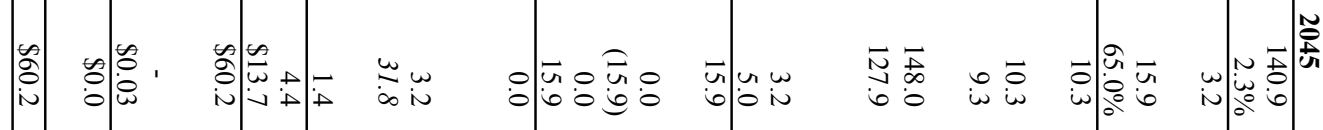

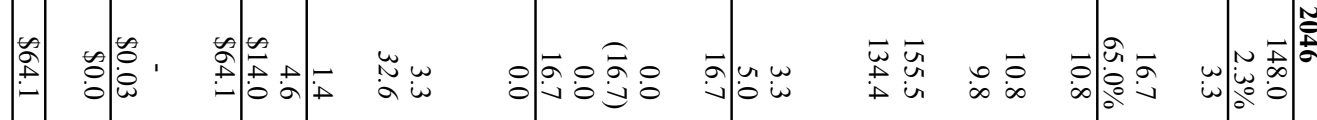

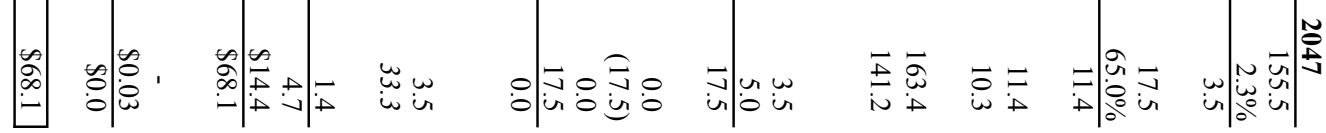




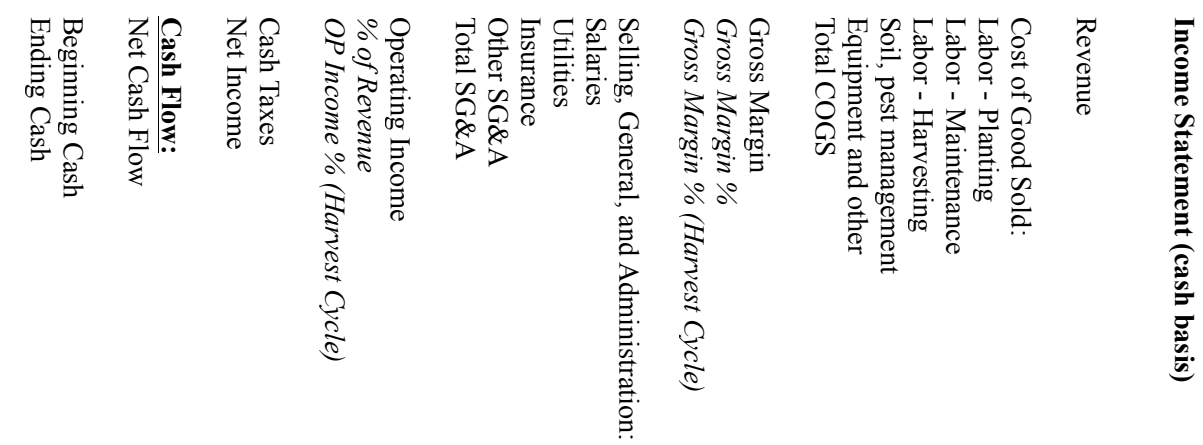

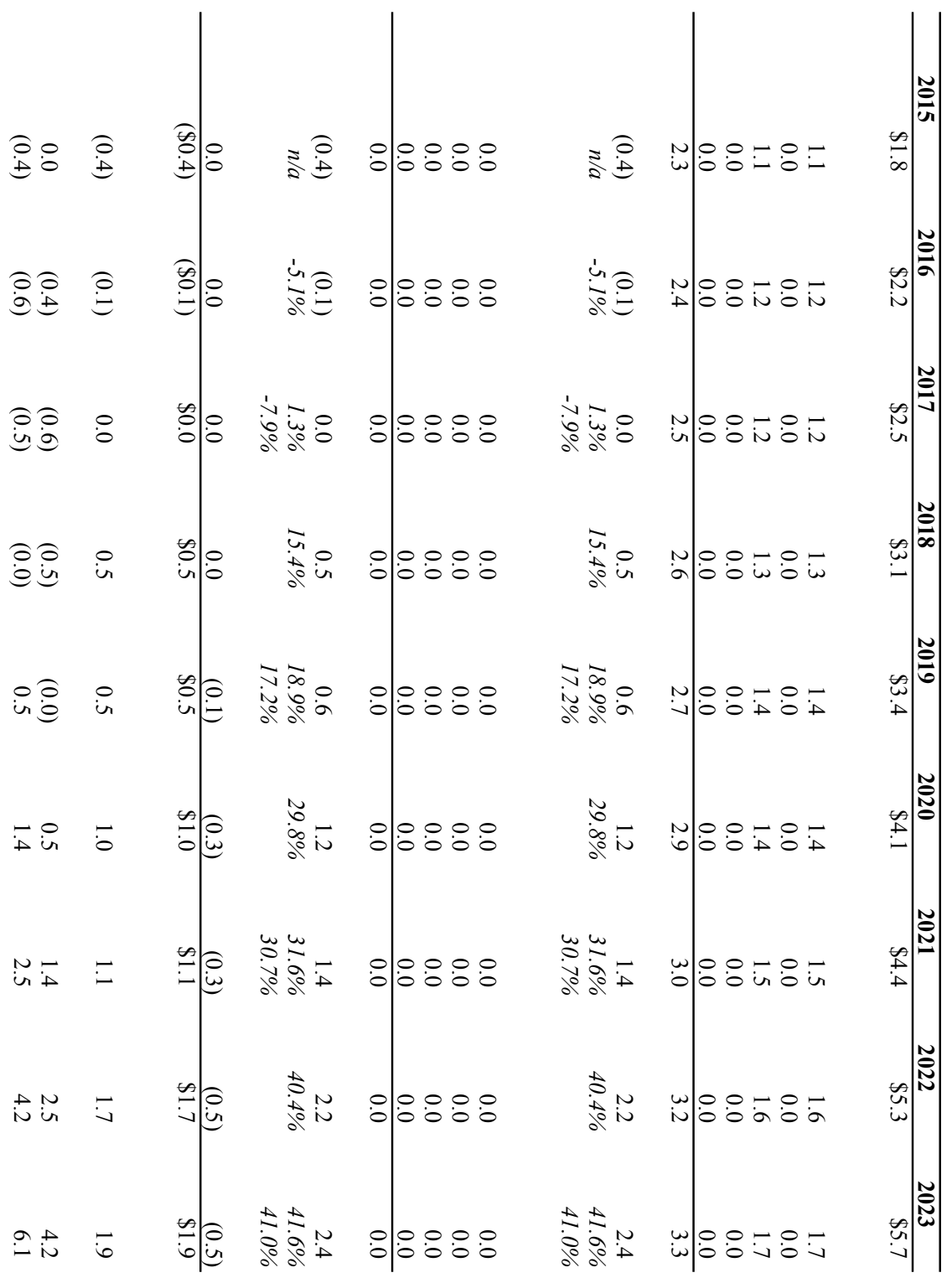




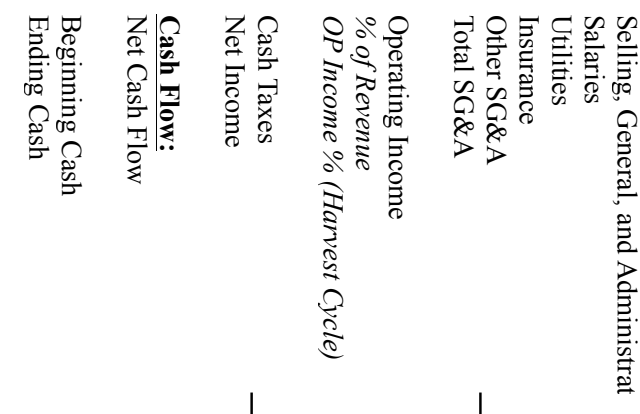

$\infty a n$ n nan

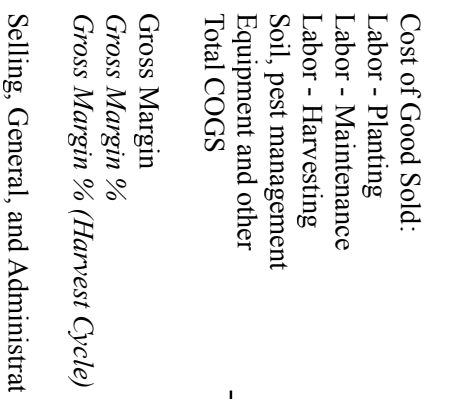

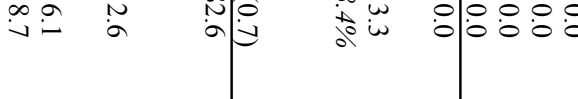

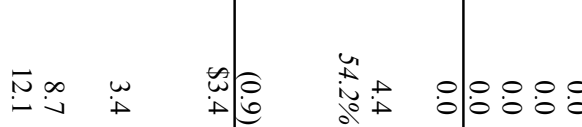

讨

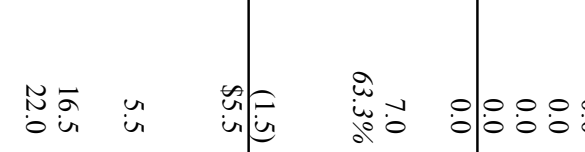

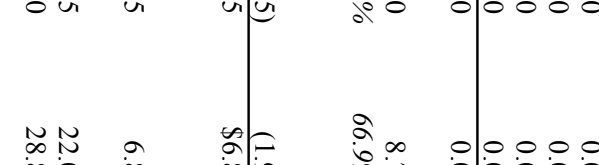

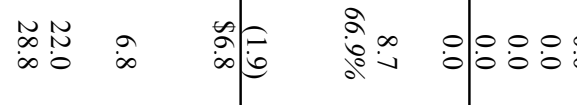

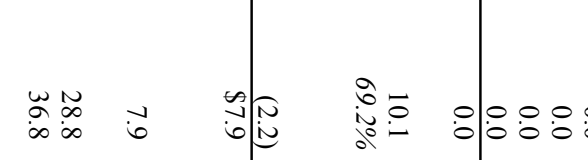

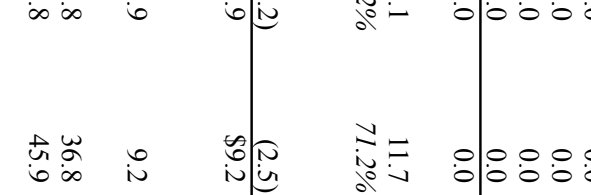

bis is iv in div

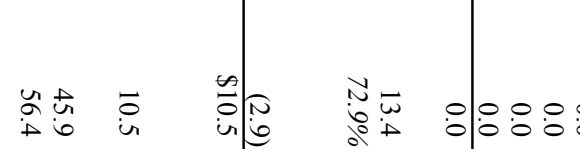

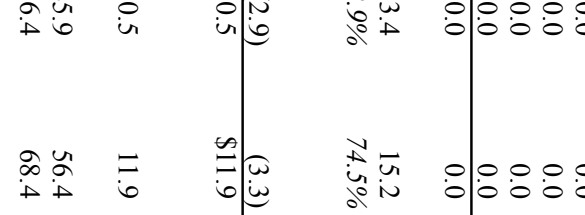

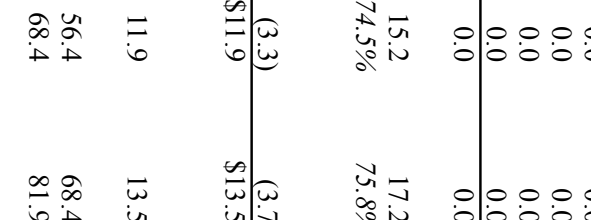

के

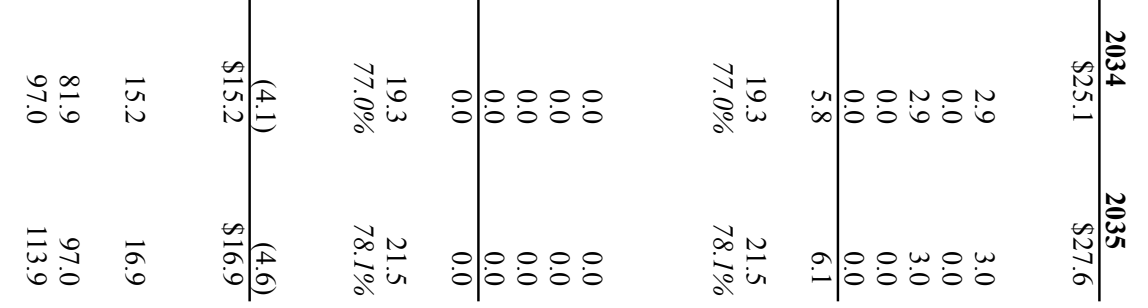



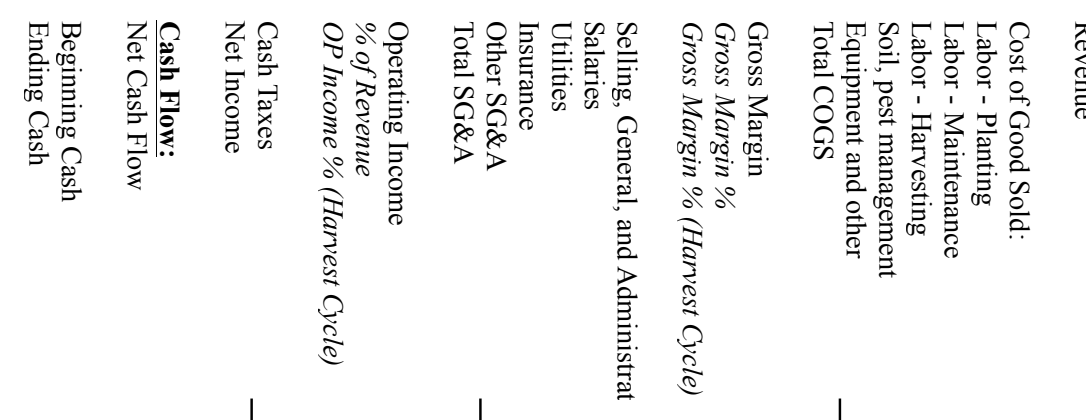

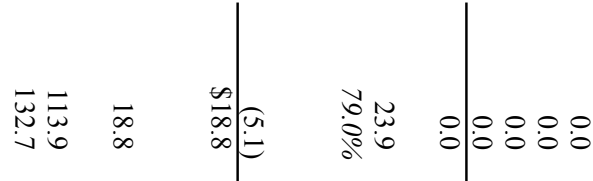

ปัn

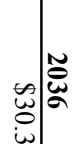

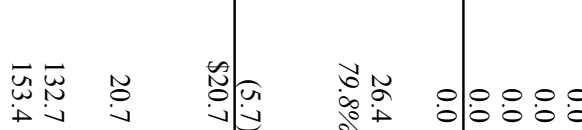

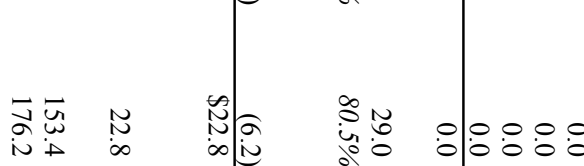

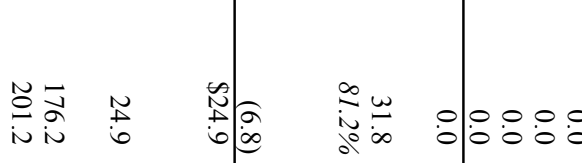

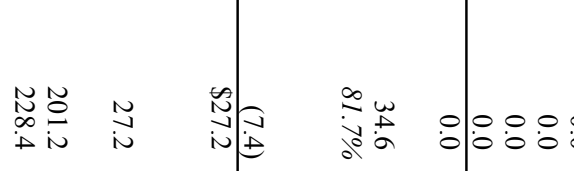

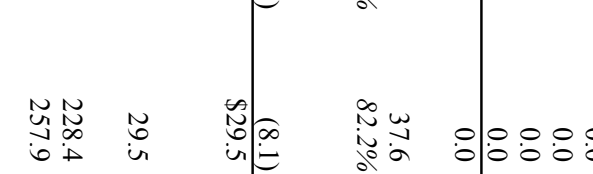

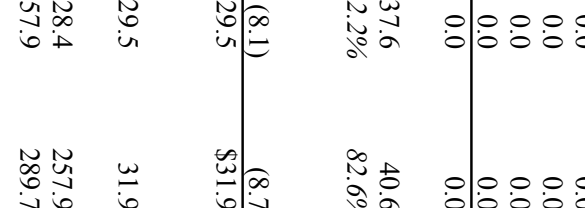

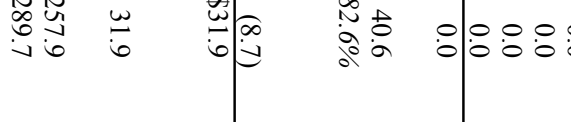

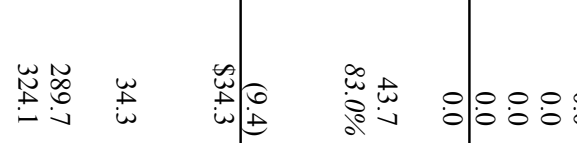

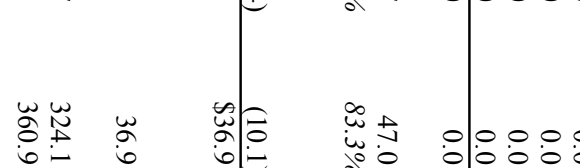

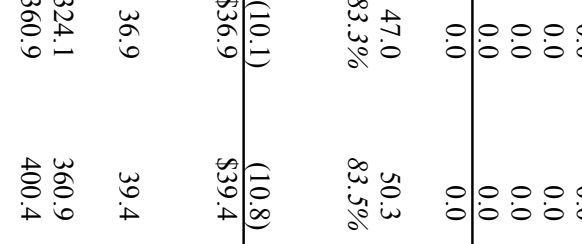

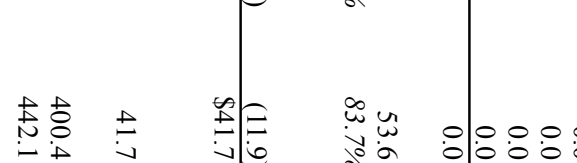

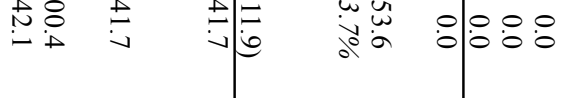

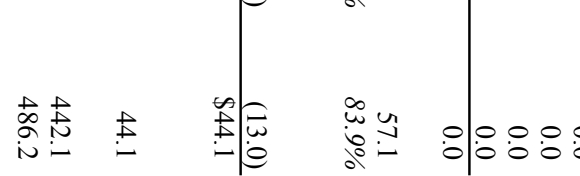




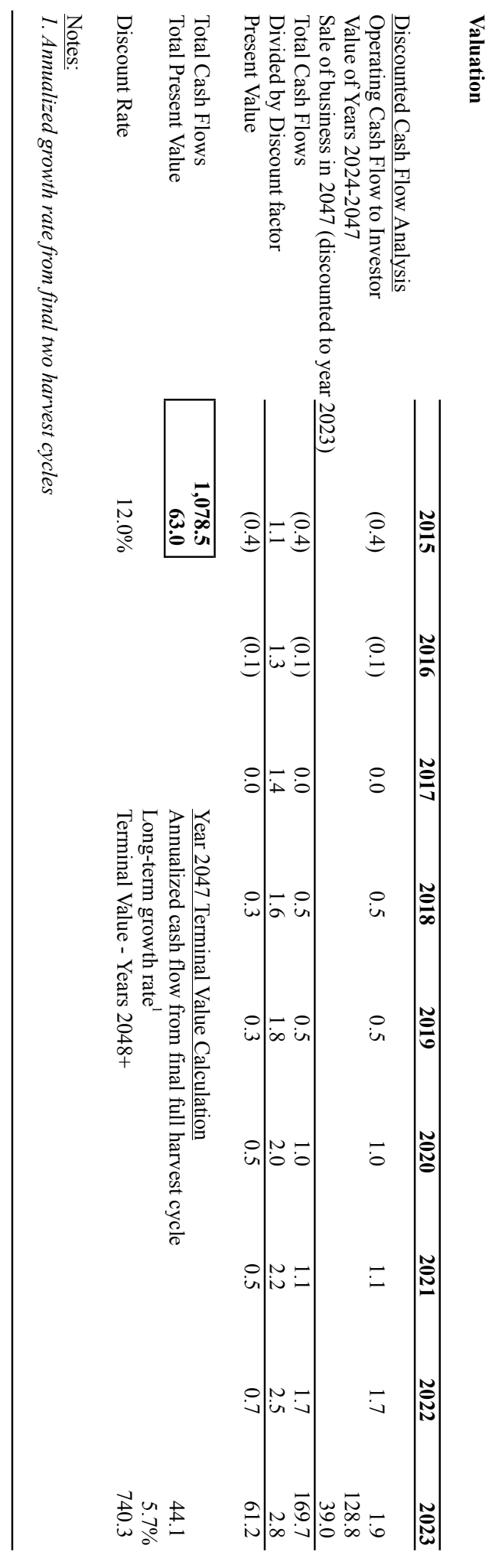




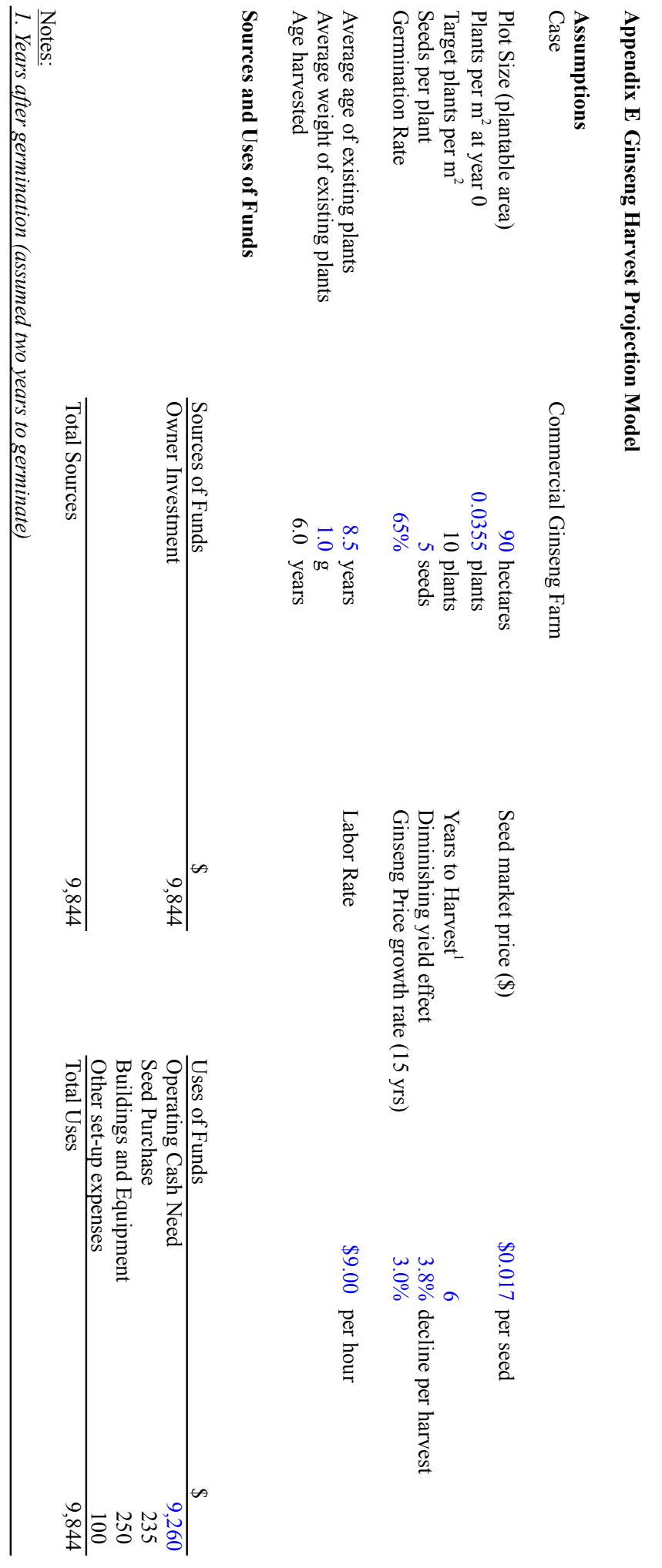




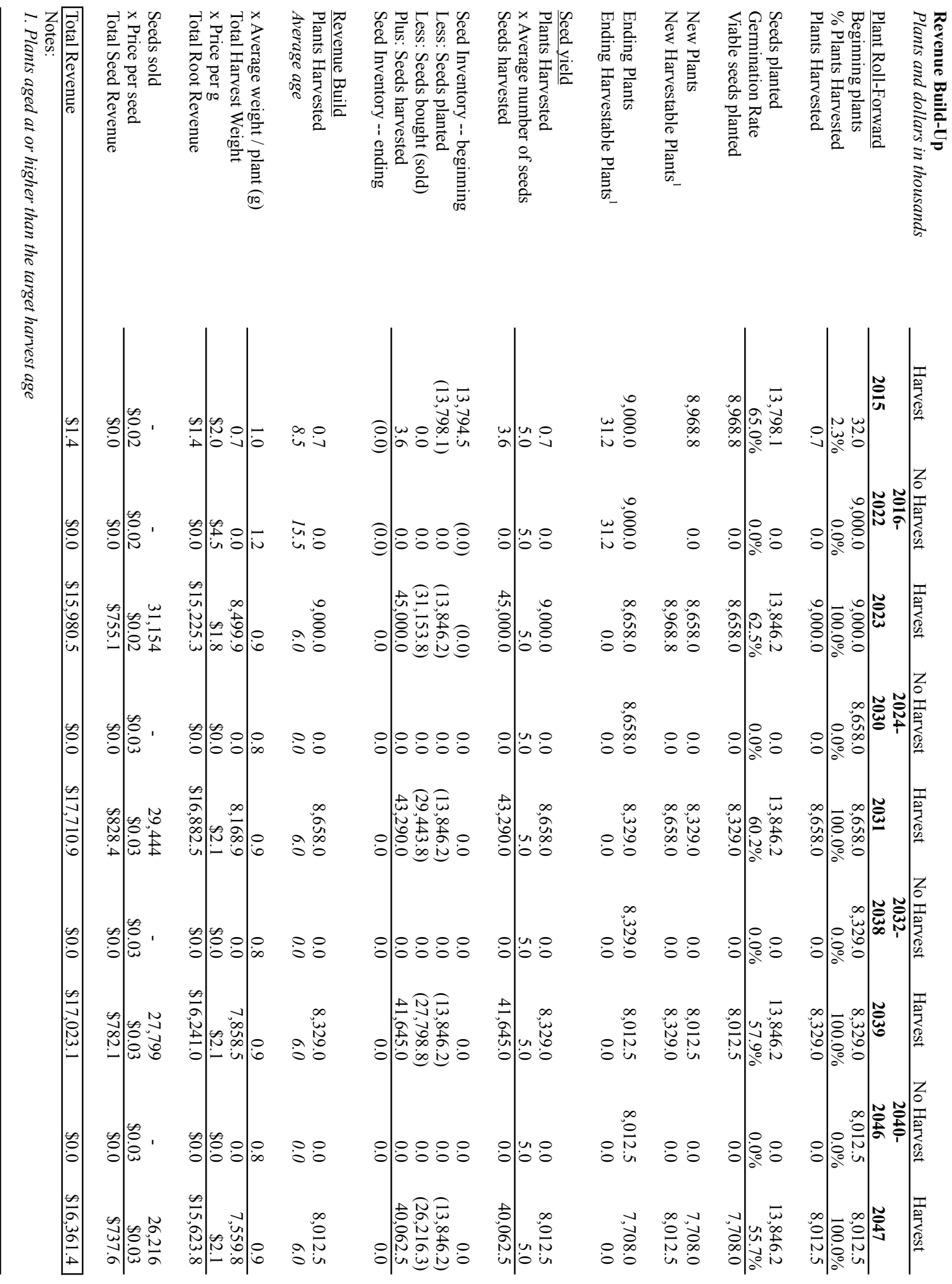




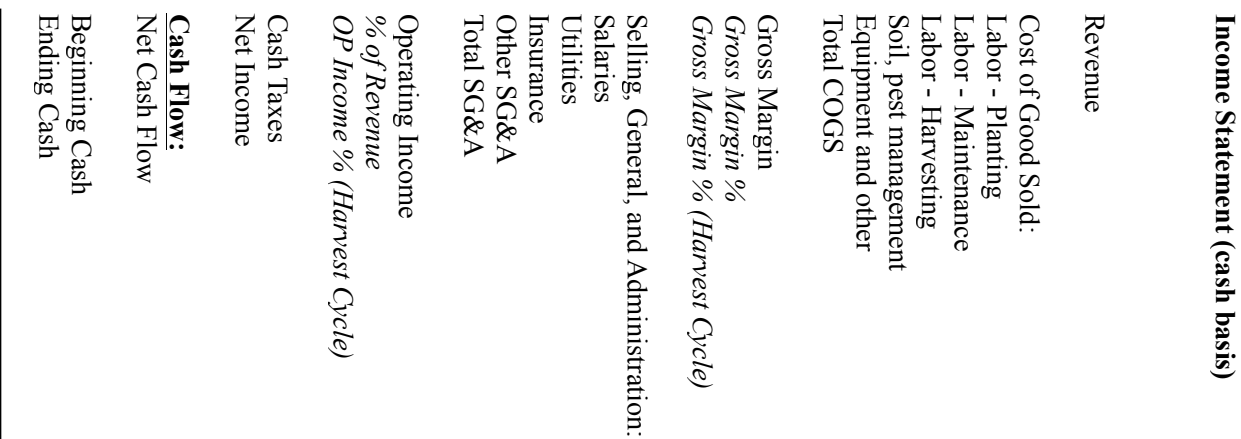

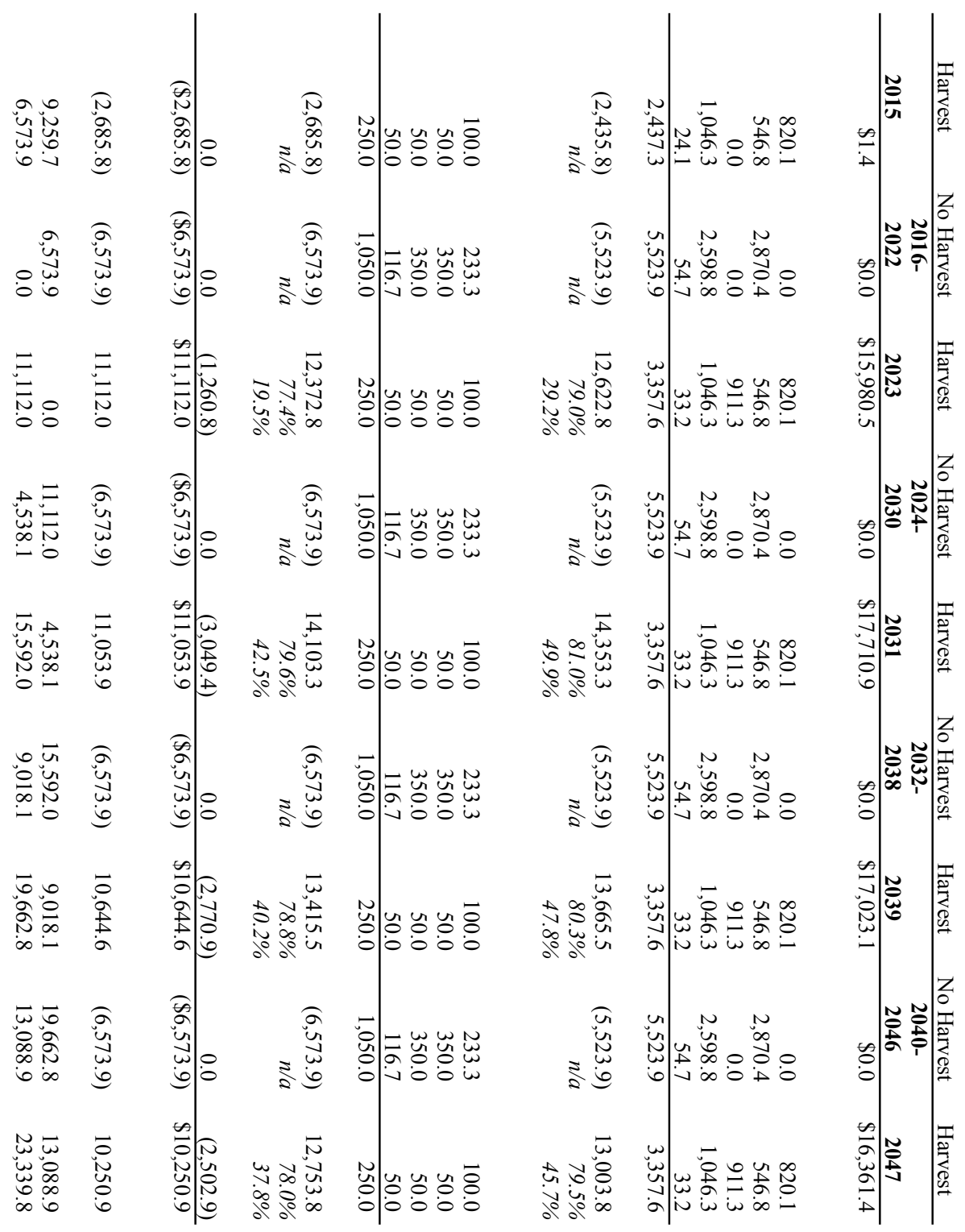




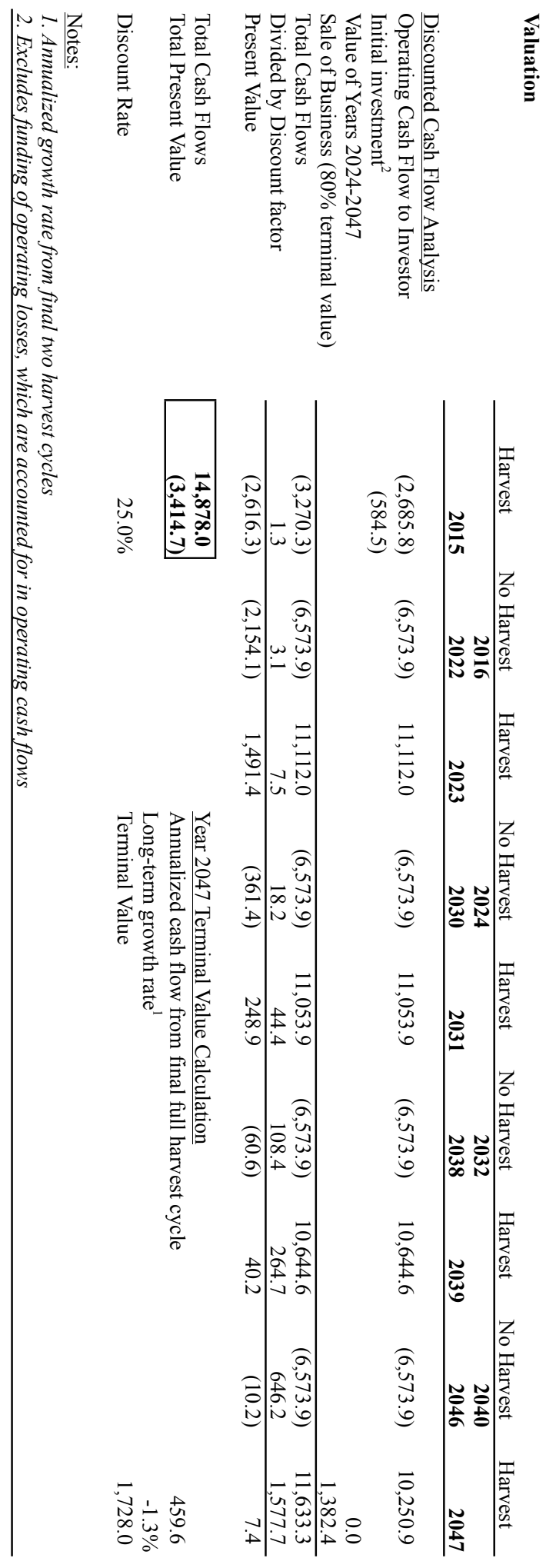



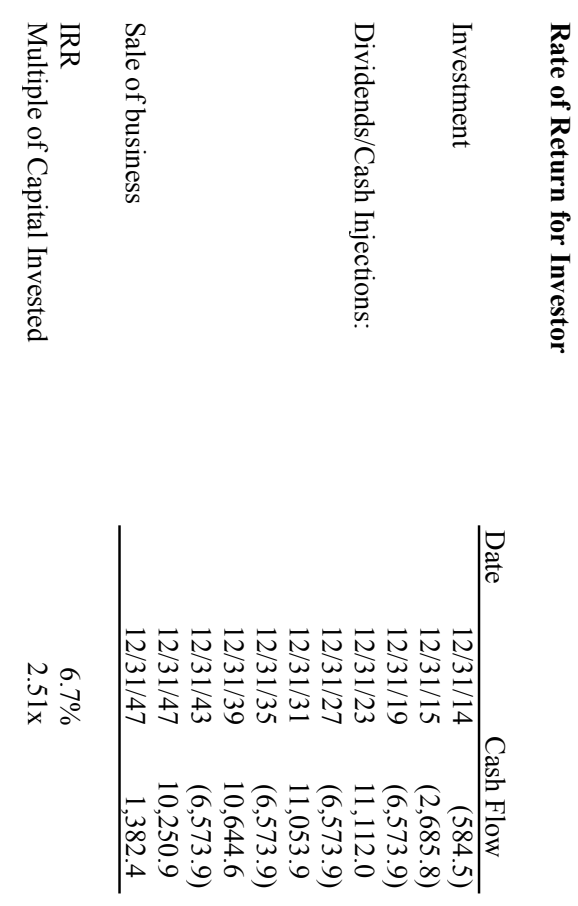